University of Louisville

ThinkIR: The University of Louisville's Institutional Repository

Electronic Theses and Dissertations

$12-2010$

\title{
A manifestation of all life : intersections of virtue ethics, philosophy of emotion, and philosophy of literature.
}

Derek Lee Penwell 1965-

University of Louisville

Follow this and additional works at: https://ir.library.louisville.edu/etd

\section{Recommended Citation}

Penwell, Derek Lee 1965-, "A manifestation of all life : intersections of virtue ethics, philosophy of emotion, and philosophy of literature." (2010). Electronic Theses and Dissertations. Paper 1113.

https://doi.org/10.18297/etd/1113

This Doctoral Dissertation is brought to you for free and open access by ThinkIR: The University of Louisville's Institutional Repository. It has been accepted for inclusion in Electronic Theses and Dissertations by an authorized administrator of ThinkIR: The University of Louisville's Institutional Repository. This title appears here courtesy of the author, who has retained all other copyrights. For more information, please contact thinkir@louisville.edu. 
A MANIFESTATION OF ALL LIFE:

INTERSECTIONS OF VIRTUE ETHICS, PHILOSOPHY OF EMOTION, AND PHILOSOPHY OF LITERATURE

\author{
By \\ Derek Lee Penwell \\ B.R.E., Great Lakes Christian College, 1987 \\ M.A.R., Emmanuel School of Religion, 1990 \\ M.Div., Lexington Theological Seminary \\ D.Min., Lexington Theological Seminary
}

\author{
A Dissertation \\ Submitted to the Faculty of the \\ Graduate School of the University of Louisville \\ in Partial Fulfillment of the Requirements \\ for the Degree of
}

Doctor of Philosophy

Department of Humanities

University of Louisville

Louisville, Kentucky

December 2010 
Copyright 2010 by Derek L. Penwell 

A MANIFESTATION OF ALL LIFE:

INTERSECTIONS OF VIRTUE ETHICS, PHILOSOPHY OF EMOTION, AND PHILOSOPHY OF LITERATURE

\author{
By
}

Derek Lee Penwell

B.R.E., Great Lakes Christian College, 1987

M.A.R., Emmanuel School of Religion, 1990

M.Div., Lexington Theological Seminary

D.Min., Lexington Theological Seminary

A Dissertation Approved on

December 2, 2010

by the following Dissertation Committee

Dissertation Director 


\section{DEDICATION}

This dissertation is dedicated to my wife

\section{Susan Parks}

who has endured great sacrifice to allow me to pursue my education. 


\section{ACKNOWLEDGMENTS}

I would like to thank my dissertation director, Dr. Nancy Potter, for her immeasurable and painstaking assistance throughout the process of writing and revising. It is no exaggeration to say that, absent her help and guidance, this work would not have been possible. I would also like to thank the other committee members, Dr. Mark Blum, Dr. Allen Furr, and Dr. Osborn Wiggins, whose helpful comments and direction have proven invaluable in this process. In addition, I would like to express my thanks to Dr. Annette Allen, director of the Humanities Ph.D. program, for her interest and encouragement over the course of this program. Also, I want to convey my many thanks to the fine people at Douglass Boulevard Christian Church for the gift of time and encouragement to finish. I would like to thank my parents, Danny and Gloria Penwell, and my inlaws, Dorman and Brenda Parks. And though neither my father nor my father-inlaw were able to see me finish, their pride in my accomplishments has helped sustain me through difficult times. I am indebted most of all to my family, chief among which is my lovely wife, which has endured considerable sacrifice to allow me to pursue my education. Susan, Samuel, Mary, and Dominic: I offer you my great thanks for your patience and love through all the time when Daddy had "work to do." 


\begin{abstract}
A MANIFESTATION OF ALL LIFE:

INTERSECTIONS OF VIRTUE ETHICS, PHILOSOPHY OF EMOTION, AND PHILOSOPHY OF LITERATURE
\end{abstract}

Derek L. Penwell

December 2, 2010

This dissertation offers a brief survey of the rise of reason and the turn to the self at the expense of emotion in Western thought. This marginalization of emotion has had deleterious effects on two areas: the cultivation of virtue and the intersubjectivity necessary to sustain human flourishing. Using current research in neuropsychology the dissertation argues that reason and emotion form a dynamic partnership in the process of attaining reliable knowledge. Moreover, the dissertation argues that the emotional experience necessary for the cultivation of virtue, as well as the ability to attend to the emotional lives of others in the service of intersubjectivity, can be augmented by simulating emotional experiences through reading literature.

The dissertation is divided into six chapters. Chapter One traces the history of the rise of reason and the turn to the self in the West, arguing that the preeminence of reason has pushed emotion to the irrational margins. Chapter two explores theories of emotion, contending that emotion is best understood as a process initiated by affective appraisal. Chapter Two also argues for an 
understanding of emotion as a necessary part of the process of knowing. Chapter Three uses an Aristotelian analysis of virtue to argue for the need for emotion in developing virtue and sustaining community. Chapter Four sets down a theory of emotional attending that argues against viewing others as objects or as mirror images of the self. Chapter Five offers an argument about the simulation of emotion and the use of the imagination in reading literature, and why expanding emotional resources is an important goal. Chapter Six provides a practical example of how reading can enrich the fund of emotional experiences upon which one draws to attend to the emotional lives of others through analysis of Richard Russo's, Empire Falls. 


\section{LIST OF FIGURES}

FIGURE $\quad$ PAGE

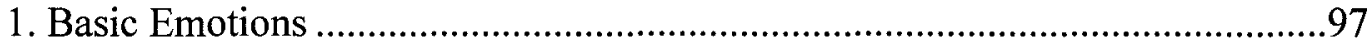




\section{TABLE OF CONTENTS}

PAGE

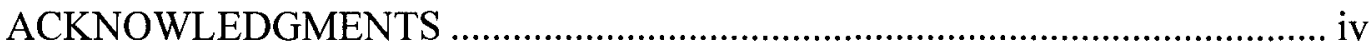

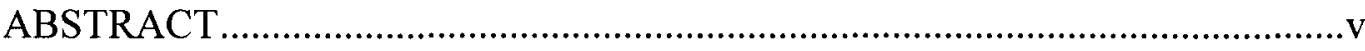

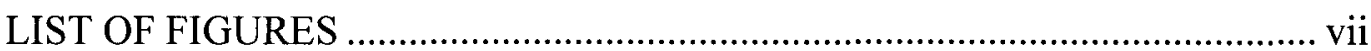

\section{CHAPTER}

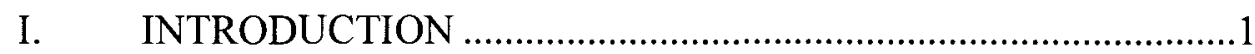

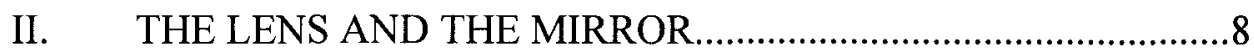

The Privileging of Reason..........................................................16

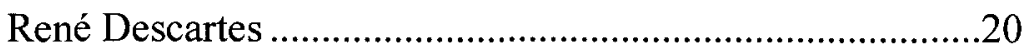

John Locke and David Hume ..............................................22

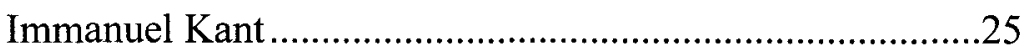

A Brief Excursus on Ethics and Aesthetics...........................26

The Marginalization of Emotion .............................................31

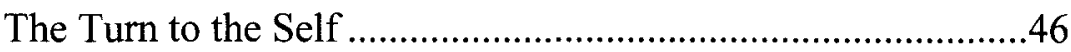

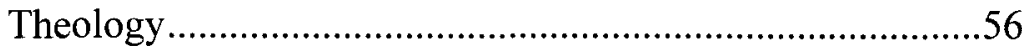

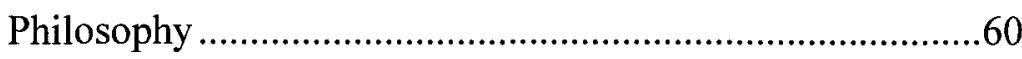

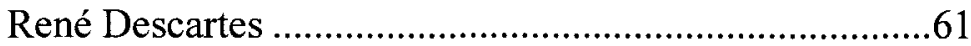

Thomas Hobbes and John Locke.......................................62

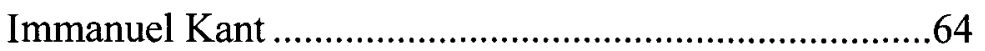

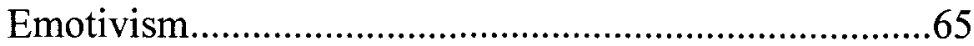

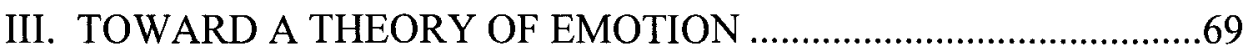


Various Theories of Emotion ......................................................

Affective or Embodied Appraisals.............................................86

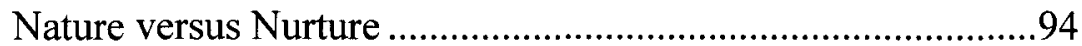

The Dynamics of Knowing ....................................................... 105

Practical Reasoning ...........................................................107

Theoretical Reasoning ...................................................110

IV. HUMANS ARE POLITICAL ANIMALS ………......................122

Humans and the Polis...........................................................129

Virtue Ethics versus Deontology and Utilitarianism ...............139

Tragedy: Plato and Repulsive Emotions ....................................153

Aristotle and Necessary Emotions ...........................................159

Emotion, Action, and Tragedy ……………………….......159

Aristotle on Tragedy: Situating the Debate..........................160

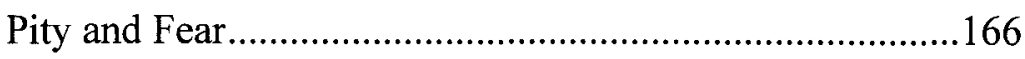

V. INTERSUBJECTIVITY: THE NEED FOR EMOTIONAL

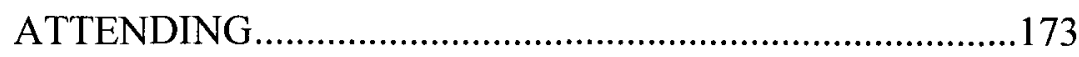

Emotional Attending, Other Sight, and Empathy ……............179

Uptake and Emotional Engagement.........................................191

Iris Murdoch and the Epistemology of Other Sight................203

VI. LITERATURE AND THE WORK OF THE

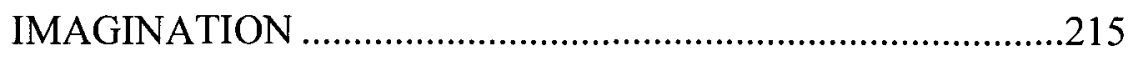

Literature and the Moral Imagination .......................................217

Literature and the Emotional Imagination ................................233 


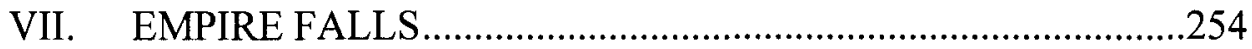

Other Sight: The Lens of Love ................................................259

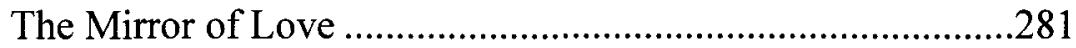

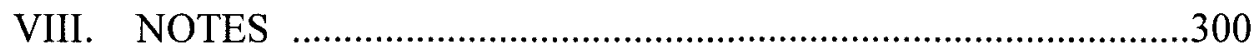

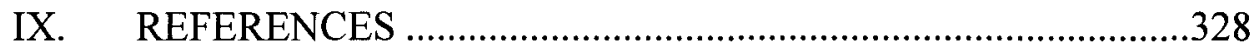

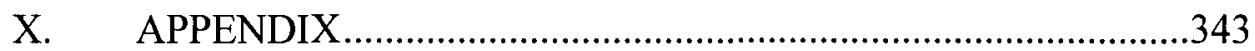

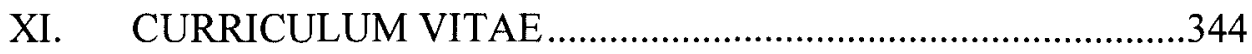




\section{INTRODUCTION}

The ties that bind people to communities in Western society have undergone a serious challenge through the rise of scientific reason, which has evolved as the de facto preserve of true knowledge. Moreover, the turn to the individual self as the primary locus of meaning has also seriously jeopardized the kinds of communal attachments that are both formative and sustaining. The reasons for this privileging of scientific reason, as well as for the evolution of the modern atomic self require attention to the history of the development of Western thought in disciplines as diverse as epistemology and moral philosophy, theology and cultural history. In this work I will attempt to tell a story that seeks to braid various strands from these disciplines into a coherent narrative, which seeks to make sense of the ways in which emotion has been displaced by reason as legitimate knowing, as well as of the ways in which human intersubjectivity is endangered by the dislocation of meaning from communal sources to the sanctuary of individual interiority. Ultimately, I want to make an argument that the humanities, in general, and literature, in particular, offer a way to fortify the emotional resources necessary for human flourishing as a means of challenging the capacious imperialism of scientific reason, as well as the socially corrosive effects of the alienation of the individual from necessary social connections of community. More specifically, I want to call attention to the ways that reading 
literature makes us more capable of attending to one another emotionally not as objects to be analyzed or targets upon which to project images drawn from human interiority, but as subjects who can only be known contextually through the just and loving vision of emotional attending. This emotional attending, I want to suggest, will help to foster an environment in which the intersubjectivity necessary for human community and flourishing can occur.

\section{On Avoiding Being an Organ Stop: Underground Man, Alienation, and the Corrosive Effects of Scientific Rationalism}

At that time I was only twenty-four years old. Even then my life was gloomy, disordered, and solitary to the point of savagery. I didn't associate with anyone. I even avoided talking, and I retreated further and further into my corner. At work in the office I even tried not to look at anyone. I was aware not only that my colleagues considered me eccentric, but that they always seemed to regard me with a kind of loathing ... No one was like me, and I wasn't like anyone else. "I'm alone," I mused, and they are everyone"; and I sank into thought.

Fyodor Dostoevsky, Notes from Underground, 30-1

So begins the second part of Dostoevsky's novel, Notes from

Underground, in which a nameless man narrates his isolation from society, and the bitterness he harbors against virtually everyone with whom he comes into contact. Cut off from meaningful human connections, Underground Man rails against both the slights he has endured at the hands of others, as well as the society that produces such injurious people. Regardless of the social rank of the people he encounters, he laments that "I almost always lowered my eyes when meeting anyone. I even conducted experiments: could I endure someone's gaze? 
I'd always be the first to lower my eyes. This infuriated me to the point of madness" (Dostoyevsky 2001).

It would certainly be tempting to see Underground Man as a visionary experiment in the chronicling of madness of an organic type. To understand it in this way would be to overlook the kind of social commentary implicit in the work, however. In fact, instead of psychopathology, Notes from Underground has the encroachment of scientific rationalism in its sights as the culprit that causes alienation. Underground Man is convinced that science is slowly corroding our humanity by marginalizing our desires and passions, labeling them irrational, at best, or madness, at worst. Underground Man decries the way he believes science reduces human action to the product of the rational calculation of self-interest. On his understanding of scientific rationalism, reason eventually clarifies what is, from an instrumental perspective, in a human being's self-interest. This clarification of reasonable options happens to such an extent that there can be no longer room left for the free exercise of the human will, since, according to Underground Man, no one knowingly does something against self-interest (Dostoyevsky 2001). Science, taken to its logical conclusion, Underground Man believes, will ultimately obviate the need for human agency, because all possible courses of human action will be accounted for by complex computation, leaving the most reasonable alternatives to be enacted. Human choice will be unnecessary because decisions, rationally derived, will make a final option in any situation so obvious and beneficial to self-interest that choosing will be unnecessary. Underground Man is convinced that once science is perfected and 
rationality finally displaces the unpredictability of human passion and desire, humanity will have been "transformed from a person into an organ stop: because what is a man without desire, without will, and without wishes if not a stop in an organ pipe?" (Dostoyevsky 2001). In other words, scientific reason, should it colonize all of human experience at the expense of other ways of knowing that involve emotion, will leave us leave us less human, and certainly more isolated from one another.

Underground Man, the product of the alienating force of rationalism, cries out to reclaim some scrap of humanity, some sense that his life transcends that which can be said propositionally of him. He realizes that life lived in a rationally pure ideal, as the sum of propositional statements, as a factor in an equation cannot but dehumanize us, cannot but leave us alone and disconnected from the community that makes human flourishing possible. Underground Man cautions: "Reason is a fine thing, gentlemen, there's no doubt about it, but it's only reason, and it satisfies only man's rational faculty, whereas desire is a manifestation of all life, that is, of all human life, which includes both reason, as well as all of life's itches and scratches. And although in this manifestation life often turns out to be fairly worthless, it's life all the same, and not merely the extraction of square roots" (Dostoyevsky 2001). I wish to suggest that art, literature in particular, is a counterbalance to science, not only because it engages "life's itches and scratches," but because it helps to shape and inform the emotional faculties that allow us to live together in meaningful ways, able finally to look into one another's eyes and not to lower our gaze. Moreover, I will argue that the "desire" 
identified by Underground Man — and what I will refer to as value and emotionis not a distraction from that with which humanity should rightfully concern itself (namely, reason), but it is, in fact, at the heart of human flourishing. Value and emotion, far from being subjective irrelevancies in a scientific age, are central to what it means to be human; they are "a manifestation of all life, that is, of all human life."

What Doestoevsky provides in Notes from Underground is an image of modern Western society's drift toward alienation, a society in which intersubjectivity is imperiled, in which humans are robbed of the emotional connections that make human flourishing possible, precisely because reason will finally have prevailed by making emotion unnecessary for navigating human existence. As Dostoyevsky's portrait of underground man demonstrates, within modern life exists the seeds of alienation from community, the potential effects of which ought to give us pause. For, the walling off of the individual threatens not only the community but the individual, who is untethered from both the normative and nurturing aspects of community. This retreat from social connection transcends an obvious decline in civility to foreshadow a more troubling set of problems that have to do with the deformation of character and the loss of the immediacy of intersubjectivity. Absent the morally formative influence of community, absent the emotional connection that helps to sustain community (as well as give rise to its necessity as a human endeavor) - human beings risk living in societies built upon a foundation of instrumental relationships, where morality and social interaction exist as problems to be worked out in terms of cost/benefit 
analysis: "What do I get out of this?" "What's in this for me?" Shorn of meaningful interpersonal commitments, which are increasingly called into question as potential abridgements of personal freedom, discussions of morality or social responsibility devolve to questions of utility, or perhaps worse, personal preference.

This work is an attempt to set down an account of how our experience of literature can provide an important resource in developing the emotional capacities that will enable us to pursue virtue in the midst of community. It is an attempt to stand over against the fragmentation of modern social life, over against the alienation of the individual by calling humanity to a recognition of the morally and socially corrosive effects of marginalizing emotional experience. Moreover, it is an attempt to challenge the assumption that my relationship to the world is a product of my interiority projected onto the world. I will suggest instead that, popular accounts of the rugged individual notwithstanding, I am located within a complex nexus of social relationships that helps, among other things, to shape and inform my identity-that my identity is not forged in the furnace of my own interiority. To accomplish this objective, I will have to sustain a fairly complex argument that includes an identification of the problem and how we have arrived at this point in Chapter One. I will then set down a survey of what emotion is and why it is important to see it as a partner rather than an adversary of reason in Chapter Two. Next, I will provide in chapter three a description of the need for community and the attendant virtues necessary to ensure flourishing, which have been threatened by the marginalization of emotion and the turn to the self, while 
Chapter Four will look at the negative effects on intersubjectivity and means by which to counteract them in emotional attending. Chapter Five will then describe how literature can assist the process of expanding our emotional experience, while at the same time refining our abilities to attend to the emotions of others. Finally, I will use the novel, Empire Falls in Chapter Six to provide a literary example of some the arguments I have been making about how our vision of others has been distorted by the mental habits we have cultivated through our privileging of reason and the turn to the self, as well as to demonstrate how literature helps us creatively imagine the emotional lives of others.

The goal of this work is to make a contribution to an alternative vision, one in which scientific reason occupies an important place, but is counterpoised by the necessary social and moral function emotion provides. I will suggest that literature, which traverses a landscape in which emotion figures so largely, offers an important resource for the kind of knowing that comes through emotional attending. And the kind of knowing that comes through emotional attendingbeyond the world that is open only to propositional description—stands as a crucial part of what it means to be human; it stands as a manifestation of all life, that is, of all human life. 


\section{CHAPTER ONE}

\section{THE LENS AND THE MIRROR}

\section{Introduction}

A particularly important technological innovation that shaped epistemology and the perspectival relationship of humans to the world was the development of pure, colorless glass sometime in the fourteenth century. ${ }^{1}$ Prior to clear glass, to see out of a building or structure, one must look through a hole in the wall, which is covered by a shutter or fabric. The advent of clear glass lets people stay indoors out of the weather, and observe a mediated view of life outdoors. Prior to clear glass, glass is colored (stained glass), letting in colored light, but not allowing an unimpeded view of life outdoors. This new perspective on the world has the effect of objectifying that upon which our attention is focused.

The uses to which clear glass is put by science leads to a further objectification of the focus of our attention (the telescope and the microscope). Both the telescope and the microscope shape now what it is possible to think about the world. $^{2}$ By allowing the sight of things previously unseen, these technological innovations mark out whole new realities. No longer are the stars and planets observable with only the naked eye, but with the telescope the mystery of space is at humanity's fingertips. Likewise, the microscope opens the door to a whole new miniature plane of existence that, prior to the invention of 
clear glass, could not even have been conceived. Not only is the world more present through this innovation, it turns out to be infinitely more complex and layered than anyone could ever have imagined. Witnessing these new portals on reality gives us the impression that reality—because of our increasing ability to observe the world—can be framed and then studied objectively.

Lewis Mumford observes:

In losing color and ceasing to serve as picture-the function it had occupied in medieval church decoration—and in letting in, instead, the forms and colors of the outside world, glass served also as a symbol of the double process of naturalism and abstraction which had begun to characterize the thought of Europe. More than that: it furthered this process. Glass helped put the world in a frame: it made it possible to see certain elements of reality more clearly: and it focused attention on a sharply defined field—namely, that which was bounded by the frame (Mumford 126).

Mumford draws attention to the symbolic way that the opacity of colored glass as a fixture in ecclesiastical settings seems to enshroud knowledge in theological mystery. The arrival of clear glass for use in everyday life signals, what seems to be, a straightforward, unobstructed view of the natural world—knowledge of the world available to all and unmediated by the special, theological knowledge of the clergy. If only metaphorically, the appearance of clear glass certainly aids the epistemic shift from divine revelation mediated ecclesiastically to a naturalistic 
epistemology in which knowledge of the world is available to all through observation.

Paradoxically, at the same time as the possibility of knowledge absent the mediating influence of the clergy suggests the possibilities of a new epistemic horizon in which the world can be investigated naturally—-that is, without divine revelation-the appearance of clear glass also allows for observation that can be done at a remove. Instead of having to be in nature to observe nature, the distance allowed by clear glass encourages abstraction, inasmuch as one can observe what one views in the pre-defined field of the microscopic slide or through the viewfinder of a telescope isolated from its natural context. It is important to point out that the distance from the thing being observed, afforded in this case by glass, will eventually become an important component of the objectivity considered necessary for scientific knowing. Something as simple as the glass window provides a border around a particular field of vision, allowing the illusion of a bounded system that can be known apart from the broader nexus of complex relationships that make such a system possible in the first place (Mumford 125-6). Put another way, the frame of the window (or telescope or microscope), taken together with the glass that sets up an impermeable barrier to nature, encourages habits of the mind that permit the viewing of things as particularities unencumbered by the complexities of systems requiring interdependent relationships - trees can be studied as trees, for instance, abstracted from their role within a multifaceted ecosystem. 
I wish to suggest that the same process of abstraction applied to natural systems can be extended to include human systems, about which I will have more to say throughout the rest of this chapter. In other words, the habits of mind that lead to abstraction in reference to nature - that is, to the goal of distance and objectivity in the observation of a particular thing abstracted from its context-are suggestive of what I wish to explore in this chapter in relationship to the ascendancy of objective reason at the expense of other ways of knowing, as well as the ascendancy of the autonomous individual self at the expense of communal attachments and commitments. Taken metaphorically, the process of abstraction encouraged by clear glass represents an increasingly common modern assumption that things in general, and the individual, in particular, can be studied objectively—and ultimately understood—in isolation from the nexus of relationships that comprise the context out of which particularities arise.

As important as these technological developments prove to be in altering our relationship to the world, through a reinforcing of reason as the faculty through which the world can be apprehended, it is another technological innovation prompted by clear glass, I will argue, that stands as a central feature of the story I want to tell. The mirror is important to what I take to be two related developments in the Western intellectual tradition. First, the mirror stands as an historic and important metaphor of the ascendancy of scientific reason as the dominant model of knowledge, knowledge that is external to the human mindthat is, knowledge that is objective, mind-independent, and unclouded by emotions and other subjective distortions. Put more simply, the metaphor of the 
mirror in this epistemological sense betokens knowledge that is a clear reflection of the real world. Second, the mirror also stands as a metaphor of the turning of the focus of observation back onto oneself. It adverts to the modern shift from an external teleological source of meaning located in the polis or in the church, to an internalized meaning created in the interiority of the modern individual. That is to say, the metaphor of the mirror betokens knowledge that is a clear reflection of the true self.

In the first instance, the mirror has served as a guiding metaphor for epistemology upon which the scientific model of knowledge is based-the paradigmatic form of knowing in Western culture-from Plato onwards. The scientific model, which has come to dominate as the arbiter of what can and cannot be considered knowledge, is predicated on the assumption that reliable knowledge is a reflection of that which exists in the world, independent of the observer. True knowledge, in other words, mirrors what is, in fact, the case. To put a finer point on it, an inadequate description of what is seen in the mirror focused on the world is prima facie evidence of inadequate knowledge. That is to say, if I report that what I see sitting at the end of my driveway - where there is a small three-wheeled vehicle down by the mailbox-is a troll instead of a tricycle, my status as a knower is put in question. True knowledge of the world, in this case, then, is the acknowledgment of an undistorted reflection in the mirror of a tricycle.

In the second instance, the mirror ultimately has had an equally profound impact on human self-understanding. As surely as the other technological 
applications of clear glass shift our gaze outward, in practice the mirror diverts it back on our selves. The development of the mirror fascinates people who had only seen passing glimpses of themselves (and distorted ones at that) in a reflection from the water of a pond, or in imperfect metal. ${ }^{3}$ Now, with glass mirrors, it is possible to look at one's face whenever one wishes. Where before one's position in the world was related to the world itself, with the advent of the mirror, it becomes possible to locate one's self interiorly.

The relocation of the self from a small piece of a universal, exterior puzzle to a larger piece of a particular, interior one has had profound implications. The exterior world, though still meaningful, has found a rival in the interior world. As long as people are small parts of an enormous enterprise, individual psychic needs may be ignored to a certain extent. However, when I become the lead actor in my own play, the exterior world's significance comes to be defined through its relationship to me. The development of the mirror reveals a bounded world in which I am persistently the central character.

In Chapter One, I will advance a two-pronged argument that will consider the Enlightenment divide between reason and emotion. The first prong of the argument will provide a brief description of the state of affairs in the West in which reason has displaced emotion as the primary way of knowing, marginalizing emotion as irrational. The second prong of the argument will suggest that, from the Enlightenment onward, at the same time as reason is eclipsing emotion as the standard for knowing, the individual is in the process of 
becoming the central referent or final authority for value and knowledge in Western thought.

My larger goal concerns the necessity of emotional resources for both virtue and intersubjectivity. To that end, I am trying to lay the groundwork for that argument by tracing the simultaneous developments in the West of the ascendancy of reason at the expense of emotion and the isolation of value to the individual. I will suggest that these two developments have had the crippling effect of cutting off morality from the emotions, while setting up barriers to intersubjectivity. In short, in this chapter I will contend that while scientific reason has sought objectivity in knowledge, there was another movement toward radical reflexivity that simultaneously relegated value to the domain of the subjective. In the first instance, emotions are viewed as an obstacle to knowing, while in the second instance, emotions represent the subjective values of the individual, who inevitably becomes the measure of what can be considered valuable, even — perhaps especially — with respect to other subjects.

I must admit up front that my argument- though it makes use of cultural, intellectual, and religious history—is not a standard historical survey, given over to a comprehensive examination of the many forces at play in the development of history. To tell such a sprawling tale is certainly a worthy task, but it is not the goal I seek to accomplish. Instead, I am trying to tell a story of how we have arrived at a place where reason is believed to be the only reliable form of knowing, and the turn to the self has cast the individual back onto her own interiority to find value and meaning. In telling this story under the limitations of 
space, I must necessarily make certain choices about what to include and what to leave out. Unfortunately, part of what I am unable to include in much depth, beyond tracing the development of certain ideas, is the cultural history that in some cases prepared particular cultures in the West to receive those ideas-and in other cases, was itself indispensible to the shaping and forming of those ideas. I would concede that there very well might be ways to tell this story by making different choices. However, the choices I have made are defensible, I think, just to the extent that the characters upon which I concentrate are, generally speaking, primary characters in virtually any account of the development of Western thought. That I have left out some arguably important figures and cultural trends is regrettable, but largely unavoidable.

Reason, in particular scientific reason, has prevailed in the West as the privileged means of arriving at reliable knowledge-almost always at the expense of other ways of knowing. Emotion, for instance, has almost always suffered when reason is viewed as epistemologically paradigmatic. I will first set out an account of the mainstream view of reason as a superior way of knowing. On this reading, emotions are viewed as passions that must be controlled, so that true knowledge might manifest itself. This privileging of reason has resulted in the loss of a particularly important way of knowing about the world - a way of knowing that reason cannot apprehend apart from emotion. Furthermore, I will offer an analysis of how this disregard for the emotions operates as an ideological bulwark for the underwriting of scientific reason-which is the de facto preserve of those who occupy positions of power- usually, white males of a certain socio- 
economic and educational background. Moreover, the rise of reason also coincides with the shift of "meaning-making" from the communal to the individual. Both the polis and the church as authoritative makers of meaning will decline in the face of the individual's increasing attempts to make meaning for herself.

At the same time as the epistemological priority of reason over the emotions was being established, the West experienced a turn toward subjectivity. I will offer a brief account of the ascendancy of the interior self in the Western intellectual tradition as the preserve of value and truth, arguing that a radical shift to the interior life of the individual as the referent for value has taken place. The effect of this subjective turn, I will contend in chapter four, is an inadequate and distorted view of the world, inasmuch as the reality of the world under these conditions cannot but be an analogical projection of the self. Furthermore, because of the split between reason and emotion, as well as a turn to the self, I will suggest that human beings are in danger of losing the kind of intersubjective connection necessary to human life.

\section{The Privileging of Reason}

The quickest method, I suppose, is to get hold of a mirror and carry it around with you everywhere. You'll soon be creating everything I mentioned a moment ago - the sun and the heavenly bodies, the earth, yourself, and all other creatures, plants, and so on. (Plato 596e). 
Beginning with Plato, and down through the Western intellectual tradition, reason has been privileged as that which identifies us as part of the human species. As such, reason has continued to occupy the privileged position in western epistemology. This privileging of reason has had the practical effect of legitimating the scientific model as a description of what is real, while at the same time being further legitimated as the true source of knowledge, through its investiture as the formal goal of science. The mutually reinforcing nature of reason as both the goal and the necessary means by which the goal is achieved makes the process of challenging reason as the sole constituent of that which is epistemically reliable much more difficult, because to do so would seem ipso facto to have offered an irrational argument. Moreover, this scientific model has pretensions not only to describe the world in which we live, but ultimately to colonize every conceivable form of human experience. By colonization I mean the sort of establishment of power implied by the ability to name and categorize. To the extent that science maps human experience in scientific terms, using scientific models, it operates as first order discourse-which is to say, as John Gunnell observes, "the primary ontological claims and assumptions, tacit or explicit, that define a universe of phenomena, constitute a vision of reality, and create a domain of facticity" (19).

It is extremely important to point out that the rise of reason, and the scientific model to which it gave birth, have produced great benefits. Reason and science have allowed humanity to make a variety of technological improvements across a broad spectrum. From things we would consider necessities, like modern 
medicine and improvements to agriculture to less urgent but no less useful innovations in modern transportation and modern conveniences like airconditioning and computers, science and reason have made human life considerably safer and longer-though, admittedly, in some cases (like weaponry) much more dangerous and shorter. Moreover, the ascendance of reason has provided a release from some of the more superstitious bonds of ancient and medieval religion. Hence, I do not want to be misunderstood to be staking out some form of neo-Ludditism, or thoroughgoing subjectivism, or an anti-religious chauvinism. Instead, because of the way reason has been championed, I want to draw attention to some of the consequences this privileging of reason brings with it.

The scientific model of knowledge depends for its intelligibility on there being an external world that corresponds to the description of it. ${ }^{4}$ C.S. Pierce in the late nineteenth century famously summarizes the optimistic belief of what he takes to be the epistemic pay-off science promises in its search for the truth:

Different minds may set out with the most antagonistic views, but the progress of investigation carries them by a force outside of themselves to one and the same conclusion. This activity of thought by which we are carried, not where we wish, but to a foreordained goal, is like the operation of destiny. No modification of the point of view taken, no selection of other facts for study, no natural bent of mind even, can enable a man to escape the predestinate opinion. This great law is embodied in the conception of truth and reality. The opinion which fated to be 
ultimately agreed to by all who investigate, is what we mean by the truth, and the object represented in the opinion is the real. That is the way I would explain reality (138-9).

In other words, Pierce evinces the Enlightenment confidence that truth is what is available "to all who investigate" because it exists external to and independent of the observer. Hilary Putnam named the epistemological position, metaphysical realism. The existence of something very much like this understanding of the world is an epistemological necessity to underwrite the scientific model. Metaphysical realism asserts that reality exists "out there," independent of a perceiver. On this view, according to Putnam, "there is one true and complete description of the "the way the world is," " assuming the perspective of a "God's eye point of view" (49). Reason, therefore, is a matter of accommodating one's self to and reflecting the truth-that is, what is really there, external to and independent of the individual. In the search for knowledge reliable enough to be called truth, the knower must avoid subjectivity at all costs. Pierce suggests that "a person who arbitrarily chooses the propositions which he will adopt can use the word truth only to emphasize the expression of his determination to hold on to his choice" (137). The epistemic assumptions of metaphysical realism are the dominant assumptions about knowledge all the way back to Plato and Aristotle. The prevailing metaphor for knowledge, according to this traditional preCartesian account of reality, is vision (Rorty 39). That is to say, knowledge consists of viewing and correctly reporting reality as it exists independent of the viewer. In fact, correct vision of the order of things is "criterial for rationality" 
(Taylor 124). I cannot truly be said to be exercising reason if my vision of reality is flawed, if my vision of reality holds gravity to be optional, for instance, or that the sun revolves around the earth. The mind, therefore, is both like a mirror and an eye in that it both reflects reality at the same time as it perceives that reality. It is not the case in this conception of reality, however, that the mirror that reflects the order of things is then viewed by an inner Cartesian eye, which occupies a neutral and unsituated position from which to examine these sense impressions; rather, the eye of the mind sees what is there, and reason is the process of adjusting itself to the reality the mind both reflects and views (Rorty 45). In Descartes, on the other hand, the mind's eye investigates the representations it finds in the mirror, and constructs reality from the basic building blocks of those representations. And inasmuch as it is Descartes who challenges the idea of a mind-independent reality, it is to him that we must first turn.

\section{i. René Descartes}

The move toward establishing scientific reason as the privileged form of knowing in the West begins in earnest with Descartes, who in the Meditations seeks to face down the niggling problem of the foundations upon which knowledge can be said to exist with apodictic certainty. In the wake of the Protestant Reformation and the Catholic Counter-Reformation, and on the cusp of the Scientific Revolution, Descartes desires to establish knowledge on firmer footing than had been available in the church's reliance on divine revelation as the true source of knowledge. He is wary of the inadequacy of the senses, believing 
that knowledge cannot reliably come to us through perception. Sensations, according to Descartes, are presented to the mind in the form of representations. He wants to make a distinction between the senses as wholly independent percipient faculties and the intellect that constructs the representations based on data it receives through the senses, believing that we confuse the senses with the judgments made by the mind, and that this is largely a linguistic problem. It is our habits of speech that confuse us into thinking that we see with the eyes or hear with the ears (Descartes 23). Descartes says that "we say that we 'see' the wax itself, if it is present, not that we judge it to be there on the basis of its colour or shape ... [but] what I thought I saw with my eyes, I in fact grasp only by the faculty of judging that is in my mind" (23).

If our knowledge of the world does not come through our experience of an objective world viewed as if in a mirror, how then do we know the world? Descartes suggests that our knowledge of the world is, in reality, our knowledge of the ideas the world evokes in us. With the senses, for instance, what we take to be properties that inhere in a thing do not in fact inhere in the thing itself, but are intellectual judgments we map onto it. Closing out the Second Meditation, Descartes concludes that bodies (things) "are not perceived because they are touched or seen, but only because they are understood. I clearly realize [cognosco] that nothing can be perceived by me more easily or more clearly than my own mind" (24). The world can be known, therefore, not as an objective reality presented to the intellect through divine revelation or by the senses, but only as representations of the world that exist as ideas grasped by the intellect. 
For my purposes, I will follow Alison Simmons' general definition that a "mental state is representational if it acquaints the mind with something existing in extramental reality."

The implications of Descartes' epistemological revolution center on the Theory of Ideas, which maintains that the world I perceive exists only in my mind. Flying in the face of traditional metaphysical realism, in which the real world exists outside, independent of the individual, whose life consists of trying to apprehend it, the Theory of Ideas suggests that a thing and the appearance of the thing are the same. That is to say, according to Descartes, what humans have immediate access to is not the world independent of the perceiver, but rather representations of that world to the perceiver. Edmund Husserl observes that Descartes "seeks apodictically certain ways by which, within his own pure inwardness, an Objective outwardness can be deduced" (3). Husserl rejects the Theory of Ideas just to the extent that it abandons the mind to functioning as a "closed sphere of interiority," the implications of which are that the mind is cut off not only from the world, but even from the body in which it is housed. This founding of the objective upon the subjective will have implications for the turn to the self shortly, but here it is important to note that Descartes' search for apodictic certainty built on the subjective nature of the ego-that is, the $I$ antecedent to and necessary for the world to exist—is an attempt to allow science to be fixed indubitably upon the sure foundation of reason. The great irony, of course, is that under Descartes the sure foundation of reason rests on the subjectivity of the perceiver. 


\section{ii. John Locke and David Hume}

John Locke begins his work on empiricist epistemology, An Essay Concerning Human Understanding, by taking aim at Descartes' belief in innate ideas, based on his observation that infants seem not to possess any ideas universally _even the idea of God. ${ }^{6}$ Instead, Locke argues that the mind comes to be furnished through experience of perception (53-4). David Hume, following up on the work of John Locke also argues that meaning not only could come through perception, it must come through perception- that no synthetic proposition about the world can be known a priori. We cannot have knowledge of anything, in other words, that does not come to us through the senses. Here the shift is not away from the individual, but to a different faculty of the individual. In the empiricism of Locke and Hume it is not mind, rationally, analytically that constructs the world from its interior vantage point, it is the percipient impressions given to the individual that build the world experience by experience.

Hume opens $A$ Treatise of Human Nature by asserting that the mind's perceptions are divided into impressions and ideas (Hume 5). He sets down his first general proposition: "That all our simple ideas in their first appearance are derived from simple impressions, which are correspondent to them, and which they exactly represent" (Hume 7). Hume argues that all knowledge is the result of ideas formed after being first presented to the individual through sense impressions. He realizes that one does not have sense impressions that represent only those things of which one has had sense impressions - like fairies and 
dragons, for instance. Instead, the individual possesses an imagination, which is capable of modifying and recombining ideas from the stock of primary impressions and simple ideas (Hume 11). ${ }^{7}$ Knowledge is predicated on the priority of the impressions that come to the individual through the senses, which can then be formed into simple ideas, which can then be re-formed into complex ideas. The crucial point, though, centers on the insistence by Locke and Hume that all knowledge of the world that exists independent of the perceiver is empirically based, which is to say, knowledge of that world is still constructed by the individual not in a "closed sphere of interiority," but through representations of that world.

The difference between Locke's empiricism and Hume's rests largely in their assumptions about divinity. Though Locke disagrees with Descartes about whether God can be known innately, both Descartes and Locke share the assumption that God is the creator who stands at the headwaters of all knowledge. Hume, on the other hand, accepts Locke's empirical epistemological vision, but remains uncommitted to the idea of a divine presence in the world.

It is important to note, though, that what empiricism accomplishes by severing ideas from any innate foundation is the undercutting of teleology. Epistemological empiricism fits neatly with the scientific revolution taking place under Bacon, Gassendi, and Newton. The scientific method, with its emphasis on objectivity of observation and measurability of phenomena assumes that knowledge worthy of rational consideration is empirically based. Inasmuch as the world is known to us synthetically, through our experience, we construct a world 
in which prior teleological meaning has been foreclosed. That is to say, truth and meaning are not something in the world awaiting discovery, but are syntheses of empirical knowledge. But because our construction of truth and meaning out of the empirical building blocks of experience are being shaped and influenced by "passion, custom and education, these syntheses are being made without awareness and without good grounds" (Taylor 165). Like Descartes, then, the empiricists want to disassemble the accretion of assumptions and return to a surer ground upon which to build knowledge.

Notice, though, that while Locke and Hume disagree with Descartes on the possibility of innate knowledge upon which a reliable account of the world can be constructed, inasmuch as knowledge of the world is constructed on the percipient impressions of the individual, the individual (or some faculty or set of faculties of the individual) remains the referent for knowledge. The question, therefore, is not whether knowledge is mediated by the individual but, rather, how. In the case of Descartes, true knowledge is constructed rationally in the mind, prior to any work of the notoriously unreliable senses. For Locke and Hume, however, the establishment of reliable knowledge is reversed; knowledge is synthetic, $a$ posteriori, the construct of the human mind based on sense impressions. In both cases, though, knowledge depends on the individual.

\section{iii. Immanuel Kant}

Immanuel Kant, in the wake of Locke's and Hume's empiricism, is dubious about the ability of the senses to establish knowledge on an epistemically reliable 
foundation. While he believes that empiricism is the epistemological answer to the phenomenal world, there is another world that Kant calls the noumenal, which cannot be epistemically established by the senses—but must be established $a$ priori. Kant's Copernican revolution in philosophy, in which the mind does not conform itself to the world, but the world is conformed to the mind, suggests that for the sense impressions of Hume to be ordered in any kind of intelligible way, they have to be ordered through the a priori invariant categories of understanding (time, space, quantity, quality, modality, etc.). ${ }^{8}$ Sense impressions, in order to make sense, have to be constructed in the mind on the framework of conceptions that cannot be known experientially, but are the pre-conditions for those impressions to be organized into an understanding of the world. Hence, the world and our experience of it for Kant conforms to the categories present a priori in the mind.

It should be emphasized at this point in anticipation of what I will address shortly in the turn to the self that reason, which comes to have primacy in the West from Descartes up through Kant, has as its touchpoint in varying degrees the individual human mind. What Descartes, Locke, Hume and Kant all share, in a departure from the metaphysical realism that had prevailed from the Greeks onward, is no longer a belief that true knowledge is a matter of correctly seeing a world that exists independent of the seer. Instead, knowledge of the world after Descartes, if not generated by the individual, is at least mediated by the individual. Vision continues to offer a fitting metaphor for true knowledge, even 
after Descartes. Now, however, the balance has shifted from what is seen to the seer, at least in terms of the orientation of knowledge.

\section{A Brief Excursus on Ethics and Aesthetics}

It is important to the larger sense of what I want to do later to spend a little time now pointing out how the notion that reliable knowledge is a matter of correctly viewing an order of things that exists independent of the viewer-which has shaped the Western intellectual tradition-is not limited to epistemology. Reason as the mirror of nature also has important implications for ethics and aesthetics. If one has a correct understanding of nature, one also understands the proper ordering of one's behavior as a reflection of the natural order. Moreover, inasmuch as mimesis comes to define art as a faithful depiction of the natural order as it exists independent of the observer, a true grasp of the natural order is a necessary condition of art.

Plato, for instance, understands morality as “doing one's job and not intruding elsewhere" (433b). That raises the question, though, about where it is that one goes to discover in what one's job consists. The answer, Plato says, is that nature equips each of us with a particular job (Plato 433a). But by what means will one be able rightly to discern what nature has equipped one to do? The answer to that question is mutually reinforcing: nature bestows on reason the wisdom to rule the self, while reason is the faculty by which nature is apprehended in order to understand the role bestowed upon the self (Plato 441e). In other words, nature has endowed reason with a capacity, the function of which is to see nature correctly, and then to rule the non-rational parts of the self in 
accordance with that knowledge. This state of affairs in the self mirrors the polity of the republic, in which there are guardians or rulers, auxiliaries (militias), and workers, since "morality is a property of whole communities as well as individuals" (368e). The guardians who rule the community have been given a job by God, which is to make certain that the separate functions of the community operate faithfully each according to its nature, rather than to some pretended function (415b). The successful political system requires that the militia protects, the farmer farms, the craftsperson exercises the craft appropriate to one's nature, and the ruler guards the good the of the community by making certain all functions are rightly fulfilled 434c). Plato lays out his full argument by concluding that "the constituent categories of a community and of any individual's mind are identical in nature and number" (441c). In other words, the self, too, is a political system in which reason rules over the non-rational parts (441e). All of this, though, is a reflection of what is the case by natural design, "formed and nurtured deep inside the earth" (414d). That is to say, morality, as well as epistemology, is a matter not of human invention or social expediency, but of seeing and manifesting what is real in the nature of the cosmos.

Aristotle, too, more or less agrees with Plato in understanding morality as a matter of correctly grasping through rational means the function and telos of a human life. ${ }^{9}$ The purpose that humans fulfill, Aristotle believes, is written into the order of things; the job of reason is to identify that purpose correctly, and then to persuade the non-rational part of the soul to act according to reason. He says in the Nicomachean Ethics that "the human function is activity of the soul in accord 
with reason or requiring reason" (Aristotle Nicomachean Ethics 1098a7). ${ }^{10}$

Charles Taylor writes, "The good order of my life is essentially connected with my being rational, both in that as my rational life reason is the most important determinant of my ends, and also that it is through one of the excellences of reason, phronēsis, that I can determine my life by this order" (125). "Presumably, then," Aristotle says, "the excellent person is far superior because he sees what is true in each case, being himself a sort of standard and measure" (EN 1113a35). Moreover, although the notion of aesthetics as a philosophical discipline does not come along until much later in history, art up until Kant is widely viewed as mimetic representation, that is, it consists of a faithful rendering of nature. It is worth noting that mimesis in art, even from early on, is not a monolithic concept. Between Plato and Aristotle, for instance, there exist differences in some fundamental respects. According to Plato, art is problematic, even socially disruptive, in part, because it is "two steps removed from truth" (602c). That is, according to Plato, truth exists in the world of the forms. Chairs, for instance, are all modeled on the perfect form chair. A manufactured chair, then, is one remove from reality. A painting of a chair is a representation of a manufactured chair, which is itself an imitation. Consequently, rather than clarify, artistic representation further obscures our knowledge of truth. Plato finds art's inexorable slide toward epistemological imprecision unacceptable, contributing to his overall case in which he argues that poets should be banished from the ideal republic. In other words, for Plato, art, as well as knowledge, is tied to a correct vision of what exists in nature. Therefore, to the extent that art (as a mimesis of 
nature) distorts our vision of what is truly real in the world of the forms, Plato believes it causes more epistemological problems than it is worth-not to mention the almost certain morally corrupting nature of art, as in tragedy with its aim of evoking emotional response (unseemly passions best left unprovoked).

Mimetic art, for Aristotle, on the other hand, never pretends to correspond to reality in a simple, one-to-one fashion. ${ }^{11}$ Were simple imitation to be the defining characteristic of art (namely, holding up a mirror to reality), art would then be history - a reporting or documenting of particular events - which, Aristotle is quick to argue, it is not: "The essential difference [i.e., between poetry and history] is that the one tells us what happened and the other the sort of thing that would happen. That is why poetry is at once more like philosophy and more worth while than history, since poetry tends to make general statements, while those of history are particular" (Poet 1451b). ${ }^{12}$ Instead, according to A. D. Nuttall, mimesis in an Aristotelian sense "involves the formal independence-the 'non-reality'—of the signifier," which makes "mimesis hypothetical."13 of course, one must have some understanding of causal relationships about the world being portrayed mimetically. Nevertheless, it must be conceded, as Halliwell notes, that mimesis for Aristotle is a representation that contains the constituent parts of the world we inhabit. What mimetic art does, on this view, is to rearrange these parts into potential patterns or constructions that would be discernible as "possible reality."14 In other words, Aristotle's view of mimetic art understands the artist giving form and shape to material already available in the world, as 
opposed to understanding the artist as performing creatio ex nihilo, that is, creating, through art, a new world from nothing.

This brief excursus on ethics and art in Plato and Aristotle is meant to be suggestive of the relationship between the metaphor of vision as a means of describing the world as it truly is and, in addition to epistemology, what that means for moral and aesthetic engagement of the world. In essence, almost from the beginning of the Western intellectual tradition, human experience on a variety of level assumes correct vision of the world as predicated on a successful negotiation of life. That is to say, ethics and art are bound together with knowledge by a dependence on a correct vision as a necessary precondition of intelligibility. After Descartes not only is the relationship between the individual and knowledge reoriented, but ethics and art will also eventually become untethered from realities that exist "out there," independent of the individual.

\section{The Marginalization of Emotion}

As reason was becoming established with science as the standard of knowledge, the emotions were simultaneously becoming further alienated from the conception of true knowledge. Emotions suffered as the binary opposite, being characterized in purely essential terms. On this reading, emotions appear as instinctive urges-spontaneous and powerful. Even the words that we use to speak about emotions, words like feeling and passion, indicate the Western tradition of viewing emotions as contingent, particular, embodied impulses, while reason has non-contingent, universal, disembodied deliberation as its goal. 
Emotions pull us not in the direction of what is true (or if they do, it is only inadvertently), but in the direction of our desires and cravings - often thought of as "animal desires." On this account, emotions are neither educable nor socially constructed; they are elemental compulsions that threaten to distract us from the important work of reason. The ways we popularly describe emotions suggest that they are like forces of nature: anger is volcanic, joy is irrepressible, sadness overwhelms, and surprise shocks; love is something I fall into, and guilt washes over me like a tidal wave, I sink into despair, and I am overcome with relief.

Certainly, as I will suggest in Chapter Two when I talk about primary emotions, there is a sense in which it is appropriate to speak of emotions as precritical impulses over which we have no control once triggered. What I will argue is that there are basic or primary emotions with which humans are hard-wiredthat is, emotions such as anger, joy, fear, disgust, and surprise-which contrast with complex or secondary emotions-for example, disappointment, anticipation, empathy, resentment, and so on-and that these basic emotions are triggered automatically. It is the triggers of those basic emotions, however, that are socially constructed and conditioned. That is to say, although fear, for instance, is a primary emotion that seems to exist trans-culturally, that which prompts fear can be calibrated (and re-calibrated) on a social level. I may learn to react with fear to an animal native to my environment because I have been taught or have seen that it is dangerous, though a person from another part of the world may see the same animal and be indifferent to it, being without benefit of that conditioning. 
The purpose of my bringing up the emotional essentialism passed down through the Western intellectual tradition is to call attention to the conventional hierarchy of human capacities in which reason occupies the top spot. On this reading, emotions are meant to be controlled by reason, so that they do not threaten reason's rule of the person. According to this view, we are at our most human when reason governs our thoughts and actions. The implication, then, is that we are somehow less human when we succumb to our emotions, that is, to the rule of those impulses that make up our "animal nature." I think this misses a hugely important point about our desire for emotional engagement as a central feature of human life qua human, as I will argue in Chapter Three. I bring it up here to suggest that this hierarchy of human capacities—when placed on a continuum in which human occupies one end of the spectrum in contradistinction to animal, which occupies the other-has implications not only for knowledge, but for the political ends that knowledge (especially in the form of scientific knowledge) serves. In this hierarchy, emotions get negatively defined against reason. Accordingly, emotions in this view are cast as irrational.

The construction of knowledge on this model presents a series of binaries, the establishment of which is a not altogether benign one. These binaries include rationality/irrationality, reason/emotion, science/art, objective/subjective, epistemology/ethics, fact/value, culture/nature, mind/body, as well as male/female. Those privileged concepts that are thought somehow to reside in the rational part of the human inexorably present a negative definition of the concepts on the obverse side of the binary. Hence, the emotions, for instance, are defined 
negatively against reason. ${ }^{15}$ Reason gets defined positively as rational, scientific, objective, factual, and, ultimately, male. In this relationship to reason, emotion is necessarily (if often unwittingly) defined as irrational, un-scientific, subjective, opinion-based, and, ultimately, female, which is to say, as anti-reason. To label the second half of these binaries anti-reason suggests a kind of active hostility toward reason, against which one should be vigilantly on guard.

The process of arriving at reliable knowledge in the West, therefore, has come to assume a suspension of just these sorts of categories of anti-reason. It is worth quoting Kenneth Gergen at length on how this theoretical process of arriving at reliable knowledge unfolds:

If the process is operating without interference, sensations serve as a mirror to the world, and the resulting categories are available for rational thought and communication through language. By implication, this set of presumptions suggests that any other form of mental process may potentially interfere with these essential functions of observation and categorization. Particularly suspect are any processes that link the individual to the external world in such a way that the individual's actions are altered, unsettled, or affected: for processes of this type are just those which may alter the individual's capacities for objective observation. Thus emotions, motives, values, and desires - as traditionally conceivedare all potentially threatening to objectivity. All link the individual to the world in such a way that certain lines of action become imperative and others become abhorrent. In the resulting clamor toward action, the 
sensitive instrument of sensation and the nuanced process of categorization may be unsettled. Biases and distortion are invited (281).

Scientific reason, Gergen argues, receives—or at the least, sustains—its authoritative force through linguistic structures designed to remove the individual from perspectival participant to objective observer. Objectivity, which is central to the scientific enterprise, requires this removal of the individual from observation, just to the extent that the individual, who remains prone to the biases and distortions of subjectivity, is thought to be the weak link in the chain of empirical scientific observation. The difficulty, of course, centers on the fact that empirical observation requires situated individual perspectives of observation, if only because individuals are situated perspectival observers in virtue of the limitations of finite humanity. Scientific empiricism faces the difficulty of simultaneously having to affirm the necessity of human sensation, while at the same time attempting to deny through a shift in language the presence of human sensation as a necessary component of observation—in effect, adopting Thomas Nagel's "view from nowhere" (The View from Nowhere). Gergen points out that the subtle way this shift is accomplished in scientific writing is through the adoption of a perspective of "impersonal collectivity," giving the appearance of the observer as the "omniscient eye" (280). Objectivity is established through a slight alteration of language from, for example, "I observed ..." to "It was observed ..." or "I found ..." to "It was found ..."-which effectively removes the subjective observer in favor of, what is meant to be taken as, an objective observer. "In effect," Gergen writes, "the well-wrought reality must first establish 
the presence of the author within the scene, and then subtly replace the author with a transcendent standpoint" (280).

Through this necessary shift from the establishment of a subjective presence to an objective observer, scientific empiricism sets up what I will call the paradox of the observer. This paradox of the observer stands at the heart of empirically based scientific knowledge. On the one hand, from Locke and Hume to the present day, empirical knowledge is built by the indispensible percipient individual, sense impression by sense impression, idea by idea. The individual constructs knowledge through perceptual information; but as thinkers from as far back as Plato to Descartes are aware, individual perception, because of distorting factors like emotion and evaluation, is not always reliable; it can be manipulated, distorted, miscategorized, or in certain cases, obstinately ignored. Therefore, the perspective of the subjective individual must be transmuted in ways that guard against its unreliability. Knowledge-as Descartes is convinced in the Meditations - if it is to be consistent and reliable must be established on firmer, apodictic ground than what is taken to be the inevitable unreliability of the senses. Since reason is continually presented with, what are taken to be by rationalists and empiricists alike, the potential distortions of emotion, and since humans are amazingly accomplished at self-deception with respect to the process at rational thought (e.g., It is no coincidence, I take it, that rationalizing is so closely related linguistically to rationality.), the irony with Descartes' rationalism is that the firm, apodictic ground upon which he seeks to establish knowledge is a hermetically 
sealed off interiority, and is no less fraught with the peril of human distortion than the empiricists, the heart of whose claims the cogito anticipates.

Leading up to the Enlightenment the search to establish scientific reason under either rationalism or empiricism is a project with a common goal: to set reason on surer footing than what is thought to be available in a system dependent upon divine revelation. To the extent that the new scientific revolution in many cases provides a superior model by which to describe the workings of the physical world and the relationships between organisms, it certainly outpaces a Medieval model dependent on miraculous reliquaries, cosmic crystal spheres, and bodily humours for comprehensive description. The argument I am making is in no way nostalgic about the time prior to the ascendency of scientific reason, which in many respects can rightly be thought of as the "Dark Ages." There is no question that the West, largely as a result of the Enlightenment championing of reason, has experienced great intellectual and social benefit—both in terms of the sheer descriptive power of science and some of the technological advances it makes possible, as well as the potentially less violent vision of human society built on a social contract, instead of on secular feudalism and religious vassalage.

Instead, my aim is to point out some of the serious implications of viewing the world as correctly understood only through reason, a view in which emotion and evaluation are always to be treated warily, as potential distortions to the process of correct description that leads to reliable knowledge. In contemporary Western society, we have come to assume that the scientific model is the only model that can be counted upon to produce facts-where what counts as "facts" is 
itself a product of the scientific method (e.g., Positivism). All other descriptive models (religious, social, artistic, etc.) are to be judged in relationship to their ability to produce output that meets the threshold standard of reason. If they make claims about the world that cannot be verified through the mechanism of scientific reason, these other descriptive models are discounted as subjective, and therefore, necessarily inferior. In that sense then, scientific reason stands above all other ways of knowing, presumably on the establishable ground of reason (if not apodictic, then certainly empirically verifiable) acting as a neutral referee, making non-evaluative judgments about the validity, or even possibility of all other truth claims.

The historical nature of the search for knowledge that can be founded on incontestable grounds external to the individual and unimpeded by the distortions of emotion not only has epistemological implications, but also political ones. Plato, for example, says that "you also appreciate that when we're afflicted by trouble in our own lives, then we take pride in the opposite - in our ability to endure pain without being upset. We think that this is manly behavior, and that only women behave in the way we were sanctioning earlier" (605d)--that is, emotionally. Of course, the advancement of the idea that woman and emotionality are correlatives is consistent with Plato's larger project, which views the political rule of the republic and the political rule of the individual as commensurable. By lumping women together with children and slaves, all of whom "evidently experience the greatest quantity and variety of forms of desire, pleasure, and pain," Plato has announced his general belief in the inferiority of 
women, equating women with the non-rational parts of the mind, both of which are fit to be ruled-by men and reason respectively $(431 \mathrm{c}){ }^{16}$

The equating of male and reason, female and emotion has become a trope in Western thought that creates an ideological subtext, underwriting the current political arrangements. ${ }^{17}$ Genevieve Lloyd observes that "From the beginning of philosophical thought, femaleness was symbolically associated with what Reason supposedly left behind - the dark powers of the earth goddesses, immersion in unknown forces associated with mysterious female powers" (Lloyd 2). As ideologies do this one gains strength by going largely unspoken. Instead of being a self-conscious assertion of the truth (in this case, a malevolent one), ideology operates on the level for the most part transparent to the culture (in this case, Western). Because it is widely assumed to be the way reality is ordered, arguments need no longer to be made on behalf of its veracity. In fact, to the extent that feminism has made successful counterarguments against the assumption that reasonable equals male and emotional equals female, it is because those counterarguments call into question the already settled nature of a traditional understanding of "the way things are." One of the implications of this ideology is that that which cannot be accounted for by the scientific model gets discounted, relegated to a category understood to be less important, a category that does not readily lend itself to scientific description and mapping (e.g., emotion, value, irrationality, beauty, etc.). ${ }^{18}$ Alison Jaggar contends:

In these circumstances, where there is a differential assignment of reason and emotion, it is easy to see the ideological function of the myth of the 
dispassionate investigator. It functions, obviously, to bolster the epistemic authority of the currently dominant groups, composed largely of white men, and to discredit the observations and claims of the currently subordinate groups including, of course, the observations and claims of many people of color and women" (Jaggar 142).

That is to say, white men are legitimated as knowers in virtue of the fact that they are white men. Clearly this is not considered universally true; people of color and women in many cases are also considered knowers. However, to the extent that people of color and women have been legitimated as knowers, it is in spite of, and not because of, the way the world is generally thought to be ordered. ${ }^{19}$

To raise the issue of ideology in the "differential assignments of reason and emotion," though, is not necessarily to assign evil intentions. Plato and Aristotle were not consciously seeking arguments to bolster male hegemony; they believed they were correctly describing the way reality is ordered. Instead, raising the issue of ideology in this instance is an attempt to highlight assumptions that generally operate beneath the horizon of awareness, the unremarked nature of which comprises much of its power as an ideology to establish what can be called "normal" and "real."

In what has become the dominant epistemological model in the West, reliable knowledge is a product of disinterested rationality. Rationality is thought to be able to claim disinterest because of an abiding commitment to objectivity. True knowledge, on this reading, is always knowledge of what is really out there-without regard to the observer. Consequently, the acquisition of 
knowledge comes through dispassionate observation that is value-neutral and non-perspectival. As Daston and Galison have observed, "First and foremost, objectivity is the suppression of some aspect of the self, the countering of some subjectivity" (36). The paradigm for this kind of knowing is physics (Code What Can She Know? : Feminist Theory and the Construction of Knowledge 32).

Viewing physics as the apotheosis of knowing carries with it some assumptions about how that unalloyed knowledge must be achieved. Mary Hawkesworth points out that knowledge constructed on a model of intellectual purity, unburdened by potential subjective human contaminants, runs into a problem —namely, that the attainment of "a decontaminated intellect presupposes that unwanted contaminants can clearly be identified" $(1994,158)$. But even if there were universal agreement on those parts of a person that obstruct rather than facilitate reliable knowledge, it would still have the effect of negatively defining everything else (that is, for example, emotions, values, sensations, imagination, desires, in short, human subjectivity) as not only unnecessary for knowledge, but as impediments to knowledge that must be quarantined, bracketed, subdued if knowledge is ever to be reliable.

Emotions, on this view, are prescinded from successfully assisting us in the acquisition of reliable knowledge. The pursuit of knowledge allows only for disinterested or dispassionate (note the use of "passion" in drawing this binary) observation. In fact, it is always individual observers who threaten to get in the way of acquiring true knowledge, because they are prone (even if unwittingly) to inserting themselves into the act of observation. 
As feminist epistemology has argued, though, the privileging of objective or dispassionate reason over subjective and uncontrollable emotion is ideological, precisely because the historical Western conception of reason is the domain of white males, while females and minorities are said to be controlled by emotion. ${ }^{20}$ That the primacy of reason operates as the most reliable source of knowledge in this epistemological model perpetuates traditional power arrangements. In the "real" world of science and ideas, male reason always trumps female emotion. As an ideology, then, this gendered epistemological model functions beneath the surface of everyday activity as the circumscription of reality. One of its primary ideological functions is to situate rival epistemological claims outside the bounds of "reality." Consequently, the privileging of reason is continually reinforced as the only way to arrive dispassionately at reliable knowledge by placing it in relationship to emotions- - then describing those emotions as unstable and as continually failing to live up to the rigorous demands of objective knowing.

This view of emotions maintains its epistemological authority by situating the entire complex process that makes up emotions as a pre-critical urge, which can only be subdued, but never educated. Jaggar argues that "the apparently individual and involuntary character of our emotional experience often is taken as evidence that emotions are presocial, instinctive responses, determined by our biological constitution" (134). The inference, of course, from the assertion that the emotional process is wholly instinctive is that no part of the process of emotional response can ever be modified or recalibrated, and that we are always at the mercy of our urges as they are; we either conquer them or succumb to them, 
but we can never change them or that which triggers them. If I am seen to be "emotional," I will be seen to have deviated from the baseline of the highest form of human response-reason. And if knowing is the goal, this deviation will be viewed as prima facie evidence that I cannot have reached true knowledge, which is to say, knowledge that would pass muster in a physics lab, discounting it and making it a necessarily inferior form of knowing. And since, as I have already discussed, women and people of color traditionally occupy the emotion side of the reason/emotion binary, and since, according to conventional Western epistemological principles, emotions are obstacles to the privileged knowledge that comes from reason, the status of women and people of color as knowers cannot but be viewed as problematic.

Referring to emotions as feelings or as passions, seeing them as biological fate, then, further underwrites an assumption that emotions are aspects of our existence that are unconditioned and uninformed. In this way, we are always at the mercy of the emotions we have inherited, constantly working to contain those emotions without hope of ever changing them. What I will argue at greater length in Chapter Two, however, is not that somehow the phenomenology of emotions when experienced feels different to the one experiencing them, or appears different to the one observing their manifestation—that is, fear, pity, grief, compassion, and so on feel and look the same whether one assumes they are essential impulses, socially constructed, or some mixture of the two. In other words, I am not making any comment here about how the process of emotional response unfolds once it has been initiated. Instead, I am suggesting that we do 
possess some control over how those emotions are formed, and therefore, what triggers a response. And if we do have some conscious control over our emotional formation, then we also bear a certain moral responsibility for consciously working to form our emotions in ways appropriate to the practice of emotional engagement. I am much persuaded by Lorraine Code's argument about "epistemic responsibility" as the responsibility to know certain things, and that to remain ignorant is not just an epistemic failure but a moral one. If, for example, I am going to Britain, it is incumbent upon me to know that people drive on left hand side of the road. Not to know what should be known in certain cases can constitute a moral failure. However, in the case of training appropriate emotional response, since I do not want to be misunderstood to be saying that emotions have cognitive content, I will confine myself at this point to speaking only of moral responsibility, laying aside arguments about epistemic responsibility. It is important to keep in mind, though, that in the argument I am making training our emotions does influence the kinds of things we can know; for example, to experience disappointment at being turned down for a job is in some way to have knowledge of the emotional responses of another in a similar situation. This knowledge of another's emotional response, if it is to be more than knowledge of potential responses to certain stimuli, if it is to be the kind of emotional attending necessary for intersubjectivity, it must be informed by something more than reason alone; which suggests that there are certain kinds of knowledge it is necessary to possess for life in community that are available as knowledge but which come to us through another faculty beside reason (see Code Epistemic 
Responsibility). Hence, as Aristotle insists, the education of the emotions so that we experience them at the right time and in the right way is fundamental to eudaimonia.

Inasmuch as reason, especially scientific reason, has gained preeminence in the West as a way of knowing, emotions have been pushed to the irrational margins, calling into question, as I have noted, the status of who can be considered knowers. Though our relationship to the world in which we live, as well as how we can know about that world, has been the subject of much contention, the status of reason as the final legitimator of knowledge has remained fairly constant, moving in fits and starts from an external world we seek correctly to reflect (as if in a mirror) to an interior world constituted rationally, to a world made available to the interior through sense perception, to a world constituted through subjective universality. From Descartes onward, though, the emphasis on the individual as the locus of value has also emerged as a crucial part of the conversation. Whether the world is presented to the individual as a series of representations that evoke ideas within the individual —a world constituted by the individual mind, as is the case with Descartes - or it is the other way around, that is, that ideas are themselves formed by the experience of sense impressions presented to the individual who constructs the world through those impressions, as is the case with Locke and Hume - or it is some mix of the two- that knowledge of the world comes through sense impressions that can only be intelligible after having been organized by the a priori categories attendant in the mind, as is the case with Kant, the centrality of the individual looms large. It is 
important to keep this epistemological shift in mind - a shift from knowledge as a reflection of the world to which the individual must adjust to a state of affairs in which knowledge is, if not a construction accomplished at the hands of the individual, then is at least, mediated by the individual. This epistemological shift informs the turn to the self as the final arbiter of value claims, a turn which was simultaneously emerging as a phenomenon in Western religious and social arrangements. It is to this shift that we must now devote our attention.

\section{The Turn to the Self}

The time is now propitious, as he guesses, The meal is ended, she is bored and tired, Endeavors to engage her in caresses Which still are unreproved, if undesired. Flushed and decided, he assaults at once; Exploring hands encounter no defence; His vanity requires no response, And makes a welcome of indifference (234-241).

She turns and looks a moment in the glass, Hardly aware of her departed lover; Her brain allows one half-formed thought to pass:

"Well now that's done; and I'm glad it's over."

When lovely woman stoops to folly and

Paces about her room again, alone, She smoothes her hair with automatic hand, And puts a record on the gramophone (249-256.

(Eliot 80-1)

In this short section from T.S. Eliot's The Wasteland the implications of the turn to the self manifest in the picture of a bored lover who, even though she is engaging in what should be a significant intersubjective emotional encounter (namely, having sex), is merely "bored and tired." 
absorbed that afterwards she is "hardly aware of her departed lover." Tellingly, her first act after sex is to look in the mirror, where presumably she will find the only object of emotional attachment she is able to engage, inasmuch as she is left to pace "about her room again, alone." This short excerpt from Eliot's Modernist masterpiece is suggestive of the turn to the self that, by the early Twentieth Century had firmly taken hold in Western culture.

The rise of the individual in Western thought is well-plowed, if fertile, ground as a subject of intellectual history. The implications of the modern development that centers on the individual as the locus of meaning are broad, but no less significant for that breadth. By referring to the locus of meaning and value that centers on the individual I am suggesting that the final arbiter of what can be said to rise to the level of reliable knowledge and of what ought to be viewed as valuable has shifted radically from the community to the individual. Through this shift epistemology and ethics have gone from matters to be settled by communal discourse and deliberation to matters now finally settled by the individual through a series of interior interrogations.

Epistemology and the individual have had an ambivalent relationship. The tension centers on whether knowledge is a stand-alone entity or a production of the individual. On the one hand, inasmuch as science in the West has come to be accorded the paradigmatic status of true knowledge, the goal of dispassionate objectivity would seem to marginalize the individual as the locus of meaning. However, the implications of Descartes' Theory of Ideas, in which the world, and, therefore, our knowledge of the world exists not objectively "out there," but as a 
subjective reality of the individual, catalyzes a radical shift toward interiority by assuming an epistemological stance of the first person perspective. The relationship between the knower and what can be known, whether knowledge is adventitious and concerns a reality independent of the individual or knowledge is generated in the mind or through the percipient faculties of the individual, has placed the individual in a tentative epistemic relationship to knowledge.

Complicating things further between the knower and what can be know, as Lorraine Code has pointed out, is that "the metaphysics of the person that underpins the objective model (and excludes knowing the person from its purview) depicts human subjects as essentially solitary, separate, self-subsistent beings, fundamentally opaque to one another. ${ }^{22}$ If Code is right, it is precisely the alienating effects of objective knowing that throw the individual back upon herself, thus creating, ironically, a dynamic in which interiority is the primary stance from which to negotiate human existence. Descartes set the modern course for what has often been called the turn to the self. In Descartes rationality, according to Charles Taylor, "is now an internal property of subjective thinking, rather than consisting in its vision of reality" (156). Without question a Cartesian philosophy of mind is viewed by most philosophers today as inadequate. There can be little doubt, however, that Descartes' influence is still with us. In moving epistemology from a search for what is really metaphysically "out there" to a reality that must be constructed by attending to the representation of impressions to the mind, Descartes has set the stage for the popular contemporary penchant for questioning the claims of all external authorities until they first past through the 
epistemic filter of the individual. Indeed, on this popular contemporary reading even what or who can be considered an external authority is a matter of individual choice. The question is not always a matter of what the facts demonstrate, but a matter of what common standard can be used to adjudicate questions of facticity.

The issue of the debate over facticity, for example, is illustrated by the contemporary chasm between scientific evolution and theistic creation. The gulf develops not with whether or not one side or the other is properly attending to the facts, but with who or what is in a position to determine the authority necessary to make factual claims in the first place. In other words, the argument is not over a common set of facts. The argument is prior to - and seemingly incommensurable with-just what standard establishes the factual nature of facts. The argument is not over whether the facts of science or the facts of the Bible are more reliable, but over whether science or the Bible has the right to claim legitimating authority for the other.

Kant retains some of the spirit of Descartes, and in the process demonstrates the link between epistemology and ethics in his essay, "What Is Enlightenment?" In it Kant argues that enlightenment is humanity's attempt to liberate itself from its "self-incurred tutelage" (3). That is to say, for Kant, humanity's moral failure consists in its convention of continuing to take direction from some external authority. According to Kant, the remedy for this rational timidity lies in enlightenment-Sapere aude! - the determination to trust one's own reason. In contemporary terms, Kant seems to be offering the exhortation to take the initiative to "think for oneself." In other words, not only should morality 
be grounded in reasons that seem fitting to the individual rather than imposed by some external authority, but that even the reason upon which that morality is based is apprehended by the individual. Kant moves away from a Greek conception of morality as tied to the polis or the Christian conception of morality as imposed by ecclesiastical mandate, arguing that true moral agency requires the unfettered freedom of the individual will—absent any exterior influence (either political or theological). ${ }^{23}$ In the process, Kant (unwittingly, I think) helps to set the stage in ethics for the popular contemporary understanding of the individual as the primary arbiter of what constitutes moral action.

Additionally, although Kant raises the issue of the necessity of dispassion and universality in aesthetics, that universality in aesthetics is the sum of percipient subjectivities. So, although objectivity and universality are what Kant strives for, he leaves the door open to those who would come behind him to understand the movement of ethics and aesthetics as beginning with the individual and moving outward. Unfortunately, in a move Kant sought to prevent through his work on aesthetic judgment, as modernity takes hold, art increasingly becomes a matter of individual taste, failing to recognize an objectivity formed by a necessarily consensual collective subjectivity.

Moreover, political philosophy, for instance, undergoes a radical transformation with the emergence of liberal democracy and the social contract as a way of empowering collectives comprised of individuals. ${ }^{24}$ In religion, the reforms of the Protestant Reformation are predicated on the assumption that ecclesiastical structures, more often than not, stand in the way of the individual's 
access to God. Individual interpretation of scripture and the emphasis on the priesthood of all believers by the Protestant Reformation effectively moves the emphasis off of the church and its clergy as the primary mediators of divine grace and firmly onto the individual. Furthermore, the rise of critical theory in the 1960s, in particular Postmodernism in its various forms, draws attention to the instabilities in structures that have traditionally been assumed to be established and constant. From questions of epistemology to questions of language, postmodern critical theory has challenged assumptions about what can be depended upon to provide meaning, even within particular cultures and linguistic systems. As a result, the individual is under mounting pressure to provide a meaning and purpose for life that emerges from a kind of radical interiority. My attention to the rise of the individual in Western thought as a phenomenon with broad implications centers not on viewing this phenomenon as an end in itself, but as an analysis of some of the problems inherent in so viewing the world. Ultimately, part of my larger argument is that regarding the individual as the locus of meaning and value has profoundly damaging implications not only for epistemology and ethics, or even for aesthetics, politics, and religion, but for the kind of emotional attention (described by Iris Murdoch as the "loving gaze") that is necessary for human intersubjectivity and, therefore, human flourishing. I point out the trajectory of the turn to the self and its implications in epistemology, ethics, aesthetics, political philosophy, religion, and critical theory not because I intend to trace this turn in each discipline-a capacious, if not impossible task in a 
single work (let alone in a chapter)—but rather to suggest initially just how sweeping this turn to the self is, and how far reaching are its implications.

Once again, my interests in the survey of the turn to the self tend toward the illustrative, rather than the exhaustive. What I seek here is to be able to trace the story of the rise of the individual in Western thought in a general way as a necessary backdrop to the later explication of the threats to intersubjectivity in that development to which I will attend in Chapter Four. Locating meaning and a purpose for life within communities underscored by intersubjectivity, and beyond the realm of the individual, I would suggest, allows one to see others as subjects with their own projects and goals - rather than as objects to be viewed through the objectifying and abstracting lens of reason or through the reflexive lens of the individual.

As I have indicated, I will have more to say about the necessity of a community that fosters the kind of emotional engagement critical to human flourishing in Chapter Four, but I want to take a moment at this point to say what I mean by community. By community I mean those sometimes formal and other times informal groups to which people belong, and from which people receive a variety of messages about what is real, true, beautiful, moral, and valuable. A community in the sense I am using the term here could be as large as a nation or a society, or as small as a family. A person may come under the influence of multiple communities at any given time - many of which overlap and offer competing messages about what is real, true, beautiful, etc. These communities construct webs of meaning that also contain within them often competing, or even 
contradictory, claims. And while it is true that the individual frequently finds herself in the position of having to discern between the claims of different communities, it is also the case that much of what comes to be understood as real, true, beautiful, etc. by the individual comes through the influence of these various communities-without a conscious decision made by the individual; and it is this conscious decision that is presupposed in modern accounts of value that purport to be individually derived.

At the same time that reason was becoming entrenched as the only path to reliable knowledge, the groundwork was being laid to establish the individual self as the locus of meaning and value, the true touchstone of reality - a state of affairs that persists in the west to this day. Charles Taylor identifies this epistemological shift, this turn to the self, as "radical reflexivity" (Taylor 131). Taylor avers that it is Augustine "who introduced the inwardness of radical reflexivity and bequeathed it to the Western tradition of thought (Taylor 131)." What we find in Augustine is an interiority that is radically reflexive in virtue of the fact that what becomes important "is the adoption of the first-person standpoint (Taylor 130)." Hence, radical reflexivity is not only an awareness of the self, but is an awareness of awareness; it is the illumination of "that space where I am present to myself (Taylor 131)." Augustine, then, stands as the predecessor to Descartes and the radical subjectivity which was to follow. ${ }^{25}$ Richard Rorty quotes Gareth Matthews to this effect, saying:

The picture of human beings as having ... both an "inside" and an "outside" is so commonplace, so (as it may seem to us) commonsensical, 
that we find it hard to realize how strikingly modern it is. But to appreciate its modernity one need only cast about for statements of it earlier than Descartes. One does find interesting anticipations of it in Augustine, but not much earlier, and not much between the time of Augustine and that of Descartes. ${ }^{26}$

The relatively recent and "commonsensical" nature of the inside/outside binary suggests its ideological nature--that is, its nature as a construct has taken on such an air of reasonableness and taken-for-grantedness that it seems impossible to contemporary minds to imagine how it could be otherwise. And yet, it is the continuation of this inside/outside binary that makes preferable the nature of knowledge, as well as moral and aesthetic judgment, as generated within the interior life of the individual possible. Traditionally, identity was assumed to be a product of a network of social relationships, the appropriation of certain kinds of roles within a community, rather than a heroic act on the part of the individual.

In this section I want briefly to trace some of the contributing factors in establishing the self at the center of Western epistemological and moral life. I will provide a brief sketch of how theology in the wake of Meister Eckhart and Martin Luther increasingly locates the important work of the spiritual life within the individual. Then, I will outline some of the developments within Western philosophy that also contributed to the process of interiorization, from Descartes through the Emotivists.

Admittedly, many factors in the intellectual and cultural history of the West bear investigation beyond the few threads I intend to follow. The turn to the self 
deserves a much more comprehensive exploration than space will permit me. My purpose in this chapter is not to trace all the possible contributing dynamics that have resulted in the tectonic shift to what I have called the turn to the self, in order to prove that this state of affairs has occurred. To do so would be a different and much more ambitious undertaking than I am able to do now. Instead, I will begin by reiterating my working assumption, one that is, I think, defensible and not terribly controversial, which is that the radical reflexivity described by Taylor is a contemporary Western reality, if not an inevitability. Taking that as an initial assumption, I am trying to weave together some of the threads that have delivered us to this place. The picture I am trying to draw in this section has to do with just a few of the various influences that illustrate the shift from a culture ${ }^{27}$ that begins with the Greeks and continues on through much of the Middle Ages. This shift highlights the movement from a time in which individuals understood themselves $q u a$ individuals primarily through their relationship to a larger community (namely, the Greek polis, and later the Roman Catholic Church) to a modern liberal culture in which the individual understands himself $q u a$ individual by a freedom to choose - $\mathrm{a}$ freedom of choice that is believed to precede the exterior influence of a community. In fact, a common assumption is that communities not only do not precede the individual, but that communities exist only because individuals have come to together and have chosen as to associate with one another. That is, on a contemporary liberal reading any commonalities that exist in communities are products of choices made by individuals who seek associations based on shared values, projects, inclinations, and so on. 
And while Aristotle says something similar-that the polis "comes to be for the sake of living, but it remains together for the sake of living well" (Politics $1252 \mathrm{~b} 9),{ }^{28}$ suggesting that the impulse to form social networks is an individual one, he is quick to point out that this impulse is not self-generated-that is, that it is not the result of an individual choice. Instead, he says that the social networks that form communities, beginning at their most basic level as the pairing for procreation, are natural impulses (1252a27). In fact, Aristotle argues that communities are prior to individuals, "since a whole is necessarily prior to its parts (1253a20). ${ }^{, 29}$ Aristotle is using "prior" in this case in the sense of prior in nature. That is to say, the polis is prior to the individual, according to Aristotle, because to speak of the individual apart from the polis is to speak homonymously (1253a22). It is, in other words, to speak of a part of the whole without reference to the whole that gives the part its function, like speaking of a hand that is detached from the body. Since a hand detached from the body can no longer fulfill its function as a hand, it no longer has meaning as a hand, making no sense to speak of it as prior to the body — because without a body a hand would not realize the purpose for which nature created it. To Aristotle, then, speaking of the individual's prior choice of the community is akin to speaking of the hand's choice to be a part of the body. The community determines the purpose of the individual, not the individual the community - admittedly a difficult word for contemporary ears to hear.

The movement toward a viewing of the self as prior to and independent of the community, however, was a gradual one. I will now turn to some of the 
factors that contributed to a general reversal of Aristotle's assumption about the relationship of the whole to the parts, various developments that, if they did not cause the turn to the self, then at least made it possible as a cultural eventuality.

\section{a. Theology}

In theology, Meister Eckhart's concept of Abgeschiedenheit (detachment) allowed for a mystical concentration on the internal person, which ultimately fueled Martin Luther's and, eventually, the Protestant Reformation's, focus on interiority. Traced through time, it is possible to identify this radical reflexivity in an increasingly fragmented Protestantism.

With the growth of towns and cities in thirteenth century Germany, one seemed always to be surrounded by people. ${ }^{30}$ It was increasingly difficult to be alone in a physical sense. Eckhart focused on Abgeschiedenheit-that is, the detachment of the individual with her or his own thoughts. The solitude of detachment, Eckhart believes, fortifies the individual against the vagaries of everyday life. He writes: "Here you should know that true detachment [Abgeschiedenheit] is nothing else than for the spirit to stand as immovable against whatever may chance to it of joy and sorrow, honor, shame, and disgrace as a mountain of lead stands before a little breath of wind" (Eckhart 288). This detachment, for Eckhart, is a renunciation of this world in favor of the spiritual world in which one strives to achieve the unio mystica. Put differently, while one has to live among people, one does not have to live the most important part of one's life there. 
Eckhart stands as a precursor to the Reformation inasmuch as he helped establish the idea in German intellectual thought of interiority and the unmediated experience of God, which Luther built on as a criticism of the Catholic Church's indispensability as a mediator of divine grace. When Eckhart suggests that "you must know that the outer man may be active whilst the inner man remains wholly free and immovable" (Eckhart 291), he is anticipating Martin Luther's two kingdom theory.

In the Protestant Reformation of the sixteenth century, Martin Luther, arguably the Reformation's most important leader, initially lays out a strong critique of the Catholic Church. One of the outcomes of Luther's attempt to reenvision the church is his two kingdom theory, which is an extension of Meister Eckhart's understanding of the relationship of the inner and outer person to the state. Luther's two kingdom theory sets a theologically distinguishable line between the earthly kingdom and the heavenly kingdom. The earthly kingdom is the outer world that must function as a political reality, and which is, therefore, the realm of "reason and law" (Witte 5). The heavenly kingdom, on the other hand, is primarily spiritual; it is the realm of "faith and love" (Witte 5). The Christian necessarily lives everyday life within the realm of the earthly kingdom, fulfilling Christian vocation in the process. However, even though one's mundane existence in the earthly kingdom cannot be avoided, the life that has eternal significance is the one lived in the heavenly kingdom - which ultimately came to be identified (pace Eckhart) with the interior life of the individual. ${ }^{31}$ 
In addition to the two kingdom theory, Luther also paved the way in theology for a turn to the self by the very issues he chose to champion. Of central importance to Luther's criticism of the Catholic Church, for example, was his belief that the Church had overreached in its role as the mediator of faith. Luther, for his part, saw faith ultimately as an experience between the individual and God, unmediated by either the Church or its clergy. In other words, the traditional priesthood, which had mediated the relationship between the individual believer and God, ought rightly to be understood as a function of baptism, rather than ordination—namely the priesthood of all believers. Luther's cry of sola scriptura (scripture only), coupled with the priesthood of all believers, was a cry for liberation of the interpretation of the Bible from the hands of the clergy and into the hands of the laity, which led him to translate the Bible from the Latin Vulgate (the language of scholarship) into German (the vernacular). Consequently, the laity was given not only permission to interpret scripture for themselves, but also access to a readable version of scripture as a means to do it. This revolutionary development in Christianity further fueled the social and theological shift from dependence on an exterior authority to an emphasis on the adequacy of the individual as the primary seat of interpretation. ${ }^{32}$

Given Luther's belief in the importance of the individual, it is ironic, then, that Luther believed that the result of original sin was that the human soul is invcurvatus in se-that is, turned inward upon itself. In his Lectures on Romans, Luther argued that "due to original sin, our nature is so curved in upon itself [incurvatus in se] at its deepest level that it not only bends the best gifts of God 
toward itself in order to enjoy them (as the moralists and hypocrites make evident), nay, rather, 'uses' God in order to obtain them, but it does not even know that, in this wicked, twisted, crooked way, it seeks everything, including God, only for itself" (159). Whether it was Luther's intention or not, the effect of the popular psychologizing of religion done in the wake of his reforms, which led to placing a greater emphasis on the individual as the access point to the divine certainly assisted the impulse of incurvatus in se that Luther believed was the result of original sin.

Moreover, it is possible to trace the impulses toward interiority from Luther down through the Second Great Awakening revivalism of the $18^{\text {th }}$ and early $19^{\text {th }}$ century (e.g., Wesley and Whitefield, and the "strange warming of the heart"), to the indigenous American restorationist movements of the $19^{\text {th }}$ century (e.g., Barton Stone and Alexander Campbell, the Baptists, and the emphasis on adult baptism as a function of the individual's choice), to the rise of the Pentecostal movement of the early $20^{\text {th }}$ century with its emphasis on the ecstatic experience of the individual - all of which have culminated in the modern fundamentalist/evangelical emphasis on the radical individualization of faith as a "personal relationship" with God, over which no outside authority ought to have any power. ${ }^{33}$ The turn to the self as the primary stance toward belief among American Christians — as anticipated by Luther, and subsequently assimilated by a fragmented Protestantism—-has left the individual Christian worshiping a God that is increasingly indistinguishable from himself.

\section{b. Philosophy}


In this section, I will briefly trace these developments that set the stage for a radical turn to the self. In philosophy, René Descartes embarked on a philosophical investigation that would further cement reason in the place of privilege, as well as decisively alienate the individual from the world, and ultimately from herself. At almost the same time, Thomas Hobbes and John Locke produced the framework of a political philosophy—-the social contractwhich emphasized the individual as the fundamental unit upon which society was built, and which held inalienable rights in the face of that society. A century or so later, Immanuel Kant developed a moral philosophy in his Second Critique predicated on the autonomy of the individual to act morally without having that morality externally imposed. Then, in the early part of the twentieth century, the Emotivists reduced moral evaluation to assertions of preference.

\section{i. René Descartes}

Seventeenth century Europe, still reeling from the destabilizing effects of the Protestant Reformation and the Catholic Counter-Reformation of the sixteenth century, and now caught up in the Thirty Years War, underwent an epistemological and cultural crisis. The church, with God at its center, had offered a traditionally firm foundation for knowledge and social stability. God, at the center of the universe, mediated through the structures of the church, provided a model through which truth about the world could be reliably known and upon which society could be reliably organized. With the division, and resulting wars 
between Protestants and Catholics, however, the fundaments of knowledge and culture were called seriously into question.

Moreover, with the emerging belief in the seventeenth century that science rather than theology provided the best model for understanding reality, René Descartes' naturalism attempts to establish truth on a firmer footing than the theological model, which appears under threat of collapse. Through his naturalistic thesis, Descartes attempts to find truth by exhausting the things one can know through a process of doubting. In so doing, he helps locate the discussion about what it is possible to know within the mind of the individual, thereby reversing the epistemological process, which, as we have said, previously involved the receiving of information of an external world that would then be processed internally.

\section{ii. Thomas Hobbes and John Locke}

In England, shortly after Descartes' work in France, Thomas Hobbes, having witnessed the threatening instability of the English Civil War, thought it necessary to reflect on how a government might be ordered in such a way as to guarantee the safety of its inhabitants against civil disorder, while at the same time guaranteeing the autonomy of the individual. Hobbes saw the necessity of a government that would impose order on a society of individuals, who are always threatening to press their own self-interests at the expense of all of the other individuals - which, of course, leads to chaos. Even though the end is the preservation of a social order, the emphasis is still on the individual as an atomic 
unit, who is freed to pursue his or her self-interest—but now within the constraints of a coercive government.

John Locke, on the other hand, saw the establishment of government as necessary not because there were no values prior to the establishment of law and government, but because individuals were often incapable of rightly observing the natural law woven into the fabric of the universe. Interestingly, Locke's understanding of morality was that it was a product of reason in a very mathematical sense. That is to say, reason was the faculty that apprehended natural law, thereby making mathematical one about what must do. However, because Locke viewed government as also bound to the standards of natural law, he believed that when the government ceased acting in accordance with that law, those who established the government retained the right to dissolve it. In other words, once again, the social contract is developed to preserve the rights of the individual against unreasonable demands, whether issued by governments or anyone else. As with Luther, the practical result is the right of the individual to interpret truth - even in the face of overwhelming communal pressure.

It is worth pointing out here that, arguably more than any other, Locke's philosophy of self-evident reason, especially as it is embodied in the socialcontract, is the foundational principle upon which American liberal democracy is predicated. Embedded within the text of the founding documents is the antiauthoritarianism that holds the individual as "endowed by [his] creator with certain unalienable rights." These rights, which are presumably the responsibility of the government to uphold, can only finally be ensured by determined 
individuals who value themselves more highly than any institutionalized authority. The Declaration of Independence lays out the foundation for a formal civic agreement among atomistic individuals whose ultimate loyalties are to themselves:

We hold these truths to be self-evident, that all men are created equal, that they are endowed by their Creator with certain unalienable Rights, that among these are Life, Liberty and the pursuit of Happiness.That to secure these rights, Governments are instituted among Men, deriving their just powers from the consent of the governed,-That whenever any Form of Government becomes destructive of these ends, it is the Right of the People to alter or to abolish it, and to institute new Government, laying its foundation on such principles and organizing its powers in such form, as to them shall seem most likely to effect their Safety and Happiness.

\section{iii. Immanuel Kant}

Immanuel Kant in Germany almost a century after Hobbes and Locke championed the unmooring of the individual from external authority. The practical effect of Kant's emphasis on the necessity of the autonomous human will from external influence was a further isolation of the individual as an indispensable function of moral agency. ${ }^{34}$ For agency to occur the will must be completely free from heteronomous constraints. ${ }^{35}$ This freedom of the individual from external authority Kant called enlightenment (Aufklärung). True 
enlightenment, according to Kant, "is man's release from his self-incurred tutelage. Tutelage is man's inability to make use of his understanding without direction from another" ("What Is Enlightenment?" 3). Therefore, any authority imposed on the individual will (even God's) is heteronomous. In fact, even God is bound by the categorical imperative to act only in ways that are universalizable for everyone: "Nay, it even includes the Infinite Being as the supreme intelligence" (Kant Critique of Practical Reason and Other Works on the Theory of Ethics 18). What is privileged in Kant, then, is the individual and the individual's responsibility (for the purposes of moral agency) to look within himself to discern morality. Granted, because of his assumptions about subjective universality - that what Kant believes the individual will find internally will be found universally when other individuals, stripped of their presuppositions-Kant is rightly understood not be a thoroughgoing subjectivist. Consequently, I do not want to be understood to be implying that Kant was a subjectivist in the sense of private morality. Nevertheless, the cultivation of a habit of turning inwardregardless of whether what one finds is produced by the individual or is a subjective discovery of what is universally the case - is still the cultivation of a habit of looking first internally as the access point to true knowledge.

\section{iv. Emotivism}

The search for meaning and truth as an expression of radical reflexivity has come to have perhaps its greatest expression, however, in the Emotivists. In the Humean tradition of the irresolvable distinction between fact and value, the twentieth century saw a new attempt to describe morality as a set of practices that 
can have no connection with reason, but which must always be merely an assertion of individual preference or attitude. Following G.E. Moore's attempt at the turn of the century to issue a final, decisive blow to an objective morality that resides external to the individual in his Principia Ethica, a group of British philosophers offered an account of morality, called Emotivism.

Emotivism, and its most significant advocate, C.L. Stevenson, suggest that there is no way to span the fact/value divide, and that, therefore, all evaluative statements (including moral ones) cannot be founded on any objective, external framework, but are merely the advancement of personal preferences or attitudes. If I say, "Barry Manilow's music is atrocious," what you hear me say is merely, "I don't like Barry Manilow's music." There is no pre-agreed upon standard of musical superiority to which we might return for the purposes of verifying this assertion as "factual." We say that matters like musical taste are not establishable as facts in the same way as whether or not water boils at 100 degrees Celsius.

Moral statements, a species of evaluative statement, and thus suffering from the same incommensurability with factuality, meet with the same fate. Alasdair MacIntyre writes: "For what emotivism asserts is in central part that there are and can be no valid rational justification for any claims that objective and impersonal moral standards exist and hence that there are not such standards" (19). In other words, emotivists claim that moral statements, because they cannot be universally established as facts are also matters of taste. If I say, "Love is good," emotivism contends that all I am really saying is, "I like love." Therefore, disputes over morals are endless and pointless, in the same way as disputes over Coke vs. Pepsi 
are endless and pointless. The point for my purposes, though, is to show another instance in which, because of the impassable divide between reason and value, the individual is thrown back on herself or himself as a "closed sphere of interiority" to make of knowledge and morality what one may.

Emotivism is an especially important instance of the turn to the self, because its assumptions about the subjective nature of moral discourse are so common. As Alasdair MacIntyre argues in After Virtue-a book given over largely to arguing that the heart of moral discourse (especially teleological moral discourse) has been undercut by the subjectivization of morality brought to its logical conclusion by emotivism - "To a large degree people now think, talk and act as if emotivism were true, no matter what their avowed theoretical standpoint may be. Emotivism has become embodied in our culture" (22). In other words, the contemporary world has embraced radical reflexivity and the turn to the self to such an extent that moral evaluation is rendered unintelligible, divorced like emotion from the objectivity of reason, and as merely the assertion of personal preference or opinion.

\section{Conclusion}

In this chapter I have set down a two-pronged argument regarding the historical currents that have brought us to the contemporary divide between reason and emotion. In the first prong, I described the Western epistemological shifts that resulted in the ascendancy of reason as the primary form of knowing. These epistemological shifts included the seeming displacement of the subjective in favor of the objective, while also moving from a metaphysical realist view of 
knowledge as knowledge of what is really the case independent of the observer to knowledge as more intimately tied with the individual's construction of it. In the case of the second prong, I gave an account of the emergence in the West of what has become a contemporary commonplace, the seeming inevitability of the first person perspective as the primary perspective for negotiating questions of value. This turn to the self represents a shift from a view of reality and one's relationship to it formed communally to a view that reality is processed interiorly, after which choices are individually made about how to respond to that reality.

In Chapter Four, I will discuss how the displacement of emotions by reason and the turn to the self affects the prospects for intersubjectivity and our abilities to view people as something other than objectified abstractions or projections of ourselves. However, before that it will be necessary for me to pause and provide an account of what I think emotions are. Moreover, I will set down an argument that rationality requires reason and emotion to work dynamically and not just antagonistically, to produce knowledge - that the complete absence of either reason or emotion signals a breakdown in rationality. 


\section{CHAPTER TWO}

\section{TOWARD A THEORY OF EMOTION}

\section{Introduction}

But he could not taste, he could not feel. In the tea-shop among the tables and the chattering waiters the appalling fear came over him-he could not feel. He could reason; he could read, Dante for example, quite easily ("Septimus, do put down your book," said Rezia, gently shutting the Inferno), he could add up his bill; his brain was perfect; it must be the fault of the world then-that he could not feel.

Woolf, Mrs. Dalloway, 8

Septimus Warren Smith, a World War I veteran, watched his friend, Evans, killed in Italy "just prior to the Armistice" (86). Witnessing the death of his friend, Septimus observes his own lack of emotion in the face of his friend's death. ${ }^{1}$ Moreover, he "congratulated himself upon feeling very little and reasonably" (86). In Septimus's ability to approach the world exclusively through reason, without emotional attachment, Virginia Woolf makes a statement about what she seems to view as the dubious stance of modern optimism, namely, that science and technology are the height of human accomplishment-indeed, the height of that which identifies us as human. In framing Septimus's plight in terms of a void of emotion, Woolf offers a counterexample to a common postEnlightenment understanding of reason as the apotheosis of what truly counts for a fully flourishing human life. 
Woolf recognizes that a key component of Septimus's chance at human flourishing has been forfeited on the battlefield. He can still reason properlyreading Dante, figuring up his bill; indeed, "his brain was perfect" (88). With great irony, Septimus declares that "one must be scientific, above all scientific" (22). Nevertheless, he understands that reason is not sufficient for human flourishing. He heard his wife crying, for instance, but "he felt nothing," which because of his awareness of this void, drove him "another step into the pit" (90). Smith realizes that he is guilty of "the sin for which human nature had condemned him to death; that he did not feel" (91). Ultimately, the absence of an emotional life, his inability to feel, makes the negotiation of common human social interaction impossible. This deficit of emotional capacity finally drives Septimus to commit suicide.

Septimus's life and, ultimately, his death embody the perception of the traditional Western trope that human beings can flourish in a world in which reason predominates and emotion languishes on the periphery of the irrational. Woolf, through Septimus, provides a persuasive argument about emotions. In the next chapter I will contend that a flourishing human life must include a rich experience of emotion, acquired in the social web of human relationships. As I have already argued in Chapter One, Western intellectual history, especially through the rise of scientific models that valorize objective reasoning, has viewed emotion as an obstacle to reasoning. This marginalization of emotion, accompanied by the turn to the self, has had the, perhaps unintended, effect of 
isolating us from one another, becoming itself an obstacle to a fully flourishing life.

Because I will make the claim later in this chapter that emotions are a necessary part of the process of knowing, it seems important, then, to offer up an account of what I consider emotions to be. Knowing, in the sense I am using it, describes a dynamic process that includes both reason and emotion to arrive at reliable knowledge of the world, as well as a way to negotiate life in it. I am using "knowing" in a broad sense to include both theoretical and practical reasoning, which, I will argue at the end of this chapter, require both propositional reason and emotion to function correctly. ${ }^{2}$ But first, I must explain what I mean by emotion.

A central purpose of this chapter is a survey of various positions concerning the nature and operation of emotions. Along the way, I will offer what I take to be the strongest arguments for various positions, but I will not be putting forward new theories of emotions, because a theory of emotion is support for and not the purpose of the overall aim of this project—which is to argue that proper access to our own emotions, as well as a functionally accurate sense of the emotions of others, is necessary for a fully flourishing life. To advance my larger argument about how emotions are implicated in ethics and in the emotional attending necessary for intersubjectivity, I will defend a theory of emotion that will inform my subsequent inferences about emotional attending in Chapter Four, as well as the ways those emotions can be triggered by literature in Chapter Five. 
To accomplish my purposes, I will briefly survey in section one some common theories of emotion: feeling theories, behavioral dispositional theories, and cognitive theories. I will point out what seem to be weaknesses with each theory. In section two I will argue that non-cognitive appraisals, seen as part of a process, better describes emotional response than theories that attempt to isolate the core component of emotional response- to the exclusion of other components. I will argue, though, that not all emotional responses need to be seen as being elicited by non-cognitive appraisals - that some emotional responses can be cognitively triggered. I will also suggest that emotions run along two tracks, one a quick and dirty mechanism whose primary virtue is speed, and the other a slower deliberative mechanism whose virtue is precision. In section three, I will argue that these two tracks of emotional response may map the divide between biologically essential (i.e., universal) emotions and socially constructed (i.e., localized) emotions. Finally, in section four, I will propose a view of knowing as a dynamic process involving cognitive (reason) and affective (emotion) input. I will contend that both in practical reasoning, as well as in theoretical reasoning, emotion is often a necessary component, the absence of which would severely impede knowing.

\section{Various Theories of Emotion}

A standard device found in books on philosophy of emotion is an initial survey of the various theories of emotion, and how all the theories that have come before are somehow lacking. The sheer number of nuanced theoretical positions 
with respect to philosophy of emotion is vast and daunting. I will briefly outline some theories that attempt to answer the question of what emotion is—only as a means of identifying the backdrop against which I will present my own theoretical position. William James, for example, is famously credited with advancing the theory that emotion is the registering of changes in the body. Gilbert Ryle, on the other hand, suggested that emotions, rather than feelings one experiences of bodily change, are prompts that dispose the body to act in certain ways. Moreover, there are those like Anthony Kenny, Martha Nussbaum, and Robert Solomon who argue that emotions are cognitive in nature, tied to beliefs, evaluations, or judgments. In addition, people like Antonio Damasio, Joseph LeDoux, Jesse Prinz, and Jenefer Robinson hold out for a version of emotion as a non-cognitive appraisal mechanism, by which a person responds to stimuli in the person's environment as positive or negative to the person's well-being. ${ }^{3}$ Before offering a constructive theory of emotion, though, I will set the context out of which the theory I defend arises, by pointing out some of the arguments lodged against the other general theories of emotion that have been popular-arguments, I believe, that show those theories to be ultimately unsatisfactory.

If one were to pay attention to common language usage, one would assume that the word "emotion" carries a self-evident meaning available to everyone. Though people typically believe themselves to be in possession of enough information to identify emotion when it is manifested, if one were to inquire about the nature of emotion, one might be told that emotions are simply feelings we experience. Feelings and emotions are commonly dealt with as 
interchangeable synonyms, as typified by such phrases as "How do you feel?" or "I feel lousy," which, loosely translated can often mean something like, "What kind of emotions, if any, are you experiencing?" or "The emotions I am experiencing are negative." Undoubtedly, feeling questions like the ones I have named can also be directed toward one's health. In either case, though, I would suggest that the references to feelings have to do with the subjective experience of somatic sensation (which by no means exhausts the range of processes involved in the manifestation of emotion, as I will argue shortly). That is to say, people commonly experience emotion as changes within the body. Told of the death of my loved one, for example, I get a hollow feeling in the pit of my stomach. If I am anticipating the appearance of my lover after a long absence, I feel may feel my heart all aflutter. Faced with the actions of an unjust boss, my face becomes flushed with anger.

However, if one were to press a bit further by asking whether or not an emotion could be experienced without a corresponding feeling, one might get different answers. One possible answer to that question might be, "No. It is impossible to experience emotion absent any bodily sensation." Another possible answer to that question, though, might very well be, "Of course people can experience emotion without feeling anything in the body. Otherwise, people whose bodies have limited abilities for sensation (e.g., quadriplegics) would be precluded from having an emotional life." The confusion one finds when moving beyond the simple equating of emotion with feeling, then, begins to point up the complexity around what is truly meant by the word "emotion." I will define 
emotions at this point as complex processes that involve somatic states caused by affective appraisals. These affective appraisals are responses to stimuli in the person's consciousness or environment. I will have occasion later to detail these complex processes, as well as to speak more thoroughly about affective appraisals. Suffice it to say, though, emotions act as evolutionarily advantageous triggers that seek to regulate mental and biological systems for the short-term purpose of thriving — not to mention the long-term purpose of survival.

A theory of emotion based on feelings, like the one put forward by James, makes the claim that emotion is the individual's perception of changes within the body. Anger, for instance, causes an increased heart rate, a rise in blood pressure, and flushed cheeks, while joy can cause an increased heart rate, a feeling of lightness, and even tears. Emotion is the subjective experience of those somatic changes. I will follow Damasio, who differentiates between emotions and feelings, noting that, for one thing, not all feelings have to do with emotions (Descartes' Error: Emotion, Reason, and the Human Brain 145). That my stomach feels empty as I write this does not immediately suggest an emotion that prompts this feeling or is prompted by it. Furthermore, depending on the context, I might associate a variety of emotions with the bodily sensation of hunger. I might associate that feeling of hunger with despair, for instance, if the prospect of eating seems a distant one. On the other hand, if I am fasting as a religious observance, I may associate that feeling of hunger with satisfaction at having accomplished a difficult task. Moreover, I might not associate the feeling of hunger with any emotional response, but merely as a tracking of somatic states. 
Many feelings exist without an association to a particular emotion, including pain, sexual arousal, sleepiness, etc. As Robinson points out, it seems ridiculous to contend that love could be reduced "to an inner feeling such as butterflies in the tummy" (Robinson 5).

Rather, a feeling — which I will define as the monitoring of bodily changes associated with thoughts about specific subject matter-emerges, then falls back below the horizon of awareness. If emotions are processes that involve somatic states elicited by affective appraisals in response to stimuli, then the feeling of emotion is a meta-tracking device that monitors the subjective experience of emotion. Feelings, on this account, are the subjective experience of emotion (Kringelbach 48). They are inextricably linked, but are not the same thing. LeDoux suggests "that the capacity to have feelings is directly tied to the capacity to be consciously aware of one's self and the relation of oneself to the rest of the world" (125). Damasio suggests that the feeling of emotion is an important component of the way we experience emotions, but that feelings are only a part of a more complex process (Damasio Descartes' Error 145). Emotions, then, are complex processes that involve physiological changes prompted by affective appraisals; feelings track these physical changes, allowing for a subjective experience of them. Feelings are a necessary, but insufficient condition for emotion.

Another problem with the theory of emotion based on feelings arises immediately, then, as evidenced by the increase in heart rate for both anger and joy. That is to say, if two different emotions produce the same bodily change, 
how is it possible for the perception of that change to act as determinative in discerning which emotion is at work? It is a problem of classification. If I were to assert that the common definition of cars centered on the fact that all cars have wheels, my definition fails when I remember that airplanes also have wheels. In their famous experiment, Stanley Schachter and Jerome Singer proposed that emotions are the product of the cognitive labeling of physiological states. They argued that "cognitions arising from the immediate situation as interpreted by past experience provide the framework within which one understands and labels his [sic.] feelings. It is the cognition which determines whether the state of physiological arousal will be labeled as 'anger,' 'joy, 'fear,' or whatever"' (Schachter 380). To prove their hypothesis about the cognitive labeling of emotions Schachter and Singer set up an experiment in which they gave participants injections of adrenaline. The subjects were told that they were being injected with "Suproxin," a vitamin compound to measure its effects on vision. After the injection, the subjects were then exposed to a "stooge," who either treated a twenty-minute waiting period as a time for play, or as an irritating inconvenience, depending on what the script called for. Schachter and Singer found that the bodily changes, including shakes, increased heart rate, and facial flushing were labeled as either euphoria or anger based on the stooge with whom they spent time. Their contention was that physiological changes, absent plausible explanations, were identified by the subjects as radically different emotions based on the context in which the experience of those physiological changes took place. They concluded that "to the extent that cognitive factors are 
potent determiners of emotional states, it should be anticipated that precisely the same state of physiological arousal could be labeled 'joy' or 'fury' or 'jealousy' or any of a great diversity of emotional labels depending on the cognitive aspects of the situation" (Schachter 398). Hence, inasmuch as somatic states (and the monitoring of those states) can be associated with multiple emotions, it would seem that emotions are more than merely the feelings of bodily changes, However, though emotions and the subjective experience of emotions (feelings) are different things, if emotions are associated with the monitoring of physiological changes, what do we say about the experience of emotion in people with limited capacity for bodily sensation, those who appear not to have the capacity to "feel" physiological changes, like quadriplegics? Do they not also experience emotions? The important word here is "limited." While much bodily sensation in quadriplegics in the torso is lost, not all is. The physiological changes with which emotions are concerned originate in the sympathetic portion of the autonomic nervous system, which regulates bodily processes like blood flow, respiration, digestion, and so forth-some, but not all of which may be affected in quadriplegics, who can still experience things like a fluttering heart and flushed cheeks, or "butterflies in the tummy."

Another theory of emotion, which views behavior as the primary focus of the make-up of emotion fails to withstand scrutiny. The contention on this account is that emotion is a mechanism—-most likely the result of evolution-that disposes the body to some action. If I see a dangerous animal, for example, the emotion of fear certainly prompts changes in my body-adrenaline surge, 
increased heart rate, drawing blood from certain parts of my body (e.g., away from digestion) to increase the volume of oxygenated blood my heart can pumpfor the purpose of preparing me to run or to fight. In other words, while feeling the changes in my body is a part of my emotional experience, those feelings are signals that my body is disposing me to act in a certain way. But might not anger or jealousy, like fear, also prepare me to fight? If a theory of emotion turns on the assertion that the primary purpose of emotion is its ability to dispose me to action, the fact that different emotions can dispose me to the same action causes the theory to lose force as a heuristic model. That is to say, if a theory of emotion does not allow me to distinguish between emotions, based on its primary premise (i.e., it disposes one to certain behaviors), its use as an over-arching theory of emotion is limited. Additionally, the question arises: What if the emotion requires no behavior? If, for example, someone I do not like receives a failing grade on an exam, I may feel schadenfruede, but it is not entirely clear for what behavior that emotion prepares me. Again, while behavioral dispositions may be a component of the work emotions do, it does not necessarily follow that at its heart emotions are simply a behavioral prompt.

More recently, a variety of cognitive theories of emotion have been advanced, which theories view emotions as a series of judgments made about representations of one's relationship to one's environment. ${ }^{5}$ On this reading, emotions are like thoughts that set off a variety of responses within the body, as well as within one's interior life. These thoughts may take the form of beliefs, evaluations, or desires about intentional objects, resulting in judgments that 
trigger bodily changes and prepare the body for action. Additionally, particular emotions are identified not by physiological changes or behavioral dispositions, but by cognitive content. This cognitive content allows these theories to account for how two different emotions can have the same behavior. The difference between similar emotions (e.g., shame and embarrassment, or remorse and regret) is not necessarily characterized by differences in behavior but by cognitive content (Robinson 8). I may act and feel the same way whether I am ashamed or embarrassed; what differentiates the two is intentional objects. In the case of shame, what is at stake is my sense of self-worth, while embarrassment signifies only my being put in an awkward situation without respect to my self-worth (8). What is important to remember, however, according to cognitive theories, is that it is the judgments that are central to emotion and not physiological changes or behavioral dispositions.

Some cognitive theories of emotion contend that emotions have cognitive content because they are the result of beliefs. ${ }^{6}$ I might be sad, for example, because I believe my dog has been hit by a car, and my sadness is the way my pain manifests. However, if I find out that it was my neighbor's dog, I can no longer cognitively hold the belief that it was my dog that was hit—and therefore, my sadness is no longer warranted (or at least sadness in the same way-if I happen to know my neighbor and my neighbor's dog). I love my best friend, in part, because I believe him to be loyal to me, willing to defend my reputation. If I overhear him agree with someone who is disparaging my character, though, my belief in his loyalty is shaken, and, therefore, my love for him will be altered in 
some way. I may not cease loving him or even love him less, for I may forgive him, but I cannot love him in the same way as I did before.

On a cognitive reading of emotions, however, should my belief change my emotions must change (Nussbaum "Tragedy and Self-Sufficiency: Plato and Aristotle on Fear and Pity" 273). If I find myself enjoying someone's company, who before had been only a source of irritation, I may take it that my beliefs about that person have also changed (even if the change is not something I can immediately articulate). In fact, though, a change in my emotions may precede a change in belief, rather than be the cause of it. If one has the moral belief that homosexuality is wrong, and therefore disgusting, one's general belief in the wrongness of homosexuality may be altered by encounters of an emotional nature with a particular gay person that changes the emotional reaction from disgust to fondness, which then might cause a reassessment of general beliefs.

Furthermore, it is possible for the emotional residue of beliefs to remain even after cognitive information shows them to be wrong-that is, I may still have the feelings associated with the emotion (Nussbaum Upheavals of Thought : The Intelligence of Emotions 36). If I were to have lived in a war zone, exposed to repeated gunfire, it would still be possible for me to react with fear to a loud noise—say, the lighting of a firecracker-even if I know it is not a gunshot because I am watching the person light the fuse. But in a case like this one, my continued response of fear in the face of cognitive information I know to be false is something I would eventually hope to modify. However, if beliefs about intentional objects are strictly causally linked to emotional response, then one 
would expect the emotions should automatically change when my beliefs change. That they sometimes do not, presents a problem for cognitive theories of emotion. There are other cognitive theories that link emotion with evaluation. That is to say, according to this type of cognitive theory, emotions are evaluative judgments, in that emotions are prompted by the valence of evaluations. Were I to be disappointed, for example, at being turned down for a job opportunity, my disappointment could be evidence that I placed a high value on getting that job. On the other hand, if I hear that the job has been offered to someone else, and my reaction is relief because it is a job I felt obliged to apply for but did not really want, my relief also reveals my evaluative judgment about working at that job. But, as Alison Jaggar has pointed out, the evaluative nature of emotions is not only confined to the individual and her values. In fact, emotions are closely tied to more general evaluations (Jaggar 137). General evaluations have to do with things like cultural or communal expectations of a shared moral framework. ${ }^{7}$ I experience joy at many of the same things that bring joy to most people: I do or witness a good turn done; I give or receive a well-intended gift; I watch people I love flourish. However, if someone I love flourishes and I do not experience joy, then because I have failed to meet a general evaluative expectation of emotional response, the cultural expectation would be that I must explain my lack of joy in this case (137). That people can argue about normative manifestations of emotion does seem to suggest that evaluations are at play. If I ought to feel joy at the flourishing of someone I love, then a kind of meta-evaluation would seem to have been made about the appropriateness of a particular evaluation. 
Still other cognitive theories note that part of the cognitive judgment may not be representations of actual situations, but of situations that are the object of one's desires. I may experience anticipatory joy when I think about my children graduating from college, for example-even though there is no immediate cause for my joy. In other words, desire prompts me to imagine objects that are related to me positively or negatively, eliciting an emotion that cannot be prompted by my body's responding to actual situations. I may make judgments, therefore, about situations that have a beneficial or threatening impact on me only in some imaginary sense. The ability of a person to respond emotionally to imagined situations (about which I will have more to say in Chapter Five), I would suggest, also strikes a blow at feeling theories of emotion-inasmuch as in the case of desire it is not clear how a bodily sensation absent any immediate object could cause an attribution of emotion to a non-existent state of affairs.

Cognitive theories of emotion, however, have come under recent attack, especially from those exponents of appraisal theories of emotion, who are quick to point out what they consider to be the shortcomings of making thought the central component of emotion. Several critiques have been made against cognitive theories of emotion, including the objection that, contrary to the assertion advanced that a judgment is an emotion, it is possible to make a judgment without experiencing the emotion that should correspond to it. If I am in an awkward situation, I need not necessarily experience embarrassment. I may find the whole thing funny, or pathetic, or of little moment (Robinson 14). 
Also problematic to cognitive theories is the fact that cognition assumes the ability to conceptualize. If emotions are foremost cognitive in nature, then my anger that my neighbor stole the newspaper out of my box derives from a concept of what stealing means and how it is that a box can be conceptualized as belonging to me. These conceptualizations are the result of representations of the world grouped together and formed endogenously. Endogenous conceptualization in this case means that emotions can be prompted without any immediate external stimulation, as, for instance, when a picture of my dead grandfather pops into my head and I feel grief, even though he has died years ago. However, as Jesse Prinz point out, "Infants and animals may have no emotion concepts at all. Their affective lives may always be under exogenous control" (Prinz 50). That is to say, as is the case with infants and animals, it is possible to experience emotion without the corresponding cognitive concepts. If one were to say that emotion requires cognitive conceptualization, one would need to offer an account of the affective states of infants and animals that would differentiate those states from true emotion. Hence, if emotion can be experienced without cognition, cognition is not an essential, let alone central, component of emotion. Furthermore, the necessity of conceptualization present in cognitive theories encounters another serious problem: the physiology of cognition. Building on Antonio Damasio's work ${ }^{8}$, Paul Thagard and Fred Kroon present a model of cognition that integrates emotion input with higher-order thought to form cognition. ${ }^{9}$ According to Thagard and Kroon, sensory input is received by the ventromedial prefrontal cortex (VMPFC) and the amygdala. The VMPFC, 
receiving simultaneous input from the amygdala—which processes somatic states—encodes both sensory information and somatic response in what Damasio calls, somatic markers. A somatic marker is a memory trace "that represents a given action and the expected consequences of that action" (Thagard and Kroon 92). The somatic marker is housed thereafter in the VMPFC as a positive or negative reminder of the outcomes associated with similar sensory inputs. As a five year-old I ate a bad plate of goulash that made me violently ill. To this day, when I see goulash, my body, as well as my conscious mind, remembers the feelings associated with that illness-thus prompting me to steer clear of goulash. These somatic markers are not stored as cognitive constructs, but as quick and dirty appraisals that take into account both cognitive and somatic information, which are encoded in the somatic marker. Once a somatic marker has been triggered by new sensory and somatic input emotional reactions signal "the predicted outcome of a given event" (92). Thagard and Kroon take Damasio further by offering up the nucleus accumbens, via input from the hippocampus, as the gate-keeper to higher-order cognition. They write: "Our extended mechanism describes how the nucleus accumbens narrows down the alternative choices by allowing only those behaviors that are consistent with the current contest to access higher-level cognitive processes and/or the motor effector sites responsible for action" (92). In other words, rather than let in all input, the nucleus accumbens limits the number of possible objects for cognitive processing. The outcome for the current action — which Prinz refers to as recalibration and calibration - then gets reintroduced to the VFPMC as a reinforcer of an already established somatic 
marker, or as a new somatic marker in its own right, potentially to be called into action again in the future when a similar situation arises.

This affective reaction to environmental stimuli described by Thagard and Kroon happens on a physiological level in a matter of microseconds. It would seem, then, that the sheer processing speed necessary for emotional reaction is the most devastating argument to cognitive theories of emotion. That is to say, there simply is not enough time for complex cognitive judgments to cause the somatic response in most cases where an emotional reaction is manifested. LeDoux argues that "prepackaged responses ... take place before the brain has had the chance to start thinking about what to do. Thinking takes time, but responding to danger often needs to occur quickly and without much mulling over the decision" (175). The amazingly small amount of time that elapses between sensory stimulation and emotional reaction, however, can be accounted for by a different kind of affective or embodied appraisal that relies on the triggering of somatic markers and not on cognitive judgments. Morten Kringelbach concludes that "conscious brain processing is serial and slow, and rarely can process more than nine elements at a time. Nonconscious brain processing can manipulate much larger amounts of information, which means that our decisions can be influenced by information from the senses that are not normally consciously available" (27). It is this "nonconscious brain processing" that I am calling affective appraisalsto which I turn next.

\section{Affective or Embodied Appraisals}


I have listed appraisal theories of emotion as another possibility in the challenge of understanding emotion. I must make an important distinction, however. Cognitive emotion theorists might very well be quick to exclaim that they too are employing an appraisal theory of emotion. What, after all, is a belief, an evaluation, or a judgment if not an appraisal? Taking into account this possible objection, it is now important to be more explicit about what I mean by appraisal theories of emotion.

An appraisal, when the term is used by a cognitive theorist, acts as the rough equivalent of a judgment. The kind of appraisal I am describing, however, would be a non-cognitive appraisal that triggers a physiological response. Neuroscience is now relatively unified in claiming that an emotional reaction is the result of sensory stimuli that trip non-cognitive triggers-that is, somatic markers or memory traces (Kringelbach 68). What Damasio calls somatic markers act as encoded reminders of past experience and predictors of future experience that help to set the context for response to current stimuli. They do this by narrowing down the possible responses to those stimuli, which responses assist decision making. Craig DeLancey and Paul Griffiths refer to the triggering of emotions as affect programs, which programs operate as syndromes that "are coordinated collections of complex biological responses that occur together" (DeLancey 3). ${ }^{10}$

Robinson and Prinz, also taking a cue from Damasio's concept of somatic markers, offer up this as a form of non-cognitive appraisal, naming it affective appraisal and embodied appraisal, respectively. Robinson writes: "We can think 
of the affective appraisal here as a kind of 'meta-response', evaluating in a rough and ready way — for example, as bad for me or good for me - an already existing cognitive evaluation" (Robinson 62). Prinz argues for something similar, suggesting that the appraisals are embodied responses. Contrary to Thagard and Kroon who contend that the somatic markers are stored in the VMPFC, Prinz believes that the embodied appraisal elicits cognitive judgments through a noncognitive data structure located in long-term memory. In essence, Prinz wants to keep Damasio's somatic markers as the bridge between non-cognitive embodied appraisals and cognitive judgments. That bridge Prinz calls calibration files, which act as a repository for representations that track and store emotional experiences (Prinz 100). On the whole, though the terminology and a few of the details are different, both Robinson and Prinz offer up theories of emotion that are similar to the theory placed on offer by Thagard and Kroon, not to mention Damasio and LeDoux, which explains (at least some) emotion as prompted by non-cognitive appraisals.

And while I believe these theories to be more or less good descriptions of emotion, they do raise questions about the broad range of emotions, many of which seem not to be prompted in this kind of involuntary reflexive way. I can grow fearful, for instance, over the course of time--not just in the event that I encounter an immediate threat. Given non-cognitive theories of emotional response times being registered in micro-seconds, then, someone might ask, how it is possible to account for emotions that take longer to manifest. We are suspicious of people, for example, who claim that they have experienced love via 
the sort of rapid response mechanism I have just been describing. Love, it seems clear, is more nuanced and slow-forming than can be elicited by the lightningquick electrical impulses necessary for non-cognitive appraisals.

Steven Horst, using evolutionary description, observes that there are some emotions that operate as "quick and dirty mechanisms that adapt the animal's behavior on a short time scale to potentially relevant environmental cues" (Horst 46-7). This tracks the process of non-cognitive appraisal I have suggested. In addition to the quick and dirty mechanism, however, is a slower-developing mechanism that makes heavy use of cognitive appraisals. These more slowerdeveloping emotions are sometimes described as complex or secondary emotions, to distinguish them from what some understand as the sorts of basic or primary emotions that are elicited through the quick and dirty mechanism. ${ }^{11}$ It is important to point out that quick and dirty non-cognitive appraisals are much more imprecise. Their virtue is speed, not accuracy. These are what Horst calls, "the junkyard dog of the soul" (55). Their task is a quick response, early warning system. However, because the trigger is so sensitive, there are a large number of false positives ("Oh, that was a garden hose, not a snake."). More complex emotions, on the other hand, use cognition much more extensively, which necessarily makes them slower response mechanisms. Many of the situations in which humans find themselves require precision in judgment that may take time. However, there are also situations in which extended deliberation would be potentially lethal ("Is that a car speeding at me at a high rate of speed? Should I move or will it miss me? Can I trust the driver to see me? Can I trust the driver 
to pay attention to traffic laws? etc.) —and therefore, evolutionarily disadvantageous.

If there are two different tracks of emotional response—one quick and dirty, and the other slow and deliberative — one might be tempted to conclude, as Paul Griffiths does, that there is no such broad category as emotion per se. Rather there are different affect programs that make up a series of independent mechanisms, with nothing like the category of emotion to draw them all together under the umbrella of a single, unifying concept (Griffiths 14-5). Of course, one might argue that the very fact that there is a conversation about whether there is a category called emotion suggests that there are enough similarities between different emotions to lead people in a commonsense, folk psychological way to speak about some larger inclusive grouping. On the other hand, the dissimilarities between emotions also suggest that not only do different emotions "feel" different from other emotions, but also that they may be elicited in different ways. I will suspend judgment, except to say that since emotion is widely considered to be a taxonomic reality, I will continue to speak of it in that way.

The differences between quick-response and slow-developing emotions can be accounted for, though, by seeing emotion as a process. ${ }^{12}$ So far, I have listed four basic theories of emotion, the central elements of which, comprise the process by which emotion manifests: bodily/feeling, behavioral disposition, cognitive appraisal, and non-cognitive appraisal. The first three theories typically make the claim that one component of emotion is constitutive of emotion. Whether it is physiological changes for the feeling theorists, action tendencies for 
the behavioral theorists, or conceptualized thought for the cognitive theorists, one component is deemed to lie at the center of emotion. While the other components may be present when emotion manifests, they are considered to be attendant phenomena, not phenomena constitutive of emotion.

The felt need to distill emotion down to its essence, while attractive in theory, may ultimately prove elusive just to the extent that the essence of emotion seems not to be localized within a single component of the emotion process, or, as is the case with physiological response, unique to emotion. If so, then none of those components of emotional response is the essence of emotion. Robinson argues that there is more to gain from viewing emotion as a process that incorporates a variety of components: 1) affective appraisals, 2) physiological responses, and 3) cognitive monitoring (Robinson 89). In making this claim, though, she affirms that there is a unifying category called emotion, while at the same time denying that there are two different species of emotion (i.e., quick and dirty, as well as slow and deliberative). She is committed to the claim that all emotion is experienced through the same process that unfolds each time in the same particular order-affective appraisal, which leads to a physiological response, which in turn is monitored cognitively.

I would like to suggest along with Robinson that there may not be any essential emotional component-that neither feeling, nor the disposition to behavior, nor cognition is a sufficient condition of emotion —or that if there were an essential emotional component, it is unclear how we might gain from having identified it. Instead, seeing emotion as a process made up different components 
seems to offer the best description of emotion. To the three steps in the process that Robinson names, I would add behavioral dispositions or action tendencies, which also seem identifiably present in most emotional responses. I suspect that Robinson would prefer to categorize action tendencies under physiological changes, arguing that action tendencies are only possible through physiological changes. In other words, anger causes a range of physiological changes that prepare a person for a confrontation, which raises the question about why it would be deemed advantageous to distinguish between the physiological changes and the behavior toward which those changes dispose the subject? Are they not of a piece? In the case of anger (and perhaps other "basic emotions"), I would agree that the connection between physiological change and behavioral disposition are clear and strong. The connection, though, between physiological changes and the disposition to particular behaviors seems much less obvious when dealing with "complex" emotions. If the physiological changes triggered in emotion have as their purpose a specific disposition to behavior, why would there be physiological changes when there appears to be no overt behavior necessary-like schadenfreude, to return to an example? I think the affirmative argument that physiological changes and action tendencies are inextricably linked is more difficult to sustain in the absence of a physiological change that seems to have no action tendency attached to it.

Moreover, I would argue that the triggering of emotion need not always happen as an affective appraisal as Robinson suggests-that any cognition involved with emotion emerges retrospectively - that is, after the affective 
appraisal (Robinson 89). I see no reason to grant Robinson's claim that all emotions are elicited by affective appraisals, nor what advantage is to be gained from denying that emotions can be elicited through another componentspecifically, cognition. Prinz proposes that emotions can "be triggered by cognitive states," inasmuch as cognition involves mental representations "under organismic control" (75). That is to say, if mental representations are not produced exogenously, then they qualify as cognitive states. To the extent, therefore, that emotion is triggered by an endogenous mental representation, it is cognitively induced.

While I admit that cognitive appraisals typically require more time to unfold than affective appraisals (which because they act as triggers, are measured in microseconds) I can envision scenarios in which an exogenous stimulus necessary for an affective appraisal could be absent. Lying in bed, having problems sleeping, my mind randomly flits from one thought to another, with no discernible pattern present. Though I am not sleepy, I am not agitated. Pleasant thoughts mix with unpleasant thoughts. For whatever reason, I think about the wonderful time we had on vacation, the way my wife has begun to look more attractive to me recently, and how I wish we were able to spend more time together doing the kinds of things we have just enjoyed doing together on vacation. Then I make a note of the fact that, because of a pressing development at work, she has had to work a number of late hours-which is not a regular occurrence, but neither is it terribly unusual. Then I remember what I thought was a wrong number, because the caller hung up on me when I answered the 
phone-noting a name on the caller I.D. that I did not recognize. None of these experiences elicited any negative emotional response by themselves. However, as I begin to think of these occurrences in relationship to one another, a gestalt emerges. This new pattern of behavior that I have pieced together cognitively, elicits the first traces of an emotional response, or perhaps multiple responses (e.g., fear, jealousy, anger). Various events that when taken individually all seemed benign, not necessarily prompting affective appraisal or physiological changes tied to suspicion, when grouped together cognitively elicit an emotional response. Only then does my stomach begin to churn, my heart begin to race. When Robinson says that "cognitively complex emotions are triggered by the same non-cognitive appraisals as 'primitive' emotions, but they are succeeded by complex cognitive activity," her argument is unpersuasive just to the extent that cognition in the scenario I described would seem to precede affective activity (89). At heart, her assertion is that the cognitive activity in the example I give comes only after the affective appraisal-I just do not know it. How, apart from its being necessary to her theory of emotional process, she knows affective appraisal must always precede cognitive activity, is never entirely clear. Absent neuroscientific or physiological data that suggests cognitive appraisal in emotional response is always caused by and never the cause of affective appraisal, we are arguing from descriptions of emotional responses that are challenged by counterexamples. Nevertheless, I agree with Robinson that emotion is best thought of as a process that includes affective appraisals, physiological changes, 
the disposition to behavior, and cognitive monitoring, rather than as a product of a single component within an emotional response.

\section{Nature vs. Nurture}

Finally, since I argue that the triggers for emotions are educable, an important question that must be discussed is the extent to which emotions are hard-wired physiologically or constructed socially. If it should turn out to be the case that emotions are hard-wired, what does that do to my thesis that emotions, in a certain sense, can be educated?

That some involuntary emotional responses are a part of the makeup of the human seems undeniable. Recalling Charles Darwin's belief, Dolan and Morris offer that "it is generally accepted that facial emotional expressions represent innate and automatic behavior patterns determined by evolutionary selection" (Dolan and Morris 226). The apparent universal nature of certain facial expressions as a physiological change prompted by an emotional response, for example, is presented as an argument that human beings have at least some inborn emotions. Prinz contends that "it is incredibly unlikely that members of completely isolated cultures invented the very same facial expressions generations ago" (106). Moreover, the presence of emotion in animals and babies seems to suggest that at least certain emotions are the product of nature. Conceding that language about emotion is imprecise, and may not map the same experiential territory—especially when emotion terms are translated between different cultures-it is still possible to observe emotional responses that on a casual 
reading appear to cut across cultural lines (e.g., anger, fear, happiness, sadness, disgust, etc.). ${ }^{13}$ That is to say that there appear to be emotions that could not be the product of social formation, inasmuch as they seem to attend all cultures. I will follow convention and call these innate biological emotions basic emotions. A strict biological reductionist view of emotions as essential to human beings rejects all attempts to explain emotion through social construction.

Someone might point out that basic emotions only cover a portion of those hundreds of words that name particular emotions. How can the rest of the emotions be accounted for? Robert Plutchik, using evolutionary biology as a platform, has proposed a variation on the "circumplex model," which looks like a color wheel, in which basic or "primary" emotions occupy the center in a bi-polar fashion, which he calls "primary dyads" (Plutchik 349). So, joy and sadness, for example, would be opposed, as would anger and fear, trust and disgust, and anticipation and trust. Secondary emotions, on Plutchik's account, would be formed by blending primary emotions, in much the same way that secondary colors would be formed by blending primary colors. Delight, then, might be formed by a mixture of surprise and joy, or irritation by a mixture of anger and disgust. Whether Plutchik correctly identifies the basic emotions is a matter of much debate. However, even if he does not get the particulars correct, his larger idea of secondary emotions being a blend of basic emotions may still have validity. 


\section{Basic Emotions}

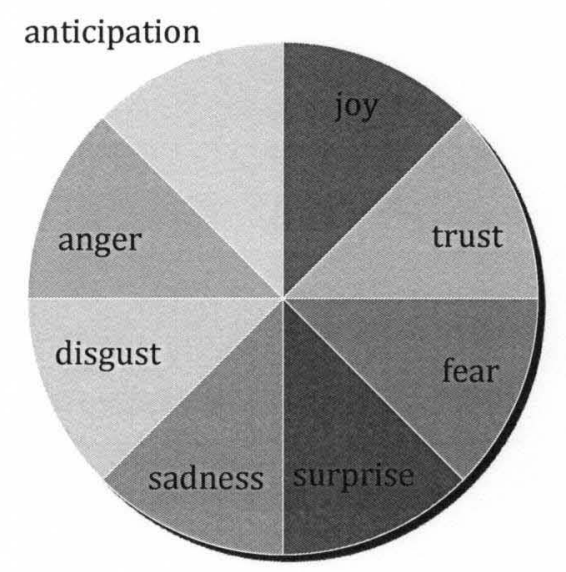

Figure 1 Based on Plutchik's basic emotions on figure 6 in Plutchik, p. 348.

Damasio takes a different tack in talking about basic emotions. Focusing on the neuroscientific data, he posits that basic emotions (or primary emotions, as he refers to them) are processed through the limbic system, in particular, the amygdala anterior cingulate (Descartes' Error 133). A stimulus, a mental representation, is affectively appraised (i.e., non-cognitively) by the limbic system, which sets off a series of physiological responses already preset to confront the particular stimulus. A mental representation in this case acts as a stand-in for the stimulus. I see out of the corner of my eye what looks to be a bird of prey swooping down at my head, and I duck reflexively; my heart beats rapidly, my muscles tense, I breathe more rapidly and deeply. However, what I may be reacting to is the shadow of a cloud or the wings of a songbird, rather than to the real threat. Hence, my body reacts not to the threat itself necessarily, but in a quick and dirty way to the representation of a threat. Though I am not being 
attacked, my affective appraisal of the representation of danger initiates a process whereby I respond as if I were being attacked, and my body prepares me to fight or to flee. Again, these representations reside within us as memory traces- - that is, as Damasio's somatic markers or Prinz's embodied appraisals. These markers, though they trigger innate responses are not themselves innate, are acquired through the unique experiences and the interpretation of the meaning and relationship of those experiences by the individual (Damasio Descartes' Error 136). Basic emotions, such as fear responses, are predetermined processes activated through the amygdala (Damasio, Descartes' Error 133, LeDoux 303). Moreover, secondary emotional responses, which implicate the cognitive process, are activated in the prefrontal cortex. To return to my earlier illustration of a cognitively initiated emotional response, consider the process through which the more complex emotions of suspicion and jealousy are activated.

However, there is not complete consensus about whether basic emotions truly exist. In their provocative 1990 article, Andrew Ortony and Terrence Turner call the premise of basic emotions into question, by noting the lack of agreement among scholars as to the number of basic emotions, as well as just what would qualify as a basic emotion (315). That is to say, if there are emotions that are universally biologically present, they ought to be fairly easy to identify. The fact that there continues to be disagreement over which emotions should be categorized as basic, they argue, weakens the case for innate biological emotions. That there is not yet a consensus on the definition of basic emotions or the makeup of the subset of emotions called basic, though, does not appear to me to be a 
fatal flaw in the theory of universal basic emotions. It may only mean that there is more to be worked out.

A strict social constructionist theory of emotion, on the other hand, argues that emotions are the product of socialization with particular cultures. That is to say, I learn through a process of socialization how I ought to respond to particular kinds of stimuli, and what are considered appropriate ways of expressing those responses. ${ }^{14}$ Moreover, not only are the emotions themselves, as well as the responses appropriate to the emotions, socially constructed, but even the kinds of emotions available to be experienced are to be found within a cultural palette of emotions. In other words, according to social constructionist theories, particular emotions are not located in a universal, essential way within the individual, waiting to be uncovered, but are rather complex products of particular cultures. In fact, different groups within the same culture can have a notably different range of emotional resources and experiences. Nussbaum argues that males, for example, may very well not have the same emotions available to them as females, emotions that are merely awaiting discovery within the male. It could be the case that males have a different "emotional repertory" made available to them through participation in a particular culture (Upheavals of Thought 150). On this view, then, emotions are not something that lie deep within the recesses of each individual, waiting only to be mined and brought to the surface for the purposes of experiencing them, but rather they are socially constructed emotional layers that come to rest on the individual, and that are habituated over time. The process of socialization through social construction, then, offers general evaluative 
information about the world the people inhabit within a culture; it helps to define the range of appropriate emotional responses to the world; and it even establishes which emotions are available to be experienced.

Marcel Merleau-Ponty offers an example of the social construction of emotions. He argues that emotion is caught up in the structures of language. Human beings make meaning by being caught up in structures and frameworks, which are more or less capable of organizing information out of what appears to be chaos. Whether or not one is a metaphysical realist or a metaphysical idealist, information must be organized in such a way as to offer human beings access to it. There may be something "out there" in a real and objective sense, but humanity does not have unmediated access to it. Human access to knowledge is organized and expressed through social constructs, or webs of meaning. That is to say, humans need ways of organizing the seemingly endless array of unrelated bits of data, to produce coherent patterns of thought. Social constructs, or webs of meaning, can be thought of as templates that organize pre-defined groupings of data into identifiable patterns, which could, if not for the template appear as random and unrelated. If, for example, I should wander past a field in which twenty-two people seem to be throwing about a brown oblong object, while chasing each other around and tossing one another to the ground, I can apply one of the templates constructed by the society in which I live to this situation and conclude that what I am observing is a football game. I am able to make judgments about what I am witnessing because I have been given the conceptual 
tools so to identify it. What might otherwise appear to the uninitiated as a potentially violent scene, or as a kind of staged drama, or simply as a series of unrelated acts among people, who may or may not have any formal connection to one another, is given meaning by the social template football game superimposed onto the activity. In no case is the complexity of the action taking place on the field intelligible sub specie aeternitatis. The template in this case is a web of meaning that provides an organizing structure for knowledge, which then renders actions and gestures intelligible. In the same way, the framework of language provides a web of meaning in which I can understand the meaningful connection between words, and therefore, between thoughts.

Merleau-Ponty extends this language/thought connection to include emotions as well. The reason that emotions, language, and thought are so closely tied in Merleau-Ponty is that they are all considered to be types of gesture. Moreover, he sees the first attempts at language "in the emotional gesticulation whereby man superimposes on the given world the world according to man" (219). Put more strongly, he writes: "It is no more natural, and no less conventional, to shout in anger or to kiss in love than to call a 'table' a 'table.' Feelings and passional conduct are invented like words" (220). ${ }^{15}$

Like a language, I learn "emotional gesticulation" through a process of socialization-namely, how I ought to respond to particular kinds of stimuli, and what are considered appropriate ways of expressing those responses. Moreover, not only are the emotions themselves, as well as the responses appropriate to the 
emotions, socially constructed, but even the kinds of emotions available to be experienced are to be found within a cultural palette of emotions. In other words, particular emotions are not located in a universal, essential way within the individual, waiting to be uncovered, but are rather complex products of particular cultures. Merleau-Ponty, in speaking about the way Japanese and Occidentals experience and express emotions, suggests that "the difference of behavior corresponds to a difference in the emotions themselves," because "it is not enough for two conscious subjects to have the same organs and nervous system for the same emotions to produce in both the same signs" (219).

On Merleau-Ponty's account, then, emotions are not biologically essential, but are rather socially constructed and sedimented emotional layers that come to rest on the individual, and that have been habituated over time. The process of socialization through social construction, then, offers general evaluative information about the world the people inhabit within a culture; it helps to define the range of appropriate emotional responses to the world; and it even establishes which emotions are available to be experienced.

The problem with strict social constructionist theories of emotion is most compellingly argued by Paul Ekman and his work on facial expression. Ekman's life's work has centered on the study of how emotion manifests in facial expression. Over the course of decades of research, Ekman has concluded that certain emotional responses are common universally, in virtue of the occurrence of shared involuntary facial expression across cultures. He did research, for 
example, on facial expression in a pre-literate culture in New Guinea, "whose members could not have learned the meaning of expressions from exposure to media depictions of emotions," finding among them a commonality of facial expression corresponding to certain basic emotions (e.g., fear, anger, disgust, sadness, or enjoyment (Ekman 384). Commenting on Ekman's body of work, David Matsumoto contends: "The universality of emotion recognition has been replicated time and again across many studies and methodologies, not only in the face" (Matsumoto 46).

Ekman, however, does not suggest that social construction of some secondary emotions does not happen. With respect to the question of whether facial expressions - and the emotions associated with them-Ekman says that over the course of his work he has "found more than one answer," and that "different aspects of expression are both universal and culture specific" (Ekman 391).

Neither, strict biological reductionist theories nor strict social constructionist theories, however, hold much attraction. Instead, like Ekman, I would argue that some blending of the two realities is more likely-namely, that some emotions are ones we are born with, while others are learned. Whereas biological reductionist theories emphasize the universality of certain emotions, social constructionist theories emphasize differences in emotional expression, all the way down to some apparently culturally unique emotional expressions. I would submit that one may draw the line between biological reductionism and social constructionism with respect to emotion by observing that it may very well 
be that those emotions that are elicited as quick and dirty mechanisms (e.g., fear, anger, happiness, etc.), and could be considered essential to human nature correspond to what are often called basic emotions, ${ }^{16}$ while the slower deliberative emotions are largely informed by social construction.

Damasio offers an interesting solution to the dilemma -one that I intend to assume as an important part of my thesis about our ability to educate emotional triggers. He contends that there are basic emotions, universally held, hard-wired into human beings, which are triggered by socially constructed inducers, which then respond reflexively (Descartes' Error 131). As LeDoux observes, emotions seem to have their own agenda, "one often carried out without our participation" (22). Additionally, it would seem that emotions often carry out their agenda against our attempts to subdue them. Damasio observes, "We do not need to be conscious of the inducer of an emotion and often are not, and we cannot control emotions willfully. You may find yourself in a sad or happy state, and yet you may be at a loss as to why you are in that particular state now" (The Feeling of What Happens : Body and Emotion in the Making of Consciousness 47). In this sense, then, Plato seems to have been correct about the unruliness of the passions as irresistible urges that arise within us unbidden. However, Damasio points out "that while the biological machinery for emotions is largely preset, the inducers are not part of the machinery, they are external to it" (The Feeling of What Happens 57). In other words, (at least) basic emotions are induced or triggered by socially constructed cues. He goes on to say that "in all probability, development and culture superpose the following influences on the preset devices: first, they 
shape what constitutes an adequate inducer of a given emotion; second, they shape some aspects of the expression of emotion; and third, they shape the cognition and behavior which follows the deployment of an emotion" (The Feeling of What Happens 57). We have, in other words, some control, perhaps not over the emotions themselves, but over that which induces emotional response- that is, the emotional triggers. I will take up in Chapter Five a discussion of the implications of literature for helping to calibrate emotional triggers. But first, I want to discuss the ways in which, popular thinking to the contrary notwithstanding, emotions work together with reason to produce knowledge-in some cases, even scientific knowledge.

\section{The Dynamics of Knowing}

The "high reason" view, which is none other than the commonsense view, assumes that when we are at our decision-making best, we are the pride and joy of Plato, Descartes and Kant. Formal logic will, by itself, get us to the best available solution for any problem. An important aspect of the rationalist conception is that to obtain the best results, the emotions must be kept out. Rational processing must be unencumbered by passion (Damasio Descartes' Error 171).

In this quote Damasio provides a standard summary of what he calls the "high reason" view. As I have argued in Chapter One, the dominant Western view of knowing is that it is the process whereby potential distractions, such as emotion, are suspended, so that reason may operate from an objective standpoint 
to observe, analyze, and offer judgments about propositions. This chapter seeks to challenge the traditional bright-line distinction between reason and emotion in Western philosophy, by taking into account the consensus claims of neuroscience that reason and emotion are inseparably entangled. Then, I will look at how it is possible that knowing is a dynamic process between reason and emotion, by viewing theoretical reason and practical reason not as discrete acts, but as a single activity with different objects in mind.

As I explained earlier, emotion itself is a process that includes affective appraisals, physiological responses, and cognitive monitoring, in which emotions are not just "felt," but are also tracked cognitively. This cognitive tracking is what allows me to bring the "feelings" to consciousness, where they can be evaluated post hoc. Whatever one may think of the idea of emotion as process, the assertion of cognitive monitoring (i.e., reason) as the evaluator of emotions, as well as having an executive function in helping to modify the individual's relationship to emotional triggers, the idea continues, at least to a certain extent, the traditional view of the necessity of cognition as a key activity in the emotional life. Additionally, and perhaps more controversially given all that I have said so far, I want to suggest in this section that emotion plays a crucial role in the rational life that challenges the assumption that emotion needs the "grown-up" presence of reason to "mind" it, while reason is always better off when emotion is absent from its operation.

The epistemological paradigm throughout the development of Western philosophy, as I have argued, assumes that only reason is reliable as the means by 
which we come to knowledge. Thagard summarizes the traditional view, which suggests that "since Plato, most philosophers have drawn a sharp line between reason and emotion, assuming that emotions interfere with rationality and have nothing to contribute to good reasoning" (171). However, he continues by noting that "current research in cognitive science is increasingly challenging the view that emotions and reason are antagonistic to each other" $(171) .{ }^{17}$ Damasio, drawing on the paradigmatic example of Phineas Gage, shows how neuroscience is concluding that emotion is crucial for practical reasoning (viz., reasoning that deliberates normatively on questions of what to do).

\section{A. Practical Reasoning}

In 1848, Phineas Gage, a construction foreman for the Rutland and Burlington Railroad, sustains a traumatic brain injury when a black powder charge he is setting blows up in his face. ${ }^{18}$ The explosion launches an iron bar through Gage's head, which enters the left cheek, passes through the front of the brain and exits the top of his head, landing over one hundred feet away. Never losing consciousness, within a couple of minutes he begins to speak, apparently normally. His wounds are vigorously treated by a physician, and after multiple bouts of infection and one abscess, Gage's physical wounds heal completely. He regains all his strength, with no damage to his senses, his dexterity, his ability to walk, or to his speech. He is able, by all accounts, to think rationally

Conventional wisdom suggests that Gage sustained a ventromedial lesion as a result of the bar passing through his brain. Though physically he was healed, 
and though his rational capacities appeared unaffected (e.g., memory, language, intelligence, etc.), he exhibited personality changes. His character was drastically altered. Antonio Damasio says, "He could not make good choices, and the choices he made were not simply neutral. They were not the reserved or slight decisions of someone whose mind is diminished and who is afraid to act, but were instead actively disadvantageous" (Descartes' Error 11). Where before the accident he had been industrious, dependable, and organized, after the accident his life began to fall apart because he was erratic, unreliable, and seemingly unable to make good decisions. He used foul language indiscriminately, and could not keep a job because he was prone to quitting in fits of pique. He eventually wound up a circus oddity at Barnum's Museum in New York, showing his wounds and the tamping iron that caused them.

The story of Phineas Gage, and the radical changes in his character, eventually prompts Antonio Damasio to begin studying people with ventromedial lesions that come about largely as a result of physiological developments like tumors. He describes one such patient, named Elliot, whose IQ remained in the superior range after the removal of a meningioma left lesions on the frontal lobe: "His knowledge base seemed to survive, and he could perform many separate actions as well as before. But he could not be counted on to perform an appropriate action when it was expected" (Descartes' Error 36-7). What strikes Damasio in working with people who suffer ventromedial lesions is the extent to which their intellectual capacities remain undamaged, but whose abilities to experience emotion are severely attenuated, resulting in significantly diminished 
capacities for practical reasoning. They make consistently poor decisions about what to do. Damasio suspects that diminished emotional capacities and defects in practical reasoning are somehow related, prompting his landmark research on the relationship between reason and emotion.

On this account, the deliberation initially necessary to the formation of intentions about what to do gets encoded in somatic markers with positive or negative emotional valence, which thereafter act as triggers for automated responses (Damasio Descartes' Error 167). These automated responses reduce the need for the time-consuming practice of full-blown deliberation, allowing for a kind of practical reasoning short-hand. If, for example, I have a bad experience at a restaurant, when I am making decisions about where to take my wife for dinner, that bad experience gets encoded as a negative emotional response to that restaurant (which can be either strengthened or mitigated based on additional experiences). This negative emotional response assists me in making decisions about where to eat by effectively limiting my options. Clearly, that is not to say that I cannot ignore those emotional responses, or try to add positive responses to the "recalibration file," to use Prinz's phrase. I may, for instance, want to cultivate a taste for the kind of food this restaurant serves, and so may go there repeatedly hoping to improve my experiences with the food they serve, and thereby attach positive valence to this restaurant. Whatever the case, though, my use of practical reason is made more efficient because of, rather than in spite of, emotional input. Damasio, and those who have followed his lead in the neuroscience of emotion, have shown that rather than always being an obstacle to 
reason, emotion is often necessary to the application of reason to deliberations about what to do. Moreover, because of the potentially endless number of options available in a given decision, as well as the uncertainty of the outcomes of each of those options, the emotional valence of somatic markers in some cases may be necessary to make practical reasoning even possible.

\section{B. Theoretical Reasoning}

Someone will most likely offer the challenge at this point that, even if emotion may be a necessary component of practical reasoning, the arena of pure theoretical reasoning must continue its vigilance against the introduction of emotion. That is to say, at least in questions of theoretical reasoning, we can say with confidence that emotion is always a potential obstacle to reliable knowledge. In fact, though, neuroscience research is increasingly aware that "the neural systems of emotion interact extensively with those underlying cognitive processes" (Phelps 51). In a meta-study of Amygdala research - that part of the brain that, with the VMPFC, is "responsible for the formation of memory traces that allow the organism to predict the future outcome of a given response" (Thagard and Kroon 90)-Elizabeth Phelps argues that the Amygdala not only affects the formation of long-term storage of emotion events as memory traces, but that it also affects the initial processing of those emotion events by capturing and facilitating attention (60). She writes that while it is true that emotion can sometimes hinder attention, there are other studies that "have shown that in situations with limited attentional resources, emotional stimuli are more likely to 
reach awareness, suggesting that emotion can also facilitate attention" (60). She recalls the classic example of the cocktail party in which, with stimulation all around through a variety of conversations, one's attention can be captured and facilitated when one hears one's name. The emotional attachment we have to our own names (whether because of curiosity, or flattery, or dread about the use of our names) allows us to filter through a variety of stimulation to attend to the one that has the most emotional force for us. In other words, because of the vast number of stimuli vying for our attention at any given moment, emotion helps us to attend to and process the stimuli carrying emotional import. Emotion, filtered through the amygdala, seems then to play a part in the cognitive process by prioritizing that to which reason will attend.

It will most likely be objected that having the emotions highjack attention is precisely the problem that science, based on reason, wants desperately to avoid. This is a reaffirmation of the traditional argument from Plato that, because emotion is capable of redirecting the mind's resources to attend to emotionally charged stimuli, it is necessary for rationality to rule over irrationality. On Plato's account, reason should subdue the emotions so that attention can rightfully be restored to that toward which reason points. If, for example, I am in the midst of scientific observation and it becomes clear to me that the data I am gathering seem to suggest that my hypothesis is increasingly unlikely to be true, which because of the large amount of research funds at stake, will elicit within me an emotional response. I may be crestfallen that everything toward which I have been working seems now to be wrong; or I may feel anxiety about how this will 
affect my career; or I may feel dread at the thought of having to face my naysayers and admit that I have been wrong, and so on. Because of those emotions (or a host of other possible emotions) I may be tempted to skew to the data fit my hypothesis. This, science says, is why emotion must be kept from the scientific process. Scientific reason dictates that I bracket my emotions and follow the data where it leads, without regard to the conclusions that will ultimately be drawn when the data is processed and analyzed. Emotion, in this case, would be a hindrance to achieving reliable knowledge-a conclusion with which I would not disagree. However, this is only one scenario, albeit an important and, I think, in many ways, paradigmatic one. I take as a settled matter that emotion can sometimes overwhelm reason, causing bad outcomes. One thinks of road rage, for example.

However, there are other ways of drawing up scenarios about the interaction between reason and emotion that show emotion to be an important contributor to the cognitive process, even in science. Paul Thaggard points out that emotion is present in very important ways prior to scientific observation, even down to the original question the scientist must answer about what kinds of things to research. The decisions about where to invest one's scientific energies "are more frequently based on emotions than on rational calculation" (175). Because of the impossibility involved in trying to determine through completely rational calculation what research areas are most likely to produce results, for instance, researchers make these decisions about what to research based on such emotionally significant criteria as the passion, the interest, and the curiosity of the 
researcher. My mother died of $x$, so this line of research has special importance for me. I am engaged in the study of this particular sub-set of $y$, because I find it so fascinating.

It might be protested here that various disciplines have predetermined sets of questions that lay down the parameters for the range of possible research areas, so that rational calculations about what to research are delimited at the outset. Leaving aside the issue of just how scientific revolutions can occur if everyone involved in the discipline engages in research rationally calculated from a predefined set of disciplinary questions, one is tempted to ask how decisions are made about which discipline to enter in the first place. Do advances in physics, for example, come from individuals who are only concerned with physics at all because an aptitude test told them that they were good candidates to work in the field of physics? Or do those advances come more often from people who get into physics in the first place because they are passionate about physics? In other words, the reasons scientists take up a particular discipline, or a specific problem within a discipline, often has more to do with emotion and its power to motivate than with the calculation of pure reason.

Still, someone might argue, surely the content of theoretical reasoning ought to be safeguarded against the distraction of emotion. Whatever else might be said, this argument suggests, two plus two always equals four--no matter the emotional investment in another answer one might possess. It is one thing to say that practical reasoning benefits from memory traces charged with emotional valence, or even that the commitments to research evinced by individual scientists 
are sometimes motivated by emotional attachments, but it is another thing to allow emotional input into questions of theoretical reasoning in hard science. Practical reasoning is normative in nature-that is, it centers on the question about what one should do. Calling upon the old fact/value distinction, though, one might argue that theoretical reasoning is always fact-based; normativity is not at issue. And there is a sense in which this is surely right in a commonsensical way; otherwise, we would exist in a world of pure subjectivity where what was true would be based solely on what I feel is true. This kind of subjectivist world, I think it uncontroversial to assert, would be unmanageable. On a linguistic basis alone, we would lose the basis for meaningful communication based assertions of the truth, since we would always be tripping over personalized versions of what constituted the truth.

On the other hand, our own commonsense understandings of the world as having objective truth untouched by subjective evaluations is not nearly so selfevident as one might believe. To appeal to facts as value neutral raises the question about the evaluative frameworks in which theoretical reasoning takes place. If practical reasoning is normative deliberation about what one should do, theoretical reasoning can also be viewed as normative deliberation about what one should believe. That is to say, the conclusions at which theoretical reasoning arrives are often intelligible only in light of the larger framework of belief that organizes those conclusions into larger arguments as assertions of truth. Richard Moran contends that "very few of our beliefs about the world arrive as the conclusion of any explicit theoretical reasoning that we undertake," in the same 
way that "very few of our desires come into existence as the conclusion of an explicit exercise of practical reasoning" (116). Instead, facts are processed according to frameworks of belief that provide an overarching account of how those facts make sense, or even why they should be considered facts. It is the organization and reorganization of facts under different conceptual frameworks, I will argue, that implicate emotion in theoretical reasoning.

In Thomas Kuhn's book, The Structure of Scientific Revolutions, he advances the argument that the kinds of scientific revolutions that can be called paradigm shifts are conceptual rather than factual, requiring a shift in professional commitments (6). The accumulation of facts can never, by itself, cause a scientific revolution, in part because that which provides the authority to grant factual status is conceptual. One's commitments to a conceptual framework have to undergo something of a conversion in order to accommodate new factual data —and the theories they generate - which conflict with the account of the world provided by the old framework. Once these conflicting data can no longer be accounted for by the old framework, the scientist may (or may not) make adjustments by adopting new theories that continue to solve the problems the old framework had previously solved, but that, in addition, draw a broader picture capable of including the new data. These newer theories need to be in place in order to process the discovery of new data as significant, requiring a new metatheory or conceptual framework in which to organize the new data and theories into an intelligible whole. 
Kuhn gives the example of the discovery of oxygen. To understand the significance of how a gas like oxygen made better sense of the world, the reigning conceptual understanding of the phlogiston theory of combustion (viz., all combustible materials have within them a substance called phlogiston that is released during combustion) had to be overthrown. New facts that pointed to the reality of oxygen as a gas, if they were to be considered facts at all, had to be seen through a different conceptual lens. The formulation of this conceptual lens, however, took time. Kuhn writes, "Though undoubtedly correct, the sentence, 'Oxygen was discovered,' misleads by suggesting that discovering something is a single simple act assimilable to our usual (and also questionable) concept of seeing. That is why we so readily assume that discovering, like seeing or touching, should be unequivocally attributable to an individual and to a moment in time" (55). Discovery, on Kuhn's account, however, is most often the result of a process that links the accumulation of factual data with the conceptualization of theory. Kuhn argues that it is only when conceptual categories are in place that the process of discovery can unfold, since raw data must be organized to understand what is important to attend to and what is not, and why it might be important to attend to it at all (55-6).

Or take the example of the nomenclature changes surrounding the diagnosis of homosexuality as a mental disorder in the American Psychiatric Association's standard classification of mental disorders, Diagnostic and Statistical Manual of Mental Disorders (DSM). This manual, now in its fourth edition, seeks to standardize diagnoses by offering scientific categorization of 
mental disorders. In their chapter on the history of the development of the third edition (DSM-III) Stuart Kirk and Herb Kutchins remark on the way "scientific issues took a back seat to political struggles about the appropriate place of various diagnoses such as homosexuality, neurosis, and post-traumatic stress disorder" (77).

Beginning in 1970, gay activists began disrupting APA conventions, agitating for the removal of homosexuality as a mental disorder in the DSM-II. Their protests shed light on what some believed to be the inequity involved in continuing to diagnose otherwise healthy homosexual individuals with a mental disorder. Homosexuality, they argued was not a disorder, but an orientation that no amount of psychoanalysis could "cure." Prior to 1970 , conventional wisdom in the social sciences (with vestiges of religious disapproval) held that homosexuality was aberrant behavior. Following psychiatrists like Charles Socarides and Irving Bieber, the common belief was that homosexuality was a pathology that could be successfully treated by therapeutic means. Socarides, writing after the change in classification, cites "intensive study, research, and individual analyses of homosexual patients over the past two decades," contending that homosexuality has its origins in either oedipal or preoedipal conditioning, rather than as an inborn trait (Homosexuality: Psychoanalytic Therapy 63$).{ }^{19}$ What is interesting to note, however, is that after the protests the conventional wisdom of the science of homosexual classification was challenged as itself unscientific by those who wished to change it. 
Kirk and Kutchins offer this observation, of particular importance for my purposes, on the way the change of classification unfolded, drawing attention to the "claim of the proponents on every side that they were being scientific and their opponents were not" (88). In fact, however, "few of the psychiatrists involved in the controversy had done studies that could pass muster as credible research, but before a decision could be made each side had to couch its arguments in the terms of science" (88). In essence, then, the argument about the classification of homosexuality took place largely beyond the scope of the kind of research that would produce the factual data necessary for theoretical reasoning as it is traditionally understood. It is only after what Kirk and Kutchins believe to be the political maneuvering is settled that factual data begins to affirm the paradigm shift that has already taken place. Admittedly, they seem to see this as an unfortunate methodological misstep in the advancement of science, but I am not so sure that politics is ever entirely removed from the kinds of shifts that lead to scientific revolutions - if by politics what is meant is the prior commitments to which the actors in the debate bear an emotional attachment. Both sides, while claiming scientific objectivity, had perspectives that allowed them to see factual data through specific kinds of conceptual lenses. Changing the conceptual lenses, however, required more than just the persuasive impact of a raft of new data. That is to say, shifting the conceptual lens through which the facts were made intelligible required something like a conversion to a new set of beliefs about the way the world is situated, before the facts themselves could be interpreted as facts marshaled in support of this new paradigm. 
Even after the paradigm shifted to preclude the classification of homosexuality as a pathological disorder, Charles Socarides remained unpersuaded by the newly emerging scientific data. In a 1995 article entitled, "How America Went Gay," Socarides continued to argue that the APA, in changing its classification from homosexuality-as-pathology, had succumbed to political pressure. Clinging to his belief in the pathology of homosexuality in the face of the overwhelming majority of the scientific community had left Socarides and his compatriots feeling like an "embattled minority" ("How America Went Gay" 20). Instead of processing hard scientific data, Socarides claimed, America had been cynically "brainwashed" to accomplish this paradigm shift ("How America Went Gay" 21).

Ironically, the science Socarides had claimed in support of his view of homosexuality as a pathology — which had, prior to the change in the DSM, comprised conventional wisdom about homosexuality—was the same "science" that later marginalized him when the scientific paradigm shifted. What changed was not the scientific data, upon which Socarides based his claims, but the conceptual framework in which the "science" that had been done prior to the paradigm shift could not "pass muster as credible research" (Kirk and Kutchins 88). In other words, Socarides and his science became "science" after the paradigm shift — which is to say, not really science at all. Like the supersession of phlogiston theory by the discovery of oxygen, what changed were not just the facts, but the very conceptual framework within which facts were given factual status. 
My point in recounting this shift in the classification of homosexuality in the DSM is to indicate the extent to which science is based on, and continually influenced by, beliefs and commitments that arise prior to the factual data of theoretical reasoning. Those beliefs and commitments, though usually informed by factual input, are conceptual frameworks that have durability, because of emotional attachments. Commitments themselves are not emotions; but that which motivates their forming and the sustaining of them is. To change a conceptual framework in the fashion of a scientific revolution, one must undergo a kind of conversion, giving up the beliefs and commitments to which one is emotionally attached, in order to be able to embrace different beliefs and commitments. Even at its most theoretical level rationality cannot so easily bracket emotion, because the very framework in which facts are made intelligible are made up of beliefs and commitments, which in turn are often created and sustained by emotional attachments.

In this section, I am seeking to illustrate just how entangled emotion is with reason, even with the most scientific of pursuits. To cordon off emotion as a pollutant in the otherwise pure enterprise of reason is to miss the extent to which emotion is inexorably bound up in rationality in ways prior and often transparent to reason. Both practical reason (reasoning about what one ought to $d o$ ) which requires the input of emotion for the purposes of deliberating, as well as theoretical reason (reasoning about propositions) which is underpinned by conceptual frameworks of belief and commitment, undergirded by emotional attachments—in many cases have their effectiveness augmented, rather than 
distracted, by emotional input. Contrary to the traditional view that rationality entails the sequestration of emotion so that reason can work unfettered by distraction, it is becoming increasingly clear as a result of neuroscience that emotion often works dynamically with reason to achieve knowing.

\section{Conclusion}

In this chapter I have attempted to lay out the initial stages of a theory of emotion. In section one I surveyed the most popular theories of emotion, from feeling theories to behavioral disposition theories to cognitivist theories. Next, I offered the problems presented by each theory. In section two, I proposed a theory of emotion that sees emotions as a process, triggered mostly by affective appraisals, stored as somatic markers in the limbic system. Moreover, I suggested that emotions proceed along two tracks, one quick and dirty, accounting for what has been called basic or primary emotions, and the other, slow and deliberative, which makes up the category of secondary emotions. In section three, I argued that these two different tracks of emotion help to explain the historically contentious debate over whether emotions are biologically essential, and therefore universal, or socially constructed, and therefore localized. I proposed that quick and dirty emotions constitute a way in which humanity as a species has developed evolutionarily advantageous responses to our environment. Slow and deliberative emotional responses, on the other hand, also add evolutionary advantages by making up for in accuracy what they lack in speed. All in all, emotions are complex processes necessary not only for the cultivation of virtue or for the 
possibility of intersubjectivity, but in very fundamental ways, for survival itself. Indeed, as I suggested in section four, rationality itself, both practical reasoning and theoretical reasoning, is in some ways dependent upon emotion to succeed. 


\section{CHAPTER THREE}

\section{HUMANS ARE POLITICAL ANIMALS}

\section{Introduction}

Aristotle famously made the claim that humans are political animals. ${ }^{1}$ Furthermore, since humans are "political animals," they gather in communities. The political organization of the polis, according to Aristotle, is a community, and "an impulse toward this sort of community exists by nature in everyone" ( $\mathrm{Pol}$. 1253a31). He suggests that the polis "comes to be for the sake of living, but it remains in existence for the sake of living well" (Pol. 1252b29). In other words, human beings possess an inherent need for community (something modern psychological research confirms), and they order their common life with a view to fostering an environment in which a fully flourishing life is possible. Admittedly, not everyone agrees that flourishing is the goal of human life, or even that human life has a single distinguishable goal. However, I will set out the argument that on a practical level a community conditioned by a lack of commitment to intersubjectivity - being with and for others, which I will contend, is centered on emotional engagement, and is a necessary condition for human flourishingcannot but be Hobbesian in nature, with each member seeking only after his own interests. 
I must pause at the outset to reflect on an important distinction that, were it left unremarked, could prove confusing. The temptation is to define polis as a synonym of community - and in many respects this would be accurate. For the sake of clarity, however, I will suggest that while both community and the polis are characterized by a collection of individuals bound together by a shared belief about a good or a set of goods, as well as the virtues necessary for the realization of the goods identified, the polis is a collection of individuals bound together by a shared belief about the highest human good, as well as the virtues necessary for the realization of that good. Under this definition, the American Lung Association or the Rotary Club or a local agricultural cooperative could comprise a community, in that they share common assumptions about a good or set of goods. They would not, however, comprise a polis in the sense I have suggested, to the extent that they do not claim to be organized around the highest human good. A community is a necessary, but not a sufficient condition of a polis. A polis, which would also presumably contain agreement on a common set of lesser goods, organizes those lesser goods in relation to what it takes to be the highest human good. Certain religious and political groups might satisfy this definition of a polis, in that they make claims about what comprises the highest good humans should pursue—heaven, for example, in a Roman Catholic parish, communal ownership and control over the means of production and the distribution of goods in a socialist collective, or nirvana in a Buddhist monastery. However, as Alasdair MacIntyre notes, polis is a difficult concept for moderns to conceive of, since a normative identification (let alone an ordering) of goods as a 
common project is prescinded by political liberalism—which sets individual choice as the basic condition for human political organization. He observes that a "modern liberal individualist world" has "no conception of such a form of community concerned, as Aristotle says the polis is concerned, with the whole of life, not with this or that good, but with man's good as such" (156). Political liberalism, in other words, fosters an environment in which each individual believes herself to be a determiner of the highest good.

My purpose in introducing the polis as a concept is not to argue that a polis, as Aristotle conceived it, is even possible in a "modern liberal individualist world"- though I think that argument can plausibly be made. ${ }^{2}$ Instead, my purpose is more modest, seeking only to draw attention to the ways that communities participate in much of the same kinds of boulesis (i.e., laying down of ends [teloi]) as a polis - only on a smaller scale, and with less universal ambition. A philanthropic organization like Doctors without Borders, for instance, views the bringing of medical relief to the impoverished as a human good. Consequently, such a community encourages and helps to cultivate the virtues of liberality (i.e., generosity), courage, and righteous indignation, but may not necessarily feel the need - for the sake of its ends - to take a position on the virtues of wittiness, friendliness, or modesty. Communities, on my account, though they do not pretend to offer up a vision of the highest human good, or attempt to order goods toward a common telos in the manner of a polis, are still a critical means by which goods are identified and virtues are articulated and cultivated to meet those goods. A city, like the fictional Empire Falls-which I 
will focus on in Chapter Six-is a community that shares many lesser goods in common (e.g., concord, a just economic system, friendship), requiring certain kinds of virtues to realize those goods (e.g., truthfulness, justice, friendliness, etc.), but makes no normative claims about the highest human good. "Lesser" as a qualifier of "goods," it ought to be pointed out, should not be misunderstood as meaning unimportant. Instead, "lesser" in this case means only "not the highest." As such, concord, just economic systems, and friendship are goods held in common, but none are normatively offered as the telos of human life.

Even though communities do not make claims to setting down the highest human good, in order to endure and to thrive as communities they need to encourage intersubjectivity —a mutual and shared subjectivity in which people are with and for others. Consequently, that which binds the community together, according to Aristotle, is friendship—even above justice: "If people are friends, they have no need of justice, but if they are just they need friendship in addition; and the justice that is most just seems to belong to friendship" (EN 1155a28). MacIntyre writes: "The type of friendship which Aristotle has in mind is that which embodies a shared recognition of and pursuit of the good. It is this sharing which is essential and primary to the constitution of any form of community, whether that of a household or that of a city" (155).

Therefore, hereinafter, should I speak of a community in which its importance to my argument centers on its holding in common the highest human good, I will specifically use polis. Otherwise, I will use community as a generic term denoting collections of individuals who hold in common shared conceptions 
of the good - both the highest human good, as well as various lesser goods. Smaller communities, rather than poleis, will be my primary focus in this work.

Perhaps I should also take this opportunity to defend my choice of Aristotle as a foundational figure for my argument, in view of the fact that a considerable amount of time and philosophical work has come and gone since his writings first helped shaped the trajectory of Western intellectual history. I would make two comments in response to questions about my use of an ancient source. First, since part of my argument has to do with the ways in which virtue ethics is better positioned to focus the kind of attention on the emotions that lie at the heart of the intersubjectivity necessary for human flourishing, and since Aristotle is the foundational figure for virtue ethicists, Aristotle seems a likely enough place to begin. Second, because it is Aristotle who first responds to Plato in defense of the emotions - setting the stage for my contention that the emotions (at least as they are triggered in us) are educable-Aristotle's ideas must be dealt with. That does not mean, of course, that Aristotle is unchallengeable as an authority; only that his arguments-though often challenged and sometimes modified, should not to be dismissed lightly.

Social organization in poleis whose goal is human flourishing requires a set of virtues or excellences that make that flourishing possible. The virtues of a polis, therefore, are directly tied to the conception of the goal of flourishing or "living well" of that polis. But in a benignly circular fashion one may also say that part of what it means to flourish is to be virtuous. ${ }^{3}$ According to Aristotle, the job of a polis, then, is to educate virtuous people with a view to human 
flourishing. The job of a virtuous person, on the other hand, is to live virtuously so as to contribute to a polis capable of producing virtuous people.

However, virtue seems to be characterized not only by virtuous action, according to Aristotle, but also by the emotional response a virtuous person would have by so acting. In other words, on an Aristotelian account, virtues "are concerned with actions and feelings" (EN 1104b14). Emotions, to recall briefly my argument from Chapter Two, are complex processes that involve somatic states elicited by affective appraisals in response to stimuli in the person's consciousness or environment. Additionally, these complex processes are an important way we relate to other human beings, communicating our desires and projects, our fears, as well as our likes and dislikes through affective states and the expressions that result from these states.

In this chapter I take up the issues centered on virtue and the emotions by making an argument that virtue ethics offers a more comprehensive ethical theory than deontology or utilitarianism, inasmuch as virtue ethics takes into account an expanded role for emotions in living a fully flourishing life. The purpose of this chapter is to begin to lay the foundation for an argument about the proper education of those triggers that induce emotions as a necessary component of virtue, and therefore, of a fully flourishing life.

In the Poetics Aristotle challenges his old teacher, Plato, who contended in Republic that the poet must be banned from the ideal republic, in part because the poet encouraged the experience of emotion. To say that Aristotle challenges Plato, however, is not say that he confronts Plato directly, but that the scope of his 
argument addresses the issue of poetry, which Plato had denounced in the Republic. Specifically, Aristotle calls into question Plato's account of the value of the emotions. Whereas Plato contends that emotions are a potentially disruptive force, the power of which must always be controlled by reason, Aristotle maintains, as I will argue, that in addition to virtuous action the cultivation of the appropriate emotional response (i.e., the appropriate emotional response at the appropriate time) is essential to the development of virtue. Moreover, on Aristotle's view, the cultivation of appropriate emotional response has implications not only for the development of individual virtue, but for the health of the body politic. As a way of entering the discussion about the role of emotions in moral development through the experience of art, I will situate the medium of tragedy as an effective means of educating the emotions within the historical context of Plato and Aristotle's disagreement. As such, tragedy acts both as a way of introducing the traditional Western view of emotions and a possible response to it, as well as an instance of how narrative art can educate the emotions. ${ }^{4}$

I must be careful to point out, however, that I am not attempting to elicit Aristotle's endorsement for a view that says reason is not somehow responsible for properly informing the emotions. Aristotle's position with respect to emotions - while different from Plato's in the belief that emotions can be educated—still identifies reason both as the faculty that differentiates us as a species, as well as the faculty that occupies the primary place in establishing knowledge and directing action (Pol. 1254b5). ${ }^{5}$ My point is much more modest: I 
only wish to argue that an Aristotelian critique of Plato on emotions suggests the beginnings of a way of viewing emotions such that emotions have a significant role to play in moral development, rather than as unruly urges to be overcome on the path to moral development. A discussion about tragedy can assist in clarifying how emotions are a necessary part of virtue, and so play a positive role in a flourishing life.

\section{Humans and the Polis}

That human beings gather in collective social arrangements is a commonplace of observation. Aristotle noted the inclination of human beings to organize themselves in social arrangements in the Politics by suggesting that this inclination is essential to human nature (1252b29). Philosophers have tended to agree with Aristotle's assessment about the apparent human need for community. What they have disagreed about, however, is the reason for this phenomenon. Political liberalism, the assumption that individuated selves come together in a collective for the purpose of establishing an environment that conduces to selfpreservation and the advancement of self-interest freely chosen by the individual, through the establishment of just laws and regulations has been a staple of western political thought from Thomas Hobbes to John Rawls. On this account, the autonomous individual seeks social arrangements that she believes will prove beneficial to her self-interest by subjecting herself to what she believes to be a just system of government. The end (telos) of life, unlike traditional conceptions inherited from the Greeks moving down through the Middle Ages, is not laid 
down by the community (polis). In fact, according to Rawls, "as free persons, citizens claim the right to view their persons as independent from and not identified with any particular such conception with its scheme of final ends" (Rawls 30). Characteristic of political liberalism, then, especially for someone like Rawls, is the conviction that universal justice precedes any conception of the good - and that the conception of the good is a matter of individual choice and political indifference (as long as one's conception of the good does not threaten the ability of another to pursue her own conception of the good). ${ }^{6}$ Michael Sandel observes that Rawls' theory does not preclude community, only that any community is necessarily made up of "antecedently individuated selves" for whom community is "not an ingredient or constituent of their identity as such" (Sandel 64).

Aristotle, on the other hand, suggested that social organization centers on the polis, which has a shared understanding of the good, and is capable of producing individuals, part of whose telos it is to foster a polis capable of realizing the good-defined antecedent to the individual. The good in this sense is a fulfillment of the function of the polis (that is, its telos) by individuals acting virtuously (or excellently). The virtues of a citizen, then, are derived from the conception of an excellent polis. In this sense, the excellent polis requires virtuous citizens - which it seeks to produce through education —if its function is to be fulfilled. The telos of an excellent person is to cultivate virtue to contribute to the excellence of the polis. The fulfillment of the telos of the polis and of the individual results in happiness (eudaimonia) - that is, a flourishing life. 
Therefore, while Aristotle agrees that social organization offers protection to the individual, he thinks that the polis rather than the individual is capable of providing a framework in which what it means to live well is both intelligible and achievable (Pol. 1252b29).

Aristotle is so convinced that human community is essential to humans that he makes the strong claim that "anyone who cannot form a community with others, or who does not need to because he is self-sufficient, is no part of a citystate-he is either a beast or a god" (Pol. 1253a28). Why, though, is the life of the individual who is unable to "form a community with others" fit only for "a beast or a god?" Presumably, a person could master enough propositional information about the world to survive outside of human society. Finding enough food to eat and shelter to protect oneself is achievable by those who have been taught the skills for survival. ${ }^{7}$ Clearly hermitages, for example, have existed throughout history. ${ }^{8}$ However, what one gives up by voluntarily choosing to leave society is not the thinking of thoughts, nor the exercise of the will, but the sharing of emotional interaction with another human being, that is, the communication with other human beings of those affective states and the objects that elicit those states that help to identify us as individuals. ${ }^{9}$ Rationality and volition have utility, regardless of one's situation. Emotional interaction with others, though, because it social by nature, is precisely what is foresworn by the kind of self-imposed isolation I am describing.

In his essay on the evaluative function of emotions, Michael Stocker contends that emotions are constitutive of what it means to be human, arguing that 
"having and being the subject of reactive attitudes [i.e., emotions] is central to being and being recognized as a person" (Stocker 183). ${ }^{10}$ The claim that emotions are constitutive of what it means to be human is perhaps too strong. After all, are people who have certain kinds of emotional blindness not also human, even taking into account the emotional deficit? It seems clear to me, nevertheless, that a profoundly important characteristic of the human species is an ability to experience emotion, as well as to understand the emotions of others. P.F. Strawson calls "the fact" of our "natural human commitment to ordinary interpersonal attitudes [i.e., emotions]" one of the key components "of the general framework of human life" (Strawson 198-9). In fact, Stocker asserts that our most fundamental knowledge of what it means to relate to other people comes on an emotional level. Understanding only the rational propositions put forward about another person takes one only a short way, if at all, down the road to knowing that person. Much of what counts for knowledge of another person as a subject (rather than as an object) is emotional. ${ }^{11}$

Having knowledge of what another person knows, or having the knowledge that another person knows a particular thing rationally is important in making all kinds of assessments about that person. For example, on an instrumental level it would be important to possess knowledge about another person's rational comprehension of internal combustion engines if what one desires in an interaction with that person is that she will fix one's car. On the other hand, knowing that she has a rational understanding of how to fix cars might also be foundational for pursuing a friendship with her involving emotional 
interaction, if one also possesses the same knowledge of and apparent interest in cars. In this case, then, having knowledge of another's epistemic holdings could prove to be an important key to having true knowledge of the person. However, knowing what another person knows is not enough to establish much more than instrumental relationships. The most significant parts of knowing this person as another subject go far beyond knowing that-and what-she knows about cars, which is to say, far beyond a sort of basic accounting of the rational understanding she possesses. To know the most significant parts about her as a subject, it will be important to come to understand why she possesses this rational understanding of cars, what ends she believes this understanding serves, and whether or not she believes this comprehension is a good or a bad thing. Knowing what she values and despises, what brings her joy or makes her depressed provide the context in which emotional interaction can take place. The knowledge of the person as a subject gained through emotional interaction is the crucial information necessary for the intersubjectivity of a shared life. This emotional interaction with another I will call emotional attending. I will set out a more complete definition in Chapter Four. But for now I will suggest a simplified definition of what I mean by emotional attending: Emotional attending is the ability to understand and respond to the emotional lives of other subjects.

If Stocker and Strawson are correct that emotions are an extremely important component of human life, and if Aristotle is correct that humans are essentially "political animals," then it does not seem too great a leap to suggest that some sort of emotional attending and human community are inextricably 
linked in a fundamental way. That is to say, on a basic level, for emotional attending to take place, it must do so within the context of a community. Likewise, for a community even to exist qua human community-rather than as a conclave of individuals bound together for self-seeking or instrumental endsemotional attending must be present. Strawson, for example, has argued that "in the absence of any forms of these attitudes [i.e., emotions] it is doubtful whether we should have anything that we could find intelligible as a system of human relationships, as human society" (Strawson 210).

For emotional attending to occur, the necessary social environment cannot be merely a Hobbesian confederation of atomic individuals, bound together only by a desire for social stability, each seeking her or his own needs, independent of all others. In some sense, this social environment supportive of emotional attending (and reliant upon it) must be a commonwealth in which one's commitments to the commonwealth transcend pursuit of a secure environment solely for the purposes of pursuing individual projects and goals.

For the ancient Greeks, and for Aristotle in particular, this commonwealth is embodied by the polis. However, he links the polis and the individual as fundamentally analogous by suggesting that "the ways and means by which a man becomes excellent are the same as those by which one might establish a city-state $\ldots$ and that the education and the habits that make a man excellent are pretty much the same as those that make him statesmanlike or kingly" (Pol. 1288b41-2; see also 1333b35-7). Furthermore, he contends that "the best life, both for individuals separately and for city-states collectively, is a life of virtue sufficiently 
equipped with the resources needed to take part in virtuous actions" (Pol.

1323b40-2). The excellent polis, then, will make certain that it concentrates great effort on producing citizens of good character, capable of virtuous action ( $E N$ 1099b29-33). As properly organized, the polis can correctly educate its young in the virtues, and can foster an environment conducive to the fully flourishing life. Because living virtuously is not only a moral achievement that strengthens the polis, but living a virtuous (excellent) life is what it means to flourish. To keep in mind my larger argument, I should point out that, as the virtue necessary for flourishing requires appropriate emotional response, so also one of the conditions necessary for an excellent polis—as well as for a flourishing life—is friendship, the enjoyment of which assumes some level of emotional attending if it is to be more than friendship of utility. In Chapter Four, I will suggest that emotional attending itself is very much like a virtue.

To the extent that the polis undertakes to produce virtuous citizens, Aristotle argues that "it is not unimportant, then, to acquire one sort of habit or another, right from our youth. On the contrary, it is very important, indeed allimportant" (EN 1103b22-5). Furthermore, he believes that there is universal consensus about the fact that one of the primary functions of a legislator centers on educating children in the virtues (Pol. 1337a10). But why does Aristotle come to this conclusion? Why should the education of citizens from a young age occupy such an important place in his understanding of the responsibility of the polis? He makes this claim as a result of his conception of human susceptibility to motivation by pleasure and pain. Since pleasure poorly trained can lead us to 
contemptible actions, and pain poorly trained can lead to avoiding correct actions, Aristotle believes that education is necessary to teach children to experience pleasure and pain properly — that is, to find pleasure and avoid pain in the correct objects (EN 1104b10-3). However, virtue is not merely a matter of subduing the individual's passions, or of placing an onerous burden on the citizen. Rather, virtuous living offers itself as an excellent end, a sort of "salvation" (Pol. 1309a34). ${ }^{12}$

But how is this end established as a goal worthy of pursuit? It is important to say a word about how wishing (boulesis) functions in the individual. And since the individual and the polis are linked by analogy, it is possible to draw some conclusions about how the polis sets down ends for itself. The individual wishes "for the end more [than for the things that promote it], but we decide on things that promote the end" (EN 1111b26). In other words, the act of wishing (boulesis) is laying down ends (teloi) and the goods that attach to those ends, which are associated with function (form, essence, etc). Practical reasoning, on the other hand, considers the ends laid down by boulesis and uses them in the process of deliberation to come to some decision (prohairesis). Prohairesis deals with how we achieve the ends laid down for us by boulesis. Hence, since identifying the best human goods is concerned with human telos and not only with a particular culture or constitution, and since the means promoted to achieve ends are virtues, there must be universal human virtues that are the means to achieving general human ends, and which transcend the particularity of convention. These goods are goods unqualifiedly. ${ }^{13}$ 
Aristotle believes that in addition to its responsibilities in setting down human ends (teloi), the polis must also set down ends for itself as well-ordered community (Pol. 1278b15). The setting down of ends within a polis, however, is a matter of legislation. Having identified the end of a polis, for Aristotle it is possible to identify the virtues necessary to the completion of that end. As he says, "The virtue of the part must be determined by looking to the virtue of the whole" (Pol. 1260b14). However, each polis is differently constituted. Therefore, it must be remembered that there is "in each constitution the sort of virtue or justice that is suited to the constitutions (for if what is just is not the same in all constitutions, there must be differences in the virtue of justice as well)" (Pol. 1309a35-8). In other words, the polis, in addition to the individual, must exercise boulesis in setting down ends.

However, it is possible to misidentify ends through faulty boulesis in the polis as well as in the individual. In this sense, then, that which is identified as a good is only an apparent good. The apparent good may be of either a universal or a particular nature. I might, for example, think that the goal of human life is the accumulation of wealth, so that I move closer to my completion as a human being in direct proportion to the rise of my net-worth. Or it may just be that I mistakenly believe that the goal of hygiene is not health, but beauty. Aristotle concludes that "for the excellent person, then, what is wished will be what is [wished] in reality, while for the base person what is wished is whatever it turns out to be [that appears good to him]" EN 1113a25). With respect to the polis, bad ends can also be misidentified. It was possible in Nazi Germany to be an 
excellent death camp commandant, for example, by killing more Jews than the quota necessitated. However, what could be construed in Nazi Germany as a virtue would be considered vicious elsewhere because of the misidentified ends of that state.

Inasmuch as there are virtues thought to be necessary to the completion of the function laid down by a particular polis for itself, it seems that there must also necessarily be virtues thought to be proper for life in that polis. The goods toward which these virtues aim, however, are qualified goods, goods for the sake of something else, to the degree that what they aim at is not the best good. For Aristotle there are unqualified goods of a general sort, as well as qualified goods of a particular sort (EN 1152b26-27). Virtues that equip the human for a virtuous life in a certain polis are of a different and qualified kind from the virtues identified as necessary for completion of the human telos. Clearly, then, Aristotle talks about virtue in two senses - the virtue of a human and the virtue of a citizen (Pol. 1277a12). In other words, he believes that there are identifiably specific human traits that are essential, and therefore, universal, which require virtues necessary to fulfill the function of a human being qua human being. At the same time, he believes that each polis will have particular needs unique to each, which require corresponding virtues for the fulfillment of the constitutive function of the polis (Pol. 1276b29).

Since Aristotle views the individual and the polis analogously, and since the context varies in which individuals are called upon to exercise virtue, we may make inferences about the extent to which this is also true for the polis. In other 
words, excellent communities vary constitutively relative to the ends laid down for each; hence, the virtues of a good citizen are varied, while the virtues of a good person are constant (1276b30-2). On this reading, it is possible to be a good citizen without being a good person. Nevertheless, an Aristotelian conception of the polis, while finding some agreement with political liberalism in the idea that there is a multiplicity of goods to be pursued - in addition to the best goodsuggests that those goods are not derivable in isolation, but are identifiable within the context of the polis.

\section{Virtue Ethics versus Deontology and Utilitarianism}

Though Aristotle believes there is a specific human telos, that is not to say that he believes a general comprehensive system of rules and regulations should result from this state of affairs, which may leave him open to the charge of relativism. A significant characteristic that distinguishes Aristotle's account of the virtues from Plato's account is his assertion that virtue is practiced in highly contextualized ways, rather than abstractly. As a consequence, an examination of the virtues will always be inexact when compared to the examination, for example, of a geometer (EN 1098a27). He prefaces his inquiry into the virtues, therefore, with the disclaimer that this sort of inquiry must necessarily be approximate (1104a1). This distinction between what is knowable to a scientific certainty and what is knowable to a virtuous person, is in some ways at the heart of my argument, and will therefore continue to be an abiding theme throughout the rest of this work—as, for example, when I speak of the difference between 
knowing the propositions about someone (scientific reason) and knowing someone through emotional attending (virtue).

The mean of virtue "is not one, and not the same for all" (EN 1106a33). As a result, Aristotle's conception of virtue seeks not to distill virtue into standardized rules to be applied without regard to context. MacIntyre argues that the laws of the polis are general, and therefore, "particular cases will always arise in which it is unclear how the law is to be applied and unclear what justice demands. Thus there are bound to be occasions on which no formula is available in advance." ${ }^{\prime 4}$ Hence, for an action to be recognized as virtuous, it requires more than that the action "have the right qualities" (1105a31). Concerning the agent, Aristotle writes: "First, he [sic.] must know [that he is doing virtuous actions]; second he must decide on them, and decide on them for themselves; and, third, he must also do them from a firm and unchanging state" (1105a31). For this reason, an action is considered virtuous not because it conforms to an idea of the good, or because it is accomplished fortuitously, but because it is the sort of action that would be performed by a virtuous person (1105b7).

There can be for Aristotle, therefore, "no fixed answers"--which is to say, no universal set of rules to be applied in all cases, without regard to context (1104a4). For if it were to be said that deliberation — which is examination of the means by which human agents seek to achieve some end (1112a17)-concerns only the identification of a certain rule to be applied universally, that assertion would fail to take into account the various complex factors that must be considered in each particular instance where virtue is to be enacted. ${ }^{15}$ On the 
contrary, inquiry into deliberation is inexact precisely because "the agents themselves must consider in each case what the opportune action is, as doctors and navigators do" (1104a6). ${ }^{16}$

Additionally, and more specifically for my purposes, virtue ethics provides an account of ethics that requires more than the rationality necessary for deontological ethics or the raw emotional energy that motivates moral action in utilitarian ethics. Part of what was at stake for Kant and Mill in turning away from a moral philosophy that was agent-centered, like the ethics of Aristotle subsequently modified by Thomas Aquinas, was the distrust of any centralized conception of the good - whether that good was identified by the polis or, more importantly for Kant and Mill at the time, the church. ${ }^{17}$

The Roman Catholic Church had seemed altogether too ready to impose its will on an increasingly secularized and an increasingly resistant European population, which ultimately helped set the stage for the Protestant Reformation. After the Reformation, ecclesiastical authority receded as an uncontestable last word on social and moral norms. ${ }^{18}$ In the process, many people began to search elsewhere for direction and for the material out of which to build a moral lifeboth communal and individual. That is to say, if the church was no longer the uncontested locus of authority for establishing social and moral norms, where and under what conditions could those norms be established? And if norms for the intelligibility of moral action were not securable by appeal to church authority, to what extent was the individual now responsible for making decisions about moral behavior based on individual freedom? 
Immanuel Kant argues that for morality to exist at all, freedom must be the conceptual ether in which it operates. ${ }^{19}$ Like the fundamental categories necessary for theoretical reason (i.e., unity, totality, plurality, etc.) freedom operates as a fundamental category necessary for practical reason. Moral agency, which I will discuss momentarily from Kant's perspective as necessary for a truly enlightened society, requires that praise or blame be attachable to actions. Robots, for instance, are not accorded the status of agents. Because they are programmed to act by another, robots do not possess the freedom to choose how and when to act. It is only when I am free to make the choice to do something that I can be praised or blamed for so acting. That is why Kant's "humanity principle" becomes central to his argument about the nature of moral action (Kant Grounding for the Metaphysics of Morals 35-6). That is to say, I am required to treat other human beings as ends in themselves, precisely because were I to treat them as means to my own ends, I would deprive them of their freedom as subjects, treating them merely as objects for the accomplishment of my own ends. In other words, I would be depriving them of the autonomy necessary for moral agency to exist. If I force someone to rob a bank for my own ends, I have preempted the free exercise of the will of another autonomous individual, treating that person as an object, a tool to be used, that is, as less than human. And if my actions were to be treated as universalizable, the concept of freedom-and therefore morality per se-would cease to exist. Therefore, Kant writes: "This principle of humanity of every rational nature generally as an end in itself is the 
supreme limiting condition of every man's [sic.] freedom of action" (Kant Grounding for the Metaphysics of Morals_37).

Indeed, for Kant, not only is the theoretical freedom of the moral sphere necessary, but for a truly enlightened society, there needs to be the practical exercise of human freedom. Kant contends that only by appropriating a space for free rational inquiry can humanity escape the bonds of its "self-incurred tutelage" to external authority (Kant "What Is Enlightenment?" 3). He writes that the motto of enlightenment is: "Sapere aude! Have courage to use your own reason!" (Kant "What Is Enlightenment?" 3). The emphasis with which modernity reads this, of course, is on your own. That is to say, Kant envisions a society in which individual freedom is cultivated so that people act morally not because they are forced to heteronomously — that is, by outside forces—but because each individual finds within her/himself the resources to act morally. Such a society of autonomous agents would be, Kant believes, a truly enlightened society. Notice, though, that the exercise of reason and moral action reside in the autonomous individual, antecedent to the influence of the community.

In addition to relying on autonomy, moral agency, according to Kant, must rest on rationality, separated from the contingencies of emotion. Iris Murdoch points out that 'Kant regards 'feelings' as dangerous to morality, sharply divides (noumenal) reason from (phenomenal) emotion, and stresses that dutiful action is something of which every man [sic.] is immediately capable" (Murdoch Metaphysics as a Guide to Morals 11). Not only are the emotions too unstable a platform to provide guidance, but Kant believes one can act morally only when 
the motivation is a sense of duty-which is to say, motivation unalloyed by emotion. To be well-disposed to a moral act through the emotions renders the act extra-moral. ${ }^{20}$ In Grundlegung Kant gives the example of a dealer who charges a fair price to everyone equally. The dealer does not act morally, however, if the reason for fair pricing is that fair pricing is good for the long-term environment in which the dealer hopes to continue to sell (Kant Grounding for the Metaphysics of Morals 10). Moreover, the dealer does not act morally if offering a fair price is the result of some abiding feeling of love for the customers. He goes on to offer up a person, who, having lost all fellow-feeling through a preoccupation with his own sorrow, nevertheless acts beneficently. According to Kant, unmotivated by emotion, "for the first time his action has genuine moral worth" (Kant Grounding for the Metaphysics of Morals 11). Moreover, for the purposes of ethics, it is only when the emotions are not part of the motivation to action that things like love and beneficence can be commanded, as in the Biblical charge to love one's neighbor as oneself. Kant reasons that it is impossible to command someone to feel love toward another; therefore, what is being commanded in those cases is love that "resides in the will" not in the emotions-which brings it into the realm of morality, and not merely "tender sympathy" (Kant Grounding for the Metaphysics of Morals 12). ${ }^{21}$

John Stuart Mill, on the other hand, views ethics as a means of maximizing happiness. His Principle of Utility, or the Greatest Happiness Principle, "holds that actions are right in proportion as they tend to promote happiness, wrong as they tend to produce the reverse of happiness" (Mill 
Utilitarianism 2.1, 55). Happiness, in this case, means pleasure, while pain consists of the deprivation of pleasure. That which is moral, then, is that which maximizes pleasure and minimizes pain. Aristotle also has something to say about pleasure and pain, which, he concludes, signifies not happiness and unhappiness, but the substance of feelings in general ( $E N$ 1252a31). Aristotle roundly rejects the idea that happiness (eudaimonia) is synonymous with pleasure, or that pleasure can be understood as a primary end, suggesting this sort of life is "slavish," fit only "for grazing animals" (1095b20).

Furthermore, Mill thinks that emotions—-what the ancients would have called passions, and what he calls desires and impulses-have a necessary function in the moral life. Unlike Kant who believes that the mixture of emotions with motivation precludes moral agency, Mill believes that impulses are the energy that drive moral agency—for good and for bad. The stronger the impulses the greater chance for evil, but also the greater chance for good (Mill On Liberty and Other Writings 60). Moral character, for Mill, consists not in having emotions appropriate to virtuous acts, but in harnessing strong emotions in the service of maximizing happiness.

Like Kant, Mill views the free exercise of the will as a prerequisite for a liberal society, which society (at least on Mill's account) seeks neutrality with respect to people's conception of the good. He believes that society has no direct interest in people's lives in areas that do not affect other people. That is to say, private thoughts, conduct, and aspirations should remain the preserve of the 
individual — unencumbered by external influence. He suggests that the "appropriate region of human liberty" consists of three things:

1. Freedom of thought and opinion in "the inward domain of consciousness."

2. Individual "liberty of tastes and pursuits" in "framing the plan of our life to suit our own character."

3. The free establishment of communities "for any purpose not involving harm to others" (Mill On Liberty 15-6).

For Mill, a truly liberal politics allows the individual the primary place in social arrangements, requiring that boulesis be the province of the individual, and not a communal enterprise. To Mill's understanding, humans, if they are to be civilized must develop individuality as a necessary pre-condition of things like education and culture (Mill On Liberty 57). Although individuality should be limited to the extent that it does not harm others, the cultivation of the idea of an individual self, responsible for all its own choices, puts the will outside the influence of others. Mill, though nodding to traditional conceptions of the education of the young, suggests that "it is the privilege and proper condition of a human being, arrived at the maturity of his [sic.] faculties, to use and interpret experience in his own way"- unencumbered, presumably, by the prejudicial presence of moral education (Mill On Liberty 58). Like Kant, Mill asserts that heteronomous influence in the exercise of the will precludes human moral agency: "He who lets the world, or his own portion of it, choose his plan of life 
for him, has no need of any other faculty than the ape-like one of imitation" (Mill On Liberty 59). On Mill's account, then, both individual moral activity and the telos toward which that activity is ordered are understood to originate at the individual, rather than the communal, level.

An Aristotelian reading of virtue ethics, on the other hand, believes that emotions should not be extirpated for the purposes of moral agency, but that they should be educated. Aristotle suggests that a disposition to virtuous action is insufficient for the cultivation of virtue, because an Aristotelian account of virtue concerns both actions and feelings (praxeis kai pathē) (EN 1104b14). And for Aristotle feelings have to do "in general [with] whatever implies pleasure or pain" $(1252 \mathrm{a} 31 ; 1260 \mathrm{a} 4-23){ }^{22}$ Feelings for Aristotle are not just involuntary impulses with which we must simply cope. We bear a certain responsibility for the emotions we have, as well as for how those emotions are cultivated, and to what ends they are ordered. He says that "we need to have had the appropriate upbringing — right from early youth, as Plato says— to make us find enjoyment or pain in the right things; for this is the correct education" (EN 1104b11). Emotions, then, are not only educable, on an Aristotelian reading, but this education is indispensable if we are to "find enjoyment or pain in the right things"; because pleasure experienced in the wrong way "causes us to do base actions," while pain wrongly experienced "causes us to abstain from fine ones" (1104b10).

Education in the virtues combines training in acting and feeling in the right ways and at the right times, while avoiding acting and feeling in wrong 
ways, at the wrong times. According to Aristotle's linkage of action and emotion, it seems reasonable to conclude that, in order to cultivate virtue, one cannot learn only to act in the right way without also learning to experience emotions in the right way, or vice versa. ${ }^{23}$ Whereas for Kant, emotional motivation precludes moral agency, and for Mill, emotions are the energy of motivation, emotions in Aristotle exist in critical relationship to our actions as finely calibrated and necessary components of moral action (1105a7). And though there are animal appetites (epithumia), these are what the incontinent person acts on $(E N 1111 \mathrm{~b}$ 15). He calls these appetites nonrational feelings, to differentiate them from rational decisions. He makes the claim, though, that "nonrational feelings seem to be no less human than rational calculation; and so actions resulting from spirit or appetite are also proper to a human being. It is absurd, then, to regard them as involuntary ( $E N 1111 \mathrm{~b} 1)$." Even though it is possible, for example, to act in ways a virtuous person would act (i.e., they accord with reason), if the emotions that a virtuous person would experience do not attend the action, then one cannot be counted as virtuous, according to Aristotle, but merely continent (1145b13). Taken in this way, Kant's conception of moral action as requiring an absence of emotional motivation argues for something very nearly resembling Aristotelian continence. $^{24}$ Aristotle, however, believes that the absence of the appropriate emotional response- that is, the reaction to environmental stimuli, about which I spoke in Chapter Two-makes continence ultimately unreliable as a long term state (hexis), just to the extent that the acknowledgment of a correct course of action without the fortification of an appropriate emotional underpinning is not a 
stable platform of character - which is the definition of virtue. Hence, inappropriate emotional response is an obstacle to virtue. ${ }^{25}$

It is worth pointing out that Aristotle does not view emotions as the equal of reason. He believes that reason ought to order the emotions to virtuous ends (Pol. 1254b5). Where he differs with Plato is in his belief that the emotions are educable, whereas Plato believes that they are only capable of being controlled. ${ }^{26}$ Another set of competitors against whom Aristotle differentiates himself with respect to the emotions are the Stoics, who claim that virtue must be purely rational, absent of the passions. Aristotle argues that "they are wrong, however, because they speak of being unaffected without qualification, not of being unaffected in the right or wrong way, at the right or wrong time, and the added qualifications" (EN 1104b25). That is to say, Aristotle believes that the Stoics paint with too broad a brush on the issue of the emotions, because "for good or bad enjoyment or pain is very important for our actions" (1105a7). This is so because virtuous actions are products of a state of character that disposes us correctly to the experience of pleasure and pain (1104b29), whereas the Stoics believe that emotions are not necessary for virtuous acts inasmuch as virtuous action can be motivated by duty alone (Nussbaum "Morality and Emotions" http://www.geocities.com/Athens/Rhodes/3724/Cytrix/cdrom5/Routledge_moralit y_emotion.html).

L.A. Kosman addresses the issue of emotions and moral action from just this perspective- that is, the dispositional nature of virtuous character. As I have noted, what is at issue for Aristotle in moral action has to do with the 
development of character, which is a "firm and unchanging state" from which moral action proceeds ( $E N 1105 \mathrm{a} 31)$. Kosman argues that character has to do with disposition - that is, "how I am to become the kind of person readily disposed so to conduct myself, the kind of person for whom proper conduct emanates characteristically from a fixed disposition" (Kosman 103). These dispositions, which are understood as potentialities, do not dispose us only to action, but also to feeling. ${ }^{27}$ While action concerns what I do (i.e., they are active), feelings concern that which affects me (i.e., they are passive) (Kosman 105). I must be well-disposed to the appropriate feelings when faced with particular situations, so that I might act virtuously.

In order to be said to have a virtuous character with respect to what Aristotle called "mildness," for example, when faced with a situation where anger is necessary, I must be angered by the right thing, in the right way, and at the right time (1125b32). It is possible to manifest either too much anger or too littleeither of which is to miss the mark of virtue. The accompanying actions for the virtuous person manifesting mildness are a necessary correlative of feeling anger in the right way, at the right time, and so on. Neither acting nor feeling in isolation are enough to comprise a character disposed to virtue. If I were to come upon a child being abused (assuming child abuse is a bad thing - something I will assert rather than argue), to be virtuous I would need to be angered in the right way. If my anger at this injustice is limited to internal seething without any external manifestation, my anger is impotent (i.e., lacking potentiality for action). To have these feelings, according to Aristotle, is in some sense to have entered 
into a state of affairs in which the end result is to be moved to action (1106a4). The realization of actions and feelings are linked by a character disposed to certain actions and feelings, which when rightly ordered result in virtue.

A Kantian analysis would suggest that injustice is wrong on universalizable grounds, and that I have a duty to confront it—regardless of whether or not I feel anger. In fact, assuming this analysis is correct, if anger is the motivation for any subsequent action in response to this injustice (e.g., I lash out at the unjust), my action loses force qua moral action, as I have already said. The question, though, is whether it is possible to confront injustice without being motivated by anger, and why this should be viewed as morally advantageous. If we take injustice to be a state of affairs in which inequity gives rise to grievance, then somehow emotional response seems implicit in the reaction injustice so identified elicits - that is, to identify something as unjust is already to have asserted the implicit assumption of a state of grievance. By Kantian standardsin which acting morally must be done only from a sense of duty-moral action would be a rare and difficult achievement, if only because our evaluations are so closely tied to our emotions.

Mill would most certainly agree that anger in the above example acts as a genuinely good motivator to a moral action that would maximize happiness. Anger operates for Mill not as an educable correlative of action, but as an urge that assists action in the moral sphere. Anger is the irresistible passion that must be controlled to carry out rationality's purposes. Mill follows Plato in this respect-that emotions act as potentially disruptive forces, which must always be 
controlled lest they wreak havoc. Mill differs from Plato, however, in that Plato has much greater confidence in the community to form the individual whose reason is called upon to harness the passions. Mill believes, on the other, hand that moral character requires that the desires and impulses "under the government of a strong will" ought only to reflect the individual's self-determined evaluations (Mill On Liberty 61). As such, the impulses and desires I have are not subject to any standard external to myself, save the Greatest Happiness Principle. Viewed in this light, any emotion I have is considered neither good nor bad, but rather helpful or unhelpful, inasmuch as it impels me to action that maximizes happiness. Emotions on this reading "are but another name for energy" (Mill On Liberty 60). That they are correlatives of certain kinds of moral action is, for Mill beside the point; whatever emotions are present that motivate moral action need not be emotions experienced in the right way, and at the right time, and so on. Rather, they must merely meet a threshold of intensity necessary to motivate action.

In contradistinction to Kant, Aristotle's theory of virtue as not solely action, but the combination of actions and feelings, recognizes the reality of the way human beings confront many situations in which a moral outcome is anticipated, offering, I think, a more realistic assessment of the moral life. In Mill's case, Aristotle's understanding of emotion as a correlative of action offers a more nuanced understanding of the relationship between "actions and feelings," an understanding that views virtue as a state of character well-disposed to both actions and feelings manifested rightly. Just any emotion--even if it is strong 
enough to motivate action - will not do for Aristotle; one must manifest actions and feelings appropriate to the situation. These feelings are not, according to Kosman, "merely the occasion for actions that are the proper realization of the virtue; they are part of the concept of that virtue considered as a disposition" (Kosman 109). Kosman is quick to add, however, that neither are these feelings themselves the realization of virtue, "but they are a part of the set of corresponding actions and feelings for which virtue is a disposition" (Kosman 109).

An Aristotelian understanding of virtue, I would suggest, offers a more complete theory of moral action than either Kant or Mill by combining action with feelings in ways qualified by their appropriateness to the situation. To see how, from an Aristotelian perspective, the emotions can be educated, I will turn to the historic debate occasioned by Aristotle's implicit response in the Poetics to Plato's proscription of tragedy in the Republic. For it is in the Poetics that Aristotle addresses the whole issue of appropriate emotional response through a discussion of the emotions elicited by tragedy.

\section{Tragedy: Plato and Repulsive Emotions}

Plato, in Book X of the Republic, opens a discussion that has fueled debate for over 2,500 years on the nature of art and the place of the artist within the ideal republic. In addition to the epistemological inexactness art engenders (Plato Republic 602c) Plato argues that art, through its evocation of the emotions, encourages injurious moral habits. Poets, in general, and tragedians, in particular, 
draw Plato's criticism for contributing to social corrosion by obscuring our knowledge of the truth through their representation of reality. Of particular concern to Plato is the way poets becloud the truth through appeals to the emotions. In Plato's view, these pre-critical passions, if unchecked, cause us to do things that—if we would only "stop and think" about them—we would never do. We succumb to our passions, and are said to be "not in our right minds." On a Platonic reading, reason is privileged as the primary way of knowing. Reason is the tool used to uncover truth, while emotions, on the other hand, are precisely what must be avoided if we are to arrive at a reliable account of the truth. They are the "low-grade part of the mind" (603a). In Plato's view, the emotions are passions that threaten to overwhelm the good judgment of reason. Left unchecked, emotion will try "to dominate and rule over things which it is not equipped by its hereditary status to rule over, and so plunges the whole of everyone's life into chaos" (442b). Reason, on the other hand, is the taskmaster that is called upon to "ride herd" over (and, ultimately, to tame) the unruly emotions (Plato Phaedrus 253d9).

A notable exception to Plato's suspicion of the emotions as unmanageable is his positive view of love, which moves the whole person toward beauty through reserved contemplation of the beloved. In Phaedrus Plato writes:

The irrational desire that has gained control over any judgement urging a man towards what is correct, and that is carried towards pleasure in beauty—in turn being forcefully reinforced by the desires related to it in 
its pursuit of the beauty of bodies - and that wins victory by its drive, taking its name from its very force: this is called love (238b10).

Nevertheless, as Plato points out later, the good horse of love (which works seamlessly with the charioteer of reason) is always in danger of being overcome by the bad horse of hubris (253-256). It is to this hubristic passion that Plato refers when he says of the poet that "he's concerned with the petulant and varied side of our characters, because it's easy to represent" (Plato Republic 605a).

But, it might be objected, notwithstanding the potential problems created through the poetic encouragement of excessive passions, does not Plato hold out for a limited use of the poet's art-in particular, for my purposes, stories that reinforce the appropriate moral responses? It is true that Plato understands the need for edifying stories as a process of the education of children who would be guardians of the ideal republic (e.g., 377/378). However, it is not at all clear that the kind of poetry Plato is prepared to allow for the purposes of moral education—relying as it does on stories which are not false portrayals that impugn the gods or appear to glorify viciousness-is even art. Indeed, he concedes that “it's not because the lines are not good poetry and don't give pleasure to most people; on the contrary, the better the poetry they are, the more they are to be kept from the ears of children and men who are to be autonomous and to be more afraid of losing this freedom than of death" (387b). Instead, what Plato proposes is the use of stories that portray the gods in a predetermined and imitable way, or true stories that display human virtue - the definition of which seems to be the history that Aristotle is keen to contrast with poetry (Poet 1451b). In short, the 
role Plato sees for art in the republic abjures art qua art in favor of morally edifying object lessons. It is important to note at the outset that my discussion will be focused primarily on literature. Inasmuch as both Plato and Aristotle have mainly poetry in mind, and inasmuch as aesthetics as a formal philosophical discipline comes much later in history (e.g., it is not entirely fair to ask either Plato or Aristotle to respond to something like modern abstract art—an aesthetic innovation they could not have anticipated), we are justified in so limiting the scope of our discussion.

Plato recognizes that mimetic art (particularly art that relies on narrative construction) is unfortunately liable to misuse as a medium, because its primary appeal is to the emotions $(604 \mathrm{c})$. Mimetic art poses a threat to good order, because whereas reason is stable, capable of withstanding manipulation, the emotions are susceptible to change (605a). Literary stories thrive on conflict, for example, which is due, I suspect, to conflict being inherently more interesting. ${ }^{28}$ The intellect is calm and stable, and, therefore, aesthetically boring (604e). Presumably, no one wants to read a book (see a play, movie, etc.) about a nice law-abiding family to whom nothing ever happens. The conflict represented in narrative forms of art is largely emotional in nature: emotional in the sense that either the conflict itself is emotional (e.g., the betrayal of friends, the jealousy of the lover, the hatred of an enemy, etc.) or some other kind of conflict (e.g., military, political, individual violence-even intellectual) that evokes emotional conflict, as a result of having to come to terms with the initial conflict. Therefore, because emotional conflict is more interesting than the absence of conflict-thus, 
causing it to be a central aspect of tragedy - poets who portray emotional conflict, in Plato's view, are forever appealing to the lowest part of us. ${ }^{29}$ In fact, according to Plato tragedy encourages the very emotions that virtuous people continually attempt to subdue through the application of reason (606a). "We are," according to Iris Murdoch, "infected by playing or enjoying a bad role."(Murdoch The Fire \& the Sun 5).

Poetry, therefore, promotes a state of affairs in which, instead of subduing emotions through reason, emotions are intentionally evoked, and thereby strengthened through their exercise. Hence, according to Plato, the poet should not be admitted into the city, because "he destroys the rational part by feeding and fattening up this other part" (Plato Republic 605b). Emotions here are imagined as the errant forces in a city to which the poet cedes political power. Plato notes that "this is equivalent to someone destroying the more civilized members of community by presenting ruffians with political power" $(605 \mathrm{~b})$. The poet, therefore, "establishes a bad system of government in people's minds by gratifying their irrational sides" $(605 b)$. Furthermore, the political metaphor applied by Plato to emotion suggests that the triggering of emotions through poetry is not merely a matter of individual rational deformation. Society, as an aggregation of individuals, is also negatively affected when emotions go unfettered. That is to say that if everyone acted on the urges of anger without restraint, for instance, the fabric of society would unravel in short order, as the safety and security offered by society would cease to exist. 
Additionally, Plato argues that reason and emotion are in conflict in other ways. For Plato, the divide between reason and emotion is as discrete and divergent as the divide between male and female. He writes: "However, you also appreciate that when we're afflicted by trouble in our own lives, then we take pride in the opposite-in our ability to endure pain without being upset. We think that this is manly behaviour, and that only women behave in the way we were sanctioning earlier" (605d). In other words, to allow reason to subjugate the emotions, to refuse to show emotion is manly, while succumbing to the passion of emotion, surrendering to the irrational is womanly-where manliness, of course, is the ideal. Hence, poetry is a feminizing force that threatens rationality. This privileging of reason over emotion, and the identification of rationality with maleness and emotionality with femaleness has shaped Western epistemology ever since. ${ }^{30}$

For Plato, the emotions elicited by art are, at best unnecessary; because he believes that the good person is self-sufficient (387d). This self-sufficiency has implications for virtue, in that Plato understands virtue to be a product of individual achievement. External circumstances have no bearing on the virtuous person's practice of virtue. In a position that later came to be associated with the Stoics, Plato holds that nothing bad can happen to a good person. Plato writes in Republic III that "one good man will not regard death as a terrible thing for another good man—a friend of his—to suffer" (387d). On this account, one need not grieve the death of a friend because the goodness of one's life does not depend on external factors-in this case, neither on other people, nor on any 
tragedy that might befall oneself or those close to one. Plato's understanding of the impropriety of emotional response for a self-sufficient person can reasonably be extended beyond grief to include the improper emotional responses of fear and pity: In the case of the death of "a friend of his," one is obliged not to extend pity to those who loved the good man, nor to fear that kind of death for oneself.

Why, though, does the good person—the self-sufficient person—remain calm in the face of the death of a friend? Being emotionally detached, the good person is capable of looking dispassionately on events that might cause a lesser person to show pity or fear. ${ }^{31}$ Pity and fear are repulsive to a self-sufficient person (605e). Pity, for example, is always bad, because if a bad thing happens to a person who deserves it, then pity is an inappropriate response; what is called for is blame. If, on the other hand, something tragic happens to a virtuous person and it is undeserved - then blame is inappropriate; it is only apparently tragic, for nothing bad can happen to a good person. Witnessing pity in another person should cause revulsion to the good person. Similarly, fear is inappropriate in a good person; it is always unmanly. The same logic applies: If nothing bad can happen to a good person, what is there to be afraid of? Seeing fear in another person should also cause revulsion. The tragedians encourage the experience of these two emotions through their portrayal of tragedy. Hence, according to Plato, tragedy ought to be banned. ${ }^{32}$

Aristotle, to whom I turn next, takes a different view of tragedy, related in large part to his difference from Plato in the understanding of emotions. Whereas Plato views emotions as impulses always in need subjugation, Aristotle believes 
emotions are educable - and that tragedy, instead of being banned, plays an important role in educating the emotions.

\section{Aristotle and Necessary Emotions}

\section{A. Emotion, Action, and Tragedy}

Aristotle offers an implicit response in the Poetics to Plato's denunciation in Republic X of the tragic emotions. Where Plato believes that the emotions educed by tragedy should be seen as disgusting in the individual and corrosive to the republic, Aristotle believes that emotions are crucial to the cultivation of virtue. I want to be clear that I am not suggesting a position for Aristotle on emotion that anachronistically imposes on him positions about which, not only did he never think, but positions about which he did not possess the conceptual resources to think. After all, Aristotle also held that the passions should be ruled by reason. Furthermore, he privileged reason with the same gender specific distinctions as Plato (Pol. 1252a31; 1260a4-23). Neither do I want to argue that Aristotle's position on emotions is the obverse of Plato's, but rather that Aristotle saw sufficient difference between his position and Plato's; this difference prompted him to respond to Plato's claim that poets ought to be banned for their ill effects on moral and epistemological order.

However, even the assertion that Aristotle is offering an implicit response to Plato is not an entirely uncontroversial one. Alexander Nehamas, for instance, has argued that whatever Aristotle's disagreements were with Plato, they do not extend to his treatment of tragedy in the Poetics. Nehamas argues that "even if 
Aristotle is confronting Plato on [the benefits and harms of poetry], he is not doing so through his very definition of tragedy itself." 33 Interestingly, though, Nehamas pins his argument to a denial of the notion that Aristotle's use of catharsis in the Poetics "involves the emotions in any way"(Nehamas 293). That is not to say that Nehamas believes that emotions have no cognitive content. Quite to the contrary, he contends that emotions "involve both content and evaluation" (Nehamas 297). However, whatever value emotions possess comes as a result of their being persuaded by reason. In fact, he argues that unless Aristotle "shows how exactly one becomes habituated into virtue without relying on a literal model of reason persuading the emotions to agree with its choices, their non-rational status will remain in question; the precise mechanism by which emotion is trained into virtue needs to be made explicit" (Nehamas 299). What Nehamas's account of the rational habituation of emotion fails to take into account, however (which is crucial to the point he wants to make), is the extent to which much of habituation takes place in a pre-cognitive way. Aristotle's understanding of habituation into virtue does not assume rationality (nor does it need to) as a prerequisite. Habituation into virtue assumes that one does not possess the cognitive resources for rational deliberation prior to beginning the process-which is precisely why habituation is necessary. Education of the emotions and habituation into virtue begins with the very young, where rational persuasion is not even possible. In fact, the process of habituation may require actions or responses that appear irrational to those who have yet to be trained, but that can only appear rational after a habit has been established. If I have a 
relationship with someone who is a gambling addict, for example, my first response to that person upon learning that gambling has brought on another financial catastrophe may be to respond with pity by rescuing that person. Pity toward those whom we love seems, at first glance, like a rational and morally defensible course of action. I may be told later, though, that an emotional response of pity in this situation that leads to some kind of rescuing behavior is precisely the wrong emotional response here. It may very well be that I have to cultivate certain counter-intuitive emotional habits before I ever understand them - that is, prior to being persuaded that they are reasonable or moral.

\section{B. Aristotle on Tragedy: Situating the Debate}

Having underscored the link between action and feeling for Aristotle, we are prepared to entertain his thoughts on tragedy, because it is tragedy as an art form that is explicitly concerned with action and emotion. In fact, a work of art has no claim to the title tragedy in the absence of action-which is why plot is more important than character in tragedy, inasmuch as plot deals with action, while character deals with a state of being: "In other words the end and aim of human life is doing something, not just being a certain sort of person; and though we consider people's characters in deciding what sort of person they are, we call them successful or unsuccessful only with reference to their actions" (Poet 1450a). ${ }^{34}$ Possessing virtue, for instance, as a state of being is never enough. True virtue consists in "activity in accord with virtue" (EN 1098b30-1099a6). 
However, tragedy deals with more than just action, because tragedy, like virtue, "is a mimēsis not only of a complete action, but also of things arousing pity and fear, emotions most likely to be stirred when things happen unexpectedly but because of each other" (Poet 1452a). Hence, to the extent that the virtues principally are concerned with actions and emotions, tragedy seems especially suited to the task of educating the virtues. To make an assertion about how tragedy is well-suited to the task of educating the emotions, though, is to raise the inevitable question about whether Aristotle understands tragedy more or less instrumentally. I will speak at greater length in Chapter Five about the historic aesthetic dilemma over whether any use of art other than for aesthetic enjoyment risks making it instrumental to some other ends. At present, though, I will suggest that there is a way to understand Aristotle on tragedy that takes into account his appreciation of form, while still understanding the capacity of that form to offer imaginative possibilities for the training of the emotions through mimesis.

Having acknowledged that Aristotle did not set out to propose an aesthetic theory, and that his view of art is not necessarily hostile to formal aesthetic accounts, we should ask about what it is he wants to accomplish in Poetics X. A straightforward reading of the text suggests that his primary intent centers on describing the function of tragedy - what it is meant to do, and how it accomplishes this task. I will argue that it is by no means a devastating admission to an Aristotelian mimetic theory to propose that the form of tragedy is inextricably bound up with its function. This sounds like a rather large claim, 
which will be crucial to the account of the emotions I am proposing, and, therefore, one which I must now defend.

To fulfill the function of tragedy, a work must first meet certain requirements of the genre, which Aristotle lays out in great detail in Chapters 6-15 in Poetics X. Properly fulfilled, the function of tragedy shapes our understanding by helping to shape our emotions-in particular, pity and fear (A. O. Rorty 2). According to Aristotle the definition of tragedy is dramatic theater that contains "a mimēsis of actions that rouse [pity and fear]" (Poet 1452b). ${ }^{35}$ Having emphasized the function of tragedy, though, it should be remembered that in his exposition on tragedy it is precisely Aristotle's emphasis on the form of tragedy (i.e., the plot structure) that makes his position with respect to emotions intelligible. That is to say, the form of the genre tragedy is efficacious in fulfilling its function. Because the form of tragedy requires the evocation of pity and fear, a piece of work that fails to elicit the tragic emotions will, by definition, not be tragedy. Hence, on an Aristotelian reading of tragedy, form and function are inseparable.

Put differently, the form of tragedy (or any other medium) is not reinvented with each work in some totally autonomous fashion, in which no claim external to the work has a claim on the work's meaning. ${ }^{36}$ The decision to use the genre tragedy, as I have said, already commits one to a particularly well-defined set of formal commitments external to the art object. The function of tragedy transcends particular works, such that changing the function of the particular work is already to have decided against the use of tragedy. As Richard Eldridge has 
noted in describing a standard criticism of an formalist conception of art: "Which aesthetic properties a work has and displays is a function of which independently historically established class of works it inhabits. Aesthetic properties are not immediately evident in perception to the nonhistorical eye or ear alone" (Eldridge 62). In other words, a piece of art stands within the precincts of particular genres and traditions, a knowledge of which allows a ground from which to judge whether a particular work is successful in fulfilling its function—or perhaps may even work to redefine what can now be said to rise to the level of success for that genre or tradition.

On this reading, then, each medium has its own pleasure unique to itself. ${ }^{37}$ Aristotle writes: "For every perceptual capacity and every sort of thought and study has its pleasure; the most pleasant activity is the complete; and the most complete is the activity of the subject in good condition in relation to the most excellent object of the capacity" ( $E N 1174 \mathrm{~b} 21)$. A painting, for example, is first of all to be enjoyed as a painting, and not as an object lesson. Likewise, the pleasure associated with tragedy ought to be appreciated for its own sake, and not as a front for making points that stand alone, apart from tragedy. Tragedy, as Halliwell observes, "does not just confirm us in pre-existing comprehension of the world: it provides us with imaginative opportunities to test, refine, extend and perhaps even question the ideas and values on which such comprehension rests" (Halliwell 253).

The broader function of tragedy, then, provides a clue about what Aristotle means in Chapter Nine in the Poetics, when he raises the issue of universality. 
Aristotle draws a distinction between the historian and the poet, suggesting that the historian recounts what happened in a particular way, while the poet offers an account of what could happen given "a strictly probable or necessary sequence" (1451a). Aristotle clearly favors the poet over the historian in this comparison, saying that "poetry is at once more like philosophy and more worth while than history, since poetry tends to make general statements, while those of history are particular" (1451b). The general (kathalou) statements made by poetry are not just abstract universals - as opposed to concrete particulars. Rather, poetry (tragedy) is about giving a general structure (read plot structure) on which to hang particular instantiations of character. That is why Aristotle says that poetry tells us "the sort of thing that would happen" to particular people. The net effect of this is to produce a tragic plot structure that, because it properly arranges action, fulfills its function by educing the appropriate emotional response in the viewernamely, pity and fear. What purpose, though, does pity and fear serve, according to Aristotle? Additionally, if tragedy has its own pleasure when its function is properly fulfilled, it must be asked what that pleasure is, and why does Aristotle think that tragedy's ability to call forth pity and fear is important? It is to answer these questions that we must now turn to a discussion on the tragic emotions.

\section{Pity and Fear}

"I will have no man in my boat," said Starbuck, "who is not afraid of a whale." By this, he seemed to mean, not only that the most reliable and useful courage was that which arises from the fair estimation of the encountered peril, but that an utterly fearless man is a far more dangerous comrade than a coward. 
Plato argues in Republic III, as I have said, that nothing bad can befall the truly self-sufficient person. Therefore, the emotions elicited by tragedy (i.e., fear and pity) should be the object of revulsion. Aristotle, on the other hand, believes that there are some things that can happen to the virtuous person that will impede the practice of virtue and the possession of eudaimonia. The eudaimon person "needs to have goods of the body and external goods added [to good activities], and needs fortune also, so that he will not be impeded in these ways" ( $E N$ 1153b15). Arguing against Plato, Aristotle says, "Some maintain, on the contrary, that we are happy when we are broken on the wheel, or fall into terrible misfortunes, provided that we are good. Whether they mean to or not, these people are talking nonsense" (153b19). In other words, according to Aristotle, there are occasions that obstruct eudaimonia —even in a person who is otherwise self-sufficient. Admittedly tragedy is not concerned with random misfortune, but with a very specifically defined set of actions, the causes for which are prompted by the poor choices (hamartia) of the central character. Nevertheless, my point here is only to indicate that Aristotle, contrary to Plato, does not view even the good person as exempt from occasions that impede eudaimonia-occasions for which pity and fear are the appropriate emotional responses. Not only is their presence not an occasion for revulsion, as they are for Plato, their presence in the right way and at the right time is necessary for virtue to exist.

Our task, then, on an Aristotelian view, is not to conquer emotions, but to train them properly. Being socialized emotionally is crucial to Aristotle's view of 
moral training-especially the training of the young (Knuuttila 25). Interestingly, though, Janko makes the case that tragedy, while beneficial to discerning adults, is precisely the kind of literary form liable to mislead impressionable youths (Janko 353). Aristotle believes that the powerful effects of tragedy may reinforce poor emotional responses in the young, in the same manner that Plato says tragedy reinforces poor emotional responses in everyone (Janko 353). Regardless, though, of the age at which it is possible to benefit from exposure to tragedy, it is clear that Aristotle believes that having the appropriate emotions (made available by tragedy) at the appropriate time works dynamically with reason to produce reliable knowledge and to promote virtuous action. For Aristotle, as has been noted, correct action must always be accompanied by correct emotion to be accorded the status of virtue. Emotion and reason work collaboratively in this way to provide practical wisdom as well as reliable knowledge. This dynamic collaboration between emotion and reason in both morality and epistemology, as I argued in Chapter Two, problematizes the traditionally distinct line dividing emotion from reason.

Hence, tragedy - the effects of which are the evocation of appropriate emotions-is a way to expand our moral and emotional imagination, allowing us to have the right emotions at the right time. ${ }^{38}$ As I will have occasion to argue in Chapter Five, the aesthetic space created by literature-tragedy for my purposes here- opens up new ways of inhabiting moral and emotional perspectives through our use of imagination. This simulation is important in helping us to experience emotions appropriate to the situation. Not to possess these emotions properly is 
to be intellectually ill equipped, as well as to be ill equipped for the pursuit of virtue, particularly the virtues of bravery and justice.

The virtue of bravery, for example, is concerned not with having no fear, but with having the right fear at the right time (e.g., fear of a bad reputation, fear of death in certain conditions, $E N$ 1115a12; 1115a25-1115b6). Interestingly, Aristotle believes fear is an inextricable part of the cognitive process, requiring a developed imagination: "Fear may be defined as a pain or disturbance due to a mental picture of some destructive or painful evil in the future. ${ }^{\prime 39}$ Consequently, it is fear that "sets us thinking what can be done" (Rhet 1383a7). An Aristotelian view of fear sees fear as a trigger for the imagination, calling into play the creative resources necessary for meeting a potential threat with at least "some faint expectation of escape" (1383a6). Between Nichomachean Ethics and Rhetoric, it is possible to conclude that the emotion of fear, for Aristotle, prompts imaginative thinking in the face of a threat. Fear, when properly trained, can help rightly assess true danger-that is, when and of whom to be afraid. Knowing the situations appropriate to fear-more specifically, that which ought to trigger fear-allows us to bring reason to bear on the situation, so that we might uncover a solution. However, the education of the emotion of fear consists not only in correctly identifying threats, but also in practicing creative responses to those threats, by having considered imaginative strategies for dealing with the threat before it arises. The cultivation of the virtue of bravery requires that we respond appropriately when faced by a threat, neither brashly nor cravenly—that is, neither with too little or too much fear. As a result, to be brave we need to fear 
the right dangers at the right time and in the right way, which requires practice and imagination.

The necessity of the practice of imaginative thinking in pursuit of virtue also emerges when Aristotle speaks about the appropriate emotional response with respect to pity. On the whole, Aristotle says, "anything causes us to feel fear that when it happens to, or threatens, others causes us to feel pity" (1382b26). Fear and pity, therefore, are linked for Aristotle in an important way. Being only slightly oversimplified, then, one may say that we fear that which threatens us, while we extend pity to others who are threatened by that which - if it were to happen to us-would cause us fear. But it must be remembered that the pity we hold out to others is based on our assessment that what they suffer is unjustified. Pity should not extend to justified suffering. If the correct emotional response of fear serves the cultivation of the virtue of bravery, the correct emotional response of pity serves the cultivation of the virtue of justice. Aristotle contends that "it is our duty both to feel sympathy and pity for unmerited distress, and to feel indignation at unmerited prosperity; for whatever is undeserved, is unjust, and that is why we ascribe indignation even to the gods" (1386b13). In other words, we feel pity when we witness someone receiving more or less than they deserve. And it is desert that is precisely what lies at the heart of an Aristotelian conception of justice, a concept I must briefly summarize.

Justice, for Aristotle, on a special level, is of two types: distributive and rectificatory. Distributive justice deals with deliberations about what is due to another "in the distribution of honors or wealth or anything else that can be 
divided among members of a community who share in a political system" ( $E N$ 1130b31). The second species of justice, rectificatory justice, concerns redress in transactions (1131a1). ${ }^{40}$ Justice is said to be "whatever produces and maintains happiness and its parts for a political community" $(1129 \mathrm{~b} 18)$. The cultivation of the correct emotional response of pity, which is an emotional response toward another within the political community that tracks desert, is therefore tied directly to the cultivation of the virtue of justice.

"Justice," according to Aristotle, "is the state that makes us just agents[that is to say], the state that makes us do justice and wish justice" (1129a7). As such, justice "is the complete exercise of complete virtue" $(1129 \mathrm{~b} 31)$. The exercise of this virtue is directed toward another person, and not just toward oneself (1129b27). In fact, Aristotle argues that many people are capable of exercising virtue when it comes to their own concerns. However, it is considerably more rare to find someone capable of exercising virtue when it concerns another (1129b34). Pity, on this reading, then, is a communal response, finely tuned to identify desert in a social way, and to respond to it. If pity is the emotion that we extend to another in the case of injustice, then, we must experience it in the correct way if we are to possess the virtue of justice. That is to say, if justice is the virtue, pity stands as an evaluative emotional response against injustice; it is, in other words, a way of negatively defining justice by identifying injustice. Furthermore, a failure to appropriately identify injustice through the emotional reaction of pity ultimately proves corrosive to the bonds of community, which rely on an accurate accounting of desert. 
To sum up briefly, then, what I have said so far: fear and pity are emotional responses necessary to the cultivation of bravery and justice, respectively. Possessing fear and pity allows one to assess threats correctlythreats either to oneself or to another. Having responded with the appropriate emotions, one is prompted by that response to offer imaginative solutions for the threat at hand, which may lead to appropriate action. Furthermore, one's current abilities to imagine possible solutions to a potential threat are directly affected by the opportunities one has already had to entertain possible imaginative solutions when faced by prior threats. The opportunity to consider imaginative possibilities, I submit, is at least part of what art, in general, and tragedy, in particular, offer us. I will say more about this in Chapter Five, when I give a fuller account of imagination and the experience of emotion in fiction.

\section{Conclusion}

In this chapter I have set down the argument that emotions are a necessary part of attaining virtue, and attaining virtue, in turn, is a necessary part of a fully flourishing life. Taking an Aristotelian view, I suggested that emotions (or at least their triggers), which are necessary to virtue, are susceptible to formation. I also suggested that a fully flourishing life is one lived in a community capable of producing virtuous people. Finally, I concluded by using the genre of tragedy as a way to show how emotions may be educated in an aesthetically creative space that exercises the moral and emotional imagination. 


\section{CHAPTER FOUR}

\section{INTERSUBJECTIVITY: THE NEED FOR EMOTIONAL ATTENDING}

\section{Introduction}

Up to this point I have argued that reason, understood as the engine of the scientific model, has been privileged in western conceptions of knowledge at the expense of emotion. The rise of reason as the preeminent form of knowing, as well as the attendant marginalization of emotion, creates an obstacle to the pursuit of virtue, which requires, according to Aristotle, not only correct action, but also the feelings appropriate to correct action. That is to say, on an Aristotelian account, to attain virtue it is not enough to act the way a virtuous person would act; one must feel the way a virtuous person would feel while so acting. Moreover, the displacement of emotion by reason as the only source of reliable knowledge has consequences for social and communal life, since one of the most important ways we interact with one another relies not only on the propositional knowledge about another provided by reason, but on our ability to understand another's emotional life.

At the same time, Western thought has experienced a "turn to the self" that has placed the individual in the center of his or her own universe. This turn to the self has had a profound impact on morality, inasmuch as it leaves morality in the position of being popularly understood as the advancement of preference. It also 
has profoundly impacted the possibilities for intersubjectivity —-that is, being with and for others, by affecting our ability to know others, leaving us as free-floating "spheres of interiority."

In this chapter, guided by Iris Murdoch, I will take up again the metaphor of vision. In Chapter One I argued that vision was the dominant epistemological metaphor for much of Western history. I want to suggest in this chapter another kind of vision, which I will call other sight, the goal of which is not the objectifying vision of scientific rationality, but a vision of subjects that undergoes constant refinement.

Traditionally in the West, true knowledge was thought to consist in seeing the world as it is. The assumption that one could offer accurate reporting about the real world set the stage for the development of science-empirical science, in particular. Objectivity, the goal of which is to observe dispassionately, emerged as a prerequisite of the accurate reporting of reality. One of the consequences of objectivity as a prerequisite of true knowledge was the process of abstraction-in which it was assumed that the particular thing being observed could be understood in isolation from the complex web of relationships that made up the whole from which the thing derived. The study of things in isolation from their context produced habits of mind that, when transferred to human beings, made it natural to begin to think that human beings were also comprehensible as atomic individuals, abstracted from the various communities from which they came. But, as Descartes was quick to point out, empirical knowledge operated with the disadvantage that came from reliance on the senses. Descartes, in a move 
designed to steer clear of the unreliable senses, turned that vision inward, believing that truth could only be found when passed through the interior filter of the individual, unencumbered by prior relationships to external authorities, like the church.

Moreover, the turn to the self that was also unfolding further severed the relationship between the individual and the community by understanding external communities as merely tyrannical and oppressive, a threat to the freedom with which humans were endowed, and which was the necessary ether in which moral agency existed. It must be admitted that certain communities often did act tyrannically and oppressively with respect to the freedom of the individual, and that the reaction against that tyranny and oppression was a necessary corrective. The Medieval Catholic Church and the various European kingdoms and principates - which is to say, religious and political communities in the Westoften exercised tyrannical control over the life and aspirations of the individual. Consequently, a move to invest the individual with the resources to stand over against some of the external demands of the church and the state by asserting the autonomy of the individual — as Kant did, for example, in his seminally influential essay, "What Is Enlightenment?"--proved a crucial counterbalance. ${ }^{1}$ However, at the heart of the problem I identified in Chapters One and Three is the popular Western assumption that community per se is necessarily tyrannical and oppressive. The issue of the locus of authority lies at the center of this tension; which is to say, who or what operates as the final moral or epistemological authority—individual or community? 
People, encouraged by Kant, were exhorted not to look to heteronomous external authorities to know how to act morally, but to embrace autonomy - that is, to "think for oneself." Again, in a culture in which the church had autocratically bounded knowledge (e.g., Copernicus and Galileo) and had at its disposal the power to enforce a particular moral code (often with deadly force), the appeal to break free of the external bonds of authority was a crucial moral and epistemological development. However, although Kant was by no means advocating radical reflexivity, his cry, "sapere aude," has had resonances for those who are so inclined. ${ }^{2}$ Put more simply, the call to think for oneself that gave rise to the democritization of knowing, while a necessary response to ecclesiastical and political oppression, has proven to be potentially just as oppressive as an end in itself, casting the individual back on himself. The movement toward radical reflexivity, and the attendant focusing of one's gaze upon oneself, shifted the referent for value off authoritative communities and onto the individual, arguably trading one master for another. The result of this shift, I will contend in this chapter, is a distorted vision of the world, inasmuch as one's knowledge of the world, and-more importantly, for my purposes—other subjects, is the result of an uncritical analogical projection of the self onto the world, and once again, onto other subjects. My use of projection is not intended to rise to the level of psychoanalytical precision. By projection I am simply referring to the tendency to assume that what is the case with me must also be the case with you. That is to say, projection is my assumption that my experience of the world is normative. This projection operates as an unwitting supposition that 
other humans are more or less just like me. By unwitting I mean that because of the habits of mind I have mentioned, which include the belief that knowledge of the world is a radically reflexive process and that such knowledge can be considered reliable only when it meets threshold levels of objectivity, individuals are prone to objectifying others. In other words, we are prone to viewing others as knowable in much the same way that the heavy metal makeup of soil composition or the migratory patterns of North American sparrows are knowable. Furthermore, by assuming that everyone else is "more or less just like me," my knowledge of others, rather than coming from attending to the complexities of their lives, begins with me attending to my own interiority. In this way, it is possible to misapprehend others as merely an extension of my interiority. Michael Stocker ties this kind of misapprehension of another to habits of mind, as well: "It could be held that if a self-absorbed person fails to see others' interests, or if having seen them fails to be moved by them, the real explanation would lie not in the emotions of self-absorption, but in the patterns of thought, attention, and desire that underlie self-absorption" (176).

The mental habit of analogical projection - which is to say, an understanding of the world that begins with the individual and moves outward, considering reality to be an extension of or easily analogous to an individual's experience-coupled with the mental habit of abstraction through the goal of objective observation has in many ways made the individual's relationship to other human beings one of subject to object. In a world where value is subjective and the objectivity of reason exists as the only true knowledge, knowledge of 
other human beings is potentially either abstract and objectifying, or a normative projection of the individual's experience onto others.

I want to suggest that the problem I have described so far is a problem of vision. We do not know how to act morally inasmuch as we do not see clearly. According to Murdoch, our frame of reference on the world is the "fat, relentless ego" (Murdoch 51). On this description, we see others through the veil of our own interiority, projecting onto them our own inner life. That is to say, we see others only as objects in the world, extensions of ourselves, rather than as subjects with their own projects and aspirations. Hence, to the extent that we see only through the opacity of our own egoic projections, we see the world blurrily, and ultimately, incorrectly. And because whatever we can know about another is ultimately a variation on what we know about ourselves, any knowledge available to us of the world inhabited by other subjects can only tell us that which we know already (Jonas 245). As a consequence, since we have been taught to see true knowledge as commensurable with scientific reason, and insofar as scientific reason is conceptually incapable of providing us with the resources necessary for the negotiation of the world of value and emotion (which, according to my argument, is crucial to being human), we are in a very real sense, epistemologically handicapped.

I will suggest a way of seeing others as subjects who are independent of us, and who should be known contextually — that is, as embedded within a complex web of relationships that comprise a life. The key to obtaining reliable knowledge of another, I will argue, comes through a practice I will call emotional 
attending. Moreover, I will differentiate emotional attending from empathy, taking into consideration the kinds of social cues, called uptake, that demonstrate understanding of another.

\section{Emotional Attending, Other Sight, and Empathy}

Of real importance in Murdoch's argument about why our vision is distorted is her belief that we are capable of truly seeing reality only inasmuch as our attention is focused outward rather than inward. Knowing other people independently of ourselves, according to Murdoch, is essential to knowing ourselves. Instead of the typical Western understanding of knowing others-in which we know the other by projection as a result of knowing ourselves - we know ourselves only inasmuch as we are able to attend to others as emotional subjects—not as objects, mere extensions of ourselves and our own projects. Therefore, to the extent that, as heirs to the western intellectual tradition, we have undergone a "turn to the self," in which our gaze is focused primarily on our inner lives, we are alienated not only from others, but ultimately, from ourselves.

Hans Jonas, on the other hand, argues for a different orientation of the self to the world. He asserts a reversal of the post-Cartesian understanding of the way an insular self can cross the social divide and engage another insular self. PostCartesian assumptions about this ability to make an intersubjective connection rest on the idea of analogy and transference (Jonas 243). In other words, I am only able to know another by interrogating my own interiority, latching onto an analogy based on my own experience, and then projecting that onto the other-I 
only know you inasmuch as you are like me. $I$ am always the referent. However, Jonas points out that "already the knowledge of our own mind, even our having one in the first place, is a function of acquaintances with other minds. Knowledge of inwardness as such, whether one's own or that of others, is based on communication with a whole human environment which determines, certainly codetermines decisively, even what will be found in eventual introspection" (244). In a very real way, then, there is no self that exists essentially, or is prior to our interaction with others. Jonas observes:

Thus we must be able to understand others before we understand ourselves, in order for us to become persons who may eventually understand themselves - for there to be anything in us to understand. An understanding of the inwardness of others, in advance of and beyond what 'introspection' could have found in one's own inwardness, is a precondition for the very emergence of such an inwardness (244).

Furthermore, inasmuch as one views one's interior life and experiences as universalizable, and therefore, worthy of projection, when one attempts to understand the emotions of another, one risks the temptation to reverse the order of knowing, seeing another subject with a different interior life and experiences as only a mirror projection of one's self. The problem with analogy in knowing others is not so much the process of analogizing, however, but our unwavering belief that our analogies are always accurate placeholders for the experience of others. We are good at superimposing our lives on the lives of others; however, 
the process often produces inaccurate portraits of the other, but a palimpsest reflecting back to us our own lives. I will argue shortly that the experience of intersubjectivity is achievable not by adopting a stance in which I am the authoritative referent for all engagement by analogy, but only when I am capable of de-centering, of "willfully view[ing] the other as a subject in his or her own right" (Potter "Moral Tourists and World Travelers: Some Epistemological Issues in Understanding Patients' Worlds" 213). This act of de-centering and willful viewing of another as a subject I will call emotional attending.

Emotional attending in the sense I am using it requires the viewing of another person as a subject with her own goals and projects, who has a complex emotional life. Moreover, in order to know this person more fully than as the sum of the propositions I am able to lay down about her, I must seek to understand her correctly. Correct understanding, of course, is a phrase seeking clarification. By correct understanding I mean the identifying of the person's emotion as what it is. If a person is sad, then I could not be said to have correct understanding of the person at a point in time were I to identify her emotional experience as anger. That is not necessarily to suggest that the person is even always able to identify her own emotional experience. She may confuse one emotional experience for another, or occupy an emotional state without being able to identify it at all. Indeed, to the extent that I am attending emotionally to another, I am attempting to understand the emotional experience in another, the knowledge of which not even she may possess - which is why introspection is not enough for selfknowledge. Additionally, I must also be simultaneously capable of understanding 
the emotional experience the person believes herself to be having. If I know, for example, that my friend has just received news that she has failed a test in school when I see her yelling at the waiter for not moving quickly enough, I am potentially able to understand her actions as related to her disappointment with her test grade - even though she is convinced she is angry at the waiter.

Obviously, there can be no way at present scientifically to prove that an emotional experience is one thing rather than another. Therefore, reliable knowledge in the case of emotional attending is founded on some other paradigm than a rational/empirical model-more like the cultivation of a set of habits necessary for virtue. Rosalind Hursthouse defines a virtue as "a character trait a human being needs for eudaimonia, to flourish or live well" (23). By this definition the emotional attending I am arguing for could be classified as a virtue, complete with a mean - where one end of the spectrum is an inability to understand the emotions of others, and on the other end, the over-identification with others, resulting in a loss of self. I do not wish as present to defend all possible objections to such a strong claim, but viewing emotional attending as something like a virtue offers a way of regarding others that suggests a practice which is constantly being refined.

Like a virtue, emotional attending is not foolproof. I must approach each encounter in which I am attending emotionally with a certain amount of humility that I may be misunderstanding the other's emotional experience, and knowing that confirmation of my judgment will not always be forthcoming from the other subject. To the extent that emotional attending is a virtue, the more practice and 
experience I get, presumably, the greater the precision I am able to achieve in understanding. Thinking of emotional attending as a virtue raises the issue of its nature as what Iris Murdoch understands as, "an endless task" (23). Emotional attending, like virtue, is a contextualized practice that continually undergoes a process of fine-tuning; it is, in other words, neither universalizable nor rule-based. There is no general formula that, if applied uniformly and correctly, will unfailingly result in predictable knowledge of another. Instead, because human beings are constantly evolving, redirecting, starting over, knowledge of them as subjects will necessarily be provisional in nature. Emotional attending is a way of seeking to see others clearly, but without the pretense that it is ever possible to see them definitively. Another way of speaking about emotional attending I will call other sight which, because the one on whom I am focusing is always in motion (literally and figuratively) I am constantly called upon to readjust my focus.

Since sight is a dominant epistemological metaphor, as I discussed in Chapter One, and since I wish to argue that emotional attending offers us a way of knowing that is different in nature from the kind of objectifying and abstracting sight that science employs, I want to appropriate the metaphor of sight for another way of knowing that takes emotion not as a threat to reliable knowledge, but (as I argued in Chapter Two) as a necessary component. This way of knowing is like the constant refocusing of a lens, a lens that strives less for definitive accuracy (as in the reportable, reproducible, empirical kind) than a lens that allows us to view others "justly and lovingly" (Murdoch 22) — which is to say, to see them clearly as subjects. Another way of putting it might be to say that instead of viewing 
reliable knowledge of another through the traditional epistemological filter of propositional statements (that is, as a set of facts to be compiled, analyzed, and abstracted) the virtue of emotionally attending to another human being seems much more readily intelligible when viewed as a learned skill, something like the successful acquisition of language, or learning to play improvisational jazz. The moves and decisions, for instance, that an identifiably accomplished writer or improvisational jazz musician make do not necessarily admit of scientific descriptions of causality or necessity, but we take it for granted that those moves are based on reliable knowledge possessed by a skilled practitioner nevertheless. To see someone justly or lovingly admittedly requires a certain amount of accuracy, but it is an accuracy that is approximate, under constant revision.

Emotional attending, or other sight, on this reading, seems to me to be better understood as a learned and habituated practice with intrinsic goods, the performance of which cannot be deduced propositionally step-by-step, but must be acquired initially through imitation. Clearly, rationality is useful to the development of this skill in the same way that learning the rules of grammar and syntax through formal teaching are useful in becoming a more skilled user of language. But the linguistic capacities of seven year-olds suggest that it is possible to embark on the mastery of a language through imitation and habituation prior to any explicit exposure to grammar and syntax. That is not to say that grammar and syntax are not present to the child implicitly through that which is imitated, only that possession of propositional statements about linguistics is not a prerequisite to the acquisition of language. Moreover, learning to play 
improvisational jazz can be aided by, but is not dependent on, a formal knowledge of music theory. It is possible, for example to learn to play expertly "by ear"; which is to say, without ever learning the theoretical framework that undergirds music. Neither does the ability to attend emotionally depend on the mastery of a theoretical/propositional framework. Were that the case, one might expect Ph.D.s in psychology to be the most emotionally integrated of all human beings. Instead, the skills necessary for emotional attending or other sight depend less on a scientific model of the knowledge of emotion than on a set of practices and habits formed intersubjectively, in imitation of a master. ${ }^{3}$ The practices and habits of emotional attending, however, cannot be done in the abstract.

To return to my friend who manifests anger toward the waiter, if I did not take into account the complex web of experiences and goals that mark my friend as a particular and unique human being, I could not begin to understand where the manifest anger originated. I may mistake her yelling at the waiter as having any number of different etiologies: maybe she doesn't like waiters in general; maybe the waiter reminds her of her high school algebra teacher who gave her a difficult time; maybe the restaurant elicits memories of a fight with her ex-husband, and she is reliving the fight when the waiter speaks to her. The point is, to understand my friend's anger and its source takes a certain amount of attention to the narrative of her life, and therefore, to her as a subject. People do not experience anger in the abstract, disembodied from set of experiences. Consequently, to attend to her emotionally, I must exercise a certain kind of imagination, in which I attempt to understand her anger as a product of her particular life experience. In 
other words, if I am to practice emotional attending, I must, to the extent I am able, see the world through her eyes. I must adopt a certain kind of visual frame that is not just a repackaging of the frame through which I view myself. Although Nancy Potter speaks about the broader canvas of a person's beliefs or values, her description is apt when applied to emotional attending: "When one is genuinely trying to understand another's reasons for her or his beliefs or values, one is trying to grasp what the world looks like from the other's point of view" (Potter "Giving Uptake" 482).

The question might be raised at this point about the extent to which I must already know a person to be able to attend to her. If I speak about focusing on the narrative of someone's life as a necessary prerequisite for emotional attending, how can I attend to someone whose life I do not already know? This question once again draws attention to the issue of the infinitely perfectible nature of emotional attending, of the constant refocusing of other sight. Since what I am doing by attending to another's life as a subject is not primarily centered on definitive accuracy, I realize that my knowledge will be progressive, undergoing continual revision. The more I learn about her life-her history, her present situation, her future aspirations - the better picture I will have of her. Since I realize that the knowledge I receive through emotional attending is always unfolding, what is important is not so much how much I know her to begin with, but how committed I am to continuing to learn about the narrative of her life.

Just now, I spoke of "the narrative of her life." I want to be careful to differentiate between the narrative of her life and the sum total of her experiences. 
Although, by definition, to have a life is to have a repository of experiences, human beings are constantly editing those experiences into a larger life narrative. In fact, even the experiences themselves are not pure experiences, but are constantly being interpreted in light of other experiences that make up a life narrative. These life narratives generally have multiple plot lines (e.g., golden child, overachiever, bad with math, etc.) that draw upon episodes from a life and weave them together to support, or sometimes to contradict, the different plots. These plots are then woven together into a meta-life-narrative that identifies one as a particular individual. It is important to make the distinction between experience and a narrative about those experiences insofar as it is the narrative one assembles from those experiences that constructs meaning and confers identity. ${ }^{4}$ Therefore, in order to attend to my friend and her emotional response, I need to take into consideration not just the episodes that comprise her life, but the meaning that she attaches to those episodes through the life narrative she is constantly composing. That is to say, to begin to understand my friend it is important that I have some knowledge about how she understands herself. For example, she may be a person who is the first in her family to go to college, so that she places enormous pressure on herself to do well; and when she does not, she has intense feelings of failure that make her angry at herself, which are then potentially transferred to others. Consequently, when she fails the test, her anger at herself boils over onto the unsuspecting waiter. My attempts at emotional attending in this case require me to work at understanding my friend's anger by 
monitoring not only her anger, but also to imagine how that anger is connected to her own understanding of her life narrative.

But someone might object that knowing certain things about my friend is factual or propositionally determinate knowledge. To which I would respond, that is true. But I am not arguing that the only important things to know about another to whom I am emotionally attending are subjective in nature. On the contrary, objective "facts" about my friend and her life are significant in coming to have knowledge of her. Knowing that she is short, that she lost her father at thirteen, that she excels at yoga and failed ninth grade algebra are all important to understanding her life narrative. What I am arguing, though, is that even if it were possible to know all of the propositional facts about her, I would still be a long way from actually knowing her as a human being. I need to know how she understands herself. What does it mean to her that she is short? How did she feel when her father died, and how does that shape her understanding of relationships? Of death? What significance does she place on her ability to do yoga well? What does she believe her inability to pass algebra says about her? All of these are questions that involve her experience and the meaning she attaches to them-not all of it conscious. She might, for instance, not fully realize just how the death of her father continues to affect her. That there are facts about her life narrative is important to know. But perhaps even more important in coming to know her is the way those facts are woven by her into a more or less intelligible narrative.

It is also important to point out that, in order to attend to another's emotional life, one need not necessarily be a trained therapist. On the contrary, what I am 
proposing constitutes a set of skills that are possessed by educated and uneducated alike-at least educated in a formal sense. The skills necessary for emotional attending require a commitment to trying to understand the emotional lives of others-an understanding that is constantly being refined and recalibrated. This understanding is informed by some knowledge of the context of another's life narrative, along with a monitoring of the other's emotional response. Moreover, in the process of attending to another, we must be aware of our own emotional lives, and the ways in which we tend to foreground them-thereby inadvertently displacing the image of another with our own. Taken together, this is what I have chosen to call emotional attending. Emotional attending, as I have described it, helps render a potentially intelligible picture of another as a subject. I say "potentially intelligible" because the possibility of error is always present, inasmuch as emotional attending is more like a virtue than a science (i.e., open to calculation, replication, abstraction, etc.).

How though, one might wonder, is emotional attending different from an established concept like empathy? Do they not amount to the same thing? I would suggest that though the difference is nuanced, there does exist a qualitative difference between emotional attending and empathy.

Empathy, as I am using it, carries the positive valence of attempting to feel what the other person feels. ${ }^{5}$ Although to have more than a theoretical understanding of a person's feelings I must have previously experienced similar feelings, I need not simultaneously feel the same feelings to be able to identify them in other subjects and to respond to those feelings as the product of another's 
subjectivity. Emotional attending is the ability to understand and respond to the emotional responses in other subjects. On this account, every instance of empathy is an act of emotional attending, but not every instance of emotional attending is empathic. Julien Deonna makes a case for something like this by saying that for empathy to occur two conditions must be met: 1) I must understand another's emotion, and 2) I must "feel in tune" with that person—which is to say, I am aware of feeling something like what the other person feels, because she feels it (99). ${ }^{6}$ These are the necessary and sufficient conditions of empathy. Emotional attending satisfies the first condition (viz., awareness of another's emotions) without requiring the second condition (viz., feeling in tune with another person). I would argue that emotional attending, which sets a lower standard than empathy, is much easier to achieve than empathy, since the meeting of condition two in every encounter would be impossible. For one thing, feeling everything $I$ feel, while also regularly feeling everything everyone else to whom I attend feels would be emotionally exhausting. Moreover, it may be the case that I and the person to whom I am emotionally attending witness the same act but have different feelings about it. My friend views the waiter as overly sarcastic, while I view him as witty. I can still understand her angry reaction to him (given all the other details about which I have spoken), without also feeling angry, or even annoyed with the waiter.

\section{Uptake and Emotional Engagement}


It will probably be pointed out, though, that one can never be entirely certain that one meets condition one of empathy, and the foundational condition for emotional attending — namely, that I understand another's emotion. I will consider whether the concept of uptake as a form of social confirmation will be helpful in trying to establish a better understanding of another's emotional experience. That I am using uptake as a form of confirmation that I have understood another's emotional experience is not to suggest that uptake is applicable to all emotional experiences. By using uptake as a form of confirmation I want to make the point that dealing with emotions and the understanding of them is not necessarily to have moved from thinking objectively and rationally about the real world to thinking subjectively and, by extension, irrationally about an imaginary world. Uptake, as I will argue in a moment, is a way of substantiating my inferences about the emotions of another that does not rely on my own interiority for validation.

But beyond uptake, though, which is not universally applicable, there remains the question of how I can be assured that I understand another's emotions-if there is no objective proof available to me that I have correctly understood. Once again, I want to argue that there are many things one can know—-that would widely be considered knowledge—which do not have to meet the strict test of objective verifiability. That is not to say that there do not often exist standards independent of individual taste; only that even those standards are not scientifically verifiable. It is possible, for instance, for me to have knowledge that Bach's music is technically superior to Barry Manilow's - knowledge that 
cannot be proved by computer modeling. A master painter can look at canvases painted by a host of others, and say with authority that this one is good, while this one is bad. To the untrained eye, the paintings may look indistinguishably similar, but to the one trained to see, the paintings contain perceptible differences, individual characters. The knowledge of a master painter is not reproducible by a scientist under laboratory conditions; it cannot be captured by equations; it is not contained within a set of physical laws; it is widely accepted as a certain kind of authoritative knowledge, though. In the same way, I would suggest that those who have learned to view human beings with other sight find themselves in possession of knowledge about the emotional lives of others, which has taken a great deal of honing to cultivate, and is not universally available to everyone else. Emotional attending, other sight, like other kinds of aesthetic and ethical disciplines, relies on another kind of knowledge that, while it is not scientific, is reliable as knowledge nevertheless. But there is at least one way of verifying the emotions of another that is independent of one's subjectivity. This is called uptake.

Nancy Potter has expanded on J.L. Austin's concept of uptake, which is the transaction between the speaker and the listener in which the speaker cannot be said to have been understood until a certain kind of acknowledgement of the import of the speech act is signaled by the listener. In response to your inquiry about what I would like to eat for supper, if I say, "A hamburger," and you say, "Of course," but then proceed to drive me to a seafood restaurant, you have failed to give me uptake. Even though you have responded that you understood what I 
was saying, your action demonstrated that you did not. Potter writes that uptake "occurs when the second party, listening to my speech act, reorients herself to me and the relation between us 'comes off' with an appropriate response. A proper response is one that conveys an empathetic attitude towards me or an earnest attempt to understand things from my point of view" ("Giving Uptake" 481).

Potter's expansion of Austin's concept of uptake, however, moves very quickly from a simple linguistic transaction —in which speech can be judged to have been heard - to the realm of the political, in which speech, because of the nature of the speaker as one of the marginalized, goes regularly unheard. She points out that the fact that people on the margins do not get uptake contributes to their ongoing exclusion from formative social discourse. If, for example, you continue to express frustration that certain people within our corporation experience barriers to advancement based on the fact that they are not white, male, and possessors of Ivy League educations, I do not give you uptake just by agreeing. If I am in a position of power, I demonstrate that I have heard you by engaging your complaint, and working to address it. In fact, the act of continually ignoring your complaint while claiming to have heard and agreed with you is not only patronizing, but isolating - excluding your concerns from the very discourse that claims inclusivity. Potter understands the extent to which the failure to give uptake tears the social fabric, maintaining power arrangements that persist in their sense of inevitability by continuing to resist all attempts at change-often with a knowing and sympathetic smile. She writes: "Hegemonic institutions give rise to 
conventions of language that render suspicious the consistent intersection of disagreement with subordination" (Potter "Giving Uptake" 482).

I refer to the concept of uptake for two reasons. First, emotional attending requires an attempt to understand the other, which is done with varying degrees of success - and sometimes, not at all. However, the goal of emotional attending, though not infallible, moves toward an understanding of another that progressively views the other person more and more as she truly is. That is not to say that emotional attending, as I have previously indicated, is a scientific calculation. That admission, however, need not necessarily render it a totally subjective practice, unbounded by any recourse to verifiability—which would presumably be only an exercise in projection. Instead, the concept of uptake is a practice that instantiates dialogical authentication. I can receive confirmation that I have heard and understood you, because I have responded to your speech act appropriately. You express anger, frustration, desire, joy and we both know that I have attended to your emotions by giving you uptake. Emotional attending relies not merely upon my claim that I understand, but is confirmable by my speech and actions in response. In that way, I am not always left guessing as to the precision of my judgments about another's emotions; I receive validation. If, for instance, I am emotionally attending to you and you express resentment that I continue to forget your birthday, I demonstrate that I understand your resentment, as well as your original desire, by getting you a gift. Your response to my action communicates to me that I have understood you by giving you uptake. If I claim to understand you, but continually fail to remember your birthday, I show that I 
do not, in fact, understand you-a continued misapprehension that you may then bring to my attention. That is not to say that every emotional experience is necessarily a good candidate for uptake. If, on the other hand, for example, you express resentment at your mother's failure to remember your birthday, there is not necessarily a particular action required of me to show that I understand your resentment. I am not suggesting that uptake is a universally confirmative practice, only that uptake is sometimes a way of helping to validate the understanding of another's emotional life that I reach through emotional attending. This discursive validation is part of the dynamic process that helps me to know if what I understand through emotional attending is a clear vision of another, instead of my own projection.

Second, uptake anticipates the kind of discursive practices of mutuality necessary for sustaining communities capable of producing virtuous people. Once again, we flirt with circularity when speaking of virtue and polis. The polis is a social arrangement that produces the kinds of virtuous people necessary for its existence as a polis. Uptake according to Potter, like emotional attending, is a form of virtue that it is necessary to acquire to sustain the kind of community necessary for virtuous people to flourish. In other words, cultivating the virtue of uptake has implications not only for interpersonal relationships, but is a social necessity - if human flourishing is to be realized. She explains:

To give uptake rightly, then, it is not enough simply to receive another's speech act with the conventional understanding. One must appreciate and respond to the spirit in which something is expressed, take 
seriously what the speaker is trying to say and her reasons for saying it, and have the appropriate emotional and intellectual responses. Furthermore, one must recognize the responsibility attending social and political privilege. Indeed, giving uptake properly is partly constitutive of the kind of person one is-it requires cultivation of a certain kind of character (Potter "Giving Uptake" 483).

As I argued in Chapter Three, successful emotional attending requires something more than a Hobbesian confederation of individuals forming a collective for the basic purpose of securing safety; it requires a particular kind of social environment, a commonwealth of sorts, in which the commitments to the commonwealth go beyond the barest form of seeking security from threats. This social environment will not be satisfied only by pursuing propositional rationality, concerned only to understand the factual claims of its inhabitants. Other human beings will be viewed fundamentally as subjects who possess their own projects and goals, and not merely as instrumental for our own purposes; this I will call "emotional engagement." Emotional engagement, on my account, will be that social environment where the emotional life of others is taken seriously, and where empathy and emotional attending can occur. Emotional engagement, in this regard, is a necessary condition for a fully flourishing life. Moreover, not only will emotional engagement require of the social environment a context in which the projects and goals of others are taken seriously, but it must also allow for the possibility that there will be times when another's projects and goals alter, transform, or even eclipse one's own. 
Though, if this social environment must operate from the baseline assumption that others within this commonwealth should be considered as subjects, the question might reasonably be raised about whether or not all social interactions, on this reading, must necessarily be emotional engagements. That is to say, according to the way I have described the social environment necessary to foster emotional engagement of another, is it the case that what I am suggesting entails that all social interactions call for emotional engagement with another human being? Perhaps more to the point, even if it is possible to find examples of human relationship that do not require emotional engagement, am I making a prescriptive statement that emotional engagement ought to characterize every human relationship?

As to the first question about whether I am suggesting that all human interactions require emotional engagement, one might argue that my line of reasoning does not oblige me to make such an assertion—merely that to flourish one must have some relationships characterized by emotional engagement. Aristotelian descriptions of friendship provide a way of speaking about the emotional engagement of others, such that not every human exchange requires an investment of emotion. Aristotle's concept of friendships of utility, for example, is not dependent on emotional engagement (EN 1156a15). ${ }^{8}$ If I have a friend with whom I share a ride to work, deep emotional engagement seems not to be a necessary pre-condition of that relationship. Though, as I have argued, on the most basic level I am required to view that person as a fellow subject with her own desires, attachments, and projects. In view of the moral position I want to 
sketch, I may not regard my friend of utility as merely an object, or merely as useful to the fulfillment of my personal needs. Instead, I have a responsibility as a moral agent within this social environment—-which will be conducive to the emotional engagement of others - to treat others as fully formed subjects, who are ends-in-themselves - beyond any utility they might have for me.

Someone might argue, however, that what I have just described as necessary for a flourishing social environment is something like respect, and that claiming we ought to respect each other is a commonplace so obvious that is not worth repeating except in teaching manners to children. First, I am not so certain that respecting others is nearly as common or obvious as we would like to believe. One need only watch political advertising or listen to certain talk radio shows to know that respect often occupies a relatively quaint place in our social and political lives. Second, neither am I certain that respect is enough to create the kind of social environment in which human flourishing can occur. For one thing, respect is too commonly associated with tolerance. Tolerance, while lauded as an enlightened humanist response, often operates as the appearance of a political reshuffling of the deck, even though it forestalls any real political change by giving the surface impression that everyone already "gets along" well enough so that drastic change is not necessary. Tolerance, and to a certain extent by association, respect, can act as non-threatening ways of maintaining the status quo power arrangements by placing a thin veneer of civility over otherwise inhospitable sentiments. True respect is hard work. 
That the bulk of human relationships seem to be transacted on the level of utility (my barber, the woman who registers my car, the child who delivers my paper), requiring no sophisticated emotional engagement appears fairly obvious. Furthermore, I think it is uncontroversial to suggest that we do not possess the resources necessary to engage everyone with whom we come into contact on a deep emotional level. It may very well be that what distinguishes us as humans from other animals is our ability to interact with others without seeing them merely as objects for our personal desires, in the way that a lion might see another animal as a source of food, or a potential mating partner, or as a genetic extension of itself into the future. A social environment that nurtures emotional engagement of others will set as a baseline responsibility of humanity that we identify one another first as subjects, before any calculation about another's potential utility.

However, to create a social environment conducive to human flourishing, I would suggest that even in friendships of utility we ought be open to one another in ways that allow for emotional attending to be a possibility. ${ }^{9}$ I think it important to raise the question of why someone might be tempted to think that we should not enter into friendships of utility with the expectation that we will attend to another's emotional life. In other words, when I go to the division of motor vehicles to register my car, why should I not carry a certain responsibility to be open to the emotional life of the person standing behind the counter-a responsibility that goes beyond basic respect for that person as a human being? When I encounter another human being —operating under the assumption that each encounter I have with another carries with it the possibility for emotional 
attending - I am free to be present in a way that allows for the kind of intersubjectivity that creates shared emotional/social space where meaningful human encounters can take place. P.F. Strawson makes the strong claim that sustaining an "objective attitude" (i.e., a detached or emotionless stance toward another) in a general way toward humanity is ultimately isolating, a stance that human beings seem incapable of (197). An emotional posture toward others that does not seek at least the potential for emotional attending as a primary stance, but instead views others merely as transactional partners for shared goals of utility, places potentially insuperable obstacles to intersubjectivity, by assuming out of hand that human beings are, for the most part, instrumental to achieving my own projects and goals - which is to say, human beings are with and for me, rather than the other way around. To enter any human encounter with the belief that I have no responsibility to offer myself to the other as a potential partner in attending to the other's emotions is to work against the social ties of community by opting for isolation. And if an Aristotelian read on human nature is correct in suggesting (as I think it is) that we are made for community, that to be able to live effortlessly in isolation goes against the very grain of what it means to be human (Pol. 1253a28), then to opt for the isolation of instrumental relationships is to opt for something that makes us less human.

This emotional/social space is important in the fostering of community not only for those to whom I attend, but to me-since I come to know who I am not simply by interrogating my own interiority but in a dynamic relationship with others who provide a kind of mirror to reflect who I am in their eyes. The images 
I see of myself through others, however, are multivalent, and sometimes in competition with one another. As such, my identity is not the straightforward product of relational transactions, not the sum of the images that I see reflected back to me from others. Instead, my identity is formed within the complex interplay of often competing images I receive through my social interactions, as well as my reflection upon those images and interactions. Once again, I feel it necessary to point out that I am not suggesting that one's interiority has no role to play, either in knowing others or in knowing oneself; only that the focus on human interiority in the West has been privileged in misleading, and, sometimes, even harmful ways - casting the individual back upon herself (incurvatus en se) as the final arbiter of what is true and what is valuable. In fact, I come to know what is true, what is valuable, who I am within an elaborate matrix of influences that is made up primarily of images I receive socially, as well as my own cognitive engagement of those images through reflection. To know, for example, what it means for me to be a man in our culture is a process of socialization (and my reflection on that process) that includes a wide variety of voices and social and emotional encounters. I cannot, in other words, know what it means to be a man simply by cross-examining the substratum of my interior. For that reason, opening myself up to the possibility of attending to the emotions of another is important also for my own identity formation.

I must be careful to point out that there are interactions between people that are situations in which continued attempts to attend to the emotional life of another can be harmful. There are situations in which one person is either being 
mistreated or the mutuality of commitment no longer exists-where emotional disengagement is precisely what is indicated. In cases of abuse, or emotional manipulation, or even emotional indifference it is sometimes necessary to refuse to attend to the abuser's emotional life. For the purposes of preserving an individual's emotional integrity, disconnecting emotionally is sometimes the appropriate choice, since the maintenance of one's emotional integrity is closely related to the dynamic by which one's identity is formed-or, in this case, malformed. If, for example, I remain engaged with another who is abusive or manipulative, to the extent that my identity is the product of the images of me mirrored back to me by those with whom I am in some relationship, the affect on my self-understanding will be distorted by the negative projections of that person onto me. Consequently, there are some emotional encounters that need to be avoided, due to a need for self-preservation. Nevertheless, as Nancy Potter has noted, this disconnection "as a social phenomenon ... is a loss" (How Can I Be Trusted?: A Virtue Theory of Trustworthiness 126). By "social loss," I take her to mean that since human social connection is fundamental to flourishing, any movement away from something like emotional attending (even for very good reasons) is just one more roadblock to human flourishing.

\section{Iris Murdoch and the Epistemology of Other Sight}

In Murdoch's now famous story of $\mathrm{M}$ and $\mathrm{D}$, a woman (M) has a daughterin-law (D) whom she believes to be unworthy of her son (Sovereignty of Good 17). M believes that " $D$ is inclined to be pert and familiar, insufficiently 
ceremonious, brusque, sometimes positively rude, always tiresomely juvenile" (16-7). Yet, M never says a word about her feelings to anyone.

Then, for whatever reason, one day $\mathrm{D}$ is no longer around $\mathrm{M}-$ whether because of death or re-location. M, being capable of self-critique, subsequently revises her opinion of D; through deliberate reflection — which Murdoch believes is focused by love and justice-M's vision of $\mathrm{D}$ has been altered, such that she no longer sees D as "vulgar but refreshingly simple, not undignified but spontaneous, not noisy but gay, not tiresomely juvenile but delightfully youthful, and so on" (17). Murdoch argues that no outward action has taken place-that the change in M's vision is what accounts for this new picture of reality. I would argue that M sets down a new narrative structure over the same set of facts, resulting in a new way of seeing the world. With this shift in vision, $M$ receives not just a slight epistemological correction. Rather her whole history with $\mathrm{D}$ has now been rewritten. The world has changed in a very real way for M. But this new world and the change that causes it —and the change that is caused by it - are not open to empirical observation.

First, a perceptive reader might point out that the transformation of M's vision I have just described, since it required "no outward action" to elicit it, sounds like it was generated within herself-which is to say, through an interrogation of her interiority. On its face, that seems a plausible conclusion to draw. However, it is not entirely the case that no outward act took place. In fact, M draws upon a wide range of episodes that actually happened. What changes is the narrative she draws from those episodes. That the narrative structure is the 
product of reflection is not damaging to the claims I am making, since the argument I am making is not that an interior life is bad, or even that it stands in opposition to that which is independent of the self. My argument is one of emphasis and orientation. The problem is not that we have an interior self, but that in the West it has become the primary resource for our engagement of the world, the fundamental repository of truth and meaning about the world. The point, with respect to $M$, is that she did not dream up her past encounters with $D$; she did not generate those experiences of D from within herself. Instead, she took those experiences, and by an act of refocusing her vision through a just and loving lens, she was able to transpose the narrative structure of her experiences with D. And it is on the subject of narrative structure that I want to concentrate for a moment.

As I have indicated, the meaning we attach to our lives, we attach largely through narratives - that weaving together of episodes in our lives to make an intelligible story arc. One of the things I will be arguing in Chapter Five is that literary and fictional narratives are important resources for augmenting our moral and emotional imaginations. Through reading these literary narratives we have a range of opportunities available to us, which give us the chance to inhabit different moral postures and emotional experiences. Inhabiting different lives from different perspectives gives us a certain kind of "subjective knowledge"that is, knowledge about "what $X$ is like" (Lamarque and Olsen 371). In addition to that, though, literary narratives help provide us training in "writing" the narratives of our own lives. My ability to tell the story of my own life (to myself 
and to others) is enhanced by my exposure to literary narratives, which usually take on the shape of a plot. Placing the structure of a plot over the top of the array of episodic material that makes up my life is an exercise in discerning the meaning and purpose not only of events, but ultimately of the meaning and purpose of my life. Through reading I receive training in helping to organize the seemingly chaotic nature of events into intelligible and illuminative stories that are not only descriptive of what life looks like, but are also prescriptive of what, given certain moral or philosophical or religious commitments, what life ought to look like. When I read The Stranger, by Albert Camus, for example, I am able to see not only what it might be like to live a life absent belief in God, and therefore (at least by Camus' account), absent any meaning external to the individual, but also what the trajectory of such an embodied life might look like as it plays out over time. Knowing what a life written in such a way might look like, I am given indications of how I might live toward that goal, or how I might live differently to avoid that goal. Nevertheless, the structure of narrative is epistemologically significant inasmuch as it provides, through its ability to focus and refocus attention, a new vision, a different understanding.

I want to suggest that the knowledge of the world that comes about as a result of a new change in vision can neither be accounted for by scientific reason, nor by a self that is attending only to a reflection of itself. If I am right, to the extent that this kind of change of vision is hampered by the way our world is presently constituted (namely, as ruled by scientific reason and conditioned by radical reflexivity), we are in danger of losing a basic element of what it means to 
be human. Because Western intellectual history has helped to cultivate in us habits of mind that tend toward objectification and abstraction, and because the radically reflexive self has become the primary authority for truth and value, our vision of one another is clouded. We tend to see each other either as disconnected from the context out of which we emerge (that is, as objects, or as types or symbols), or as projections of ourselves through the mirror of our "fat, relentless egos." To the extent that we are unable to see one another justly and lovingly, to the extent that we see each other through lenses adjusted to focus on the objective and the abstract (or fail to see each other because we are looking at mirror-images of ourselves), we risk cutting ourselves off from one another-since our knowledge of one another requires an understanding that goes beyond what can be observed objectively, beyond what we project onto one another from our own normative experience. We need to be present to one another in ways that leave open the possibility that the deepest, most vulnerable, most subjective part of ourselves will be encountered in each other; this is, as I have argued, in a very fundamental sense, at the heart of what it means to be human. Moreover, when this sort of emotional attending is achieved (it is an achievement, after all), we have one of the critical pieces in place for a community of human flourishing.

To return to $\mathrm{M}$ and $\mathrm{D}$ : It might be objected here that an emotional change cannot be epistemologically significant inasmuch as the world that is changed by my example is not the real world. Nothing changes materially in the world when $\mathrm{M}$ realizes this new gestalt. Red is still red, cows are still mammals, and gravity still makes apples fall from trees-no matter what M thinks about it. To which I 
would respond: that objection is exactly my point —-that is, we think that only that which we can observe, analyze, quantify can rightfully be called "real"; everything else (emotion, value, beauty, irrationality, etc.) gets relegated to the irrational margins. That is just the argument I am making-namely, the world in which "red is red" is the world that we are taught to call real- the world of scientific taxonomies and physical laws; but, I am arguing, a world in which love and justice shape our vision of the intersubjective world we inhabit is arguably more real than the one that can be colonized by science.

I need to pause for a moment to point out again that it is against the imperialistic designs of science that I am arguing. More specifically, I want to call into question the underlying assumption in the West that science is sufficient to account for that which we would term "real." In fact, not only is science insufficiently incapable of accounting for all that is real, but it does not, on my argument, account even for some of the most important parts-namely, our moral commitments and emotional lives, as well as the community made possible by them. Iris Murdoch points in this direction when she says that the sort of things that make up the realm of the non-scientific "do not move about within a hard world set up by science and logic. They set up, for different purposes, a different world" (Sovereignty of Good 27). One of the consequences of the ascendance of reason has less to do with distinguishing between the world of reason and the world of value and emotion (although, as I argued in Chapter Two, the line between those two worlds is much blurrier than we are accustomed to believe), than with the assumption that all that is reliably, demonstrably true-and 
therefore, of significance-happens in the world of reason. Or as Terry Eagleton has so colorfully highlighted the distinction: "It is rather like saying that thanks to the electric toaster we can forget about Chekov" (Reason, Faith, and Revolution 7).

One of the practical effects of framing morality and emotional knowledge as a problem of vision is that the will becomes much less a faculty for the enactment of reasoned decisions, or even an independent faculty, which moves, chooses, and decides only through the sheer force of volition. The will, on Murdoch's reading, is substantially marginalized as a component of morality. The will came to be, as a result of the divide between reason and the emotions, the means by which rational human beings could be moral agents with the power to speak and act evaluatively. Accordingly, the task of the moral person when presented by an ethical decision was to weigh optional responses through reason, and then to choose (through the will) a response upon which to act. Both deontological and utilitarian accounts of ethics assume this kind of dilemmabased moral decision-making - either through the application of rules or the calculation of the greatest good. In either case, the will acts as the force to put into action what the reason has decided.

Murdoch, on the other hand, suggests through her use of the imagery of vision that continuous loving and just attention on another deemphasizes the need for heroic choices by the will. She asserts that "if I attend properly I will have no choices and this is the ultimate condition to be aimed at" (38). In other words, my constant attention to another subject in a loving and just way (like $\mathrm{M}$ does with $\mathrm{D}$, 
for example) gives me knowledge about another person, another state of affairs that would otherwise be unavailable to me if my relationship with the subject consisted of choices reasonably made through the calculus of the application of rules or the calculation of the greatest good. And it is this emotional knowledge that I want to suggest is a morally and epistemologically more integrated way of knowing than systems of knowing and acting based on the privileging of reason and will.

However, here I want to draw a distinction between Murdoch's position and my own over the implications of the use of vision as a moral and epistemological metaphor. While I agree that loving and just vision can reorient us to reality, I also want to argue that the mere knowing of another through constant attention, does not necessarily lead us to the kind of moral behavior Murdoch claims. The concern here is as old as Plato, who believed that one could not knowingly do something wrong: That is to say, Plato argued that immoral behavior comes about as a result of ignorance. However, Plato-and Murdoch, to the extent that she follows Plato here—-begs the question, by suggesting that any wrong doing that is done with knowledge is done only with apparent knowledge (i.e., if you really knew what you were doing, you wouldn't do it). Possessing knowledge, however, is not necessarily a hedge against acting immorally. Murdoch seems to suggest that simply the possession of true knowledge, which comes as a result of loving and just behavior, is enough to ensure moral behavior. I would want to add that the constant focusing and refocusing of the lens through which we lovingly and justly attend, is a practice, the perfection of which comes 
through habituation over time. We are not born knowing that others do not exist simply as objects or as extensions of ourselves. We learn over time, to the extent that we learn at all, that others have emotional lives (hopes, fears, joys, hatreds) that exist independently of us, and that part of what it means to grow as a human being is to learn how to attend to others on terms dictated by their lives and not by our own needs. There is, in other words, a commitment to a certain kind of action toward another implicit in the phrase, "the constant focusing and refocusing of the lens through which we lovingly and justly attend." I see you more clearly because I am committed to the practice of attending to you, viewing you more lovingly and justly.

Moreover, as a result of our attending to others, we have better insight into how we ought to act toward them. That is to say, loving and just attention is not just an epistemological achievement; it is the result of a set of moral practices habituated over time that leads to action. On an Aristotelian reading it is impossible to become moral only through knowledge of another, because virtue is not a matter of knowing the good, but of actually being good (EN 1103b 28). In other words, the knowledge of another I gain is not necessarily an end in itself, but is fundamental in helping me to know how I should act toward that person. In this sense, then, the work accomplished by emotional attending or by other sight is moral at its heart. I learn not only about you, but also about who I am called to be and how I ought to act in relationship to who you are. As I see you more lovingly and justly, I am better equipped to respond to you as a subject. What I first took to be indifference toward the world, for instance, I now see is my 
friend's way of coping with the world's disappointments. The way I act toward her is colored by the knowledge that my actions may be understood by her to be a reaffirmation that the world is a place that never quite manages to do right by her. Consequently, when I make a promise to her, my keeping it is not just a matter of submitting to a universal maxim about promise-keeping, or about maximizing the utility of keeping this particular promise, but about considering her life, her expectations of what the world has to offer, and about my responsibilities to a person whom I call my friend. When I attend to her, I possess knowledge not only of what is right (which requires no personal relationship), but increasingly of what is right with respect to my relationship with her.

To put the moral implications another way: if I were asked whether or not it is the right thing to do to give a child chocolate cake for breakfast, generally speaking I would say no. But that answer is largely unsatisfying inasmuch as my moral commitments are almost never enacted in a general way. Instead, I am much more likely to be faced with a situation in which a child asks to have chocolate cake for breakfast, and in which I am expected to have an answer. So, to the question about whether it is right to give a child chocolate cake for breakfast, my response is that it depends. Yes, but on what does it depend? It depends upon the child and upon the context in which the question is asked. If the child is sick with cancer, for instance, and has not eaten anything because the chemotherapy has taken away the appetite, my answer to the question about whether it is right to feed chocolate cake to the child might very well be an enthusiastic yes. The point, of course, is that ethics is practiced in particularities. 
And if it is to be done well, ethics needs to take into consideration the contextthe people toward whom, or on behalf of whom I am acting. Emotional attending aids me in knowing how to answer particular ethical questions as they pertain to others, since not only are general ethical principles taken into account, but also the life narrative of others to whom I am attending.

Someone might wonder, though, about the many situations in which I have no knowledge of the person toward whom I am called to act morally. First, I would suggest that the act of identifying a "person toward whom I am called to act morally" is already an act that establishes some amount of knowledgenamely, that it is a person, and not a bus or a parakeet. Since I am dealing with a person, I already possess, as I have argued, some implicit threshold moral responsibilities to regard the other as a human subject. Second, that there are many people about whom I initially know very little is, to a certain extent, my point. I am arguing that emotional attending is an exercise in committing oneself to learning progressively more about another person over time by continuing to pay attention to that person. Since it is a perfectible practice - which is to say, in this case, a virtue-I am always seeking knowledge, not just to know how to act, but to know how to act better over time.

\section{Conclusion}

In this chapter I introduced two concepts that I called emotional attending and other sight, which are different means of talking about the ways we engage other people as subjects. I argued that because of the ascendancy of reason as the 
primary way of knowing, as well as because of the turn to the self, we have developed habits of mind that make us prone either to objectification and abstraction of others, or to viewing them as projections of our selves. For us to foster the kind of intersubjectivity necessary for community, and therefore, for human flourishing, we need to cultivate new ways of regarding one another within the context of life narratives, which tell us not only about one another's lives, but about how we bring meaning to those lives. I argued that the kind of knowing made available through emotional attending or other sight is not just epistemologically significant, but also morally significant in that it provides with us with information about how better to be available for one another over time. 


\section{CHAPTER FIVE}

\section{LITERATURE AND THE WORK OF THE IMAGINATION}

\section{Introduction}

After the seas are all cross'd, (as they seem already cross'd,)

After the great captains and engineers have accomplish'd their work, After the noble inventors, after the scientists, the chemist, the geologist, ethnologist,

Finally shall come the poet worthy that name, The true son of God shall come singing his songs.

"Passage to India" (Whitman 346)

Given the hegemonic nature of reason in Western culture, with its attendant privileging of scientific ways of knowing the world, as well as the radical reflexivity evinced by the turn to the self, it is no surprise that the emotions have been dismissed as somehow inferior parts of us with which we are stuck, but which nevertheless need to be subdued by reason. I have argued that the epistemological trajectory in the West subordinates emotions to reason. I have also argued that a turn to the self has managed to isolate us from one another because of our penchant for seeing in others not subjects but reflections of ourselves. I have also contended that the primacy of reason and the marginalization of emotion, as well as the perspective of radical reflexivity present us 
with a question about how we can we extricate ourselves from this predicament and recover the virtue and intersubjectivity necessary for living a flourishing life in community. In Chapter Four, I suggested that the answer to this question is emotional attending - the ongoing commitment to refining our view of others as human subjects, who possess lives situated in complex social matrices that I have called life narratives. Emotional attending, however, requires not only a commitment to its practice, but a fund of emotional experience from which to draw. In this chapter I will argue that that fund of emotional experience is enriched by reading literature. ${ }^{1}$

Reading literature does at least two important things upon which I want to focus. First, it helps to expand our moral imagination by creating an aesthetic space in which imaginatively we can experience life and the moral implications of action from a variety of different perspectives. By reading ourselves into literature (an almost unavoidable byproduct of reading) we begin to imagine what motivates behavior and, just as importantly, something of what it feels like to be so motivated, as well as what it might feel like to act in a particular way. We may inhabit, in a virtual sense, the process of moral reasoning that leads to both vicious and virtuous behavior, providing us with a nascent kind of experience from which to draw in our own lives. Second, reading literature helps to expand our emotional imagination with respect to the emotional lives of others. By reading about emotional experiences - by which I mean the experience of the unfolding of the emotional process I outlined in Chapter Two - and having some of those emotions elicited in us, we are able to have the beginnings of an understanding about emotional experiences we have never had occasion to enjoy in real life. Having these virtual emotional experiences from which to draw - even if only partial and 
suggestive—-provides us with expanded emotional resources, which resources are critical to understanding the lives of others through emotional attending.

\section{Literature and the Moral Imagination}

Aristotle suggests that feelings have to do "in general [with] whatever implies pleasure or pain." As I argued in Chapter Three, though, Aristotle does not view emotions as irresistible impulses that must be extirpated. Instead, they are educable to the extent that we must be trained to exhibit them at the right time and for the right reasons. If we cannot control our non-cognitive affective appraisals, which are the basis for emotional response, how can we educate the emotions? As I noted before, while our emotional responses are largely involuntary—in this respect, Plato was correct-we do have some control over the triggers that induce emotional response. I raised the issue of emotional triggers in Chapter Two, referring to them as those encoded mechanisms that respond to stimuli-both internal and external. As a consequence of these triggers, emotions are educable —not the emotions themselves, as perhaps Aristotle believed, but the triggers that elicit emotional response. It is these triggers that are subject to recalibration. In other words, we bear a certain responsibility for recalibrating those emotional triggers. If I am aware that my friend's smile evokes disgust in me, for instance, because it looks like the smile of my ninth grade government teacher who I found disgusting, and if we are to remain friends, I have a responsibility (to the extent that I am aware of it), to do the cognitive work necessary to reframe my friend's smile as unique to her. I am not saying that this recalibration is easy; only that it is possible. Aristotle believes that this process ought to begin early, saying that "we need to have had the appropriate upbringing — right from early youth, as Plato says - to make us find 
enjoyment or pain in the right things; for this is the correct education" (EN 1104b11). An Aristotelian account of the emotions views the recalibration of emotional triggers as vital if we are to "find enjoyment or pain in the right things," and abstain from vicious ones (1104b10).

Moreover, calibrating and recalibrating these emotional triggers goes to the very heart of virtue, inasmuch as virtues "are concerned with actions and feelings" (1104b14). The cultivation of virtue, then, relies not only on the habituation of right action in the right ways and at the right times, while avoiding wrong action in the wrong ways, at the wrong times, but also on the recalibrating of emotional triggers so that the emotions are experienced rightly at the appropriate times and in the appropriate ways. Emotions, as I have said before, exist in critical relationship to our actions (1105a7). How, though, can we be intentional about the recalibration of those emotional triggers? An Aristotelian answer to that question, I will argue, is through reading literature. Literature allows for an aesthetic experience that asks the audience to enter a creative space and to participate in the construction of meaning through narrative, as I discussed in Chapter Four. Taking potential acts that seem random and episodic, literature provides a way of facing the chaos and imposing order on it through plot.

Before examining how art may expand the moral imagination, I will address two possible objections, the first of which has to do with the nature of morality, and whether or not I am placing a moral theory on offer. The second possible objection centers on the question about when the use of art for purposes of moral education crosses over into aesthetic instrumentalism. 
The first objection deals with my contention that literature can expand the moral imagination, and whether that commits me to setting down a universally prescriptive moral theory. I want to be careful about the assertion of our ability to identify with characters in literature as a way of exercising our emotions or expanding our moral imagination for another reason. While this avenue of inquiry is fruitful, it raises a serious question about which morality is being formed. I must take a few moments to address this issue.

Unfortunately, the question of expanding moral vision through literature is not the end of a discussion, but the beginning of a much longer one. The problem is that to use literature as a sort of moral laboratory in which one may creatively imagine oneself in the role of the characters in a book raises the larger question of making determinations about what are the moral actions to be inhabited by the reader. If I say that The Death of Ivan Ilyich is worth reading because it sets down what it feels like to be transformed through the process of dying —and that feeling that is worth imitating - I must first answer the question about what kind of moral framework I inhabit that makes this kind of transformation through dying a model for imitation. If another reader finds this sort of transformation objectionable because the moral framework she inhabits posits that an honorable death is one faced stoically and alone, then The Death of Ivan Ilyich could be viewed as distorting rather than expanding her moral imagination. In other words, the question of what can rightly be called morally good is what is at issue - antecedent to any literature that might be employed to expand the moral imagination. The problem, of course, is that there is no incontestable general morality that stands as foundational for an assertion about literature and the moral imagination. Whose morality is being served? is a 
key question. Therefore, a broad generalization about literature's ability to expand the moral imagination exists as a metatheory, just to the extent that it is a theory about how moral theories can be enriched, and not which particular moral theory. However, in this case it would be difficult for me to say in a general metatheoretical way that literature allows the reader to expand moral imagination without also answering the question, "Which morality is in play?"

At this point, the question might be raised about whether I have not already expressed a general moral theory in embracing virtue ethics. After all, does not Aristotle put forward a generalized objective moral account of virtue nested in the teleological function of the human being? The answer to the second question, I believe, is yes. Aristotle locates universal virtue in the framework of the human telos, while locating particular virtues in the telos of the polis. That is to say, Aristotle believes that some virtues are common to all people, while other virtues are specifically relevant to particular kinds of poleis. However, as to the first question, I would respond that while Aristotle may have held out for universal virtues, I do not feel myself bound to replicating his thought—similar to my understanding of Aristotle's aesthetics. Instead, part of what seems most Aristotelian (and therefore, most attractive) about using Aristotle as a place to start is the belief in the development and extension of a conversation or a line of inquiry to fit new circumstances. I would depart from Aristotle not on the existence of universal human virtues, but on universal human virtue available in a form unmediated by some community.

Morality mediated through community, though, I submit, does not necessarily throw us back on ourselves to find out what morality means in individual conceptions. It 
could be argued that whatever the truth of objective morality, my only way of apprehending the truth of that knowledge is through a narrative about morality passed on to me within the context of a particular community (or through the variety of communities of which I am a part). On this view, objective morality is beside the point, inasmuch as our access to reality as something "out there" is never immediate, nor uncontroversial. Whatever the truth of objective morality, our access to it is always perspectival.

On this account, I know what to regard as moral, not necessarily because it occupies some privileged objective universal category, but because I occupy a community whose moral framework has a narrative that accounts for something as a virtue. Empirically, it is possible to claim that some virtues are counted as virtues by nearly all communities (e.g., promise keeping, truthfulness, etc.). That these are almost generally accorded the status of virtue does not begin to tell how they might be differently embodied in different cultures and communities. The objectivity of a virtue in some unmediated state, then, is not what is at stake, because our knowledge of it must always be mediated through narratives that locate it within particular contexts. The narratives that endeavor to account for virtues are produced within communities engaged in the process of attempting to describe what a virtuous life looks like. A virtuous life in Elizabethan England and a virtuous life in tribal Papua, New Guinea may have many similar features, but even something like truthfulness will be narrated in ways that make its abstraction from a particular context distorting.

Competing narratives exist within different communal contexts, each of which purports to describe the world as truthfully as it can. In fact, a single person may exist 
simultaneously in a variety of communal contexts that have fundamental disagreements between them about what can rightfully be called moral. These fundamental disagreements between competing moral narratives are not immediately resolvable by reference to a universal moral standard capable of adjudicating the discrepancy. Being a committed Muslim and a Tea Party advocate, for example, underscores this conflict between competing moral systems. Each community must advance its case, attempting to provide the most compelling account of morality in the face of the other. Whichever community is most convincing, though, still must proceed within a world in which its account may yet be shown to be lacking. Each account of morality, in other words, is always open to further interpretation in light of new circumstances. That is not to say that we must act as if we know nothing about morality; only that whatever we may be said to know is always open to question by other communities. ${ }^{2}$

As a consequence of what I take to be the difficulty of putting forward an unmediated universal morality, my contribution here will center on the process by which morality can be shaped through the imaginative practice of reading literature. Even given the broad spectrum of moral commitments, it is still possible to find ways to expand one's moral imagination by entering into the creative aesthetic space provided by artespecially literature.

A second possible objection might be raised about my claims that literature can be useful in expanding the moral imagination. A particularly important aesthetic question centers on whether it is possible for literature to be morally formative without being merely instrumentally useful to that end. Can literature be morally formative (for my 
purposes) of the emotional life without turning it into propaganda for moral positions already held — that is, without making it into an object lesson?

R.W. Beardsmore has helped frame the aesthetic debate over the extent to which art can be useful and still be considered aesthetically. What he calls moralism, ${ }^{3}$ and what Berys Gaut calls ethicism, ${ }^{4}$ are pitted against what Beardsmore labels, autonomism. Moralism at its most radical is the aesthetic position that finds art as merely a useful tool in dressing up "antecedently established moral principles" (Beardsmore 65). ${ }^{5}$ Autonomism, on the other hand, is a more or less formalist account of aesthetics, which argues that art has no cognitive or ethical connection to anything outside itself. In this view, the claim is "not that individual works of art have no relation to artistic traditions, but rather that the traditions themselves stand in no relation to anything else" (Beardsmore 43). Beardsmore develops a picture of aesthetic "moralism" as a view of art that understands art as instrumentally useful in the pursuit of larger projects, most notably ethics. Standard conceptions of mimesis fall under Beardsmore's critique of aesthetic moralism. Immanuel Kant's aesthetic judgment, on the other hand, is autonomist or formalist, understanding art as an end-in-itself (namely, art is to be experienced as art, and not as "public relations" for a more important idea external to the artwork). ${ }^{6}$ Immanuel Kant, in reacting to the traditional Western account of art as overly concerned with content (in this case, moral or ethical content) found mimetic theories of art too uncomfortably purposive, which is to say, too easily co-opted for purposes external to art itself. Art, for Kant (and here we should also include Schiller), occupies its own aesthetic sphere, subject only to judgment on an aesthetic, rather than on a cognitive or conceptual level. ${ }^{7}$ Aesthetic judgment, for Kant, is differentiated from 
cognitive judgment through its relationship to the subjective. Whereas cognitive judgment is concerned with the object (i.e., a thing external to the subject), aesthetic judgment is a sensation internal to the subject in virtue of its relationship to the object. Therefore, to determine whether something is beautiful, one must refrain from the impulse to inquire after (or even to care about) whether an object represents a thing whose "real existence" is establishable. ${ }^{8}$

Moreover, an aesthetic judgment of art requires that the object be pleasing for its own sake (i.e., "good in itself") (§4). On a Kantian view, mimetic theories of art, on the other hand, are entirely concerned with a thing's real existence, seeing the object of art as "good for something" (i.e., useful); hence, as theories capable of assisting us in cultivating aesthetic judgment, they fail. For Kant true aesthetic judgment conceives of art as an end-in-itself, rather than viewing it as a tool, useful for the pounding of some other antecedent and unrelated conceptual nails. The only basis upon which an object can be judged aesthetically, therefore, is its "bare form," which is the only basis that is "universally communicable" $(\S 11)$. It is worth noting, then, that a Kantian version of aesthetic judgment offers an advantage over instrumentalist conceptions of art by viewing art as having intrinsic value.

On the other hand, a purely formalistic understanding of art in which art has neither cognitive content, nor any relationship to the actual world we inhabit is also unsatisfying. Inasmuch as a formalist view seeks to isolate art from the world we inhabit (i.e., Schiller's "world of substance"), the pursuit of art threatens to devolve to the pursuit of art as the "plaything of empty pleasure." While Kant's initial claims regarding aesthetic judgment being unconcerned about the real existence of a thing, about art being 
good in itself, and about form as the only thing being open to specifically aesthetic judgment was an important corrective to the moralist view of art-as-instrumental-tosome-greater-good, aesthetic judgment was subsequently transformed by the modern "art for art's sake" movement at the turn of the twentieth century. ${ }^{10}$ This transformation consisted of turning art into art-as-autonomous-enterprise, the meaning of which comes not from some external source, but on its terms. It is only fitting, then, that this formalist evolution in art has been labeled, "autonomism." Autonomism rejects the notion of the ethical criticism of art, just to the extent that art is held not to possess ethical content (Gaut 67). The danger, of course, in the isolation of art from the world is that ordinary people will be tempted to say, "If art has nothing to do with the world in which I live, why should I even bother about it at all, then?"

There are no easy answers to the dilemma of how art should be experiencedthrough its form or its content. Wayne Booth, however, frames it well when he says, "Defenders of aesthetic purity have rightly deplored the temptation of moralists to judge narratives by standards they might use in teaching a Sunday school class or conducting a court for juvenile offenders; 'art' does offer us riches entirely its own, unrivaled by any other part of 'life"' (7). One might misread Camus' The Stranger, for example, and conclude that it is a morality tale, which sets out a warning about how trying to live life without some conception of the divine is morally tenuous and could possibly leave one as a candidate for the commission of the most violent sorts of crime. Or one might read the Oresteian Trilogy as a caveat about the intra-familial consequences of disharmony, rather than as a commentary on the movement from a primitive society ordered by lex talionis to a society based on a system of just laws. 
I believe, contrary to strict autonomists, that the fine line between art-as-formative and art-as-instrumental can be negotiated. ${ }^{11}$ The key to this question, I am persuaded, lies in pointing out that one of the possible contexts in which the education of emotional triggers takes place is aesthetic. That is to say, since the worlds created by aesthetic experience are by nature imaginative, it makes sense to believe that these aesthetic worlds allow us imaginatively to experience emotions. One way that we recalibrate those triggers that elicit emotion is through real world experience. My disappointment at looking in my mail box, and finding a rejection letter, for instance, can be modified over time by becoming dulled to it (if I receive enough of them), or by having conversations with other authors who help me to see the benefit of good criticism over the long term. However, I might also have my disappointment in seeing a rejection letter modified by reading a novel in which a character seeking to become an author eventually comes to see a pile of rejection letters as inspirational—when she realizes that becoming a writer entails enduring setbacks. Either way, real or imagined, actual or aesthetic, one of the triggers for my disappointment (rejection letter) can be altered or recalibrated.

Moreover, we can learn from reading fictionalized accounts of the lives of others about what it might mean to inhabit other (or even rival) moral positions through identification with literary characters. Identification with a character is a process that may lead to the triggering of emotional experience as one sees what the world might look like through another's eyes. Identification, on this reading, offers a context in which emotions may be triggered in the reader. What is gained through identification is a perspectival sense of the benefits and consequences involved in holding certain beliefs or engaging in certain activities. Scott Stroud writes: 
What is identified with in cases of successful identification is the value that is an important part of the character and a value that the reader judges will be beneficial to her own life projects. Unsuccessful cases of identification, such as that with villains, involve some relevant dissimilarity that spurs us not to change to be more in line with that character's values or action strategies. Both aspects are important to an account of identification on the part of the reader, and both center on the change (or potential change) of one's beliefs, values, and/or action strategies (35).

In other words, identification with literary characters can present moral positions to be imitated or cautionary tales to be avoided, by allowing the reader an opportunity to simulate experiences under imagined conditions.

I would argue that it is possible, contrary to autonomist concerns about the potential for instrumentalist uses of art, that we may experience literature as having its own aesthetic value intrinsic to itself-while at the same time, literature does what cannot be done otherwise, through more prosaic, discursive means. On the account I am putting forward, then, moral education —in the training of the emotions through literary narrative - is intimately bound up with the creative aesthetic sphere we enter through fiction. We learn things from literature that we could not learn in any other way. Because of the nature of art, literature illuminates creative possibilities that would have remained otherwise hidden in darkness. Martha Nussbaum contends that much of the important work that needs to be done in expanding our moral imaginations is inaccessible to anything but the narrative nature of literature. She writes: 
The moral work involved ... could hardly be shown us in a work of formal decision theory, it could not be shown in any abstract philosophical prose, since it is so much a matter of learning the right sort of vision of the concrete. It could not be shown well even in a philosopher's example, inasmuch as an example would lack the full specificity, and also the indeterminacy, of the literary case, its rich metaphors and pictures, its ways of telling us how characters come to see one another as this or that and come to attend to new aspects of their situation ("Finely Aware and Richly Responsible" 160-1).

Literature, because it presents new information, attitudes, values, and so on indirectlythat is, not through straight-line discourse-is often easier for people to absorb. In literature the reader is not necessarily confronted directly with explicit claims about the way the world is—which would require rejection or assent—but with possibilities to be explored, tried on, ruminated over. The knowledge that emerges from literature, then, is knowledge about what the world looks like from different perspectives. For the purposes of this work, then, I will assert rather than defend extensively the proposition that art can be experienced as both aesthetic and educative at the same time, with full awareness that among aestheticians this issue is far more nuanced than I am able to set down here. ${ }^{12}$ But I will give a brief account as to how I think this balancing act might work.

I would suggest that literature constructs a hypothetical, aesthetic space in which new worlds may be created. ${ }^{13}$ I want to advance a theory of mimetic art that is sympathetic to a qualified Schillerian view of art. By this I mean, a mimetic theory in which literature creates whole new worlds that are not merely imitations of our worldor even necessarily composed of all the same constituent parts of the world we inhabit- 
while at the same time insisting that the new worlds these creations represent to us are intelligible only insofar as we can understand their novelty through reference to the world we inhabit. An act of love, or hatred, or pity, or fear portrayed in a work of literature need not have an actual referent in reality, but the portrayal of that act assumes of the spectator or the reader an accumulated fund of knowledge about each of those things so as to render their creative portrayal intelligible. R.W. Beardsmore argues that the artist does not necessarily offer any new information through art. Instead, the artist provides a hypothetical space in which to consider things anew, things that we already understand on some level, perhaps "to see them in a new light" (73).

One might initially be tempted to say that something like science fiction acts as a counterargument to Beardsmore. However, he is not saying that imaginative details in these creative worlds (e.g., Vulcans or Wookies) are prescinded, merely that the great artist "does not impart new facts about hypocrisy or about love or about human degradation" (73). To press the point even further, it is not necessary for mimesis, for instance, that a novel include a law of gravity that corresponds to our own law of gravity; only that to the extent that it does not, the reader must understand the cause and effect relationship of non-gravity to the new world that has been created. Indeed, it would be difficult to describe this world of non-gravity without referring at some point to the fact that everything in it floats around, which is a way of drawing attention to the fact of a new world that is unlike the one we inhabit. We begin to understand this new world by the way that it differs from our own—but the world we inhabit always acts as a referent.

By new worlds I mean imaginative worlds that may or may not resemble the world in which we live, but that have their own norms, customs, and internally consistent 
logic with which the reader might engage. ${ }^{14} \mathrm{~A}$ world might be a small town in Middle America or serf village in feudal Europe or tribal enclave in Africa, or it might be Middle Earth or Narnia. Moreover, the characters that make up the world may or may not be human, but will have encounters that humans will either recognize or that will be unrecognizable precisely because they contrast with human encounters. ${ }^{15}$ It is the hypothetical aesthetic space created by literature that allows for the reader to discover and contemplate new worlds that provide experience beyond one's own world.

These creative worlds, as I have suggested, may not necessarily bear much resemblance to the world we inhabit, but we make sense of these new worlds through reference to the world we inhabit. In this way literature is mimetic, in that it represents possible worlds intelligible to us by their points of contact with the world in which we live; but this mimesis is not particularly concerned with the "real existence" of that which is represented. The aesthetic space in literature-unbounded by the constraints of the world we inhabit but still recognizable to us as in some way related to that world—allows us to engage multiple situations and roles within a generally safe environment. ${ }^{16}$ Because this aesthetic space offers potential situations and not actual ones, we are able to consider a range of possible stances and responses that would be otherwise unavailable to us. ${ }^{17}$

Moreover, the reading of literature is a rehearsal in bringing some kind of order to what otherwise might appear to be chaos. To the extent that human beings find themselves in a world that seems not to be guided by any underlying plot structure, people try to make sense of the world around them through the construction of narratives. ${ }^{18}$ Wayne Booth argues that "we all live a great proportion of our lives in a surrender to stories about our lives, and about other possible lives; we live more or less in 
stories, depending on how strongly we resist surrendering to what is 'only' imagined" (14). It is through these narratives that one's life and the actions of others are understood. Without some narrative, life appears to be a disjointed series of random episodes, unrelated to any larger story. Humans gain a certain mastery of the world through a narration of life that offers meaning, where before the narration, there was none. Reading literature helps to shape our capacity for engaging our own stories by continually exposing us to the practice of imposing narrative order on what would otherwise be experienced as a seemingly endless series of episodes with no goal, and therefore with no purpose.

Jonathan Lear, in discussing the literary genre of tragedy offers an example of this exercise in making meaning through narrative. He argues that the function of tragedy is to absolve the world of what appears to be meaninglessness, by placing the responsibility for the tragedy that befalls the tragic hero back on the hero. If tragedy happens randomly, we have no choice but to see the world as chaotic. According to Lear, Aristotle understands tragedy to reinforce, through the convention of an error (hamartia) made by the tragic hero, the picture of a rational world - a world resting on a stable structure of rational cause and effect. Tragedy underscores Aristotle's belief that the world is not irrational and chaotic. Oedipus, for example, is not merely the victim of bad luck, but of a series of choices he makes-even if unwittingly. The fault lies within human beings, and not within an irrational universe. Lear writes: "In Aristotle's conception of tragedy, the individual actor takes on the burden of badness, the world as a whole is absolved. And there is further consolation is [sic.] recognizing that even when they are responsible for their misfortunes, humans remain capable of conducting themselves with dignity and 
nobility" (Lear 335). Put differently, Lear concludes that the pleasure we derive from tragedy is in being able to place ourselves imaginatively in situations where we have seen the worst life has to offer, and have then acted with dignity, so that "the fundamental goodness of man and world are reaffirmed" (Lear 335). By eliciting the emotions appropriate to tragedy, our moral imaginations are trained through literature to see the world in a new way that makes intelligible our moral responsibilities and the consequences of failure.

However, expanding moral imagination by reading literature is not necessarily an inevitability. Iris Murdoch offers this caution about the limitations of art: "Art presents the most comprehensible examples of the almost irresistible human tendency to seek consolation in fantasy and also of the effort to resist this and the vision of reality which comes with success. Success in facts is rare. Almost all art is a form of fantasyconsolation and few artists achieve the vision of the real" (Sovereignty of Good 62-3). She goes on to say that "the greatest art is 'impersonal' because it shows us the world, our world and not another one, with a clarity which startles and delights us simply because we are not used to looking at the real world at all" (Murdoch 63) ${ }^{19}$. The question arises about what it is she intends to suggest about the relationship of fantasy to the real, as well as what she means by referring to "our world and not another one."

I read Murdoch not necessarily as insisting on mimesis, in the sense of requiring a one-to-one correspondence to reality. I take her to mean, for example, that something like fantasy as a genre can be revelatory, by disclosing that which is true about the world we inhabit -even though the world we inhabit is never specifically named in the work. Conversely, literature that might be categorized as realistic can obscure reality, by 
presenting a picture of reality interested in only the facts, without sufficient reference to the intersubjective milieu in which characters act and are acted upon. Art, for Murdoch, captures us and disarms us because of its nature as fiction, while it simultaneously refers us back to the world we inhabit. Its force for good, however, comes when it discloses reality, when it reveals what is true, rather than allows us to maintain our fantasies. Her description of reality, I believe, is a thick one that includes more than just a report of the possible propositions relevant to the narrative; it includes things like a thoughtful depiction of motives, desires, purposes, fears--in short, context. It is the process of paying attention to this context within fictional narratives that helps the reader attend to the context of life narratives in actuality. Put another way, reading gives us the kind of preparation for attending to the subjects that make up a community by simulating experiences of attending to fictional subjects. Ultimately, that attending to fictional subjects has at its center attending to the emotional lives of others, to which I will turn now.

\section{Literature and the Emotional Imagination}

According to Murdoch, art teaches us how to look beyond our fat, relentless egos - which mediate reality in a distorted fashion - to attend to the world imaginatively and, ultimately, she thinks, truthfully (Sovereignty of Good 51). If science encourages us to see the world as objectifiable, and if Western culture has bequeathed us an unfortunate set of mental habits that results in a vision of the world that looks more like a projection of the interior self, art allows us to refocus our sight, to employ, in my terms, other sight. Murdoch argues that this is possible because "great art teaches us how real things can be looked at and loved without being seized and used, without being appropriated into the 
greedy organism of the self" (Sovereignty of Good 64). Art, good art, draws us out of ourselves for the purposes of attending to a person or a thing external to us. Literature, in particular, because of its narrative nature can reveal the kinds of possibilities available to us in negotiating our interactions with others. In other words, it can expand our emotional imaginations, and thereby expand our awareness of the emotional experiences of others by allowing us to simulate an enormously wide range of emotional experiences.

I should take a moment to comment on an obvious question - that is, what role does banal art play? Additionally, how we go about adjudging a piece of art to be banal? There are certainly more aesthetically sophisticated ways of discerning between great art and banal art but, for simplicity's sake, if we contrast Murdoch's line of thinking about great art (which draws us out of ourselves), banal art is art that draws us inward, diverting our attention from the world back onto ourselves, causing us to attend to our own interiority. I would suggest that banal art also takes certain shortcuts with respect to emotion, offering sentimentality and triteness in neat, pre-digested packages that require little intellectual or aesthetic investment of the reader or viewer. Additionally, I think banal literature is potentially objectifying, calling upon the reader to view human subjects as objects to be used or conquered. Romance novels, for instance, can establish or reinforce cultural tropes about what love ought to look like, and about what kinds of people are candidates for love (e.g., the good looking, the wealthy, the successful) that can warp emotional experience. Banal art, on my account, along with great art, also trains the emotions to the extent that it helps to recalibrate emotional triggers- - but banal art often does so in potentially harmful ways. How, though, does this recalibration of emotional triggers through reading literature function? 
Marcel Proust writes suggestively about how literature operates as a repository of imaginative possibilities in Swann's Way. He reminds us that "[The novelist] for the space of an hour ... sets free within us all the joys and sorrows in the world, a few of which only we should have to spend years of our actual life in getting to know, and the most intense of which would never be revealed to us because the slow course of their development prevents us from perceiving them" (117). In these words, Marcel Proust, has staked out a position over against the autonomist aesthetic concerns, then popular, of Oscar Wilde and the "art for art's sake" movement. "Art for art's sake" was an attempt to steer the aesthetic ship away from what was considered to be the shoals of the aesthetic moralism of those moralists (e.g., Tolstoy) who, as I have indicated, understood art (literature, in particular) as a mimetic tool to be wielded in the formation of moral individuals.

Consequently, aesthetic autonomists increasingly clamored for art that concentrated on form, in order to avoid any confusion that content-which they took to be subjective-was important to the work. On this formalist reading, art should evoke only aesthetic experience, because to evoke an emotional or moral experience risked tripping people up by focusing on the content rather than the form. Modernist painting takes this concern to its ultimate conclusion in painters like Mondrian and Kandinsky, where there is no content-only form. Literature, on the other hand, found pure form much more difficult to execute. But innovations in literature (e.g., stream-ofconsciousness, shifting temporal perspectives) drew attention away from the content of representational or traditional plot and toward the form of the expression itself. 
Proust, however, in Swann's Way is not convinced that novels have no work to do. He suggests that the novel has the capacity to expand the emotional imagination by placing the reader inside events that would, because of the lack of experience by the reader, be otherwise inaccessible. A human life, bounded as it is by the limitations of time and space can only contain a finite number of experiences. I cannot experience in reality even a fraction of the experiences possible to a human being. I may never fight in a war, experience a natural disaster, be stalked by a serial killer, and so on. Moreover, some experiences are closed off to me altogether. I will never, for example, be able to experience in my real life what it means to be a woman. I will never know firsthand what it means like to be born poor, or disabled, or Chinese. However, through literature I can begin to get some sense of what those experiences entail emotionally, and the kinds of beliefs and values that come from those perspectives. In "What Is It Like to Be a Bat?" Thomas Nagle makes an argument about the inadequacies of objective, scientific description to circumscribe all that is knowable. He argues that experience is both perspectival and subjective, and that knowing what it is like to be $\mathrm{X}$ is not reducible to objective physical descriptions. Instead, he argues that we know what it is like to be $\mathrm{X}$ by being able to take up the point of view of X. And, to the extent that "one can take it up roughly, or partially, then one's conception will also be rough or partial" (Nagel "What Is It Like to Be a Bat?" 442). That is to say, by reading literary accounts of lives and experiences different from our own, we are given some conception not open to us through scientific description, if only rough or partial, of what it is like to experience life from different points of view. 
An important objection to my assertion that reading literature can provide knowledge of experiences I have not actually had is that it does not meet the test of propositionally determinate knowledge. That is to say, epistemologically, fictional literature does not offer us propositional knowledge about the world we inhabit, but only knowledge of fictional worlds. In other words, knowledge garnered in pretend worlds amounts to little more than pretend knowledge; and pretend knowledge fails to meet the conditions of real, objective, verifiable knowledge. But, as I have argued, the privileging of this kind of objectivist account of real knowledge is problematic, just to the extent that it fails to consider other ways of knowing the world that do not require propositional standards be met to establish knowledge (namely, in this case, knowledge of others). The kind of knowledge literature contains does not necessarily seek to describe the world in which we live with scientific rigor. Instead, the kind of knowledge literature offers is perspectival in nature- -knowledge of the world from a particular perspective, and not knowledge of the world sub specie aeternitatis, or Nagel's "view from nowhere."20 Because of the almost limitless possibilities for perspectival knowledge, to the extent that it is subjective, those possibilities can never be exhausted through actual experience. The knowledge we derive from literature has to do with simulating the experiences of others from their particular perspectives. Consequently, the knowledge we gain is not "knowing how" or "knowing that"—standards for propositional knowledge—but "knowing what $x$ is like" (Nagel "What Is It Like to Be a Bat?" 442). Knowing what it feels like to swim, for example, is different from knowing the physical and mechanical laws that make swimming possible. The way the water feels as one moves through it, or the euphoric feeling that floating gives some people does not admit of propositional precision. Or, 
more to the point with respect to literature, knowing what it feels like to find oneself subjected to sexual harassment, for instance, is different from knowing the legal definitions and possible psychological implications of being sexually harassed. Knowing the fear one might experience when one is alone with a particularly offensive supervisor, or knowing the kind of endless calculations one must continually make in such a circumstance (e.g., Can I or should I endure such offenses? Is speaking up worth it if it costs me this job? Can I afford to lose this job?) fall under the category of a certain kind of knowledge. According to Scott Stroud the experience of what it is like to be $x$ in situation $y$ is a type of knowledge-subjective knowledge (27). That subjective knowledge is not open to scientific verification does not, I would suggest, preclude it from being an important form of knowing about the world.

Subjective knowledge of the world can be had experientially, as one would imagine. However, beyond actual experience, one of the most expansive resources for this kind of knowing comes through fictional accounts, in particular for my purposes, literature. This way of knowing, according to Stroud, "is a cognitive gain; it can be discussed and recounted in a linguistic fashion and is something that the reader would not cognitively possess unless she actually had that exact experience or read that exact fictional account (which involves imagination in its simulative function)" (32). Literature makes available to us ways of knowing the world that would otherwise be inaccessibleways that are important for the social life made possible by intersubjectivity. If we are to attend to one another emotionally, then the ability to possess knowledge from perspectives other than our own is critical, since emotional attending requires an exercise of the imagination to understand another's emotional experience from her point of view. 
Through reading, we accumulate a fund of experiences that allows us to make inferences about the world from perspectives other than our own. Admittedly, these inferences are not infallible. We may, for instance, draw the wrong conclusions about what it feels like to experience life from someone else's perspective. We may casually assume by reading Huckleberry Finn, for instance, that the life of adolescents who roam freely is romantic and adventurous, rather than perilous and lonely. But if, as I have suggested, our vision of others is infinitely perfectible, even these wrong conclusions (if we pay attention to them) become a part of the fund of subjective knowledge we will employ in the future as we emotionally attend others. Through reading we gain practice at looking at human subjects with other sight. That is to say, reading assists us in refocusing the lens of love by regarding a fictional character not as an extension or a projection of my self, but as independent of me and my own needs. No matter what my needs happen to be, I regard Willy Loman, for instance, as a character over whom I have no objective power, no possibility for imposing my own program for personal or vocational improvement. I engage Jane Eyre as a character situated in a context not of my own design, placed there not simply for my private entertainment. They lead fictional lives that invite me in, but that do not cede control to me. I am welcome to identify with the characters, but I realize in some sense that the fictional lives they live are not dependent upon me for their intelligibility as human lives. These fictional human lives, though, are capable of eliciting some kind of emotional phenomenon.

But here we run into the problem of the paradox of fictional emotions. How is it that fictional worlds seem to elicit emotional responses in real world readers? The paradox of fictional emotions can be summarized in this way: 
Regarding certain fictional characters (and situations) F, it is

simultaneously true that:

1 We have genuine and rational emotional responses towards $\mathrm{F}$;

2 We believe that $\mathrm{F}$ is purely fictional;

At the same time, it is also true that:

3 In order for us to have genuine and rational emotional responses towards a character (or situation), we must not believe that the character (or situation) is purely fictional (Gendler 241).

The paradox emerges when we realize that it is possible to hold any two of the conditions simultaneously as true. However, taken together, all three present a contradiction. Kendall Walton describes the paradox by giving the example of a moviegoer named, Charles. Charles watches a scary movie about green slime. ${ }^{21}$ He exhibits the signs of someone who is frightened, even claiming to be "terrified" (5). Walton argues, however, that Charles cannot truly experience fear, since, if he is rational, he does not believe that there is any green slime about to overtake him. That is to say, according to Walton, it is irrational to be afraid of something you know does not exist. But what then do we make of Charles's apparent fear response? Walton believes that what Charles experiences is "quasi-fear" (6). This quasi-fear is a function of the "make believe" world Charles has chosen to inhabit through fiction (13). In this way, Walton believes he can offer a description that makes sense of the paradox of emotional engagement with fiction.

Since Charles cannot rationally believe that the slime is any threat to him, and since, according to Walton, real emotions are the product of beliefs about the real world, 
Charles must therefore not be experiencing real emotion. However, it is Walton's commitment to a cognitive account of emotions-in this case, belief-dependent emotions-that causes him to undergo great theoretical contortions in an attempt to solve the paradox of fiction. For one thing, on a commonsense level, if what I feel as I read Oedipus Rex feels the same as the experience of what I would feel if I were watching the same circumstances on the nightly news, it is not immediately apparent what is achieved by drawing a hard line to distinguish between "quasi-emotion" and "real emotion?" If "quasi-emotion" and "real emotion" feel the same, it is not apparent for the purposes of the philosophy of literature or for my argument about the emotions we experience when reading literature what practical advantage is to be gained by differentiating between the two. $^{22}$

Furthermore, a "quasi-emotion" theory, as I have just mentioned, fails to account for the ways that emotions are believed to function according to modern neuroscience. As I suggested in Chapter Two, cognitive accounts of emotions depend upon beliefs, evaluations, or desires as the key to understanding emotional response (e.g., I believe my dog is dead, which makes me sad.). Moreover, as I argued earlier, cognitive accounts of emotions are problematic on a number of different fronts; but most devastating to the cognitive theories is the insufficient physiological response time necessary for cognition to track with emotional response. Put simply, we have emotions (in most cases) before we think about them. If, however, we view emotions not as the product of beliefs, but as a process initiated by affective appraisals, the paradox of fiction dissolves. For the purposes of my argument, then, the question is not the objective question of categorical description: "quasi-emotion" versus "real emotion"-but the subjective question of 
experience: Does the emotional experience I have when I read literature track the emotional experience I might have under the same circumstances in real life?

In Chapter Two I discussed the encoding of somatic markers or embodied appraisals; in this chapter I am going to expand on that discussion. Emotions are triggered, by and large, affectively, meaning that they happen involuntarily. My urge to duck when I see something flying at me is not initially bordered by a set of cognitive beliefs, which must be weighed and then acted upon. Instead, my response to the flying object is filed with all of the other experiences of flying objects in the Ventromedial prefrontal cortex as a somatic marker or embodied appraisal. The experiences that make up that somatic marker or embodied appraisal become this quick and dirty response system, activated automatically. These somatic markers or embodied appraisals act as involuntary trip wires, or triggers, for emotional response. That is not to say that emotional response via somatic markers or embodied appraisals is a static thing-that these triggers are set in stone. On the contrary, these triggers are constantly undergoing recalibration to account for new input. Therefore, what triggers an emotional response today may very well be recalibrated, and therefore, not trigger an emotional response in the future. That the scent of lilac perfume, for instance, causes me to experience sadness because it reminds me of my grandmother does not mean that I am doomed to feel sad for the rest of my life when I smell lilac perfume. It may be that after some time lilac perfume triggers an entirely different response-nostalgia say, or wistfulness. Alternatively, I may come to associate lilac perfume with another person who brings me happiness, which could recalibrate the scent of lilac perfume to trigger a joyous emotional response in me. The point is that though I experience sadness at the loss of 
someone I love in much the same way, the kinds of triggers associated with that emotion are constantly undergoing recalibration as new experiences are filed. I will come back to these triggers momentarily.

Proust describes just this sort of affective appraisal in the famous episode describing the unfolding of emotional response, triggered by eating the madeleine in Swann's Way:

The sight of the little madeleine had recalled nothing to my mind before I tasted it ... [but]. . . as soon as I had recognized the taste of the piece of madeleine soaked in her decoction of lime-blossom which my aunt used to give me ... immediately the old grey house upon the street, where her room was, rose up like a stage set to attach itself to the little pavilion opening on to the garden which had been built out behind it for my parents (63).

Marcel experiences nostalgia not because of any particular beliefs he has initially about the madeleine he is tasting. Instead, the taste itself initiates a process, first physical, then cognitive, in which a memory trace is activated. The activation of this memory trace, the calling forth of this somatic marker or embodied appraisal elicits not only an intellectual recollection; it recalls also the feelings associated with the memory. In some very real way, then, Marcel not only remembers his grandmother's room in the old grey house by its sights, sounds, and smells, he also feels the traces of the feelings he felt as a child while in that room. The feelings associated with this memory, however are not the product of some intellectual achievement, having analytically weighed his beliefs about the goodness of his grandmother's room (as cognitive theories of emotion might suggest); 
the memory trace triggers an involuntary emotional response-where emotional response is a complex and unfolding process that includes the affective, the physiological, the dispositional, and the cognitive.

The argument I am making about emotions and literature follows the same kind of path. When I read literature, I respond emotionally not because I have beliefs about the reality of a fictional work, but because my emotions have been triggered in the creative aesthetic space I am inhabiting. As I am imagining the world about which I am reading —itself, I think, a largely involuntary action—-the sorts of situations I encounter in the fictional world are candidates for triggering my real world emotions. Imagining Anna Karenina in anguish after her clash with Vronsky, waiting for him at the train station, finally throwing herself under the train in despair, my own emotions are triggeredempathetically at the despair she feels, as well as sadness at her death. My beliefs about whether there was ever a suicide with a real person named Anna are largely beside the point. I feel something for the fictional Anna that approximates my feelings for a real person in a similar situation. Whether my emotional reaction to Anna's death is triggered by a past experience I have had with suicide, or because I am able to think prospectively about the practical and emotional impact of suicide, or because I make associations with her suicide and other tragedies with which I have had experience, the point is that my emotional response to the fictional world is real, having implications for my emotional life in the real world. That is to say, through experiencing Anna's suicide imaginatively, I can feel grief and sadness, to a greater or lesser degree. In other words, my embodied emotional response can be triggered by experiencing Anna's fictional suicide through reading. My throat clenches up and tears form in response to a fictional loss because my 
emotional response is triggered by an embodied appraisal, rather than by cognitive beliefs about the truth or falsity of the account—not necessarily of the same intensity or duration as if the suicide happened to someone I know in real life, as I will comment on shortly, but at least tracking along the same emotional trajectory.

Those fictional human lives offer me a host of images of people's emotional lives from which to draw as I navigate my interactions with others. The narrator of Swann's Way, Marcel, recalls that in reading novels "afternoons were crammed with more dramatic events than occur, often, in a whole lifetime" (116). In experiencing the emotions attendant to these fictional events, the narrator says that the novelist taps into something important with respect to emotions. He says that for a person to experience an emotion in real life, one must get "a mental picture" of the "joys or misfortunes" experienced by a real person (116). In other words, for me to be sad about the death of my grandmother, I must picture not only my grandmother, but the experiences I had with her (to which a variety of emotions are invariably attached), as well as the experiences I will be prevented now from having with her in the future. Presumably, this is why, though I may experience an intellectual loss upon reading of the death of someone else in the newspaper, I may have little emotional investment because I have no pictures of that person upon which to call. On the other hand, if I read that the person was a grandmother who engaged in activities like the ones engaged in by my grandmother with me, then I may begin to form pictures of this unknown person's life. According to the narrator in Swann's Way, a "real" person is limited emotionally by the fact that he or she cannot possibly have a wide enough experience of the different variations of events that would produce the sophisticated emotional imagination of a committed reader of novels. The 
genius of the novelist is to write in such a ways as to evoke images within the reader, images that provide access to emotions, allowing the reader to expand his or her emotional imagination, without actually having to experience in reality the broad range of "dramatic events" necessary to the cultivation of those emotions (116).

Leaving aside the cognitive resonances of Marcel's "mental picture," what he refers to can be accounted for by somatic markers or embodied appraisals as a memory trace. These memory traces are not stored as cognitive holdings (though I have cognitive memories triggered by theses calibration files or somatic markers), but as quick and dirty affective triggers that recall particular emotional experiences. In other words, my experience of sadness over the loss of my grandmother calls upon more than just my memory of her as a human being related to me. My memory of her includes my emotional experiences of her. I am able, if only to a certain extent, to identify with people (even strangers) as subjects because my emotional imagination builds on experiential points of contact with others. I must, therefore, have a fund of emotional experiences from which to draw to be able to make the analogical leaps necessitated by these experiential points of contact. That is to say, I need have a broad range of emotional understanding to be able to have some idea about what it is like to experience the world from some other point of view. Reading literature, as I have argued, is one way for expanding the base of emotional experience. How, though, are these emotions induced within us by reading literature?

At one point in Swann's Way, the narrator takes a sip of tea, which immediately elicits within him an experience of "all-powerful joy." He begins to question where this emotion comes from. How can such a small thing trigger such an intense emotion? He 
finally concludes that "the truth I am seeking lies not in the cup but in myself" (61). In other words, the narrator determines that the emotion evoked within him comes not because of the tea he has just drunk, but because of the emotionally creative connections surrounding the drinking of that kind of tea. Something independent of the narrator causes him to make connections located within his memory, bringing about a new awareness of himself. This connection between memory and emotion makes sense when one recalls that emotion is an embodied process, triggering memory traces, which are both somatic and cognitive in nature. According to Proust, reading fiction may provide us as readers with the emotional resources necessary to undertake, what Husserl would call, a phenomenological investigation of the emotions. ${ }^{23}$ If Proust is right, the content of art (in this case the novel), in spite of formalist objections, is significant in illuminating ways of knowing that do not rely for their illuminative powers on propositionally determinate knowledge. Instead, reading literature provides us with subjective knowledge - that is, knowledge from another point of view about what it is like to be X. The subjective knowledge we acquire through literature is invaluable to emotional attending inasmuch as it expands the repository of emotional experiences, and thereby expands our emotional imaginations.

It might justifiably be argued that the emotions one experiences by reading literature are not necessarily of the same intensity as emotions in real life. Although they might occasionally approach that intensity, they almost certainly do not approach the duration of the most intense emotional experiences. I do not, for example, grieve the loss of Anna Karenina for the same length of time I would grieve the loss of my grandmother. My point, however, is not to say that emotions elicited while reading 
literature track in exactly the same way as emotions elicited in real life; only that some affective parts of the emotional process "feel" identical between fiction and real life. Again, the question to be put to the emotions induced by reading literature is not an objective categorical one about whether real emotions and simulated emotions can be objectively described as identical in every respect. The question, instead, is a subjective experiential one about whether real emotions and simulated emotions "feel" the same.

It might also be asked whether the emotions elicited by literature that I am describing are not merely simulations of emotions. That the emotions educed by literature within this aesthetic space are simulations of emotions, and not the actual emotions one would need to exhibit appropriately in real life is not a damaging admission. Any simulation, by its very nature, is suggestive of the range of responses (emotional, physical, etc.) available to one when facing the actual situation being simulated. The objective of military training, for instance, is not to put one's life in danger, but to give one a glimpse into what that danger looks and feels like, so that when faced with a similar situation in actuality, one will have a certain familiarity with danger through having lived with it in an imaginative space, and thus be more liable to respond appropriately. Just so with literature, the simulation of emotion can enrich the resources I possess for confronting life-although not always, as is the case with banal literature. ${ }^{24}$

Though they may not be entirely identical, emotions elicited by reading fiction offer insight into the emotional lives of others (both fictive and real) by giving ushowever attenuated it may be - the ability to feel what it might feel like to have a certain kind of experience. In this creative aesthetic space, we can begin to imagine how others experience life as subjects-not as objects, or as extensions or projections of the self. It 
is this exercise of the imagination that will be crucial for developing the resources necessary for emotional attending. In The Lovely Bones, for instance, Alice Sebold introduces us to a fourteen year-old girl, Susie Salmon, who is raped and murdered in the first chapter, and narrates the rest of the book from heaven. The rest of the story deals with the aftermath of her death, and how her family attempts to come to terms with it. Through Susie's eyes the reader begins to see what it might look like to love a victim of a violent crime- the initial panic of a missing child, the wrenching grief at the loss, the enduring pain and emptiness. The book is intensely affecting. And while, admittedly, there can be no equivalent between the emotions experienced by those who lose a loved one to violent crime and the emotions experienced when reading about the loss of a loved one to violent crime, the emotional understanding one receives by reading about this kind of experience gives one a sense of what it might feel like to lose someone to violence. The kind of subjective knowledge of what it is like to be $\mathrm{X}$, if only in a partial way, allows one better to be able to attend to that person.

It is imagination that allows for the transfer of knowledge gained from reading fiction to real life social interactions. And when it comes to emotional attending, imagination is a key component. In Chapter Four, I spent a great deal of time speaking about imagination—both moral and emotional. I will expand on that discussion here. Social interaction requires imagination-even on the most basic levels. Antonio Damasio writes:

The somatic-marker account is thus compatible with the notion that effective personal and social behavior requires individuals to form adequate theories of their own minds and of the minds of others. On the basis of those 
theories we can predict what theories others are forming about our own mind. The detail and accuracy of such prediction is, of course, essential as we approach a critical decision in a social situation. Again, the number of scenarios under scrutiny is immense, and my idea is that somatic markers (or something like them) assist the process of sifting through such a wealth of detail-in effect, reduce the need for sifting because they provide an automated detection of the scenario components which are more likely to be relevant. The partnership between so-called cognitive processes and processes usually called "emotional" should be apparent (Descartes' Error 174-5).

The part of the brain responsible for imagining and predicting during social interactions has been dubbed by Leslie Brothers, the "social brain" (Brothers). Chris Frith explains that "it is the social brain that allows us to interact with other people. As with all our interactions with the world, we can do much better if we can predict what is going to happen next. The better we can predict what someone is going to do next, the more successful our interactions with that person will be" (671). This is so because all of life requires a degree of predictability. I have to be able to take a number of things for granted to get through the day. I need to be able to take for granted the prediction, for example, that when I drive down the road that people going the opposite way know that they are supposed to stay on the other side of the yellow line. I need to be able to predict with some certainty that the pills my pharmacist places in my medicine bottle are the correct ones. The same is true of my interactions with others on an emotional level. The better I am at predicting how my wife will respond to a given situation, the more likely I am to respond to her successfully. If I know that the anniversary of her father's death is 
approaching, and that that anniversary causes an intensification of her grief, I will be better prepared to be with and for her. To accomplish this skill at predicting, we have developed highly skilled capacities for imagination.

These capacities for imagination are linked to capacities for memory recall. Addis, Wong, and Schacter confirmed, through a fMRI study, the connection between the regions in the brain that mediate construction and elaboration of both past and future events (1363). In the study, participants, while undergoing fMRI scanning, were given cues about whether they were to recall a past event or imagine a future event. They were given a timeframe (e.g., last week/next week, last year/next year). Then, they were given a concrete episode (e.g., the birth of one's child). When they had the event in mind, they were to push a button, ending the construction phase, and beginning the elaboration phase-where the participants were asked "to expand the event representation by retrieving or generating as much detail as possible" within the twenty second time limit for each event (1366). What they found was that there was overlap in the neural system between past and future events-that is, between retrieval and prospective thinking—in both event construction and elaboration. Event elaboration, however, "was characterized by extensive overlap between past and future events" (1375). Addis et al. suggest that "this striking neural overlap is consistent with findings that amnesic patients exhibit deficits in both past and future thinking, and confirms that the episodic system contributes importantly to imagining the future" (1363).

In other words, our imagination of future events, our ability to think prospectively about things that have not yet happened is closely linked to our ability to recall experiences from the past. We take past experiences and imaginatively reshape them to 
fit new sets of circumstances. Having started new jobs in the past, for example, I am able to imagine what my first day on a new job will feel like. Having experienced the disappointment of losing a competition, I am able to begin to imagine what it might feel like for you to lose. Reading literature, therefore, enlarges the fund of emotional experience I need to expand the imaginative capacities I employ in emotional attending. To the extent that I am unable to draw on past experience, I am unable to imagine the future. ${ }^{25}$ Imagination acts like a reassembly agent, building as yet unexperienced situations from the building blocks of past experience. David Hume believes something like this about the connection between memory and imagination. He argues that the mind receives sense impressions, which are then transformed into ideas. These ideas are then combined to form memories. Moreover, the ideas formed out of impressions can also be recombined in new and novel ways, which he calls the imagination. I see the tree, for example. My impression of the tree becomes an idea (e.g., a picture of the tree, the smell of the leaves, the feel of the bark, etc.), which I can recall as a representation of the tree in a memory. I can also use that idea of the tree, combine it with other ideas in my imagination to form other trees, or forests, or Ents from Middle Earth. This process of the recombination of ideas in imagination, according to Hume, is how we get "winged horses, fiery dragons, and monstrous giants" (11). I am arguing that this is how our minds work in calling upon the kinds of emotional experiences we have when we read literature to be used by our imaginations as we attend to the emotional lives of others. The emotions I experience when I read about the grief and anxiety of Susie Salmon's parents becomes something I can draw from to imagine the grief and anxiety of a parent to whom I attend in real life. 
Someone might object that I am contradicting myself here by describing a way of knowing others that comes from my interiority—which I have previously said obscures my vision. That I have an interior life is something that I neither wish to dispute nor denigrate. Indeed, interiority, as I have said already, is the very place from which springs the kind of literature that takes seriously the emotional life of people. As I argued in Chapter Four, the problems presented by radical reflexivity have less to do with having an interior life-which is a good thing — than with believing that true knowledge of the world, of others, and of how we are to live morally are generated by the isolated self. It is, finally, a matter of humility. I see in the emotional lives of others not a mirror image, not merely an affirmation of my own emotional life, but a life in which the subtleties and complexities of a life narrative chart a course, often similar to my own, but always unique in their particularity. The inferences I draw from other people's life experience are always tempered by the humility that I may have gotten it wrong. Knowledge of others humbly drawn from my emotional experience and imagination and focused on another's complex life narrative seems a different kind of practice to me than the kind of colonizing certainty that everyone's emotional experiences and life are like my own. In the first instance, I try to take my cues about your emotions from attending to you in your particularity, while in the second instance I start from the premise that I already understand you, because I possess enough information about emotions and life in general, drawn from my own interior life. The question is finally: Is our knowledge of others generated from within and then applied (imposed?) on the emotional lives of others, or is our knowledge of others first a product of attending to them in their particularity? As I 
have argued, I think the most helpful way to view our knowledge of others begins with our focus upon them, before it is ever directed back upon ourselves.

\section{Conclusion}

In this chapter I have argued that reading literature offers an important means by which we increase our imaginative capacities. First, I suggested that reading literature helps us expand our moral imaginations by allowing us to adopt the process of moral reasoning of fictional characters, allowing us to understand the implications and consequences of a variety of moral perspectives. Second, I argued that reading literature expands our emotional imaginations through the simulation of the emotional experiences of fictional human lives-and that these emotional experiences in the reader track the emotional experiences of real life. In short, reading literature aids us in both the pursuit of virtue, as well as in our ability to engage in emotional attending. In the final chapter I will try to give a practical example of what I have been talking about by offering an analysis of the Richard Russo's Empire Falls. 


\section{CHAPTER SIX}

\section{EMPIRE FALLS}

\section{Introduction}

Richard Russo, in an interview about his book, Empire Falls, talks about his understanding of what literature can do. He says, "The thing that I would say about literature in general, the thing that I love most about it, is that when I'm in the world of a gifted writer I'm able to see that world through that writer's eyes, not my own" (http://www.identitytheory.com/people/birnbaum20.html). In Empire Falls Russo creates his own world in small town Maine, exploring the relationships of its inhabitants, in particular diner owner, Miles Roby, and his daughter, Tick. Of specific interest to Russo is the characters' lifelong effort to understand people within their world more fully. Miles, on a quest to understand others, begins to understand himself more fully as he sees himself not as the lead actor in a self-produced psychodrama, but as a human being embedded in a complex web of relationships. Miles recalls one of the things his mother always said about small towns "was that they accommodated just about everyone; the lame and the disfigured were all your neighbors, and seeing them every day meant that after a while you stopped noticing what made them different" (Russo 21, emphasis mine). In other words, seeing people as human beings embedded in a communal matrix, rather than as individuals abstracted from the communities that make their lives intelligible, 
allows for a kind of sight, what I have called other sight, that focuses not on the peculiarities that are always open to abstraction. Abstraction, as I am using it, means being considered apart from the intricately woven fabric that makes up a life lived within community - while other sight means focusing on the whole person within the context of a community, an integrated human subject complete with all the particularities and idiosyncrasies that implies.

Russo uses the metaphor of sight throughout the work, which, I will suggest, offers an opportunity to think epistemologically about knowing another-not in the scientific sense, as an object to be observed as if through a microscope, but as a subject to be regarded through the lens of love. By love I mean less a feeling than a commitment to taking the other person seriously on her or his terms - which is to say, in relationship to the other's life narrative-instead of as an object of study or as an extension of my own emotional needs. In the account of emotional attending I am developing, sight operates as a metaphorical synonym of attending. I watch you, I see you, and I am able to understand you better as a part of a whole, from whence derives your projects and goals, likes and dislikes, that which you care about, as well as that which you despise.

I want to be clear at the outset of my discussion of Empire Falls, which is a novel about a small town in Maine, that I do not intend to sentimentalize small town life as an idyll, or as somehow superior to other communal living arrangements. Though small town life can share all the positive aspects of community, including intimacy, support, accountability, and so on, it can also achieve great heights of alienation, discouragement, and censure. In fact, neither should community per se be glorified as an unassailable good, since there can be communities, as I mentioned in Chapter Three, that have laid 
down bad ends (telos), and are therefore malformative and destructive. Small towns, communities, families — all can accomplish wonderfully nurturing and sustaining environments in which people can flourish; they can also accomplish great evil.

So far, I have tried to put forth an argument in which humans, through the ascendancy of reason and science, as well as through a turning to the self, have developed habits whereby we view others as atomic individuals, abstracted from the contexts that helped to produce them, and seen through the filter of Murdoch's "fat, relentless, ego." The metaphor of sight in this traditional epistemological sense, however, which has been the hallmark of Western ways of knowing the world, is inadequate as a manifestation of all life to the extent that it is a sight calibrated for seeing objects, for things, for analysis, for calculation —instead of a sight calibrated for seeing subjects, for motives, for intentions, for human beings. Hence, sight as a metaphor for reliable knowledge has done double duty - the sight of the eye (reason), and the sight of the heart (emotion). Unfortunately, though the metaphor of sight may be apt in both cases, we have often acted as though the knowing that relies on reason and the knowing that relies on emotion were the same process, the goal of which is the same. And while I have made a case for understanding knowing as a dynamic process involving both reason and emotion, that which is to be known - that is, object or subject-ought to determine the kind of process one uses to achieve reliable knowledge. Although most people would recoil from the thought that it is possible to know a proton through the same process by which it is possible to know a lover, nevertheless, we bring some of the same habits of mind to bear on the latter (abstraction, objectification, etc.) that we bring to the former.' 
In this chapter I will trace, on the one hand, the development of the image of vision in Empire Falls, specifically how the nature of the knowledge of another changes between characters with the sharpening or blurring of the vision the characters have of one another. I will try to show how the modification of one's vision of another as a subject allows for the discovery or recognition of new knowledge about the world the subject inhabits (c.f., Murdoch's Sovereignty of Good $51 \mathrm{ff}$.). ${ }^{2}$ This knowledge of others as subjects within community also constitutes a framework in which our actions take on moral significance, becoming morally intelligible as expressions of communal life, rather than as universal maxims to be satisfied or utilitarian calculations-- both of which, as I argued in Chapter One, encourage the kind of abstraction that is counterproductive to intersubjectivity. On the other hand, I will also examine how one's self-understanding undergoes modification. Put differently, when seeing with other sight, one is freed up to view oneself through the eyes of others, helping to reshape one's understanding of oneself. Next, I will explore the way a flourishing community is created by emotional attending and threatened by bad attending. That is to say, I will focus on the way that viewing others as subjects with their own projects and desires fosters an atmosphere in which the intersubjectivity necessary for human flourishing can occur, and in the absence of which, that intersubjectivity is threatened-intersubjectivity being a state of affairs in which I am freed up to be with and for another. I will also make the claim that community is bound together by more than the positive feelings each member is able to generate. Finally, I will seek to use Empire Falls to illustrate how the simulation of emotional states during reading, which I set down in Chapter Five, provides the reader 
with an opportunity to begin to expand her understanding of emotions through the use of imagination, and therefore, her capacity for emotional attending.

\section{Other Sight: The Lens of Love}

Miles Roby, who dropped out of college after his junior year to look after his dying mother, took over the management of the Empire Grill as a way to support himself. What began as a temporary job to help Miles make ends meet turned into his life's work. Of course, it is the dawning realization that his life-which everyone believed held such promise in the beginning - has consisted mainly of his attempts to keep a failing restaurant in the declining town of Empire Falls above water that provides the narrative tension in the book. The town of Empire Falls, once a prosperous lumber and textile producer under the oversight of generations of the Whiting family, has fallen on difficult economic times. It is the widow of the last scion of the Whiting empire, Francine Whiting, who owns the Empire Grill, and who uses her power to manipulate the town in general, and Miles in particular.

The story involves the interactions that take place in a small town between people trying to negotiate often complicated relationships. Miles, for example, tries to figure out how to parent his precocious teenage daughter, Tick. At the same time, Miles must deal with his ex-wife, Janine, and her fiancé, Walt Comeau—both of whom are selfish and venal—and their impending wedding, his insightful but troubled brother, David, an obnoxious police officer (Miles's childhood neighbor), Jimmy Minty, the intrepid Mrs. Whiting, Miles' cadging father, Max, as well as a host of other townspeople, many of whom work at or frequent the Empire Grill. 
While Russo employs the perspective of multiple characters in the novel, the plot largely revolves around Miles' attempt to keep the Empire Grill open amid the economic pressures of a declining population and shrinking job market--at least until Mrs. Whiting dies, at which time he has been promised that he will become the owner of the Empire Grill. In the process of trying to hold a shaky business together, Miles also finds himself trying to hold together relationships with family and friends, which are threatened by all manner of domestic troubles, not to mention the problems associated with living in a dying town. Miles' relationship to his daughter, Tick, acts as a moral center for the novel by concentrating on how two people can continue to try to keep one another in focus during the inevitable change each undergoes. Over the course of the novel, Miles faces a number of questions about whether he should stay at the Empire Grill or strike out on his own, about how he should deal with the demands on his time and his loyalties, about his responsibilities toward his family, his friends, and his town.

The climactic scene in the novel, however, centers on a school shooting. John Voss, a high school student in Tick's art class, launches a fatal attack witnessed by Tick. A great deal of attention is paid to how the town receives John Voss, and what sorts of things compel someone to such violent acts. Of significance to the plot and the trajectory of the growth of the characters is the fallout from the shooting on Miles and Tick and their relationship. Russo explores the kind of complicated context out of which can emerge both great acts of love and great acts of violence.

The book implicitly poses the question about whether the measure of a life is best understood as the sum total of one's achievements or as the quality of the relationships to which one devotes oneself. Judged by the former, Miles sees his life as a failure, defined 
by an expanding list of missed opportunities. We become increasingly aware that the value of Miles' life in the dying town of Empire Falls changes dramatically when the measure of its success is recalibrated to standards that take into account love and loyalty, compassion and commitment. Despite the fact that the town of Empire Falls can produce such goods, though, it cannot escape the fact that it is equally capable of producing treachery, selfishness, and hatred. Such an insight into the human condition, of course, is not novel. What makes Richard Russo's narration of this insight noteworthy, though, lies in his attention to attention - which is to say, his concentration on the ways that attending (and failing to attend) to others is revelatory, both of the person who is attended to and of the one who seeks truth through emotional attending. Russo uses vision effectively to draw the reader's attention to the way that characters see, or fail to see, one another. That is to say, the metaphor of sight offers cues to the reader about whether a character is successfully attending to another, by concentrating on whether the subject being attended to is seen clearly or is out of focus. The quality of the relationships produced through emotional attending bespeak a strength through which community may be sustained, even though economic distress seems to be unraveling the social fabric. However, when emotional attending is not achieved, when relationships fail, as they sometimes do in Empire Falls, those failures threaten the community.

Emotional attending in Empire Falls, as I have mentioned, is highlighted through Richard Russo's use of the metaphor of sight. The role of sight in everyday life is always multivalent, operating on an empirical, sensory level, which leads to its traditional Western usage as an epistemological metaphor. That is to say, "I see that the bird is on the wire" operates as a propositional statement about the location of the bird, a verifiable 
report of the way things really are. Additionally, though, sight operates on a level seen as much less certain. If I say, "I see that she is confused," I seem to be making the same kind of propositional statement about the way things really are. But because my statement does not admit of rational or empirical verification, its status as knowledge is judged to be inferior. But sight under this second description, as a way of understanding and reporting human emotions and motives, though not open to the same sorts of verification as other ways of knowing, is as important to negotiating a fully flourishing human life as the empirical sense of sight. This second kind of sight I have called other sight, which I will use more or less as roughly synonymous with emotional attending. I must take just a moment to call to mind my discussion of other sight in Chapter Four. Other sight, on my account, is the understanding of another that comes through emotional attending. Both kinds of sight - physical sight and other sight -- give us knowledge of the world, but in fundamentally different ways. Other sight is similar to Murdoch's idea in The Sovereignty of Good_of seeing another "justly or lovingly" (22). When she distinguishes seeing another "accurately" from seeing another "justly or lovingly," she calls attention to the different ways of seeing - one way of seeing that is concerned with objective precision in observation, and the other way with seeing another as a human subject caught up in a complex and vastly connected life narrative. She describes what I mean by other sight quite nicely when she speaks of "the progressive attempt to see a particular object clearly," a progressive process that is "infinitely perfectible" (23). The progressive and perfectible nature of the kind of sight she refers to as just and loving is what I will call the image of the lens of love. To think of a loving or just lens through which another is seen, reinforces the infinitely perfectible nature of emotionally attending 
to another. The subject to which I am attending, the person I am watching, is dynamic, moving, changing. As a consequence, my focus will have to be constantly adjusted so that I can keep the subject in focus. Emotional attending is, as I have said in Chapter Four, less like science than virtue, since one can never achieve a definitive vision of another.

Knowledge of another in the traditional Western epistemological sense, while useful as a descriptor of those parts of a person open to propositional verifiability, can be in the case of other sight a failure truly to see another as a human subject, just to the extent that by reciting propositions about another, one may be tempted to believe one knows her. I may be able to describe my wife accurately - the color of her hair, the date of her birth, the kind of clothes she wears, and so on - but not truly know her. In fact, I may in practice substitute the verifiable knowledge I have about her for true knowledge of her as a subject, thereby failing to see her with other sight. So, the habits of objective observation we hold up as the standard of true knowledge for the purposes of describing everything from gravity to the mating habits of ground squirrels we are tempted (conditioned?) to bring to the observation of human subjects- which, if taken by itself as the only knowledge we may reliably possess of another, can but prove deceptive.

Furthermore, because of the turn to the self, which I argue in Chapter One has become a reality in Western thought, my habits of mind might produce nothing more than a distorted picture of another that looks curiously more like me and my prejudices and assumptions than the person about whom I believe myself to possess knowledge. I know myself to be unprincipled and self-serving, for instance, when it comes to (fill in the blank). Therefore, I assume that given the same set of circumstances your 
motives and desires will mirror my own. It is in the phrase "mirror my own" that the nature of the potential distortion becomes apparent. Because, while your motives and desires may reflect my own, I cannot know whether this is true entirely through either objective observation or introspective reflection. The process of knowing whether your motives and desires "mirror my own" can only be known over the course of time, through a commitment to attending to you and to why you do what you do and why you care about what you care about. Perceiving motives and desires is a significant part of what it means to attend to the emotional life of another.

In Empire Falls, Miles Robey's daughter, Tick, is apprised of the penchant for projection of oneself onto others in a conversation with John Voss, who will bear close watching as the book reaches its climax. John Voss, a socially awkward and shy teenager in Tick's art class, is someone for whom Tick feels a great deal of sympathy. The fact that John Voss is a social outcast does not deter Tick from trying to engage him in conversation. Since she is the only character in the book who makes any real effort to get to know him, we see Tick's sensitivity to others as a sign that, though she is a teenager, she possesses an emotional depth not demonstrated even by most of the adults in the novel. In Tick, therefore, we find a character through whom the reader may begin the difficult task of trying to see the world through John Voss' eyes; and it is a difficult task, given his social and emotional isolation. Tick, in one scene faces the problem of projection faced even by those who show some proficiency in emotional attending. She asks at one point why John Voss hasn't depicted one of his dreams in a painting—an assignment for art class. He tells her the reason is because he never dreams. Tick says, "Everybody dreams." 
He meets her eye for the first time now, reminding her of something, she can't quite think what. "You're one person," he says, as if to suggest that's just as well, that he wouldn't have wished her to replicate.

"True," she allows. "So?"

"So, how does that qualify you to know what everybody in the world does or doesn't do?"

Tick, having already had this conversation with her father, feels pretty confident of the intellectual terrain. "It's called an inference," she says. If she were certain she could speak with such authority in class, she wouldn't be so quiet. "I infer that no two snow-flakes are alike. I don't have to examine everyone."

The boy doesn't miss a beat. "That's not a very good example," he says, as if he, too, may have had a similar conversation before. "When you say that I must dream because you do, you're inferring that nobody can be different from you, not that everybody must be similar" (182-3).

In this exchange John Voss strikes at the heart of the issue by pointing out the kind of hubris it requires to believe that one's inner life provides a normative example that other lives necessarily follow. Again, the problem is not the having of an inner life or seeing one's inner life as analogous, but the assumption that one's inner life is normative.

To understand others I must attend to them in an entirely different way from the way I customarily go about pursuing knowledge. What I take to be a lens through which I view others may turn out to be either a microscope that offers up pieces of a person 
abstracted from the whole or a mirror in which I view only an image of myself that I mistakenly take to be the image of another. This tendency to abstract or objectify another, as well as the tendency to project from a normative inner life onto another, I will call bad attending. Bad attending not only fails to give us a good understanding of another, but because the practice itself is transparent to us, it can be doubly harmful, providing illusions we believe to have been arrived at through objective observation, through introspective reflection, or, more likely, through a combination of the two.

In contrast to bad attending, good emotional attending takes place when there is a commitment to viewing another as a particular individual located within a shared social matrix, both a contributor to and a product of community, a subject complete with projects and desires. In Empire Falls Miles Roby works to understand his teenage daughter, Tick, by emotionally attending to her as she evolves from, what he believes to be, a simple child into a complicated adolescent. Miles assumes that the difficulty he has in understanding his daughter has something to do with his divorce from Tick's mother, Janine, although he is not entirely sure. He suspects that the change in his relationship with Tick has just as much to do with him as with her. Nevertheless, he focuses his attention on Tick, trying to understand how their relationship has changed:

Since spring he couldn't seem to get Tick to stand still long enough to get a good fix on her. She was maturing, of course, becoming a young woman instead of a kid, and he grasped that there were certain things going on with her that he didn't understand because he wasn't supposed to. Still, it troubled him to feel so out of sync. Too often he found himself needing to see her, as if only her physical presence could reassure him of her well-being; yet when she did appear, she 
seemed different from the girl he'd been needing and worrying about. The week they'd spent together on the Vineyard had been wonderful, and by the end of it he'd felt much more in tune with Tick than at any time since he and Janine had separated. But since they'd come home, the disconnected feeling had returned with a vengeance, as if losing sight of her might lead to tragic consequences (29$30)$.

This excerpt bears comment for a few reasons, apart from the fact that it sets down vision as an important metaphor for understanding the emotional lives of others. First, through Miles the reader is invited into the difficult experience at the heart of other sight - that of attempting to focus on "a moving target." The reader gets a sense of the frustration involved in continually trying to understand the emotional life of another. Miles cannot bring Tick into focus for very long at any one time, because she is continually moving, changing, growing. Second, Miles demonstrates the extent to which we are always in danger of conflating physical sight with other sight - as if the two constitute essentially the same practice. He feels a need to see Tick's observable physical presence as a way of reassuring himself that she is all right. Of course, what Miles is really worried about - that is, her wholeness as a human being — is only betokened by her physical presence. What he really wants to "get a good fix on" is her emotional presence, her health (physical, emotional, social, and so on) as a developing human subject. In attending to his daughter, Miles seeks to understand the extent to which she is flourishing. Third, Miles's intuition that "losing sight of her might lead to tragic consequences" both signifies his belief that he must be vigilant in keeping Tick in focus if he is to understand her, as well as foreshadows his belief that his failure to see Tick 
clearly will ultimately contribute to her proximity to the tragedy that comes at the end of the book.

Miles, though he seeks to attend to his daughter, sometimes misses important cues. As the father of a teenage daughter, Miles is prone to idealizing her-which is to say, to seeing her still as an innocent little girl, in need of protection. Miles, like many other fathers, appears reluctant to see his daughter grow up. The reader senses the struggle in Miles between genuinely wanting to see his daughter clearly and needing to see her as the little girl he can still shield from the dangers of the world. Through the struggle in Miles the reader is invited to experience the conflicting impulses that make other sight such a difficult exercise. In one scene Tick, who, at her prior year's physical, was deemed underweight, is watched vigilantly by one of the waitresses at the diner for signs of undereating. However, Miles fails to notice her artful penchant for pushing food around the plate in an attempt to fool him into thinking she has eaten. Janine, Tick's mother and Miles's soon to be ex-wife, realizes Miles has a "blind spot" when it comes to seeing Tick clearly, and complains that Tick is taking advantage of her father, that Miles is too easy on her. Miles objects to the implicit assertion that he is not paying sufficient attention to Tick as a burgeoning young adult by saying that "she's just a kid." Tick, at sixteen, of course, is no longer "just a kid." And the fact that Miles believes this still to be the case points up the extent to which he must refocus to get a true picture of Tick. In pointing this fact out, Janine pantomimes thrusting a spoon into her temple "as if to drive it home," saying, "Miles. You're wrong. First, she's not a kid. You don't believe me, just look at her. Try using the eyes you look at other people with" (110). Miles, prone to idealizing Tick, is shown his failure to attend to his daughter, to see her with other sight; 
instead he sees an image of Tick that is more a product of his own needs than a true vision of who she is.

Though Miles is just as prone to distorting the image of others through projecting his own needs onto them, the book continually shows him making an honest attempt to see others clearly. Sitting in Francine Whiting's office-a wealthy dowager and the owner of the Empire Grill, which Miles manages-Miles looks at the portraits of the Whiting men—owners of the big textile mill in Empire Falls. The mill, now closed, stands as not only a symbol of the fortunes of the town; but, as its largest employer, it bears (at least in part) a causal connection to the general decline of the town and the accompanying malaise. The Whiting men, including Mrs. Whiting's dead husband, Charlie, as founders and managers of the mill are associated with a more robust economy in Empire Falls, and are therefore widely viewed in town with nostalgia. That the Whiting men have left a mixed legacy to Empire Falls is not widely (or publicly) acknowledged. Miles, however, does not succumb to easy sentimentality, understanding the part that the mill and the Whiting men have played in fouling the local environment, and leaving many people jobless after closing the mill. An interesting dynamic develops over the years between Miles and Mrs. Whiting that Miles is hard-pressed to understand. What Mrs. Whiting knows—and what Miles does not yet know at this point, but will find out later-is that Miles' mother, Grace, at one time had an affair with Mrs. Whiting's husband, Charlie. And though Grace tries to atone for her transgression by taking over the care of the Whiting's disabled daughter, Mrs. Whiting's relationship with Miles carries with it an undertone of hostility, manifested in her attempts to manipulate him. 
Mrs. Whiting, whose failed marriage—only one in a long line of failed Whiting marriages - causes her also to regard the Whiting men with a certain bitterness, turns to look at one of the portraits of Elijah Whiting, remarking that "they were all mad as hatters, you know. In one way or another. You can see it lurking behind their eyes if you look" (60). And though Miles isn't burdened by his own needs to see them through the false lens of bathos the way that much of the rest of the town seems to need to see them, neither does he need to see them through the lens of Mrs. Whiting's animosity. Miles, released from his own ego needs, "did look, though he didn't see what he was supposed to. There was a quality of zealousness perhaps, of bigotry maybe, but not insanity" (60). Miles demonstrates an admirable commitment to other sight, to trying to see beyond himself to see others justly or lovingly. Miles is able, because of his commitment to seeing people in context, instead of as abstractions (or, in this case, as symbols) or as extensions of his own ego needs, to see the Whiting men for what they were: flawed human beings, capable of offering economic and civic goods to the community, while also tearing at the fabric of the community through the ultimate recklessness of their personal and business decisions.

Miles' commitment to other sight extends beyond seeing relative strangers clearly to attempting to see those closest to him justly and lovingly. In a scene involving Miles and two of his greatest antagonists, Miles's father, Max, and Miles's childhood neighbor, Jimmy Minty, we find that other sight cuts both ways. In the scene, Miles and his father, Max, are seated at a window booth at the donut shop. Miles regards Max, whom he considers shiftless, lazy, and the possessor of atrocious grooming habits, and wonders why his beautiful mother had ever been attracted to him, suspecting that to love Max, she 
had had to "overlook" him. The word overlook is deceptive, inasmuch as what is meant is not that in order to love Max, Miles's mother had to quit looking at him, but that because Max generally cuts such an unsavory figure, she must look at him with other sight through the lens of love-seeing in him not what others see, but what she believes is truly there unseen by everyone else.

Miles's reflections on his mother's love for his father cause him to study Max, offering the observation to Max that he has crumbs in his beard. The crumbs in Max's beard act as a kind of visual shorthand for the kind of person Max is in Miles' estimation — that is, sloppy, lazy, and unconcerned with what others think of him. Miles refers to his father as "a walking appetite suppressant" (89). What ensues is a long conversation that eventually leads to Max asking for money, a common but unwelcome practice that brings great aggravation to Miles.

In due course, Max excuses himself to use the restroom. While he is gone, Jimmy Minty, uninvited, joins Miles in the booth, and proceeds to aggravate him even further. Jimmy starts needling Miles about the fact that Miles' car is rusting, causing Miles to reflect on the annoying habit Jimmy has always displayed by using Miles as a kind of yardstick against which to judge his own success—especially financially. Miles reflects that Jimmy has a "way of taking inventory behind his eyes" (91). Before Max returns from the restroom, Jimmy asks if that was Max he saw sitting at the table with Miles before he came in. Miles, says that it was, in fact, Max, and that Jimmy knows it was Max, since Jimmy sat outside in his car staring into the window where Miles and Max sat. Jimmy, in what will become an important insight later for Miles, protests that he couldn't see in the window because of the glare. The glare operates as a metaphor for the 
way that Jimmy, because of his self-absorption, is unable to see others clearly. And in this case, even when he does see clearly, he lies about it. The reader is invited to experience Jimmy as someone prone (inveterately, it would seem) to the dishonesty that encourages bad attending.

When Max finally returns from the restroom, he sees Jimmy sitting in the booth and slides in next to him. The first thing Max says is, "Jimmy Minty. My God what a stupid kid you were growing up." Max, with a smile on his face, continues to reminisce about what a "stupid kid" Jimmy Minty was, making Jimmy visibly uncomfortable. Miles, who does not like Jimmy, smiles to himself knowing that "few social situations were improved by Max Roby's participation, but this was one of them" (94). However, Max soon turns his sights, offering a variety of insults about Miles, who refuses to give him any money (which Max wants so he can go down to the Florida Keys for the winter) or to hire him to help Miles paint the church that Miles has volunteered to paint. Eventually, Miles excuses himself and leaves Max and Jimmy in the booth.

Sitting outside in his car, Miles looks through the window to see Max and Jimmy still seated on the same bench in the booth. His father starts to knock on the window, trying to get Miles's attention. Miles, reluctant to look up, finally does, and "is immediately glad that he did, for the scene framed in the window was priceless. In order to rap on the glass, Max had to lean across the booth in such a way that his moist, fragrant armpit was practically covering the policeman's face. Miles couldn't help but smile. He was grateful for his father's existence, just as Minty told him he should be" (96). Seeing his father "framed in the window" gives him an opportunity to view him through a different lens from the one he normally uses. In a brief moment of clarity, 
Miles is offered a picture of his father through other sight that takes all of his annoying characteristics into account, and finds a way to view them as - rather than sources of aggravation - the lineaments of a person for whom he is abidingly grateful. This small epiphany does not mean that Miles will no longer be impatient with his father; but it does mean that rather than settle for an understanding of his father that suits his own picture of the way things are, Miles's willingness to employ love as a lens gives him a broader, and I would argue, truer, picture of Max. This framing of Max is a way to offer the reader perspective on what it feels like to have strongly negative feelings for another person, which are, from time to time, recalibrated so that a completely different picture emerges. Like M's view of D in Murdoch's example from Chapter Four, we get a glimpse of the kind of gestalt that occurs in Miles. We see Max from Miles' newly acquired point of view, not as ignorantly socially crude, but as someone self-aware enough to know how he "comes off" to others without being overly concerned by it. The reader is given access to what this kind of change in perspective, no matter how brief, might feel like.

At the same time, Miles also sees Jimmy Minty more clearly. In this case, however, his vision crystallizes his assessment of Jimmy as meretricious and deceitful. Russo writes of Miles:

As he watched the two men slide out of the booth, he realized that Jimmy Minty hadn't been telling the truth about light reflecting off the donut shop window. Everything on the other side of the glass possessed the stark clarity of an Edward Hopper painting, which meant that Jimmy had pretended to be unable to see what had been plainly visible. A silly lie. A lie so small and to so little purpose that it suggested to Miles a way of life, a strategy for confronting the 
world, and this was further reason-if any was needed - to doubt the truth of everything the man had said inside (97).

Miles, since childhood, has been constructing an image of Jimmy as "sneaky and mean and envious and dangerous" (99). Whether it is because Jimmy wants Miles' approval or because he wants to prove himself superior to Miles, Miles resents being used as the yard stick against which Jimmy measures his own self-worth. Jimmy is the kid Miles is glad to have changed high schools to escape. In seeing Jimmy framed in the window-having caught him out in a meaningless lie-Miles experiences a clarifying of his thoughts about Jimmy's character that allows the reader to encounter this shift in vision once again from Miles' viewpoint. ${ }^{3}$

This reframing of Jimmy in the window points up an important reality about other sight and the lens of love, which has to do with both the nature of love as well as the practice of looking at another justly or lovingly. Love in common usage means something like feeling favorably disposed toward another, or feeling strong affection toward another. Lest my use of the lens of love be misunderstood to be merely a gilding of our images of one another, it is important to point out what I mean when I speak about love. As I have indicated, the love that stands as the lens through which we see others has less to do with feelings of affection, or even favorable disposition toward another, than with an attitude with which we view others as subjects worthy of our just attention, as worth taking seriously, and ultimately as worthy of giving uptake. ${ }^{4}$ When love is spoken of in our culture, its use is often associated with romance or fond sentiment, as with one's lover or one's friends or family. Its use commonly connotes feelings with strongly positive valence. Love, however, if only in common sense ways has as much to 
do with a commitment to another than with feelings toward another. That is not to say that the feelings of love are somehow unimportant; only that were love to exist merely as a positive feeling, one's relationship to the object of one's love would always be an open question, depending on one's feelings at any given moment. But love cannot operate solely as a feeling, since one does not feel continuously affectionate or positively disposed toward the beloved. If, for example, my love for my children depended on feelings of affection, I could regularly be accused of not loving my children when they disappoint me, or annoy me, or anger me. To say, "I love my children" is a different kind of statement from, "I am disappointed with my children." The first implies a state; the second can be either a state (as in, "I am perpetually disappointed in my children, since they have repeatedly failed to keep in touch with me.") or a simple episode (as in, "I am disappointed with my children, since I told them to load the dishwasher when I left, and they did not.").

Love as a state or commitment suggests a boundary inside which all sorts of emotions (often conflicting) can roam about without necessarily threatening the commitment. If I were to wait for these feelings of affection to emerge before acting lovingly toward my children, I could not parent them. Were I to need a swell of fondness to lodge itself in my heart before being prompted to act lovingly toward them, diapers would often go unchanged, meals would go uncooked, and tuition would go unpaid. I make these loving gestures even when I don't feel particularly solicitous or favorably disposed toward my children, because my love for them transcends my feelings for them at any one time. Love as a state of commitment helps to explain how it is that one can simultaneously love and despise the same person. 
Again, I am aware that I risk being misunderstood when I say that Miles looks lovingly at Jimmy Minty, since Miles's general feelings toward Jimmy involve antipathy, verging often on hatred. In fact, at one point, Miles breaks Jimmy's nose in an unprovoked act of hostility. However, I want to suggest that the commitment to community that runs throughout the novel, Empire Falls, requires more than positive feelings toward everyone. True community, where intersubjectivity is a possibility, requires a commitment to taking everyone seriously, to seeing them justly, to seeking to understand them in all their complexity, and not as we need for them to be. Miles, in continually working to see both Max and Jimmy clearly, foregoes the easier route of a static vision of them as set pieces in his own psychodrama, upon whom he can uncritically superimpose his own self-serving picture of who they are. Instead, Miles continually revises his understanding of those within the community - which is to say, even those he does not seem to like-in order to arrive at a clearer understanding of those who populate the world he inhabits.

Not all attending that goes on in community is emotional attending in a good sense. There exists, as I have suggested, bad attending — viewing others either as objects, abstracted from their life narrative or falsely through the filter of the "fat, relentless ego." Jimmy Minty, in another scene, sits again in his car waiting to be seen by Miles. Jimmy begins to think about his own father, a wife beater and small time thief, remembering his father's theories about how power is allocated in the world, such that a nameless "they" have everything figured out, even down to "who they'll let you marry" (281). Jimmy remembers thinking that he wants to choose his eventual wife-somebody like Miles's mother, Grace Roby. 
From where Jimmy sat in the living room he was able to see the Roby house across the driveway. Many evenings Miles's mother would pass behind their living room window, sometimes stopping to pull the curtains shut. At nine years old, Jimmy had thought Mrs. Roby the prettiest woman he'd ever seen, including girls, and he wondered what it would be like to live in the same house as her. He guessed maybe it'd be different if she was your own mother, but he couldn't imagine not having the hots for Mrs. Roby, no matter whose mother she was. He'd caught his father looking across the way a couple times, too. Jimmy had even made the mistake of telling Miles how lucky he was having her for a mother, all to himself, most of the time, Mr. Roby being gone as much as he was home. He'd also asked Miles if he'd ever seen his mother naked, hoping for a description, and Miles hadn't spoken a word to him for a week, until he apologized which Jimmy was quick to do, because he was afraid Miles would tell his mother that he was a dirty boy" (281-2).

Jimmy attends to Grace, but in a bad way. His gaze is framed in such a way that she becomes an object to be leered at, not a human being to be appreciated. ${ }^{5}$ It might be objected that this is a memory about a nine year-old boy, doing what nine year-old boys often do. I would agree that there is nothing exceptional about a young boy staring at a pretty woman. However, this is a story in which this particular anecdote is intended to be illuminative of Jimmy Minty's character. That the grown Jimmy Minty has this memory in the context of the story is intended to reveal something about the continuity of Jimmy's character - that is, as one who is the kind of person prone from very early on 
(and influenced by his father) to objectifying others. In fact, even Jimmy's son, Zack, who has had a previous relationship with Tick, is shown as a teenager to have an untrustworthy character. Miles hopes that a boy whom Tick has met on a vacation to Martha's Vineyard will "free his daughter from any lingering attraction she might feel for a boy [i.e., Zack] who, like his father and grandfather before him, bore more or less constant watching" (40). Jimmy is framed for the reader as someone who comes from, and contributes, to a long line of men of vicious character; and Zack is framed in the same way.

In two scenes involving Jimmy Minty, the view of others is both literally and metaphorically framed through a window. What is different is not the physical act of seeing, but the relationship of the spectator to the one being seen—good emotional attending versus bad attending. In the first case, the frame through which Miles sees Max and Jimmy reveals Max in a positive way, while Jimmy is viewed negatively — but in both cases the view offers clarification about the ones being viewed, since Miles sees with other sight. In the second case, Jimmy sees Grace Roby framed in a way that reduces her to a body to be possessed, a vision that obscures rather than reveals who she really is. It seems to me that Russo is aware of the metaphorical power of framing to objectify women - a commonplace of modern Western culture. However, by using a device that frames people in windows, under diverse circumstances, Russo helps to show that the vision of another is never straightforward. One can gain clarity of vision by gazing intently on another as a subject, or one can gaze at another in a distorting way that conceals as it abstracts and objectifies. Both are possibilities. 
Jimmy Minty and Francine Whiting offer a moral and emotional counterpoint in the novel to Miles and Tick. While Miles and Tick commit themselves to seeing others justly and lovingly, Jimmy Minty and Francine Whiting allow the reader to get a glimpse of the kind of character given over to bad attending. Selfish and conniving, Jimmy and Mrs. Whiting help the reader to understand that though the community can survive those whose emotional selfishness is evidenced by bad attending, their presence is ultimately corrosive. Additionally, not everyone in a community needs to get along, since the community is bound together by something stronger than any individual's personal preferences - that is, by some good or set of goods held in common by the community.

Another particularly telling scene of bad attending occurs when Miles is at the rectory of the Catholic Church, speaking with the young priest, Father Mark. The retired priest, Father Tom, who is suffering from the beginning stages of dementia, happens upon the conversation. In an act of bad attending, he fixes "Miles with a particularly menacing glare," and proceeds to call him "an evil bastard" (49).

"This is no evil bastard, Tom," Father Mark said calmly. "This is Miles, our most faithful parishioner. You baptized him and you married his parents."

"I know who he is," Father Tom said. "He's a peckerhead and his mother was a whore. I told her so too."

Miles sat back down. This wasn't the first time the old man inspired by only God knew what, had taken one look at Miles and offered a poor opinion of his moral character, though he'd never before insulted the memory of Miles's mother. This was clearly the man's dementia talking, but for the second time that 
afternoon Miles fleetingly considered how satisfying it would be to send another human being into the next world. This time, a priest.

"Look at him. Look at that face. He knows it's true," the old man said, taking in Miles's paint-splattered overalls. "He's a filthy degenerate is what he is. He's tracking his filth into my house" (49-50).

Father Mark tries to reason with the demented Father Tom to no avail. Father Tom continues to insist that Miles is "a peckerhead."

Father Mark, his patience exhausted, slid out of the booth and took him by the shoulders, rotating him gently but firmly. "Tom," he said, "look at me." When he continued to glare at Miles, Father Mark placed the tips of his fingers on the old man's stubbled chin, turning his head. "Look at me, Tom."

Finally he did, and his expression instantly morphed from disgust to shame (50).

A couple of important things happen in this scene that are noteworthy for my purposes. First, the whole idea of vision as the epistemological gateway to knowledge is reinforced. The knowledge that Father Tom arrives at about Miles comes from the way he looks at Miles. However, the way Father Tom attends to Miles is bad; his "menacing glare," is historically the one that he has used to view Miles. This glare, however, once again fails to reveal anything about Miles, but very much about Father Tom—which leads to the second notable point, having to do with the coupling of bad attending and dementia. Russo cleverly juxtaposes Father Tom's dementia with his inability to see Miles. What Father Tom continues to see when he glares at Miles is a picture that has 
nothing to do with who Miles really is (i.e., the parish's "most faithful parishioner), and everything to do with the barrier to Father Tom's sight—dementia. In effect, the reader is invited to make the connection between the loss of mental capacities that attends dementia and the inability accurately to attend to another person. I would not want to press the connection between dementia and bad attending too far, but its presence in the story summons the reader to assess the extent to which there is a relationship between Father Tom's bad attending and his gradual loss of himself. What is worth noting, however, is the impression we are left with that, though dementia is the obstacle to a clear vision of another in this instance, bad attending is characterized less by pathology than by a consistent failure to see another person in ways that reflect who he really is.

The view of others we receive from emotional attending does not tell the whole story, though. As I argued in Chapter Four, the way we understand the world does not come first from an interrogation of interiority, but through the way we are formed in community. I understand the world primarily not by radical reflexivity, but through the reflections of others. Emotional attending is an exchange, one in which one hopes to get a clearer image of another person, but additionally, one in which a view of oneself reflected in the eyes of another assists in providing a clearer vision of oneself. It is to this second part of emotional attending in Empire Falls we must now turn.

\section{The Mirror of Love}

In the previous section I mentioned that often what poses as knowledge of another is merely a projection of the self. Returning to the metaphor of sight, I suggested that rather than focusing upon another through a lens of love, it often turns out to be the case 
that vision is focused on a mirror instead of a lens. Hence, what one sees is not another subject, but the distorted reflection of oneself. What I want to argue in this section is that, counter-intuitive as it sounds, when I employ other sight to view another, the clarity with which I see the other also allows the mirror of another to reflect to me images of who I am in another's eyes. If, when I view others what I see is a distorted image of myself, then I gain neither real knowledge of others, nor real knowledge of myself. There are mirrors when attending to another that can clarify rather than distort, but clarity requires that the image viewed also first be viewed through the lens of love. It is possible, in other words, to see myself through the eyes of others when I emotionally attend them, when I use other sight.

In Empire Falls there are two particularly important examples of how seeing oneself through the eyes of another are formative. In the first instance, Miles's understanding of himself is shaped by the view his mother had of him, the expectations she set down for who he was to become. Miles remembers that

from the time he was a boy, he would look up from a book he was reading to find [Grace] quietly studying him. "My little scholar," she'd say, smiling. Later, in college, he'd been greatly attracted to the exciting life his professors seemed to lead, richly furnished with books and ideas worth arguing over, and he'd thought that maybe his mother was right, that the life of the mind was his own truest destiny. One thing was for sure. He'd never aspired to feeding other professors twice-cooked noodles for a living (202). 
Grace's vision of Miles gives shape to his own vision of himself, and what he is ultimately destined for. Miles realizes that she wants nothing more than to be able to know that he is able to move away from Empire Falls-which is to say, to escape the life she has led. So that when he fails to live up to Grace's image of who he is supposed to be, he sees his failure reflected in his mother's eyes. In one flashback scene, Miles has quit college to return home in the final semester of his final year, because his mother is dying. However, he cannot bear to be around her, because he sees her disappointment in him, as a result of his quitting college and returning to Empire Falls. An important question from Grace haunts his time with her: "Didn't he realize, she kept asking, that the mere sight of him only increased her suffering?" As the flashback continues to unfold, a scene on one particular night shapes Miles's vision of himself, seen through his mother's eyes. Miles finally goes to see his dying mother, who "was awake when he appeared, and upon seeing him in the doorway she'd simply turned her head and looked away, a gesture so eloquent in its futility that it had backed him out into the hall" (451). The problem for Miles is that because he loves his mother, when he sees himself in the way she sees him, his failure to live up to the expectations she has had for him (and therefore, that he has had for himself) is overwhelming. He cannot bear the image of himself that he sees, and must retreat from it.

The reader, however, is invited to assess Miles' choice to return to Empire Falls and tend to his mother sympathetically. Though by his choice Miles is prevented from living out the dreams his mother had for him, it is this choice that allows him the opportunity to become one who is with and for others in Empire Falls. Miles grows into the kind of person whose life is centered not on himself, but on others. Over the course 
of the novel, the reader can see that the act of coming back to Empire Falls ties Miles to a community that helps to shape him as one who is capable of attending to the emotional lives of others.

That Miles finds Empire Falls a community capable of fostering intersubjectivity does not mean that everyone finds it so. One young man, John Voss, a student in Tick's art class, cannot bear the vision of himself that he sees in everyone else's eyes. John Voss is a victim of bad attending in the novel. In one scene Tick Roby and John Voss are eating lunch by themselves in the cafeteria, having been put there together by the principal in an effort to find someone with whom John Voss can connect. Tick sees that John Voss—-whom we eventually learn has been living by himself in his grandmother's trailer, months after she has died-is hungry. She offers to share her sandwich with him, but he declines, telling her that he is full. Though because of his blank affect and reluctance to communicate, John Voss is not immediately a sympathetic character, the horrible nature of the details of his life inspires a certain kind of sympathy in the reader. We see him as a largely forgotten young man, consigned to the margins of the community. Expecting little from anyone, his pessimism about the community's ability to meet his needs is regularly confirmed, either through being ignored or through outright hostility.

Tick and John Voss are supposed to be alone in the cafeteria because of the special arrangement made by the principal, "when the boy's eyes flicker at something over her shoulder" (184). Just then "Tick glances at the cafeteria, where Zack Minty is framed, motionless, in one of the small rectangular windows" (184). Zack's appearance startles Tick, so that "she nearly flinches, since something the stillness of the face in the 
tiny window suggests that it's been there for a long time, observing them" (184). Tick's reaction to the framing of Zack in the lunchroom window offers a cue to the reader about the ominous nature of Zack's sudden appearance. However, we notice that not only is Zack framed in the window, but that from his perspective, Zack is busy framing Tick and John Voss, having apparently "been there for a long time, observing them" (184). In Zack's case, though, it soon becomes apparent to the reader that Zack's attending has little to do with trying to see Tick and John Voss as subjects; if we see Tick and John Voss through Zack's eyes, we see only characters on display in Zack's own drama. They are, in Zack's mind, there with and for him—and not he for them.

Zack Minty, still reeling from Tick's breakup with him, enters and comes over to where Tick and John Voss are seated. Like virtually everyone else in John Voss's life, Zack torments him. Zack, a bully like his father, Jimmy Minty, focuses on John Voss. But Zack can only see John Voss as something less than human. The reader senses John Voss' vulnerability as Zack fixes him in his gaze. Russo writes: "Zack hasn't looked at [Tick] yet, but is staring at John Voss as if searching in vain for a reason for this kid's existence" (185). Zack, with no reason apparently other than to torment, picks up a quarter lying on the table and throws it at John Voss, hitting him in the forehead. John Voss does not flinch. This detail provides the reader with an insight into the kind of barriers to social interaction John Voss erects to protect himself—especially given that the reader has just learned that Tick "nearly flinches" when she glimpses Zack framed in the window. The lack of a reflexive flinch, which might be seen in someone else as courage or stoicism, appears in John Voss to be either an inability to feel anything, or perhaps just a simple resignation to the pain and indignity of life on the periphery. 
Zack finally shifts his attention from John Voss to Tick, wanting to know why she refuses to give him a second chance. He turns to John Voss and asks, "Why don't you go away?" adding that "my old girlfriend is going to explain why she doesn't like me anymore" (186). John Voss retreats to the other side of the cafeteria, sitting down at another table, and turning his back to them. Tick watches him go, surprised that he is so easily cowed, but observes that "he's apparently come to accept humiliation as his lot in life, perhaps even made it his friend" (186). Tick's perception of John Voss' humiliation tells the reader something about Tick's ability in the midst of a tense situation to use other sight to see the resignation in a figure almost everyone else seems content to ignore. Once again the reader is invited to understand John Voss' life as one in which humiliation seems to be an inevitability.

Zack continues to torment John Voss, calling him "dickhead," until Tick finally agrees to leave with Zack. She is furious that Zack treats another human being this way, and tries to distract Zack from his abuse of John Voss. Finally, outside the doors of the cafeteria, Tick asks Zack why he acts this way. Zack, laughing, says he has no idea. Tick "knows better than to glance over her shoulder at the small rectangular windows of the cafeteria doors, but she does so anyway and regrets it immediately, wishing she hadn't glimpsed John Voss taking a hungry bite out of her leftover sandwich" (190). It is this "glimpse" that reveals John Voss as a young man who is not only hungry, but who is ashamed of his need — both his physical need of food, as well as his emotional need to be engaged as a subject by another human being. Moreover, Tick is also revealed by this glimpse to be a person whose attending to others, because she has so successfully cultivated this virtue, is almost reflexive. ${ }^{6}$ Once again Russo uses a window as a way of 
framing vision, as a way of suggesting a new understanding of another person through the presentation of visual cues.

After it is discovered that his grandmother is dead, her body having been tossed on a garbage heap, John Voss runs away. He stays gone for over a week, until showing up one day back at school. Tick watches him approach the building through a window in the art room. She tries to fix him in her vision, but he keeps shifting in and out of focus, head bobbing between visual obstructions. That John Voss shifts in and out of focus draws the reader's attention both to the particular difficulty in trying to attend to someone who- because of the walls of protection with which he has surrounded himself-is so elusive. Moreover, the reader's attention is drawn to the broader truth about the ongoing and perfectible nature of emotional attending, which assumes, as I have said, constant revision. That is to say, people continually move in and out of focus.

At length, John Voss enters the room, carrying a folded grocery bag. And even Tick, the person who has tried most valiantly to attend emotionally to him, can't help but wish he had not returned: "One look at him now—head down, shoulders hunched forward, resolutely silent, as if he thinks he can walk into art class and take up where he left off-brings back to her the thoughts she'd tried so hard to ignore last week, which she was too embarrassed to admit even to her father: that everyone was better off with this boy gone" (445). Tick continues thinking as she watches him, concluding that

No, his disappearance has been a blessing, allowing the whole horrible story [of finding his grandmother's body in a garbage dump] to recede from public consciousness. True, for the last five days everyone in Dexter County was looking for him, but the truth is, nobody hoped to find him. Is there a term for 
that? Tick wonders. The thing everyone is searching for and hoping not to find? The thing you're secretly glad has made a clean getaway, lest you yourself be blamed should it ever be located (446).

In a very short period of time John Voss has gone from a tormented loner-not an optimal state, to be sure, but at least a human being - to a non-person, one nobody wants to find, one who is considered refuse, worthy of being tossed on another kind of garbage dump. In short, people have failed finally to attend to him as a subject at all, but merely as an object, worthy of abstraction from the life narrative that helped to shape who he is, or perhaps only as a projection of people's darkest fears about themselves. This failure to attend to John Voss is a community failure. As I indicated earlier, communitieswhen they set down bad ends (teloi), or when they fail to live up to good ends—can stand in the way of human flourishing. In any case, this sort of bad attending on a comprehensive scale prevents John Voss from seeing himself or others any longer as human beings. His appearance, that is, the way he looks to others, is described as animallike, complete with a "rancid smell," his clothes "wet and caked with dirt," and "his hair knotted with bits of leaves and twigs" (446).

As Tick watches in terror, John Voss pulls a gun from the grocery bag, and after firing four fatal shots, "John Voss slowly turns to look at her" (447). The question arises for the reader about what John Voss sees as he observes the one person who has attempted to look at him through the lens of love. The reader, who has followed John Voss' alienation from the community, is able to see the end result of the dehumanizing effects of bad attending, as the attempt of one human to attend to his emotional life is finally not enough. Tick, as frightened as she is, 
faces John Voss as bravely as she can, knowing it will all be over soon. Her vision has now narrowed to the point where she can barely make him out, his face bloody, his eyes almost sad. When he speaks, his voice comes from a long way off. "This is what I dream," he tells her, in answer to the question she asked him so long ago. Then he squeezes the trigger, and she hears what she is certain will be the last sound she will ever hear, and feels herself thrust backward into blackness" (447).

There is, of course, no literal causal relationship between Tick's losing sight of John Voss and his violence. However, I would argue that metaphorically it is precisely John Voss's fading from sight, that is, his slipping from the attention of others within the community that calls into question his humanity—causing him to feel as worthless and abandoned as others view him. He finally becomes Aristotle's man without a polis—a beast, and clearly not a god. Even Tick ultimately loses sight of him, feeling "herself thrust backward into blackness." That Tick finally loses sight of John Voss is significant, inasmuch as Tick has occupied a primary moral focus of the novel, the one person willing to try to see him as a human being, a subject with dignity and desires and projects. Tick's inability in the end to focus on John Voss because he has been rendered nearly invisible—since Tick alone has proven herself willing to attempt emotional attending with someone on the extreme margins of the community—lodges itself as a significant critique of the community of Empire Falls.

Finally, John Voss turns the gun on himself, while Tick blacks out. Miles Roby is escorted through the police cordon, where he kneels at his daughter's side, saying her 
name repeatedly. She has withdrawn into herself, presumably as a defense mechanism against the chaos and fear. Miles loses track of how often he calls out Tick's name "before her eyes flickered, or how many more before they came into something like focus" (455). When her eyes finally do focus on her father, "she saw him for who he was. In that instant she was suddenly back, and her expression first relaxed, then came apart, and she was sobbing, "Daddy, Daddy, Daddy" (455). It is this sight of Miles that orients Tick, reminding her of who she is, and where she is located, not only her own life narrative, but in the life narrative of the community. That is to say, she comes to find out who she is through the intersubjective connections that anchor her to the reality of her life, through the lens that focuses loving attention onto the mirror of love, all of which is described metaphorically as a function of the faculty of sight. Though the community fails utterly sometimes, as is the case with John Voss, the town of Empire Falls nevertheless provides a context in which people like Miles and Tick can learn to attend to the emotional lives of others. The intersubjective connections that make community possible, and that which threatens it, however, need a bit more attention.

\section{The Ties that Bind . . . and Loose}

What Empire Falls offers is a way of viewing the texture of community and the nexus of relationships that sustain (define?) it. Those relationships, and therefore, the community capable of fostering human flourishing, depend upon intersubjectivity, upon the ability of those within the community to attend to one another emotionally, to view one another with other sight. People come to know who they are through these communal connections. When the community fails a member, though, not only is the life 
of the individual affected but the very fabric of community can be threatened. In the aftermath of the school shooting, Miles takes off with Tick to Martha's Vineyard in an attempt to protect her from the shockwaves he believes the tragedy will give off; Jimmy Minty starts drinking and is arrested for possession of stolen goods when the police find a number of stolen appliances in his home; Francine Whiting sells everything, but drowns before she is able to move out of Empire Falls.

Communities, though, because they are complex organisms, educate and form people in different ways. Jimmy Minty, for instance, offers one view to Miles of the difference between the ways people are formed in the community of Empire Falls. It is worth quoting at length:

Thing is, Miles, people in this town like you. A lot of people. You got friends, even some important friends. I admit it. But here's something that might surprise you. People like me too. Something else? I got friends. Might surprise you to hear we even got some of the same friends. You're not the only one people like, okay? And I'll tell you something else. What people around here like best about me? They like it that they're more like me than they are like you. They look at me and see the town they grew up in. They see their first girlfriend. They see the first high school football game they ever went to. You know what they see when they look at you. That they ain't good enough. They look at you and see everything they ever done wrong in their lives. They hear you talk and maybe they're thinking the same thing you are, except they can't say it like you do and they know they won't ever get any credit. They see you and your buddy the principal with your heads together, deciding how things are gonna be, talking 
the way you talk and making your little jokes, and they know they'll never get no place with either one of you, not ever. But me? Maybe they might just get someplace with me, and that's why they like me (295-6).

Leaving aside the issue of Jimmy's arguably skewed vision of his and Miles's roles—an interesting case of projection, it would seem—this passage points up the ways we are bound together, that teach us to see ourselves and others not as atomic individuals, roaming about as totally unencumbered private selves and moral free agents, but as interconnected in ways that help us to learn who others are, as well as who we are as a result of those connections. The clarity of both our knowledge of others and of ourselves depends, as I have argued, on our abilities to attend emotionally to one another, to see one another justly or lovingly.

The character of the relationships in Empire Falls relies on the kind of commitment to seeing one another with other sight. It is when other sight is lost entirely, as in the case of John Voss, that not only is an individual lost, but the very web of social relationships is threatened. This community is symbolized by the Empire Grill, where people come repeatedly to be in one another's company_again, even those who do not particularly like one another. Miles's ex-wife, Janine, and her obnoxious soon-to-be husband, Walt Comeau, are regularly in attendance-a fact that vexes Miles, in particular. Max, Miles's father, is often there, exasperating Miles with his requests for money, his surreptitious dipping into the till. Miles's brother, David, the former alcoholic works at the grill, as does Charlene, a waitress Miles has had a crush on since he was a young teenager. Tick is there, struggling to makes sense of adolescence in the presence of a father who is also struggling to make sense of her adolescence. Even John 
Voss, the one who imperils the continued existence of community, is at the Empire Grill, having been given a job after Tick entreated her father to take him on as a dishwasher. A host of characters, bound together, and congregated in the Empire Grill, which acts as a metaphor for the wider community — which is to say, a group of people who live in relationship to each other not because they agree, but in spite of the fact that they almost never do.

The Empire Grill, I would suggest, operates in the novel as a kind of synecdoche of the larger community of the town of Empire Falls; it is a microcosm, at the very least, of the kind of people, fears, joys, conflicts, and so on that also arise in the town. And while Empire Falls will most likely never mirror Aristotle's vision of a true polis, inasmuch as it makes no claim to be able to identify the highest human good in a way common to all its inhabitants, it can nevertheless aspire to being a community, in which the lesser goods of concord, a just economic system, and friendship can be held in common, prompting the cultivation of the virtues necessary to realize those goods. And, as my argument suggests, good emotional attending is at the cohesive center of this kind of community, since it allows people to be valued as human subjects, and helps to avoid the alienation and enmeshment that threatens community. In this way, emotional attending is basic to intersubjectivity, which in turn is a necessary condition for flourishing. Consequently, when Miles and Tick attend to the emotional lives of those around them, they strengthen the context in which flourishing can occur. That is to say, in the kind of circular logic of virtue ethics, as Miles and Tick practice the virtue of emotional attending in Empire Falls, they make it more likely that the virtue of emotional attending will be learned and performed by others—since they are helping to sustain a 
community characterized by intersubjectivity, which can, in turn, produce people capable of the virtue of emotional attending.

What the Empire Grill and the town of Empire Falls share is a common locus, a space not bounded by geography, but by their commitment to showing up, when often showing up seems the least rational thing to do. The Empire Grill is at the heart of the metaphor of community in Empire Falls, where identities are shaped and influenced by the nature of the relationships that bind people together, ultimately freeing those people to live as human beings, to pursue their dreams and desires, knowing that they have a stable platform from which to venture out into the world. So that when Mrs. Whiting seems to regret the decline of the restaurant and wonders "out loud why she [needs] the aggravation of a business that [produces] so little revenue" (37), we may read that not only literally, but also as a commentary on a community that seems to produce so little in the way of relational "revenue." In other words, the Empire Grill operates as a place where people continue to come together; but it often seems as though things change so imperceptibly between people that the Empire Grill suffers from inertia. And yet, in the same manner that the absence of actual revenue generated does not tell the whole story of the value provided by the Empire Grill to the community, the quality and sustaining power of the relationships formed at the Empire Grill cannot be quantified in terms of the relational "revenue" of immediately perceptible change. Nevertheless, there are also occasions "when Miles himself had become discouraged and offered the same argument" to Mrs. Whiting (37). It is upon these occasions that Mrs. Whiting sees the necessity of the Empire Grill, the necessity of community, urging "him not to give up, reminding him that the Empire Grill was a landmark, that it was the only non-fast-food establishment in 
town, and that Empire Falls, if its residents were to remain at all hopeful about the future, needed the grill to survive, even if it didn't thrive" (37).

That which finally endangers community in Empire Falls is a failure of attending, when the community loses sight John Voss, noticing him—if at all—as something less

than human. Not only is community threatened in a literal, physical way by the killing of some of it members, but also in terms of instersubjectivity. To the extent that emotional attending is like a virtue, it requires the cultivation of habits, which lead to flourishing. When bad attending occurs, like a vice, it also is the product of habits- only the habits of bad attending are insidious, leading not to flourishing but to isolation, to the dissolution of the ties that bind the community together, or in other cases, to a further enmeshing that encourages the view of others as extensions of oneself. Imperfections in emotional attending, lapses of loving attention, are to be expected inasmuch as attending is "infinitely perfectible." However, bad attending that leads to the utter alienation of one of the community is corrosive to the community, potentially even deadly. This bad attending can come either as vicious and intentional bad attending (e.g., Zack Minty's bullying of John Voss) or as neglect (e.g., the community's negligence of John Voss). And it is precisely this threat to community in the person of John Voss that literature lets us imagine.

\section{Literature and Imagination}

failbetter: Empire Falls is a timely work that has some clear connections with the problems of modern day society. I am referring to the implications of the troubled boy John Voss. Did you find yourself writing about the tortured school teen from 
the angle of an inquisitive author, or more from the view of a real life parent seeking a plausible explanation for such tragedies?

Russo: I'd been thinking about school violence since the incident in Paducah, however long ago that was, and I was right in the middle of writing Empire Falls when the events at Columbine took place. I'm not sure I can separate the inquisitive author and terrified father functions, at least not now, after the fact. But after the Columbine shootings, when everyone was asking why, I remember thinking (in inquisitive-author-mode) that answering this kind of question is what fiction is best at. The sociological explanations for school violence-the easy availability of guns, too much violence in the media, too little parental supervision of today's youth—are not terribly satisfying. We suspect that if solutions to these very difficult problems could be engineered, the question of why would still remain. What we really want to know is more like, What did it feel like to aim the gun and pull the trigger? What sequence of events led to this moment? The only knowledge that will be even remotely satisfying is the kind that comes from living that horrible moment imaginatively and understanding what led up to it. That's what literature offers us-the visceral experience of the living moment. So, yes, I was interested in investigating that. But it was out of my role as a terrified parent that the book really grew, I suspect. Like Miles Roby, I've often thought that as parents we have to be vigilant, and the first chapter of the novel opens with Miles anxiously awaiting his daughter's return from school, hoping to catch sight of her, to make sure she's okay. What Miles also knows (and I fear) is that no matter how vigilant you are, the moment you're needed most, you'll likely be elsewhere, 
dealing with some other distraction. Such knowledge is the basis for parental night sweats, and I've come to think of this book in exactly those terms--one long, vivid, parental night sweat ("Interview with Richard Russo, failbetter.com http://www.failbetter.com/04/Russo.html).

One of the things literature does, as I have argued in Chapter Five, is to offer us creative worlds in which to have emotional experiences that we might not otherwise have occasion to have. Having these experiences gives us more extensive emotional resources with which to attend emotionally to others. Since good emotional attending requires that we have some understanding of another's emotions, we are in the position of admitting that many of the emotional experiences of others will be unfamiliar to us as actual experiences. However, it is possible to experience emotions, at least in some partial or simulated way, through reading literature. Because emotions are not cognitive, as I suggested in Chapter Two, but are affective appraisals--which is to say, something like trip wires that trigger physiological, and then cognitive, responses to stimuli-emotions may be elicited by imaginatively inhabiting the emotional experiences of characters in literature. In other words, literary characters need not be "real" to prompt emotional experiences within the reader. And having these emotional experiences through literature allows us better to recognize the same sorts of emotional experiences in those to whom we attend.

In Empire Falls Richard Russo explores the emotional abandonment of John Voss, wondering what it took to drive him to commit wanton murder, what it might have felt like committing the act itself. Russo believes that imaginatively exploring the emotional lives of his characters, in this case, John Voss, he can begin to arrive at some 
answers about what motivates people to do what they do. He suggests that "sociological explanations" - that is, those answers calibrated to render a scientific analysis-fail to satisfy, since scientific analysis cannot speak intimately to the issue of individual motivation. Individual emotion requires context, a locatedness within a story that takes into account life narrative. Science cannot satisfactorily provide an adequate causal account that makes motive intelligible - since individuals respond differently, even to the same situations. To provide such an account, we need practice in the virtue of emotional attending, of seeing human subjects with other sight, of understanding people as complex human subjects, of recognizing individuals as members of nexuses of communal relationships. In Empire Falls the reader finds two people, Miles and Tick Roby, who are involved in trying faithfully to attend to the emotional lives of others. Through the attempts of Miles and Tick to attend, the reader is offered an opportunity to see an embodied manifestation of what it looks like to attend to others. Moreover, the reader is invited to simulate a wide variety of emotional experiences - from the anxiety of a father for his teenage daughter's well-being to the wistfulness of a man who has come to question the choices he has made in life, from the struggle of an adolescent in finding out who she is, and in light of that knowledge, how she ought to treat other people (even those very different from her) to the feelings of alienation that result from the object of bad attending.

Russo contends that what literature offers us is "the visceral experience of the living moment." Through literature it is possible to imagine what it might feel like, for example, to be abandoned by the community, to be lost from the sight of those who help shape one's identity, and to feel like one no longer has a home. To be able in some way 
to begin to understand the emotional life of another in the imagination makes the possibility of recognizing it in another who is actually having similar experiences that much more likely. And that understanding is necessary to preserve the community, necessary to the context in which flourishing is made possible. 


\section{NOTES}

\section{CHAPTER ONE: THE LENS AND THE MIRROR}

${ }^{1}$ An exact date for the development of clear glass is elusive. However, credit for the perfecting of clear glass probably goes to the island of Murano, adjacent to Venice. Cristallo glass, thin, flawless, and colorless, is first mentioned in 1409. See Alan Macfarlane and Gerry Martin, Glass: A World History (Chicago: University of Chicago Press, 2002) 21.

${ }^{2}$ The development of the microscope is generally attributed to a father and son, Hans and Zacharias Janssen in the mid 1590s. See, for example, Robert E. Krebs, Scientific Development and Misconceptions through the Ages: A Reference Guide (Westport, Conn.: Greenwood Press, 1999) 44. Zacharias Janssen also found himself in a dispute with Hans Lippershey over the development of the telescope in 1608 , the news and the implications of which were not lost on Galileo who subsequently popularized the technology. See Brian S. Baigrie, History of Modern Science and Mathematics, 4 vols. (New York: Charles Scribner's Sons, 2002) 47.

${ }^{3}$ The Venetian brothers, Andrea and Domenico d'Anzolo del Gallo applied for a patent on a new kind of shiny backing for glass in 1507 that created the first truly detailed mirror. See, for instance, Mark Pendergrast, Mirror Mirror : A History of the Human Love Affair with Reflection (New York: Basic Books, 2003) 119. See also Lewis Mumford, Technics and Civilization (New York,: Harcourt, 1963) 129-30.

${ }^{4}$ For more on the correspondence theory of epistemology, see Bradley P. Armour-Garb and J. C. Beall, Deflationary Truth, Open Court Readings in Philosophy 1 (Chicago: Open Court, 2005). Richard A. Fumerton, Realism and the Correspondence Theory of Truth, Studies in Epistemology and Cognitive Theory (Lanham, Md.: Rowman \& Littlefield Publishers, 2002). Michael P. Lynch, 
The Nature of Truth : Classic and Contemporary Perspectives (Cambridge, Mass.: MIT Press, 2001).

${ }^{5}$ For a detailed discussion of what is at stake in the argument over Cartesian representations see Alison Simmons, "Are Cartesian Sensations Representational?," Nous 33.3 (1999). I am aware of the difficulties associated with a philosophical use of the word "representation" with respect to the relationship between the intellect and the extramental world. Simmons lists some of the questions raised by the use of representation: Does the mental representation have to present the thing to the mind just exactly as it is in extramental reality? Does the thing have to be part of the causal chain that produces the representation? Can there be mental representations of potentially but not actually existing things?" Engaging those important questions, though, is beyond the scope of the modest story I am trying to tell about the rise of reason in the West as the dominant way of knowing about the world.

${ }^{6}$ However, Locke is quick to say that an innate idea of God is unnecessary since "the visible marks of extraordinary wisdom and power appear so plainly in all the works of the creation, that a rational creature, who will but seriously reflect on them, cannot miss the discovery of a Deity," in John Locke, An Essay Concerning Human Understanding, ed. Alexander Campbell Fraser, [New ed. (New York: Barnes \& Noble Books, 2004) 39.

${ }^{7}$ A view of imagination similar to this will be explored in Chapter Five.

${ }^{8}$ It is important to point out that Kant's Copernican Revolution was not a suggestion that there exists no mind-independent reality, but that there is no way finally to have access to that reality prior to the structuring of the mind that allows us to experience that world. Kant, in other words, is not arguing that the reality of the world is a subjective projection outward; instead, the world that exists independent of the mind can only be intelligible through the conceptual framework made available by the mind. Johann Fichte, a short time after Kant, argues for just such a subjective projection: "You realize then that all knowledge is only knowledge of yourself, that your consciousness never goes beyond yourself, and that what you take to be a consciousness of the object is nothing but a consciousness of your positing of an object which, in accordance with an inner law of your thought, you necessarily engage in together with sensation" in Johann 
Gottlieb Fichte, The Vocation of Man, trans. Peter Preuss (Indianapolis: Hackett Pub. Co., 1987)

45.

${ }^{9}$ Aristotle disagrees with Plato over some matters related to morality, though, for example, the precision with which political science can be studied.

${ }^{10}$ Aristotle, Nicomachean Ethics, trans. Terence Irwin, 2nd ed. (Indianapolis, Ind.: Hackett Pub.

Co., 1999). Cited hereafter as $E N$.

${ }^{11}$ In fact, Iris Murdoch argues that, even for Plato, uninspired replication does not adequately describe the work of mimesis. She writes, "Surely art transforms, is creation rather than imitation, as Plato's own praise of the 'divine frenzy' must imply," in The Fire \& the Sun : Why Plato Banished the Artists (Oxford [Eng.]: Clarendon Press, 1977) 7.

${ }^{12}$ Aristotle, Poetics, trans. M.E. Hubbard, Aesthetics: The Classic Readings, ed. David Cooper (Oxford: Blackwell, 2002). Hereinafter cited as Poet.

${ }^{13}$ A.D. Nuttall, Why Does Tragedy Give Pleasure? (Oxford: Clarendon, 1996), 37.

${ }^{14}$ Stephen Halliwell, Aristotle's Poetics (Chapel Hill: Univ. North Carolina Pr., 1986), 58.

${ }^{15}$ Lorraine Gaston and Peter Galison make the same case for the objectivity/subjectivity binary, by saying that they "define each other, like left and right or up and down. One cannot be understood, even conceived, without the other" in Lorraine Daston and Peter Galison, Objectivity (New York: Zone Books distributed by MIT Press, 2007) 36-7.

${ }^{16}$ While it might appear that Plato's view of women should be read through the lens of Book VII of The Republic as egalitarian or proto-feminist, Morag Buchan has argued that this view of Plato does not take into account Plato's strong view of the inequality between men and women as a general matter. Although Plato admits that in theory women and men have equally innately distributed qualities, he hastens to add that women "are the weaker sex in all respects" (455e). Nevertheless, as Buchan points out, "That some talented women may show Guardian potential and must cease to be private wives and mothers does not alter the fact that it is men, not women, whom Plato releases from the stricture of family since it is men, not women, who have the highest capacity for virtue and who will become Philosopher Kings. They must consequently be placed in an environment which is protected from the worst aspects of family and female nature, so that 
their full potential may be realized" in Morag Buchan, Women in Plato's Political Theory

(London: Routledge, 1999) 154. To the extent that Plato understands women having any equality with men, it is an equality tempered by "the inherent inequalities in human beings and the inherent differences between men and women" (154).

${ }^{17}$ In using political to describe the relationship between the male/female binary and the reason/emotion binary I am following Terry Eagleton: "I mean by the political no more than the way we organize our social life together, and the power-relations this involves" in Terry Eagleton, Literary Theory : An Introduction : Anniversary Edition, Anniversary ed. (Malden, MA:

Blackwell Pub., 2008) 169.

${ }^{18}$ C.f. Iris Murdoch, who states: "Moral language which relates to a reality infinitely more complex and various than that of science is often unavoidably idiosyncratic and inaccessible," in Iris Murdoch, Sovereignty of Good, Routledge Classics (London: Routledge, 2001) 33.

${ }^{19}$ Interestingly, Genevieve Lloyd points out that "In western thought, maleness has been seen as itself an achievement, attained by breaking away from the more 'natural' condition of women," in Genevieve Lloyd, The Man of Reason: "Male" And "Female" In Western Philosophy (Minneapolis: University of Minnesota Press, 1984) 38.

${ }^{20}$ See, for example Lorraine Code, Epistemic Responsibility (Hanover, N.H.: Published for Brown University Press by University Press of New England, 1987)., and Lorraine Code, What Can She Know?: Feminist Theory and the Construction of Knowledge (Ithaca: Cornell University Press, 1991). Alison M. Jaggar, "Love and Knowledge: Emotion in Feminist Epistemology," Women, Knowledge, and Reality : Explorations in Feminist Philosophy, eds. Ann Garry and Marilyn Pearsall (New York: Routledge, 1992). Lloyd, The Man of Reason: "Male" And "Female" In Western Philosophy.

${ }^{21}$ I should point out that I am by no means unaware of the irony that attaches to my use of postEnlightenment literature as a way of talking about the turn to the self. There can be no doubt that the literature I use in this endeavor is made possible, in large part, by the emphasis on interiority that begins with St. Augustine, and is eventually picked up in earnest by Descartes. The psychological depth evident in Western literature after the Enlightenment is an important 
manifestation of the story I am trying to tell. Consequently, I want to be clear that I understand my indebtedness to the very trend I am critiquing. What is problematic, and therefore, what I am addressing has primarily to do not with the familiarity one has of one's interior self; I believe that to be largely a good thing. Instead, I am seeking to call into question an orientation that points people first toward the self as the primary referent for meaning, value, and purposes, rather than to some exterior authority.

${ }^{22}$ Code, What Can She Know?: Feminist Theory and the Construction of Knowledge 52.

${ }^{23}$ By "influence" I am speaking specifically of Kant's understanding of heteronomy (i.e., external inclination to action), as opposed to autonomy (i.e., action that emerges as the product of the individual's free will—which is, to Kant, a necessary precondition for establishing moral agency). ${ }^{24}$ I understand that the idea of identifying social contractarianism as encouraging the privileging of the individual as the center of political life seems counter-intuitive. However, when it is realized that the social contract (as it has come down to us in modern liberal democracy) acts as a tool for the securing of political goods for the individual, who agrees to act in concert with others for the purpose of advancing individual self-interest, the truth that it is the individual who is the focal point of the social contract begins to emerge.

${ }^{25}$ It is important to point out, however, that Taylor makes a distinction between Augustine and the Cartesian tradition of interiority. Augustine, though radically reflexive, escapes the charge of radical subjectivity inasmuch as for Augustine it was not the self, but God who occupied a position above the individual's reason. For Augustine, the self was merely the beginning of the journey toward reason — not its final destination. Truth, for Augustine was not something one manufactures according to one's own specifications (Taylor 133).

${ }^{26}$ Gareth Matthews, "Consciousness and Life," Philosophy 52 (1977), 25 in Richard Rorty, Philosophy and the Mirror of Nature (Princeton, N.J.: Princeton University Press, 1979) 51.

${ }^{27}$ I use culture here not in the anthropologically and sociologically specific sense of identifiable people groups, delimited by geography, nationality, ethnicity, and so forth. Instead, I use it here in a much more expansive global sense that includes local cultures, but that also transcends those local cultures, including them in a broader sweep of time-almost epochal in its scope. 
${ }^{28}$ Aristotle, Politics, trans. C. D. C. Reeve (Indianapolis, Ind.: Hackett Pub., 1998). Cited hereinafter as $P o l$.

${ }^{29}$ C.D.C. Reeve says that Aristotle uses prior in three different ways: 1) $\mathrm{X}$ is prior in nature to $\mathrm{Y}$ if $\mathrm{X}$ can exist without $\mathrm{Y}$, but $\mathrm{Y}$ cannot exist without $\mathrm{X}, 2) \mathrm{X}$ is prior in substance to $\mathrm{Y}$ if an only if $\mathrm{X}$ is more nearly perfect or more complete than $\mathrm{Y}$, or 3) $\mathrm{X}$ is prior in definition (or formula) to $\mathrm{Y}$ if and only if $\mathrm{X}$ is mentioned in the definition of $\mathrm{Y}$ but not $\mathrm{Y}$ in the definition of $\mathrm{X}$ in Aristotle, Politics 258.

${ }^{30}$ See especially the chapter, "Trade in the Northern Half of Central-Eastern Europe: Great Poland, Pomerania, Prussia and Mazowia" in M. M. Postan and H. J. Habakkuk, The Cambridge Economic History of Europe, 2nd ed. (Cambridge,: Cambridge U.P., 1966).

${ }^{31}$ That Luther was an Augustinian monk I take not to be entirely coincidental in setting a precedent for Luther's own radical reflexivity.

${ }^{32}$ Perhaps not coincidentally, it is important to note that if Luther's presumption of interiority as the ground from which springs true devotion appears anti-Aristotelian, it is because, as Diarmaid MacCulloch points out, Luther disapproved of Aristotle, a philosopher for whom "he developed a lifelong hatred." Diarmaid MacCulloch, The Reformation, 1st American ed. (New York: Viking, 2004) 117.

${ }^{33}$ George Bush and Dick Cheney's ignoring of the anti-war resolution put forward by 96 United Methodist Bishops (the denomination to which they both belong) on November 9, 2005 calling for an end to the war in Iraq is but an instantiation of Luther's two kingdom theory, coupled with the anti-authoritarian, anti-ecclesiological realities of American Christianity.

${ }^{34}$ It must be emphasized, however, that Kant would not recognize the modern use of "private"; I am merely pointing out here how it is that Kant's ideas have come to be used-that is, as undergirding the turn to the self. Private, for Kant, does not anticipate the interior space occupied by the individual and her "personal" convictions and projects—-the notion of which is itself intelligible only as a post-Enlightenment product of modernity. Rather, private, for Kant, signifies an identifiable role one takes on publicly, but with commitments to a particular community, guild, or set of practices, which is why Kant uses as examples clergy, academics, and military officers. 
In that sense, then, one is not free to assume a public role, without submitting oneself to the rules of the community or guild to which one has gained access. A military officer qua military officer, for instance, is not free to disobey an order from a superior (for Kant, duty is duty, after all). However, as a public function of being recognized as a credentialed master of a particular community or guild (i.e., as a scholar of that discipline), one is freed up to - for Kant, perhaps, responsible to - offer up reasoned argument and critique when the order is in error See his discussion of private and public in Immanuel Kant, "What Is Enlightenment?," On History, ed. Lewis White Beck (Indianapolis,: Bobbs-Merrill, 1963).

${ }^{35}$ See Kant's discussion of agency in which he writes: "The autonomy of the will is the sole principle of all moral laws, and of all duties which conform to them; on the other hand, heteronomy of the elective will not only cannot be the basis of any obligation, but is on the contrary, opposed to the principle thereof, and to the morality of the will" in Immanuel Kant, Critique of Practical Reason and Other Works on the Theory of Ethics, trans. Thomas Kingsmill Abbott (New York: Barnes \& Noble Books, 2004) 19.

\section{CHAPTER TWO: TOWARD A THEORY OF EMOTION}

${ }^{1}$ Interestingly, Septimus Warren Smith's lack of emotion resembles real life figure, Phineas Gage, about whom I will have more to say shortly. For a brief recounting of Gage's story see Jesse J. Prinz, Gut Reactions : A Perceptual Theory of Emotion, Philosophy of Mind Series (Oxford ; New York: Oxford University Press, 2004) 59. See also Paul Thagard and Fred Kroon, Hot Thought: Mechanisms and Applications of Emotional Cognition (Cambridge, Mass.: MIT Press, 2006) 89. For a fuller account of Phineas Gage and the scientific aftermath of his injury, see especially Chapters One and Two in Antonio R. Damasio, Descartes' Error : Emotion, Reason, and the Human Brain (London: Penguin, 2005).

${ }^{2}$ Since a survey of theories of reason is beyond the scope of this paper, I will use reason (unless otherwise indicated, e.g., practical reason or theoretical reason) in the sense of propositional knowledge. For an excellent bibliography on epistemology and the various way reason can be 
described, see Keith DeRose, The Epistemology Page, July 13, 2009, Yale University, Available: http://pantheon.yale.edu/ kd47/e-page.htm, March 19, 2010.

${ }^{3}$ I do not have enough room in the span of a chapter to do an exhaustive survey of available theories of emotion. However, to see excellent discussions of the possible theoretical options open to the philosopher of emotion see, for example, Paul E. Griffiths, What Emotions Really Are: The Problem of Psychological Categories, Science and Its Conceptual Foundations (Chicago, Ill.: University of Chicago Press, 1997) 21-43. Prinz, Gut Reactions : A Perceptual Theory of Emotion 3-51. Jenefer Robinson, Deeper Than Reason : Emotion and Its Role in Literature, Music, and Art (New York: Oxford University Press, 2005) 5-56. Craig DeLancey, Passionate Engines : What Emotions Reveal About Mind and Artificial Intelligence (Oxford ; New York: Oxford University Press, 2002) 31-48.

${ }^{4}$ For more on this see William James, The Principles of Psychology, vol. 2 (New York: Dover, 1950). James originally proposed the theory of emotion as feeling.

${ }^{5}$ Because of the possibility for mistaking cognitive emotion theories with cognitive psychology, Paul Griffiths prefers the term "propositional attitude theory." That is to say, emotions are that attitude one takes toward a proposition. If I say, for example, that the plane on which my wife is a passenger is landing, I am stating a proposition. That value I attach to the proposition or the attitude I take as a result of it is emotion. I may say, "Great! The plane with my wife whom I miss is finally here." Or I may say, "Oh no! My shrewish wife has finally returned." The proposition remains constant, but my attitude toward it constitutes my emotional response. Part of Griffiths' critique of cognitive emotion theories is that methodologically they are at heart philosophical, consisting entirely of conceptual analysis; which is to say, they lack the methodological rigor of the experimental methodology present in cognitive psychology. Therefore, to call them cognitive is to risk confusing with them cognitive psychology, thereby giving them more credit than he believes they deserve. Griffiths, What Emotions Really Are: The Problem of Psychological Categories 2. For the purposes of this chapter, though, the use of cognitive in relationship to emotion theory will suffice, inasmuch as I am clear that I am not speaking of cognitive psychology. 
${ }^{6}$ Here I am indebted to the discussion of an Aristotelian conception of emotions as grounded in beliefs in Martha Craven Nussbaum, The Fragility of Goodness : Luck and Ethics in Greek Tragedy and Philosophy (Cambridge ; New York: Cambridge University Press, 1986) 383-4.. ${ }^{7}$ I realize that nailing down just what that shared moral framework consists of, and where one might go to find it is problematic, in the same way that nailing down any general or universalizable moral code is. I am not arguing that there $i s$ such a thing, only that people often act as though there were. What I am speaking of here as a shared moral framework is what I mean to be thought of as nothing more than an assumed baseline civility; it often operates under the cover of words like "commonsense," "conscientiousness," and "fairness." We can see it in common sentiments: "People aren't supposed to take things from other people's gardens." "You shouldn't cheat on your taxes." "He ought to be kinder to his wife." "Aren't," "shouldn't," "ought to" all bespeak a basic shared moral code that raises general expectations about attitudes and behaviors. ${ }^{8}$ Antonio R. Damasio, Descartes' Error: Emotion, Reason, and the Human Brain (New York: Putnam, 1994).

${ }^{9}$ Thagard and Kroon, Hot Thought : Mechanisms and Applications of Emotional Cognition. See especially his chapter, "Spiking Phineas Gage."

${ }^{10}$ DeLancey reserves the manifestation of affect programs, however, to "basic emotions" (3).

${ }^{11}$ Whether there are basic and complex emotions or affect programs that act as specialized modules that are triggered for specific purposes, but which cannot be reliably grouped under the heading of emotion, I will not argue here. I will suggest, though, that however one describes them, the fact that this kind of mapping is thought necessary suggests that there is enough differentiation between kinds of emotions and the ways in which they are elicited that attempting some kind of taxonomy in which fast-acting and slow-acting emotions are qualitatively differentiated seems eminently reasonable. How those emotions get carved up, though, will be a matter of long-lasting debate.

${ }^{12}$ Here I am following Jenefer Robinson. See her chapter, "Emotion as Process," in Deeper than Reason, 57-99. 
${ }^{13}$ For an excellent summary of the various kinds of arguments for basic emotions and their proponents, see Table 1 in Andrew Ortony and Terrence J. Turner, "What's Basic About Basic Emotions?," Psychological Review 97.3 (1990): 316.

${ }^{14}$ I must acknowledge a distinction between social construction and socialization. By socialization I mean only the learning and habituation of the language and roles within a particular culture, which are necessary for successfully negotiating life within that culture. What one learns, though, need not be socially constructed. One could be socialized, for example, into the proper use and meaning of an essential characteristic. In other words, one could hold that emotions are part of the essential make-up of human beings, and that one needs to be socialized correctly in order properly to manage them-not as social constructionism would have it that the emotions themselves are what need to be learned.

${ }^{15}$ Furthermore, he says that "even those which, like paternity, seem to be part and parcel of the human make-up are in reality institutions" (220).

${ }^{16}$ I realize that there is no general conception about which emotions, if any, occupy a category called basic emotions. Although, a short list that includes anger, disgust, fear, happiness, sadness, and surprise seem be a good start (see Damasio, Descartes' Error 149; Prinz, 150).

${ }^{17}$ See also Elizabeth A. Phelps, "The Interaction of Emotion and Cognition: Insights from Studies of the Human Amygdala," Emotion and Consciousness, eds. Lisa Feldman Barrett, Paula M. Niedenthal and Piotr Winkielman (New York: Guilford Press, 2005).

${ }^{18}$ For this account I am indebted to Antonio Damasio's detailed retelling of the story in Descartes' Error, especially 3-17.

${ }^{19}$ See especially his chapter, "The Theory of Preoedipal Origin," in which he gives a brief historic survey of the argument in Charles W. Socarides, Homosexuality: Psychoanalytic Therapy (Northvale, N.J.: J. Aronson, 1989) 63-88. For a fine discussion of the history of homosexuality and psychiatry, see Ronald Bayer, Homosexuality and American Psychiatry : The Politics of Diagnosis, Princeton Paperbacks (Princeton, N.J.: Princeton University Press, 1987).

\section{CHAPTER THREE: HUMANS ARE POLITICAL ANIMALS}


${ }^{1}$ Aristotle, Nicomachean Ethics, 1097b12. Aristotle, Politics, 1253a3, 79a19.

${ }^{2}$ See, for example, Stanley Hauerwas and William Willimon, Resident Aliens: Life in the Christian Colony (Nashville: Abingdon Press, 1989). Hauerwas and Willimon make the case for viewing the church as a polis.

${ }^{3}$ Aristotle alludes to the self-reinforcing nature of the virtues when he says that "abstaining from pleasures makes us become temperate, and once we have become temperate we are most capable of abstaining from pleasures. It is similar to bravery; habituation in disdain for frightening situations and in standing firm against them makes us become brave, and once we have become brave we shall be most capable of standing firm" (1104a35-1104b4).

${ }^{4}$ I will use the genre of tragedy as an example of literature's affect on emotion. I will expand my study of the relationship between literature and emotion in Chapter Five. By using tragedy I am merely citing a traditional touchpoint for the discussion of the relationship between literature and the emotions. Admittedly, the tragedy about which Aristotle and Plato spoke was experienced primarily as theater, rather than in written form-which we would ordinarily associate with literature. However, nothing in my argument turns on reading versus spectating — both are capable of eliciting similar emotional responses. But because literary criticism begins in earnest with Aristotle's commentary on the nature of plot in tragedy, literature is never too far removed from the implications of Aristotle's critique.

${ }^{5}$ Richard Rorty writes: "Between Plato's Phaedo and the seventeenth century, the standard philosophical argument for immortality had always revolved around our ability to do what beasts cannot—know unchanging truths rather than just particular facts," in Richard Rorty, Philosophy and the Mirror of Nature 53.

${ }^{6}$ In this respect, Rawls mirrors Mill's convictions about the necessity of the individual as antecedent to the polis, and the individual's choices being sacrosanct, bounded only by the limits of another's right to pursue the good. See John Stuart Mill, On Liberty and Other Writings, Cambridge Texts in the History of Political Thought, ed. Stefan Collini (Cambridge [England] ; New York: Cambridge University Press, 1989) especially 56-7. 
${ }^{7}$ It should be pointed out here that the solipsism to which I refer is a voluntary one. A person cast unwillingly out of society may be nourished as a human being through the memory of past emotional engagement and/or through the hope of future emotional engagement when one may one day be restored (e.g., a prisoner in solitary confinement). Admittedly, there are those isolated incidents of children involuntarily cast out into the wilderness, who survive as "wild children," perhaps without recourse to the memory of emotional contact (though that is difficult to know with any certainty), and therefore without hope of it. However, their status upon being returned to human society more closely resembles the very "beast" that Aristotle identifies as those capable of surviving outside human society. Presumably, though, a person who leaves society as a matter of choice on a permanent basis does so because that person wants to minimize, if not altogether eliminate, exposure to emotional contact.

${ }^{8}$ But, in the case of Christianity, even hermits are sustained by their desire for emotional engagement-only now with God instead of other humans. In Hinduism, on the other hand, the time of the hermit is a temporary one in which the one who chooses it does so with the knowledge that he (most likely a male) will return to the family.

${ }^{9}$ By objects I mean the stimuli that elicit emotions, which may truly be objects (for example, a speeding car headed toward me), or may be my own thoughts, or may be the emotions of another (for example, when I see your anger, I may become angry or afraid or amused.) The object of my affective state, then, is that which stimulates the emotions, calling the complex emotional process into action.

${ }^{10}$ See also Morten L. Kringelbach, The Pleasure Center: Trust Your Animal Instincts (New York: Oxford University Press, 2009) 47.

${ }^{11}$ In Philosophy of Mind, of course, what I am describing has resonances of Bertrand Russell's distinction between knowledge by acquaintance and knowledge by description. Without rehearsing the argument over the failings of knowledge by acquaintance (a sort of first-hand, eyewitness knowledge) to give us truth about objects (e.g., I may only be dreaming that the car is yellow), it is important to point out that knowledge by acquaintance may offer some insight with respect to acquiring truth about subjects. One criticism of acquaintance theory is that it is 
imprecise in defining the relationship between the knower and what is known. However, when the relationship between the knower and its object is a subject, as is the case with an individual, such knowledge is not necessarily inferential or open to empirical verification, and will, therefore, appear dubious as a form of knowledge classically construed. However, one of the critiques of knowledge by description is that it assumes a foundation of inference that determines what can even be called knowledge, dismissing what cannot be accounted for propositionally, and is, therefore, arguably the sort of political move I will ultimately want to address.

${ }^{12}$ C.D.C. Reeve believes this "salvation" signifies the preservation of a stable community. Politics lxiii-lxiv.

${ }^{13}$ It is important to draw attention to what will be an enduring tension throughout this work, and that is over whether there are such things as universals - be they essential human teloi or universal virtues that are spatio-temporally transcendent—identifiable as such, or whether all evaluative discourse is necessarily local, contingent, and particular; or whether emotions are essential and, therefore, universal or the products of local, contingent, and particular social construction. I will address these at greater length as they come up in subsequent chapters, in particular in Chapter Five. However, I will suggest for now that if there are universals, they remain contested to such an extent that not only is there not a universally accepted account of universals, but there does not even exist a consensus on what would be received as acceptable evidence and standards by which to judge whether universality has been achieved. To what bar of appeal would one have recourse in adjudicating disputes over claims of universality? I raise this issue here because I will argue that normative teleology can be taken seriously without resorting to an essentialized version of Aristotelian metaphysics or anthropology, by offering up an argument concerning the possibility of discourse between seemingly incommensurable systems of meaning.

${ }^{14}$ Alasdair C. MacIntyre, After Virtue : A Study in Moral Theory, 3rd ed. (Notre Dame, Ind.: University of Notre Dame Press, 2007) 152.

${ }^{15}$ There are times when the demands of virtue require opposing actions in different situations. The whole idea of the mean suggests that what might be considered generous in one context (e.g., I give a person who has no money some money to buy food.) would be considered profligate and 
harmful in another context (i.e., if I gave that same amount of money to another person who had no money, but whom I suspected would use it to buy narcotics).

${ }^{16}$ Aristotelian virtue ethics has been criticized just to the extent that-because of an insistence upon the contextual nature of practicing virtue-it seems to invite relativism into the moral sphere. The lack of regulative guidelines for determining how one should act is seen as a deficiency of virtue ethics by deontologists and utilitarians. The charge lodged against virtue ethics centers on the belief that virtue ethics provides no clear guidelines for acting in particular instances, giving rise to the oft-repeated commonplace: "Virtue ethics does not tell one what to do; it is concerned with telling one what kind of person to be." Unfortunately, it is thought, this leaves the virtue ethicist without anything to say when confronted by an ethical dilemma. A deontologist can say of lying, "You must never lie, because there is a universal maxim prohibiting it." A utilitarian faced with the same question has recourse to a formula in which the answer to the question about lying is to be found in determining which course of action promises to maximize utility. A virtue ethicist, on the other hand, is thought incapable of providing specific direction in this case because virtue ethics does not rely on rules like, "Do not lie"—only on exhortations to be honest. So while virtue ethics might supply good general principles about strengthening character, as an ethical system it fails to offer the kind of precise direction necessary for life situations. In short, virtue ethics, it is argued, is not normative. This general argument over the superiority of ethical systems, while important, is beyond the scope of this chapter. However, Rosalind Hursthouse has put forward a persuasive argument that virtue ethics can offer normative guidelines for action by making reference to the virtuous person as a guide. See her excellent essay in Rosalind Hursthouse, "Normative Virtue Ethics," How Should One Live? Essays on the Virtues, ed. Roger Crisp (Oxford: Oxford University Press, 2003).

${ }^{17}$ By agent-centered I refer to a conception of morality that begins with what kind of person one ought to be in order to know how one ought to act, as opposed to act-centered conceptions of morality that begin with a deliberation over the principles and requirements for moral action, which is a necessary prerequisite for a discussion of the moral agent. 
${ }^{18}$ In fact, epistemology itself went from being oriented to divine revelation to being oriented to the human pursuit of knowledge through science and philosophy.

${ }^{19}$ It is worth pointing out that freedom for Kant is a purely theoretical but necessary concept, "even though experience shows the opposite of those requirements represented as necessary under the presupposition of freedom," (Immanuel Kant, Grounding for the Metaphysics of Morals_trans. James W. Ellington, 3rd ed. (Indianapolis: Hackett Pub. Co., 1993) 56.

${ }^{20}$ It should be noted, however, that I am not making the claim that the presence of motivations to act beyond a sense of duty render the act immoral in some way; only that to the extent that emotion operates as primary motivation, it is, for Kant, something beyond the scope of a moral act. For an excellent survey of interpretations of Kant on motivation see Michael Weber, "More on the Motive of Duty," Journal of Ethics 11 (2007).

${ }^{21}$ Kant suggests that in those cases where love is commanded-for example in John 13:34, where Jesus says, "I give you a new commandment, that you love one another. Just as I have loved you, you also should love one another" (NRSV) - that that sort of love must be a conscious act of the will. To the extent that emotions cannot be commanded, they must not be under the control of the will. To speak of love -at least some forms of it—as a function of the will—that is, as a moral issue - will strike many readers as odd. And while the scope of this chapter will not allow for an extended discussion about the ways love may differ as an act of the will or as an emotion, Kant recognizes, at minimum, the ways in which language about emotions are imprecise. Additionally, though, he may also have identified one of the instances in which cognition is implicated in secondary emotions in ways that basic emotions will not allow-as I suggested in Chapter Two. ${ }^{22}$ While it is important to differentiate between feelings and emotions-inasmuch as feelings suggest the essentialist, pre-rational responses against which I am arguing - that distinction is not central to Aristotle's argument. And because I am merely using Aristotle here as suggestive of a starting point for a more fully developed argument about emotion, it will be sufficient for our present purposes to treat them at this point as unproblematic synonyms. As I argued in Chapter Two, however, they should not be thought of as the same things. 
${ }^{23}$ I find myself in agreement with the assertion Richard Janko advances in presupposing that correct emotional response must be present before true virtue can be said to exist. He writes: "Just as we become good by habitually doing good, until good action becomes a 'second nature' to us, so too by feeling emotion appropriately we become habituated to having the correct emotional responses" Richard Janko, "From Catharsis to the Aristotelian Mean," Essays on Aristotle's Poetics, ed. Amélie O. Rorty (Princeton: Princeton University Press, 1992) 343, Janko, "From Catharsis to the Aristotelian Mean."

${ }^{24}$ As I have indicated, Kant seems to suggest that the less inclined one is to an action required by duty, the greater the moral achievement. He writes, for example, that "if adversity and hopeless sorrow have completely taken away the taste for life, if an unfortunate man, strong in soul and more indignant at his fate than despondent or dejected, wishes for death and yet preserves his life without loving it—not from inclination or fear, but from duty — then his maxim indeed has moral content" Kant, Grounding for the Metaphysics of Morals, 10.

${ }^{25}$ On the other hand, learning to have the emotions appropriate to the virtuous person, without ever acting in the way a virtuous person would act is even less desirable, because "some sort of actions and activities are the end [telos]" (1098b19). Feeling, for example, like an auto mechanic is not sufficient to the techne of automotive repair. To be an auto mechanic, one would actually have to fix cars.

${ }^{26}$ I will speak more about this shortly.

${ }^{27}$ I am using potentialities in Aristotle's primary sense in which a thing is "said [to be] either of acting or being acted upon" in Aristotle, Metaphysics, trans. Montgomery Furth (Indianapolis: Hackett Publishing Company, 1985) 1046a16. This is to distinguish my usage of it from his other sense of potentiality as related to actuality. In this sense of potentiality, potentiality has to do with the realization of a thing's telos. Hence, actuality is to potentiality "as what is awake to what is asleep, and as what is seeing is to what has its eyes shut but has sight, and as what has been shaped out of the matter is to the matter, and as the wrought is to the unwrought" (1048b1). 
${ }^{28}$ Although I am not prepared to offer this as a statement of universal truth, I am unaware of a narrative artistic tradition, regardless of culture, which does not rely on conflict as essential to the development of the plot.

${ }^{29}$ Someone might object that intellectual forms of conflict are also interesting - an assertion with which I would agree. Intellectual conflict, however, seems not to be nearly so well represented as emotional conflict as the focus of art. Moreover, one might wonder to what extent intellectual conflict has an emotional component, like, for example, the thrill or fear elicited by the clash of ideas. See my argument on the intertwining of reason and emotion in knowing in Chapter Two. ${ }^{30}$ See my argument concerning feminist epistemology having made a persuasive case that the privileging of the rational operates as a political move on the level of ideology in Chapter One.

${ }^{31}$ The extent to which our own language continues to reflect the ideal of an emotionless rationality serves to demonstrate the persistence of Plato's influence in epistemology. Again, as I have already indicated, feminist epistemology has something to say about the possibility of objectivity and how maintaining objectivity as the standard of rationality underwrites power arrangements in which males are identified as objective and dispassionate observers, while women are viewed as emotional, and therefore, incapable of the objectivity.

${ }^{32}$ For an excellent discussion of Plato's ideal of self-sufficiency, see Martha Craven Nussbaum, "Tragedy and Self-Sufficiency: Plato and Aristotle on Fear and Pity," Essays on Aristotle's Poetics, ed. Amélie O. Rorty (Princeton: Princeton University Press, 1992) especially 268-70. ${ }^{33}$ Alexander Nehamas, "Pity and Fear in the Rhetoric and the Poetics," Essays on Aristotle's Poetics, ed. Amélie O. Rorty (Princeton: Princeton University Press, 1992) 293.

${ }^{34}$ See also Martha Craven Nussbaum, The Fragility of Goodness : Luck and Ethics in Greek Tragedy and Philosophy. Nussbaum says that "there is no loving action without someone to receive and return it; there is no being a good citizen without a city that accepts your claims to membership. In these cases hexis and praxis, character and activity, are so intimately connected that it would not even be possible to represent the appropriate character-states without representing action and communication" (381). 
${ }^{35}$ Pity and fear are commonly referred to, therefore, as the tragic emotions.

${ }^{36}$ The now famous aesthetic position identified by R.W. Beardsmore as autonomism suggests a view of art in which each artistic work exists independent of any external influence or meaning. Art in this conception cannot be engaged as art if any considerations other than aesthetic ones are used. Therefore, form is emphasized over content.

${ }^{37}$ It seems plausible to suggest that for Aristotle the pleasure of tragedy results from tragedy fulfilling the function associated with its genre. For a more contemporary discussion of the "paradox of tragedy," see Susan L. Feagin, "The Pleasures of Tragedy," American Philosophical Quarterly 20 (1983): 95-104. For an interesting counterargument to Feagin see, Stacie Friend, "The Pleasures of Documentary Tragedy," British Journal of Aesthetics 47.2 (2007): 184-98.

${ }^{38}$ Imagination, as I am using it, is one's ability to take past experiences, images, representations, and so on, and creatively blend them together to produce new and as yet unrealized scenarios. With respect to emotions, the creative scenarios produced by imagination allow for the anticipation of one's emotional response to fictitious circumstances.

${ }^{39}$ Aristotle, Rhetoric, trans. W. Rhys Roberts, Ingram Bywater and Friedrich Solmsen, 1st Modern Library ed. (New York,: Modern Library, 1954) 1382a21.

${ }^{40}$ Here Aristotle explains that rectificatory justice deals with two types of transactions: 1 ) voluntary (e.g., business transactions), and involuntary-because they are secret (e.g., theft) or coerced (e.g., murder). Rectificatory justice concerns restoring "the unjust situation to equality" (1132a6).

\section{CHAPTER FOUR: INTERSUBJECTIVITY: THE NEED FOR EMOTIONAL}

\section{ATTENDING}

\footnotetext{
${ }^{1}$ See Immanuel Kant, "What Is Enlightenment?"

${ }^{2}$ In fact, Onora O'neill has argued against a traditional critique of Kant as purely oriented to the interior self, since Kant is so dubious about "the reliability of introspection." See Onora O'neill, "Kant's Virtues," How Should One Live? Essays on the Virtues, ed. Roger Crisp (Oxford: Oxford University Press, 2003) 88.
} 
${ }^{3}$ See, for instance, Rosalind Hursthouse who argues for a normative view of virtue ethics in the face of utilitarian and deontological criticisms. She writes that "the acquisition of moral knowledge involves the training of the emotions in a way that the acquisition of scientific knowledge does not." "Normative Virtue Ethics" in How Should One Live? 32.

${ }^{4}$ A nice summary of narrative in the sense I am using it is provided in Alasdair C. MacIntyre, After Virtue: A Study in Moral Theory. MacIntyre writes: "To be the subject of a narrative that runs from one's birth to one's death is ... to be accountable for the actions and experiences which compose a narratable life. It is, that is, to be open to being asked to give a certain kind of account of what one did or what happened to one or what one witnessed at any earlier point in one's life than the time at which the question is posed. Of course someone may have forgotten or suffered brain damage or simply not attended sufficiently at the relevant time to be able to give the relevant account. But to say of someone under some one description ('The prisoner of the Chateau d'If') that he is the same person as someone characterized quite differently ('The Count of Monte Cristo') is precisely to say that it makes sense to ask him to give an intelligible narrative account enabling us to understand how he could at different times and different places be one and the same person and yet be so differently characterized. Thus personal identity is just that identity presupposed by the unity of the character which the unity of a narrative requires. Without such unity there would not be subjects of whom stories could be told" (218).

${ }^{5}$ Zaki, Bolger, and Ochsner make a qualitative distinction between affective empathy and cognitive empathy, where "affective empathy refers to perceivers' experience of sharing the emotions they observe in social targets"; this roughly corresponds to my use of the word empathy. They define cognitive empathy, on the other hand, as "the ability of a perceiver to understand the internal states of targets and is often measured as the accuracy with which a perceiver can assess the thoughts and feelings a target is experiencing"; this is what I am choosing to call emotional attending. I believe that a clear distinction between the terms empathy and emotional attending, is more descriptive and less confusing for my purposes than affective and cognitive empathy. Jamil Zaki, Niall Bolger and Kevin Ochsner, "It Takes Two: The Interpersonal Nature of Empathic Accuracy," Psychological Science 19.4 (2008): 399. 
${ }^{6}$ To say I feel it "because" she feels it is to differentiate between empathy and simultaneous feeling, where simultaneous feeling is a phenomenon like two people observing the same spectacle and having the same feeling synchronously. In the case of simultaneous feeling, the emotion is, what I would call, a first order feeling occurrence. Empathy, on the other hand, would be a second order feeling occurrence that depends for its existence on the first order feeling occurrence of another.

${ }^{7}$ So as not to confuse terms, I must point out that Potter's use of the word "empathetic" need not entail what Zaki, Bolger, and Ocshner term "affective empathy," but could be satisfied by what they call "cognitive empathy," and what I have called "emotional attending."

${ }^{8}$ What Aristotle calls "friendships of utility" (or even friendships of pleasure) are not, in their strictest sense, friendships in the way we commonly understand them when we say something like: "Bill is my friend"; they are much closer to what we would refer to as business associates, or casual acquaintances, or co-workers. What binds us to these people has very little to do with any emotional investment in the relationship. Rather, it revolves around our usefulness to one another. On this point, Aristotle is clear: "Those who are friends of utility dissolve the friendship as soon as the advantage is removed; for they were never friends of each other, but of what was expedient for them" (EN 1157a17).

${ }^{9}$ C.f. Michael Stocker who suggests that emotional engagement is primarily reserved to those with whom we have (or hope to have) a relationship, those with whom we play. He writes: "One wants, and quite properly so, engagement-emotional engagement - with those one plays with. Indeed, one of the important reasons for playing is to be emotionally engaged with the play, with oneself, and with others" in Michael Stocker, "How Emotions Reveal Value and Help Cure the Schizophrenia of Modern Ethical Theories," How Should One Live? Essays on the Virtues, ed. Roger Crisp (London: Oxford University Press, 2003) 180.

\section{CHAPTER FIVE: LITERATURE AND THE WORK OF THE IMAGNATION}

\footnotetext{
${ }^{1}$ I am aware of the argument that the term literature encompasses more than just fiction—say, perhaps, literary biographies and so forth. I am also aware of the especially knotty debate over
} 
just what constitutes "literature," and how it may be distinguished from other literary forms like instructional manuals or cookbooks. I do not need to put forward a comprehensive definition of literature, since my argument does not turn on questions of historicity, but on thick narrative descriptions of human life. Consequently, I will use "reading literature" and "fictional human life" more to suggest narrative description than to distinguish between actual and virtual worlds. ${ }^{2}$ See, for instance, the prologue to Alasdair C. MacIntyre, After Virtue : A Study in Moral Theory. In it MacIntyre speaks about the kinds of things necessary for a confrontation between competing systems of enquiry, like the ability to think within the system of one's rival. Then, one would need to identify "the unresolved issues and unsolved problems-unresolved and unsolved by the standards of that tradition - which now confront those adherents and to enquire how progress might be made in moving towards their resolution and solution" (xiii). If no resolution or solution can be found, one must then ask whether the system of enquiry is ill-suited because of standards internal to the system to offer resolution or solution? If so, it may be the case that resolution or solution can only be offered by a rival tradition.

${ }^{3}$ R. W. Beardsmore, Art and Morality (London,: Macmillan, 1971).

${ }^{4}$ Berys Nigel Gaut, Art, Emotion, and Ethics (Oxford ; New York: Oxford University Press, 2007). Gaut defends monotonic or full-blooded ethicism, which is the position that "a work is always aesthetically flawed in so far as it possess an ethical demerit that is aesthetically relevant; and a work is always aesthetically meritorious in so far as it possesses an ethical merit that is ethically relevant" (52).

${ }^{5}$ See also Gaut who suggests that this type of radical moralism is characterized by a contention that the "ethical merits or demerits [in art] are always relevant"; and he points out that this kind of radical moralism is not seriously held by anyone in the debate at present Gaut, Art, Emotion, and Ethics 51.

${ }^{6}$ See Beardsmore 65.

${ }^{7}$ Iris Murdoch wryly observes that "Kant's examples of pure conceptless beauty, in art or nature, have a Platonic simplicity: birds, flowers, (tulips for instance, of which Kant appears to have been 
fond), Greek-style designs, patterns of foliage on wallpaper. (Plato would not have objected to unpretentious wallpaper.)" in The Fire \& the Sun: Why Plato Banished the Artists (Oxford [Eng.]: Clarendon Press, 1977) 19.

${ }^{8}$ Immanuel Kant, "The Critique of Aesthetic Judgment," trans. J.C. Meredith, Aesthetics: The Classic Readings, ed. David Cooper (Oxford: Blackwell, 2002) §2.

${ }^{9}$ Richard Thomas Eldridge, An Introduction to the Philosophy of Art (Cambridge, UK New York: Cambridge University Press, 2003) 62.

${ }^{10}$ Gaut notes a third aesthetic trajectory beyond ethicism and autonomism - immoralism - the extreme version of which is the mirror opposite of radical moralism. That is to say, according to Gaut, radical immoralism "holds that a work is always aesthetically flawed in so far as it possesses an ethical merit that is aesthetically relevant; and that it is always aesthetically meritorious in so far as it possesses an ethical demerit that is aesthetically relevant"-which no one defends (53). Gaut goes on to argue that a less than radical immoralism should better be thought of as a strain of contextualism, which advances the idea that the value-relation between an artwork and its aesthetic appreciation are "sometimes positive, sometimes negative," depending on the context (54).

${ }^{11}$ See Derek Penwell, "Education in the Virtues: Tragic Emotions and the Artistic Imagination," Journal of Aesthetic Education 43.4 (2009). In this article I make the argument for the ways in which tragedy may be thought to be morally educative of the emotions through just this kind of imaginative encounter.

${ }^{12}$ For an excellent account of the problems associated with a view of literature has having cognitive content see Peter Lamarque and Stein Haugom Olsen, Truth, Fiction, and Literature: A Philosophical Perspective (Oxford: Clarendon Press, 1994). To see other accounts that find literature to have cognitive value, see Noël Carrol, A Philosophy of Mass Art (Oxford: Clarendon Press, 1998). Also, see Scott R. Stroud, "Simulation, Subjective Knowledge, and the Cognitive Value of Literary Narrative," Journal of Aesthetic Education 42.3 (2008). For an interesting argument that literature ought to stay away entirely from cognitivist aspirations, which are too objective, and seek purely subjective knowledge, see Alex Burri, “Art and the View from Nowhere," A Sense of the Word: Essays on Fiction, Narrative, and Knowledge, eds. John Gibson, 
Wolfgang Heumer and Luca Pocci, Routledge Studies in Contemporary Philosophy (New York: Routledge, 2007).

${ }^{13}$ By qualified I mean here a view of art that recognizes the value of Schiller's "world of semblance," an aesthetically imagined world, characterized by the free play of ideas ("Nothing need here be sacred to [the artist] except his own law, if he but observes the demarcation separating his territory from the actual existence of things, that is to say from the realm of nature," Letter $26, \S 8,127)$, but that does not assume, with Schiller, that the aesthetic world created must be hermetically sealed off from reality ("Only inasmuch as it is honest [expressly renounces all claims to reality], and only inasmuch as it is autonomous [dispenses with all support from reality], is semblance aesthetic," Letter $26, \S 11,128)$ Friedrich Schiller, "On the Aesthetic Education of Man," trans. E. Wilkinson and L. Willoughby. Cooper, in Aesthetics: The Classic Readings,.ed. David Cooper (Oxford: Blackwell, 2002) especially 123-36.

Moreover, in referring to aesthetic or hypothetical space I am not attempting to make any complex metaphysical claims about "possible worlds." Rather, I am employing what I take to be an uncontroversial claim about the capacity of the imagination to conceive of things "as if." Literature depends upon just this ability to imagine what is not explicitly there-in particular, that part of the narrative that falls between the gaps of what is explicitly named as essential to the story.

${ }^{14}$ See Maria Lugones, who has an interesting discussion of the ways that those on the margins always find themselves inhabiting different worlds, as well as the kind of imagination necessary to travel between those worlds in Maria Lugones, "Playfulness, 'World'-Traveling, and Loving Perception," Hypatia 2.2 (1987).

${ }^{15}$ A world might exist, for example, of beings from the planet Zorfam, who relate to one another always as strangers. The way that human readers might be engaged by that world would be imaginative, a constant cross-referencing of human experience, in which there are a variety of people to whom one relates as familiar; or one might be engaged by that world by imagining the similarities with a human being bearing some kind of cognitive or memory deficit. Though the 
world of Zorfam is hypothetical, as with other possible worlds, the creative aesthetic space is habitable through an act of the imagination.

${ }^{16}$ I say "generally safe" inasmuch as a literary villain presents no real, physical threat. However, I understand that some experiences are so traumatic in real life that to recall them even in an imaginary literary world could render that world unsafe emotionally or psychologically for some people.

${ }^{17}$ Nuttall, for example, argues for a view that sees one form of literature, tragedy, "as an exercise in understanding in advance the real horrors we may meet and the psychic violence they may cause," in Nuttall, 104.

${ }^{18}$ See David Carr's fine survey of recent thought on the construction of narrative in David Car, Time, Narrative, and History (Bloomington: Indiana University Press, 1991), especially his chapter, "The Self and the Coherence of Life," 73-99.

${ }^{19}$ Unfortunately, however, it is possible to read Murdoch as placing too much emphasis on a theory of mimesis that assumes reference to the world we inhabit as a necessary condition of "great art." It must be admitted that the way she describes the characteristics of great art and bad art risk confusion. Nevertheless, what I think she says about art is important, if perhaps potentially misleading.

${ }^{20}$ Thomas Nagel, The View from Nowhere (New York: Oxford University Press, 1986). Knowledge, on Nagel's account, starts as subjective and perspectival and moves toward knowledge that is increasingly objective and non-perspectival-the apex of which is opposite of the view from some particular place - that is, a view from no particular place.

${ }^{21}$ Though Walton uses a movie, rather than literature, as an example for his theory of quasiemotional responses to fiction, what he has in mind applies equally as well to fiction.

${ }^{22}$ One argument about why differentiating between "real emotion" and "quasi-emotion" could be important under non-literary circumstances is taken up by Arlie Hochschild in her book, The Managed Heart. She contends that acting as though one has feelings one does not really possess is a way to manage emotions to secure one's employment. She uses the example of flight attendants who are trained to reframe anger at passengers by drawing different cognitive 
conclusions about the object of their anger (e.g., a needy passenger could be conceived of as suffering from a fear of flying, or a drunken passenger could be viewed as "just like a child") Arlie Hochschild, The Managed Heart: Commercialization of Human Feeling (Berkeley: University of California Press, 1983) 25. Another strategy offered by a trainer to deal with anger involves "preventative tactics," like "deep breathing, talking to yourself, reminding yourself that 'you don't have to go home with him"' (25).

There are two problems, however, with seeing emotions themselves as manageable. First, the force of Hochschild's argument in this instance-that is, of the example of managing emotions as a strategy for flight attendants--is that this act of "managing emotions" alienates oneself from one's true feelings by acting, because of the demands of one's job, as though one feels a particular emotion when one does not. She extends Karl Marx's argument about the alienation of oneself from one's labor to include the alienation of one's true emotional self from one's "emotional labor"-which she defines as labor that "requires one to induce or suppress feeling in order to sustain the outward countenance that produces the proper state of mind in others" (7). Acting as though one feels something one does not, or "managing emotions," on Hochschild's account is potentially alienating. The second problem with seeing emotions proper as manageable, as Hochschild does, is that to do so is to view emotions once again as cognitive constructions of belief, judgment, or evaluation. Under her description of how emotions may be managed, one has to change one's cognitive appraisal to change emotions. A drunken passenger, for instance, is no longer infuriating if one believes the offending passenger to be "just a child." Making such a cognitive shift can transform how one feels about the passenger. What such a cognitive reconception does, however, is not necessarily to change emotion itself but to change one's relationship to that which triggers the emotion. For, to make such a cognitive shift is to make a category adjustment. It is to say of drunk people in general that drunkenness should no longer trigger my anger, but that it should trigger in me pity, or disappointment, or wry amusement, and so on. What changes initially is not my emotion, but that which triggers my emotion. 
As to the issue of whether the kind of management of emotion suggested by Hochschild offers an argument about why it might be helpful to distinguish between "quasi-emotions" and "real emotion," I take her caveat about the potential for the alienation of one's emotions from one's emotional labor through a form of acting to be an important insight. If there were to be any advantage conferred by differentiating between "quasi-emotion" and "real emotion," it would be in some account like Hochschild's, which assumes that pretending to have an emotion for the sake of one's livelihood can, over the long term, be alienating. I am not arguing, however, about pretending to have emotions to secure one's employment, but about simulating emotional experiences through reading literature for the purpose of better understanding the emotional lives of others-and by extension, as I have argued, better understanding myself. Hochschild's purposes for differentiating between true emotional experiences and emotions appropriated for public consumption as a vocational necessity and my purposes in calling attention to simulated emotional experience are altogether different.

${ }^{23}$ It strikes me that Proust, in holding out for the important educational component of fiction, through its expansion of the imaginative possibilities for the emotional life, describes, in part, Husserl's phenomenological project. That is to say, to do a phenomenological investigation of emotion requires that the investigator be able to imagine certain states of affairs. However, because of the limitations inherent within the experience of temporal beings, most likely we will not have had the broad range of experiences necessary to form all emotions adequately. However, in phenomenology the actual experience is less important than the ability to imagine the nuances and complexities of that experience. An object in phenomenology need not necessarily refer to a tangible thing one can put one's hands on. Rather, according to Husserl, an object here means an "object of consciousness"- or that which is intended by intentionality Edmund Husserl, Cartesian Meditations : An Introduction to Phenomenology, trans. Dorion Cairns, Springer Classic Titles in Philosophy (Dordrecht: Kluwer Academic Publishers, 1999) 42. An object in a phenomenological investigation, therefore, could be basset hound or a memory, a Chrysler Cordoba or an aesthetic 
experience of literature. However, this is a line of inquiry that is beyond the scope of this present work.

${ }^{24}$ See my previous discussion of the potential dangers of banal literature.

${ }^{25}$ See the study in Demis Hassabis, Dharshan Kumaran, Seralynn D. Vann and Eleanor A. Maguire, "Patients with Hippocampal Amnesia Cannot Imagine New Experiences," Proceedings of the National Academy of Sciences 104.5 (2007).

\section{CHAPTER SIX: EMPIRE FALLS}

${ }^{1}$ I should note an interesting exception to the idea that science ought to exclude such potentially contaminating language and perspectives as emotion. Evelyn Fox Keller's book on Barbara McClintock, considered for years a maverick scientist, details McClintock's belief in the relationship between science and emotions: "Good science cannot proceed without a deep emotional investment on the part of the scientist." In Evelyn Fox Keller, A Feeling for the Organism: The Life and Work of Barbara Mcclintock (New York: Henry Holt and Company, 1983) 198.

${ }^{2}$ See Chapter Four, "Intersubjectivity and the Need for Emotion."

${ }^{3}$ It is important, having raised the issue of Jimmy's character, to point out again the connection I wish to make between emotional attending and virtue. Virtue, according to Aristotle, is practiced from a "firm and unchanging state" ( $E N$ 1105a31). Bad character, then, is also a platform for action and emotions that are ill formed. To the extent that one's character is bad, therefore, one will be prone to bad attending. Since Jimmy is presented to the reader as "sneaky and mean and envious and dangerous" (99), the reader is left to conclude that Jimmy's ability to attend to the emotional lives of others is distorted by his vicious character.

${ }^{4}$ Alasdair MacIntyre says something similar about an Aristotelian view of friendship: "Friendship of course, on Aristotle's view, involves affection. But that affection arises within a relationship defined in terms of a common allegiance to and a common pursuit of goods. The affection is secondary, which is not in the least to say unimportant. In a modern perspective afection is often the central issue; our friends are said to be those whom we like, perhaps whom we like very much. 
'Friendship" has become for the most part the name of an emotional state rather than of a type of social and political relationship" in After Virtue: A Study in Moral Theory 156.

${ }^{5}$ Laura Mulvey's work on the issue of the male gaze is important to note. She writes: "In a world ordered by sexual imbalance, pleasure in looking has been split between active/male and passive/female. The determining male gaze projects its phantasy on to the female figure which is styled accordingly. In their traditional exhibitionist role women are simultaneously looked at and displayed, with their appearance coded for strong visual and erotic impact so that they can be said to connote to-be-looked-at-ness. Women displayed as sexual object is the leitmotif of erotic spectacle: from pin-ups to striptease, from Ziegfeld to Busby Berkeley, she holds the look, plays to and signifies male desire." In Laura Mulvey, "Visual Pleasure and Narrative Cinema, "Media and Cultural Studies, eds. Meenakshi Gigi Durham and Douglas M. Kellner (Malden, MA: Blackwell Publishing, 2006) 346.

${ }^{6}$ I say "almost reflexively," in that I realize that the cultivation of virtue requires more than just mindless repetition. There is a sense, though, that virtue allows one to cultivate habits in a conscious and decisive way that does not necessarily assume conscious deliberation in each instance. 


\section{REFERENCES}

"Interview with Richard Russo". 2001. failbetter.com. Eds. Didato, Thom and David McClendon. <http://www.failbetter.com/04/Russo.htm>.

Addis, Donna Rose, Alana T. Wong, and Daniel L. Schachter. "Remembering the Past and Imagining the Future: Common and Distinct Neural Substrates During Event Construction and Elaboration." Neuropsychologia 45.7 (2007): 1363-77. Print.

Aristotle. Metaphysics. Trans. Furth, Montgomery. Indianapolis: Hackett Publishing Company, 1985. Print.

--.. Nicomachean Ethics. Trans. Irwin, Terence. 2nd ed. Indianapolis, Ind.: Hackett Pub. Co., 1999. Print.

---. Poetics. Trans. Hubbard, M.E. Aesthetics: The Classic Readings. Ed. Cooper, David. Oxford: Blackwell, 2002. Print.

--.. Politics. Trans. Reeve, C. D. C. Indianapolis, Ind.: Hackett Pub., 1998. Print.

---. Rhetoric. [1st Modern Library ed. New York,: Modern Library, 1954.

Print.Armour-Garb, Bradley P., and J. C. Beall. Deflationary Truth. Open Court Readings in Philosophy 1. Chicago: Open Court, 2005. Print. Baigrie, Brian S. History of Modern Science and Mathematics. 4 vols. New York: Charles Scribner's Sons, 2002. Print. 
Bayer, Ronald. Homosexuality and American Psychiatry: The Politics of Diagnosis. Princeton Paperbacks. Princeton, N.J.: Princeton University Press, 1987. Print.

Beardsmore, R. W. Art and Morality. London,: Macmillan, 1971. Print.

Booth, Wayne. The Company We Keep: An Ethics of Fiction. Berkeley: University of California Press, 1988. Print.

Brothers, L. "The Social Brain: A Project for Integrating Primate Behavior and Neurophysiology in a New Domain." Concepts Neurosci 1 (1990): 27-51. Print.

Buchan, Morag. Women in Plato's Political Theory. London: Routledge, 1999. Print.

Burri, Alex. "Art and the View from Nowhere." A Sense of the Word: Essays on Fiction, Narrative, and Knowledge. Eds. Gibson, John, Wolfgang Heumer and Luca Pocci. Routledge Studies in Contemporary Philosophy. New York: Routledge, 2007. Print.

Carr, David. Time, Narrative, and History. Bloomington: Indiana University Press, 1991. Print.

Carrol, Noël. A Philosophy of Mass Art. Oxford: Clarendon Press, 1998. Print. Code, Lorraine. Epistemic Responsibility. Hanover, N.H.: Published for Brown University Press by University Press of New England, 1987. Print.

---. What Can She Know? : Feminist Theory and the Construction of Knowledge. Ithaca: Cornell University Press, 1991. Print. 
Daston, Lorraine, and Peter Galison. Objectivity. New York: Zone Books distributed by MIT Press, 2007. Print.

Damasio, Antonio R. Descartes' Error : Emotion, Reason, and the Human Brain. London: Penguin, 2005. Print.

---. Descartes' Error : Emotion, Reason, and the Human Brain. New York:

Putnam, 1994. Print.

---. The Feeling of What Happens : Body and Emotion in the Making of Consciousness. 1st ed. New York: Harcourt Brace, 1999. Print.

DeLancey, Craig. Passionate Engines : What Emotions Reveal About Mind and Artificial Intelligence. Oxford; New York: Oxford University Press, 2002. Print.

Deonna, Julien A. "The Structure of Empathy." Journal of Moral Philosophy 4.1 (2007): 99-116. Print.

DeRose, Keith. "The Epistem Deonna, Julien A. "The Structure of Empathy." Journal of Moral Philosophy 4.1 (2007): 99-116. Print.ology Page". (July 13, 2009): Yale University. March 19, 2010. $<$ http://pantheon.yale.edu/ kd47/e-page.htm>.

Descartes, René. Meditations on First Philosophy: With Selections from the Objections and Replies. Trans. Moriarty, Mike. Oxford: Oxford University Press, 2008. Print.

Dolan, Raymond J., and John S. Morris. "The Functional Anatomy of Innate and Acquired Fear: Perspectives from Neuroimaging." Cognitive Neuroscience of Emotion. Eds. Lane, Richard D., Lynn Nadel and 
Geoffrey Ahern. Series in Affective Science. New York: Oxford

University Press, 2000. x, 431 p. Print.

Eagleton, Terry. Literary Theory : An Introduction : Anniversary Edition.

Anniversary ed. Malden, MA: Blackwell Pub., 2008. Print.

--- Reason, Faith, and Revolution. New Haven: Yale University Press, 2009.

Print.

Eckhart, Meister. "On Detachment." Meister Eckhart, the Essential Sermons,

Commentaries, Treatises, and Defense. Eds. Colledge, Edmund and

Bernard McGinn. The Classics of Western Spirituality. New York: Paulist

Press, 1981. xviii, 366 p. Print.

Ekman, Paul. "Facial Expression and Emotion." American Psychologist 48 April (1993): 383-92. Print.

Eldridge, Richard Thomas. An Introduction to the Philosophy of Art. Cambridge, UK New York: Cambridge University Press, 2003. Print.

Eliot, T. S. "The Wasteland." Collected Poems, 1909-1935. New York,: Harcourt, 1936. 220 p. Print.

Feagin, Susan L. "The Pleasures of Tragedy." American Philosophical Quarterly 20 (1983): 95-104. Print.

Fichte, Johann Gottlieb. The Vocation of Man. Trans. Preuss, Peter. Indianapolis: Hackett Pub. Co., 1987. Print.

Friend, Stacie. "The Pleasures of Documentary Tragedy." British Journal of Aesthetics 47.2 (2007): 184-98. Print. 
Frith, Chris D. "The Social Brain?" Philosophical Transactions of the Royal Society $B$ (2007): $671-8 \mathrm{pp}$.

Fumerton, Richard A. Realism and the Correspondence Theory of Truth. Studies in Epistemology and Cognitive Theory. Lanham, Md.: Rowman \& Littlefield Publishers, 2002. Print.

Gaut, Berys Nigel. Art, Emotion, and Ethics. Oxford ; New York: Oxford University Press, 2007. Print.

Gendler, Tamar Szabó and Karson Kovavich. "Genuine Rational Fictional Emotions." Contemporary Debates in Aesthetics and the Philosophy of Art. Ed. Kieran, Matthew. Malden, MA: Blackwell Pub., 2006. xi, 370 p. Print.

Gergen, Kenneth J. "The Mechanical Self and the Rhetoric of Objectivity." Rethinking Objectivity. Ed. Megill, Allan. Post-Contemporary Interventions. Durham: Duke University Press, 1994. 265-87. Print. Griffiths, Paul E. What Emotions Really Are : The Problem of Psychological Categories. Science and Its Conceptual Foundations. Chicago, Ill.: University of Chicago Press, 1997. Print.

Gunnell, John G. The Orders of Discourse : Philosophy, Social Science, and Politics. Lanham, MD: Rowman \& Littlefield, 1998. Print.

Halliwell, Stephen. "Pleasure, Understanding, and Emotion in Aristotle's Poetics." Essays on Aristotle 's Poetics. Ed. Rorty, Amélie O. Princeton: Princeton University Press, 1992. 241-60. Print. 
Hassabis, Demis, et al. "Patients with Hippocampal Amnesia Cannot Imagine New Experiences." Proceedings of the National Academy of Sciences 104.5 (2007): 1726-31. Print.

Hauerwas, Stanley and William Willimon. Resident Alien: Life in the Christian Colony. Nashville: Abingdon Press, 1989. Print.

Hawkesworth, Mary E. "Rethinking Objectivity." Post-Contemporary Interventions. Ed. Megill, Allan. Durham: Duke University Press, 1994. 151-77. Print.

Hochschild, Arlie. The Managed Heart: Commercialization of Human Feeling. Berkeley: University of California Press, 1983. Print.

Horst, Steven. "Our Animal Bodies." Philosophy of Emotions. Eds. French, Peter A. and Howard K. Wettstein. Midwest Studies in Philosophy. Notre Dame, Ind.: University of Notre Dame Press, 1998. 34-61. Print.

Hume, David. A Treatise of Human Nature. New York: Barnes \& Noble, 2005. Print.

Hursthouse, Rosalind. "Normative Virtue Ethics." How Should One Live? Essays on the Virtues. Ed. Crisp, Roger. Oxford: Oxford University Press, 2003. Print.

Husserl, Edmund. Cartesian Meditations : An Introduction to Phenomenology. Trans. Cairns, Dorion. Springer Classic Titles in Philosophy. Dordrecht: Kluwer Academic Publishers, 1999. Print.

Jaggar, Alison M. "Love and Knowledge: Emotion in Feminist Epistemology." Women, Knowledge, and Reality : Explorations in Feminist Philosophy. 
Eds. Garry, Ann and Marilyn Pearsall. New York: Routledge, 1992. 129-

55. Print.

James, William. The Principles of Psychology. Vol. 2. New York: Dover, 1950. Print.

Janko, Richard. "From Catharsis to the Aristotelian Mean." Essays on Aristotle's Poetics. Ed. Rorty, Amélie O. Princeton: Princeton University Press, 1992. 341-58. Print.

Jonas, Hans. "Change and Permanence: On the Possibility of Understanding History." Philosophical Essays : From Ancient Creed to Technological Man. Chicago: University of Chicago Press, 1980. 237-60. Print.

Kant, Immanuel. "The Critique of Aesthetic Judgment." Trans. Meredith, J.C. Aesthetics: The Classic Readings. Ed. Cooper, David. Oxford: Blackwell, 2002. 94-122. Print.

---. Critique of Practical Reason and Other Works on the Theory of Ethics. Trans. Abbott, Thomas Kingsmill. New York: Barnes \& Noble Books, 2004. Print.

---. Grounding for the Metaphysics of Morals Trans. Ellington, James W. 3rd ed. Indianapolis: Hackett Pub. Co., 1993. Print.

--.. "What Is Enlightenment?" On History. Ed. Beck, Lewis White. Indianapolis,: Bobbs-Merrill, 1963. xxxi, 154 p. Print.

Keller, Evelyn Fox. A Feeling for the Organism: The Life and Work of Barbara Mcclintock. New York: Henry Holt and Company, 1983. Print. 
Kirk, Stuart A., and Herb Kutchins. The Selling of Dsm: The Rhetoric of Science in Psychiatry. New York: Walter de Gruyter, 1992. Print.

Krebs, Robert E. Scientific Development and Misconceptions through the Ages : A Reference Guide. Westport, Conn.: Greenwood Press, 1999. Print.

Knuuttila, Simo. Emotions in Ancient and Medieval Philosophy. Oxford: Clarendon Press, 2004. Print.

Kosman, L.A. "Being Properly Affected: Virtues and Feelings in Aristotle's Ethics." Essays on Aristotle's Ethics. Ed. Rorty, Amélie O. Berkeley: University of California Press, 1980. 103-16. Print.

Kringelbach, Morten L. The Pleasure Center : Trust Your Animal Instincts. New York: Oxford University Press, 2009. Print.

Kuhn, Thomas S. The Structure of Scientific Revolutions. 3rd ed. Chicago, IL: University of Chicago Press, 1996. Print.

Lamarque, Peter, and Stein Haugom Olsen. Truth, Fiction, and Literature: A Philosophical Perspective Oxford: Clarendon Press, 1994. Print.

Lear, Jonathan. "Katharsis.” Essays on Aristotle's Poetics. Ed. Rorty, Amélie O. Princeton: Princeton University Press, 1992. 315-40. Print.

LeDoux, Joseph E. The Emotional Brain: The Mysterious Underpinnings of Emotional Life. New York: Simon \& Schuster, 1996. Print.

Lloyd, Genevieve. The Man of Reason: "Male" And "Female" In Western Philosophy. Minneapolis: University of Minnesota Press, 1984. Print. Locke, John. An Essay Concerning Human Understanding. Ed. Fraser, Alexander Campbell. [New ed. New York: Barnes \& Noble Books, 2004. Print. 
Lugones, Maria. "Playfulness, 'World'-Traveling, and Loving Perception." Hypatia 2.2 (1987): 3-19. Print.

Luther, Martin. Luther: Lectures on Romans. 1961. Trans. Paulk, Willhelm. Louisville: Westminster John Knox Press, 2006. Print.

Lynch, Michael P. The Nature of Truth : Classic and Contemporary Perspectives. Cambridge, Mass.: MIT Press, 2001. Print.

MacCulloch, Diarmaid. The Reformation. 1st American ed. New York: Viking, 2004. Print.

Macfarlane, Alan, and Gerry Martin. Glass : A World History. Chicago: University of Chicago Press, 2002. Print.

MacIntyre, Alasdair C. After Virtue : A Study in Moral Theory. 2rd ed. Notre Dame, Ind.: University of Notre Dame Press, 2007. Print.

Matsumoto, David. "Paul Ekman and the Legacy of Universals." Journal of Research in Personality 38 (2004): 45-51. Print.

Merleau-Ponty, Maurice. Phenomenology of Perception. London ; New York: Routledge, 1962. Print.

Mill, John Stuart. On Liberty and Other Writings. Cambridge Texts in the History of Political Thought. Ed. Collini, Stefan. Cambridge [England] ; New York: Cambridge University Press, 1989. Print.

---. Utilitarianism. Oxford Philosophical Texts. Ed. Crisp, Roger. Oxford ; New York: Oxford University Press, 1998. Print.

Moran, Richard. Authority and Estrangement : An Essay on Self-Knowledge. Princeton, N.J.: Princeton University Press, 2001. Print. 
Mulvey, Laura. "Visual Pleasure and Narrative Cinema." Media and Cultural Studies. Eds. Durham, Meenakshi Gigi and Douglas M. Kellner. Malden, MA: Blackwell Publishing, 2006. Print.

Mumford, Lewis. Technics and Civilization. New York,: Harcourt, 1963. Print. Murdoch, Iris. The Fire \& the Sun: Why Plato Banished the Artists. Oxford [Eng.]: Clarendon Press, 1977. Print.

---. Metaphysics as a Guide to Morals. 1st American ed. New York, N.Y., U.S.A.: Allen Lane, Penguin Press, 1993. Print.

---. Sovereignty of Good. Routledge Classics. London: Routledge, 2001. Print.

Nehamas, Alexander. "Pity and Fear in the Rhetoric and the Poetics." Essays on Aristotle's Poetics. Ed. Rorty, Amélie O. Princeton: Princeton University Press, 1992. 291-314. Print.

Nagel, Thomas. The View from Nowhere. New York: Oxford University Press, 1986. Print.

---. “What Is It Like to Be a Bat?" Philosophical Review 83.4 (1974): 435-50. Print.

Nussbaum, Martha C. "Finely Aware and Richly Responsible": Literature and the Moral Imagination." Love 's Knowledge. New York: Oxford University Press, 1990. 148-67. Print.

---. The Fragility of Goodness : Luck and Ethics in Greek Tragedy and Philosophy. Cambridge ; New York: Cambridge University Press, 1986. Print. 
---. "Morality and Emotions." Routledge Encyclopedia of Philosophy. <http://www.geocities.com/Athens/Rhodes/3724/Cytrix/cdrom5/Routledg e_morality_emotion.htm>.

---. "Tragedy and Self-Sufficiency: Plato and Aristotle on Fear and Pity." Essays on Aristotle 's Poetics. Ed. Rorty, Amélie O. Princeton: Princeton University Press, 1992. 261-90. Print.

---. Upheavals of Thought : The Intelligence of Emotions. Cambridge ; New York: Cambridge University Press, 2001. Print.

O'neill, Onora. "Kant's Virtues." How Should One Live? Essays on the Virtues. Ed. Crisp, Roger. Oxford: Oxford University Press, 2003. 77-97. Print. Ortony, Andrew, and Terrence J. Turner. "What's Basic About Basic Emotions?" Psychological Review 973 (1990): 315-31. Print.

Pendergrast, Mark. Mirror Mirror : A History of the Human Love Affair with Reflection. New York: Basic Books, 2003. Print.

Penwell, Derek "Education in the Virtues: Tragic Emotions and the Artistic Imagination." Journal of Aesthetic Education 43.4 (2009): 9-31. Print.

Phelps, Elizabeth A. "The Interaction of Emotion and Cognition: Insights from Studies of the Human Amygdala." Emotion and Consciousness. Eds. Barrett, Lisa Feldman, Paula M. Niedenthal and Piotr Winkielman. New York: Guilford Press, 2005. 51-67. Print.

Pierce, C.S. "How to Make Our Ideas Clear." The Essential Pierce: Selected Philosophical Writings. Eds. Houser, Nathan and Christian Kloesel. Vol. 1 (1867-1893): Indiana University Press, 1992. 124-41. Print. 
Plato. Phaedrus. Trans. Rowe, C. J. Penguin Classics. London ; New York: Penguin Books, 2005. Print.

---. The Republic. Trans. Ferrari, G. R. F. and Tom Griffith. Cambridge Texts in the History of Political Thought. Cambridge ; New York: Cambridge University Press, 2000. Print.

---. Republic. Trans. Waterfield, Robin. Oxford [England] ; New York: Oxford University Press, 1993. Print.

Postan, M. M., and H. J. Habakkuk. The Cambridge Economic History of Europe. 2nd ed. Cambridge,: Cambridge U.P., 1966. Print.

Potter, Nancy Nyquist. “Giving Uptake.” Social Theory and Practice 26.3 (2000): 479-508. Print.

Potter, Nancy Nyquist. How Can I Be Trusted? : A Virtue Theory of Trustworthiness. Feminist Constructions. Lanham, Md.: Rowman \& Littlefield, 2002. Print.

Potter, Nancy Nyquist. "Moral Tourists and World Travelers: Some Epistemological Issues in Understanding Patients' Worlds.” Philosophy, Psychiatry\& Psychology 10.3 (2003): 223. Print.

Putnam, Hilary. Reason, Truth, and History. Cambridge [Cambridgeshire] ; New York: Cambridge University Press, 1981. Print.

Plutchik, Robert. "The Nature of Emotions." American Scientist 894 (2001): 34450. Print.

Prinz, Jesse J. Gut Reactions : A Perceptual Theory of Emotion. Philosophy of Mind Series. Oxford ; New York: Oxford University Press, 2004. Print. 
Proust, Marcel. Swann's Way: In Search of Lost Time. Trans. Moncrieff, C.K. Scott and Terence Kilmartin. Vol. 1. New York: The Modern Library, 2004. Print.

Rawls, John. Political Liberalism. Columbia Classics in Philosophy. Expanded ed. New York: Columbia University Press, 2005. Print.

Robinson, Jenefer. Deeper Than Reason : Emotion and Its Role in Literature, Music, and Art. New York: Oxford University Press, 2005. Print.

Rorty, Amélie O. "The Psychology of Aristotelian Tragedy." Essays on Aristotle 's Poetics. Ed. Rorty, Amélie O. Princeton: Princeton University Press, 1992. 1-22. Print.

Rorty, Richard. Philosophy and the Mirror of Nature. Princeton, N.J.: Princeton University Press, 1979. Print.

Russo, Richard. Empire Falls. 1st ed. New York: Alfred A. Knopf, 2001. Print. Sandel, Michael J. Liberalism and the Limits of Justice. 2nd ed. Cambridge, UK ; New York: Cambridge Universtiy Press, 1998. Print.

Schachter, Stanley and Jerome E. Singer. "Cognitive, Social, and Physiological Determinants of Emotional State." Psychological Review 695 (1962): 379-99. Print.

Simmons, Alison. “Are Cartesian Sensations Representational?” Nous 333 (1999): 347-69. Print.

Socarides, Charles W. Homosexuality : Psychoanalytic Therapy. Northvale, N.J.: J. Aronson, 1989. Print.

---. "How America Went Gay." America 17316 (1995): 20-2. Print. 
Stocker, Michael. "How Emotions Reveal Value and Help Cure the Schizophrenia of Modern Ethical Theories." How Should One Live? Essays on the Virtues. Ed. Crisp, Roger. London: Oxford University Press, 2003. Print. Strawson, P.F. "Freedom and Resentment." Proceedings of the British Academy. London: Oxford University Press, 1963. 187-211. Print.

Stroud, Scott R. "Simulation, Subjective Knowledge, and the Cognitive Value of Literary Narrative." Journal of Aesthetic Education 42.3 (2008): 19-41. Print.

Taylor, Charles. Sources of the Self: The Making of the Modern Identity. Cambridge, Mass.: Harvard University Press, 1989. Print. Thagard, Paul, and Fred Kroon. Hot Thought : Mechanisms and Applications of Emotional Cognition. Cambridge, Mass.: MIT Press, 2006. Print.

Walton, Kendall. "Fearing Fictions." Journal of Philosophy 75.1 (1978): 5-27. Print.

Weber, Michael. "More on the Motive of Duty." Journal of Ethics 11 (2007): 6586. Print.

Whitman, Walt. Leaves of Grass. New York: New American Library, 2000. Print. Witte, John. Law and Protestantism : The Legal Teachings of the Lutheran Reformation. Cambridge ; New York: Cambridge University Press, 2002. Print.

Woolf, Virginia. Mrs. Dalloway. San Diego: Harcourt Brace, 1997. Print. 
Zaki, Jamil, Niall Bolger, and Kevin Ochsner. "It Takes Two: The Interpersonal Nature of Empathic Accuracy." Psychological Science 19.4 (2008): 399404. Print. 


\begin{abstract}
APPENDIX
Grateful acknowledgment is made to The Journal of Aesthetic Education for permission to reprint portions of the following:

Derek Penwell, "Education in the Virtues: Tragic Emotions and the Artistic Imagination." Journal of Aesthetic Education 43.4 (2009): 9-31. Reprinted with permission.
\end{abstract}




\section{CURRICULUM VITAE}

NAME: $\quad$ DEREK LEE PENWELL

ADDRESS: College of Arts and Sciences

Bingham Humanities Building

University of Louisville

Louisville, KY 40292

DOB: $\quad$ Michigan City, Indiana - May 18, 1965

EDUCATION

\& TRAINING: $\quad$ B.R.E., Language and New Testament

Great Lakes Christian College

1983-87

M.A.R., Church History

Emmanuel School of Religion

$1989-90$

M.Div., Divinity

Lexington Theological Seminary

1991-1993

D.Min., Divinity

Lexington Theological Seminary

1996-2000

Ph.D., Humanities

University of Louisville

2005-2010

AWARDS: Faculty Favorite

University of Louisville

2009, 2010

Black and Red Faculty Mentor

University of Louisville

2008 
Chalice Press Award

Lexington Theological Seminary

2000

Field Education Award

Lexington Theological Seminary

1993

\section{PUBLICATIONS:}

"Tragic Emotions and the Artistic Imagination," The Journal of Aesthetic Education 43, no. 4 (Winter 2009) 9-31.

"Like the Words You Speak," Biblical Preaching Journal 19, no. 1 (Winter 2006) 11-12.

"On Becoming Like Christ: A Theological Justification for the Passing of the Peace During Communion," Lexington Theological Quarterly 38, no. 2 (Summer 2003) 119-124.

"Getting in the Way," Biblical Preaching Journal 17, no. 2 (Spring 2004), 17-19.

"What Do You Want Me to Do for You?" Biblical Preaching Journal 16, no. 4 (Fall 2003), 9-11.

"I Will Not Keep Silent," Biblical Preaching Journal 15, no. 4 (Fall 2002), 34-36.

"A Different Reality," Biblical Preaching Journal 15, no. 2 (Spring 2002), 10-12.

"The Stuff I Have," Lexington Theological Quarterly 36, no. 2 (Summer 2001), 115-120.

"The Changing Role of Elders in the Disciples of Christ," Lexington Theological Quarterly 35, no. 2 (Summer 2000), 63-82.

"Elders as Leaders, Not Managers," Lexington Theological Quarterly 35, no. 2 (Summer 2000), 83-96. 